\title{
ENERGY FLEXIBLE \\ COMMERCIAL BUILDINGS AND \\ THE ELECTRICITY GRID
}

By

Sandi Sirikhanchai

A thesis

submitted to Victoria University of Wellington

in fulfilment of the requirements for the degree of

Master of Building Science

Victoria University of Wellington

2019 



\section{Preface}

This thesis was submitted in fulfilment of the requirements of the degree for Master of Building Science to the School of Architecture, Victoria University of Wellington.

\section{Author}

Sandi Sirikhanchai

School of Architecture

Victoria University of Wellington

Email: sandi.sirikhanchai@hotmail.co.nz

\section{Research Supervisor}

Dr. Michael Donn

Associate Professor

School of Architecture

Victoria University of Wellington

Email: michael.donn@vuw.ac.nz 



\section{ABSTRACT}

New Zealand's energy and electricity system is likely to undergo serious changes with climate change and the decarbonisation of the grid playing a significant role. Research in New Zealand around flexibly managing the electricity grid using buildings has focused on thermoelectric appliances in the residential sector while there has been limited research and quantification of the energy flexibility offered by commercial buildings. Despite this, managing the grid using energy flexible commercial buildings represents an opportunity to achieve meaningful reductions in electricity demand from buildings that are far less numerous than residential buildings.

The aim of this thesis was to establish whether energy flexible commercial buildings in New Zealand can maintain the current quality of indoor thermal comfort and achieve reductions in demand that are sufficiently large that grid operators consider them significant contributors to grid management. By understanding the contribution, we can understand whether energy flexible commercial buildings are worth further investigation. In this thesis, energy flexibility means the ability for a building to manage its demand and generation according to user needs, grid needs, and local climate conditions. Energy flexibility in commercial buildings could then support the integration of more variable renewable energy sources and increase demand response capability which is a cost-effective way to manage network constraints and reduce non-renewable electricity generation.

Case studies of New Zealand commercial buildings represented as Building Energy Models (BEMs) were simulated under energy flexible operation in a building performance simulation software (EnergyPlus). The selected case studies were small commercial buildings less than $1,499 \mathrm{~m}^{2}$ in size and which all contained heat pumps. The buildings were of office, retail, and mixed-use types. Two simple energy flexibility strategies were simulated in the buildings and the results from each building were then aggregated and extrapolated across the New Zealand commercial building stock. The strategies simply shifted and shed heating electricity demand. This was done to test whether implementing basic energy flexibility strategies have the potential to reduce electricity demand by a meaningful magnitude.

At best the commercial building stock's peak demand could reduce by 177MW by energy flexibly operating $45 \%$ of the commercial building stock, this was equivalent to around 11,700 buildings. In this scenario heating was shifted to start 150 minutes earlier in the morning. The study concluded that there is energy flexibility potential in New Zealand commercial buildings that 
results in demand reductions sufficiently large enough for grid operators to consider significant for grid management. This could be achieved without seriously jeopardising the current quality of indoor thermal comfort and warrants further investigation into energy flexible commercial buildings. This thesis also presented a refined methodology and energy modelling practice that could be used by other researchers to model and evaluate energy flexible buildings without the need to recreate the same methodology. 


\section{ACKNOWLEDGMENTS}

Firstly, I would like to thank my supervisors Michael Donn and Daniel Gnoth. Thank you for your time, guidance, and support throughout this research project.

Thank you to the Building Research Association of New Zealand and Callaghan Innovation for providing financial assistance for this research.

Thank you to Powerco for having me on board as a research fellow. Thanks again to Daniel Gnoth as well as Elizabeth Chisholm for taking the time to meet me in 2017.

Thank you to my building science classmates for your support and encouragement.

Thank you to my close friends for still being my friends. Sarah, Phoebe, Ruby, Shannen, and Craig. Thank you to my sister Annie Sirikhanchai for always being there for me. Thank you to the flatmates too.

Finally, thank you to my Mum and Dad for everything. 



\section{TABLE OF CONTENTS}

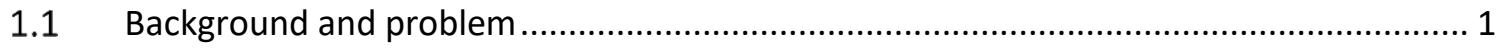

1.2 A demand-side solution in commercial buildings ...................................................... 3

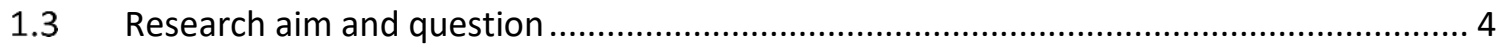

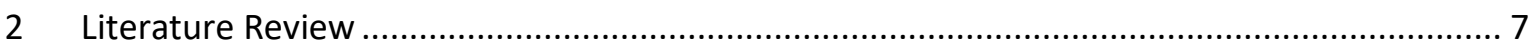

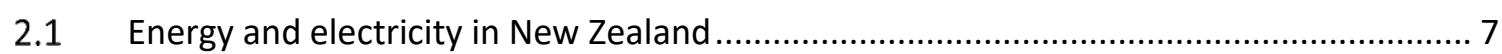

2.1.1 What is our energy and electricity future? ...................................................... 8

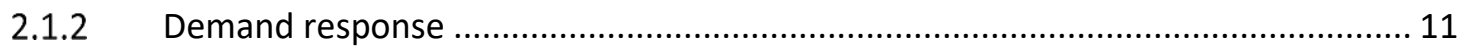

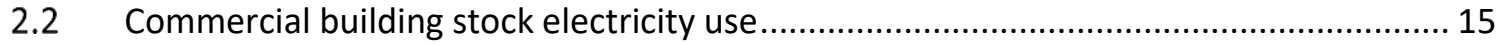

2.2.1 Retrofitting Net-Zero Energy Buildings. .......................................................... 18

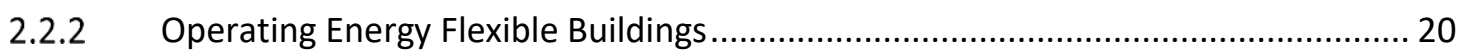

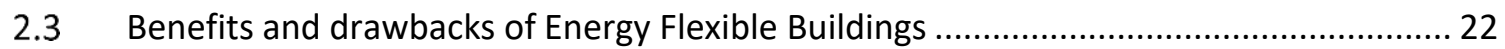

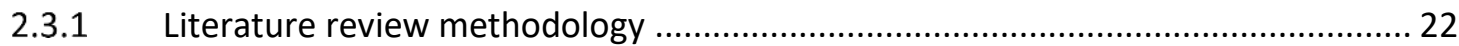

2.3.2 The benefits of Energy Flexible Buildings.......................................................... 23

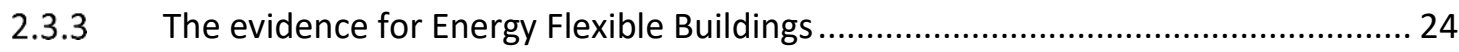

2.3.4 The drawbacks of Energy Flexible Buildings....................................................... 26

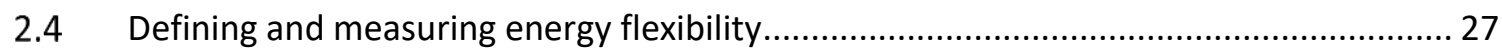

2.4.1 How has energy flexibility been defined? ....................................................... 27

2.4.2 What does energy flexibility mean in this research? ............................................ 30

2.4.3 How has energy flexibility been quantified?........................................................... 30

2.4.4 How is energy flexibility quantified in this research? ............................................ 31

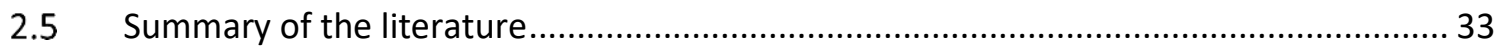

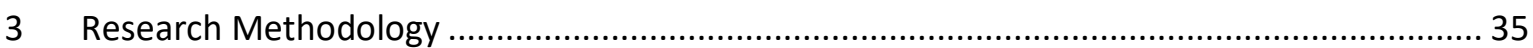

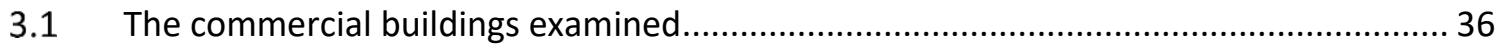

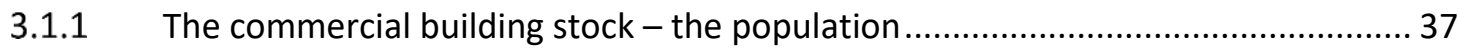

3.1.2 The case study - a sample of 48 buildings ........................................................... 40 


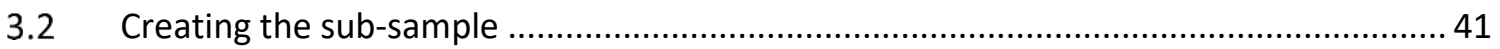

3.2.1 Grid signals to inform which buildings should be energy flexibly operated ............ 42

3.2.2 Buildings that should be energy flexibly operated............................................. 43

3.2.3 Buildings that could be energy flexibly operated................................................. 46

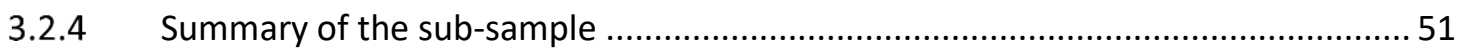

3.3 Strategies to minimise peaks in winter morning demand ............................................ 54

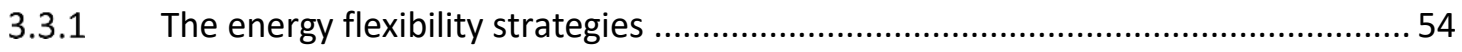

3.3.2 The appropriate method for estimating energy flexibility in existing buildings. ..... 56

3.4 Can the BEMs be trusted for analysing energy flexibility? .............................................5

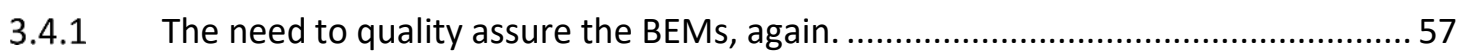

3.4.2 Testing the influence of simulation timesteps and reporting frequency.................59

3.4.3 Testing if the BEMs reflect electricity demand and temperature as expected.........60 60

3.4.4 Testing if the peaking characteristics of the BEMs are reasonable ..........................63 63

3.4.5 Testing if the outputs reflect the inputs for energy flexible operation .................... 65

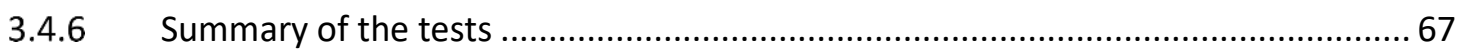

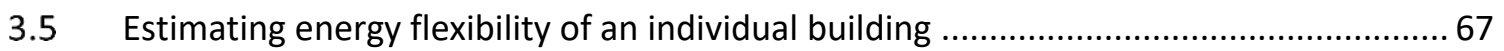

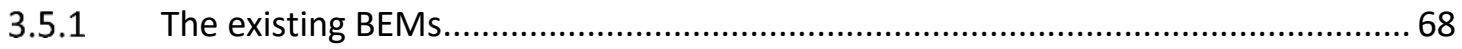

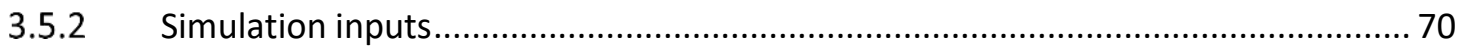

3.5.3 Simulation outputs and processing to measure energy flexibility ........................... 71

3.5.4 Evaluating energy flexibility of individual buildings ............................................ 73

3.6 Converting energy flexibility of individual buildings into an aggregated unit to measure

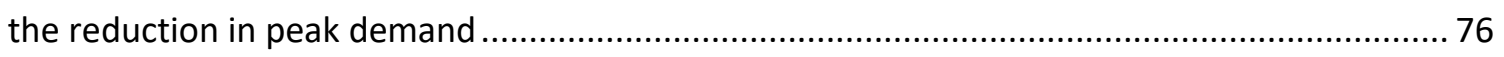

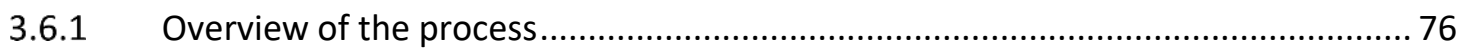

3.6.2 Measuring the reduction in the commercial building stock's peak demand ............78

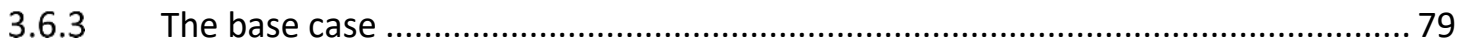

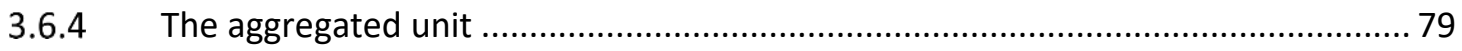


3.6.5 Reporting the results.

3.6.6 Evaluating the peak demand reduction from each test

3.7 Extrapolating the energy flexibility results of the sub-sample across larger buildings.... 83

3.7.1 Overview of the process.

3.7.2 The percentage of energy flexibly operated buildings........................................... 86

3.7.3 Extrapolating the results of the peak demand reduction ..................................... 86

3.7.4 Extrapolating the results across two groups of larger buildings ............................ 87

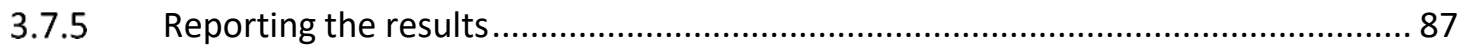

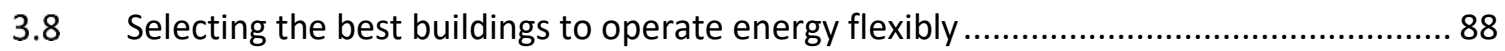

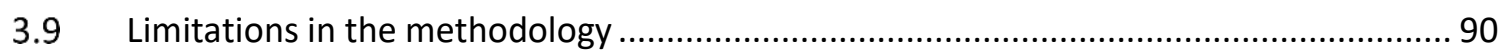

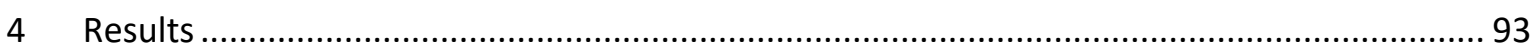

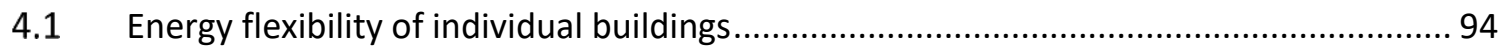

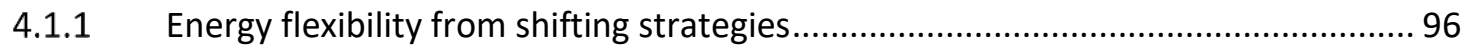

4.1.2 Energy flexibility from shedding strategies...................................................... 112

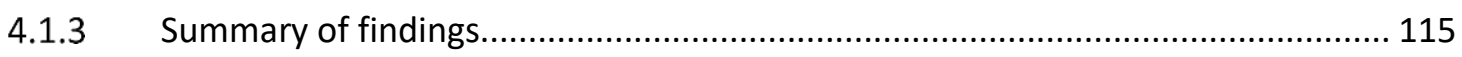

4.2 Reduction in demand from energy flexibly operating small commercial buildings....... 116

4.2.1 Buildings which met the aggregation criterion .............................................. 117

4.2.2 Reduction in the commercial building stock's peak demand .............................. 118

4.2.3 Energy flexibility results to be extrapolated .................................................... 120

4.2.4 Distribution of 5-minute demand data within an hour..................................... 121

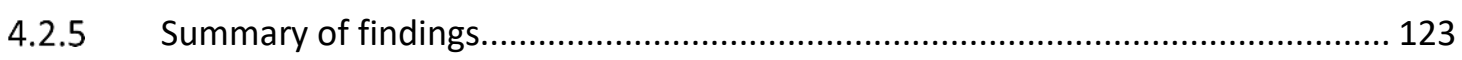

4.3 Reduction in demand from energy flexibly operating small and larger commercial buildings

4.3.1 Reduction from energy flexibly operating larger commercial buildings with heat pumps 125

4.3.2 Reduction from energy flexibly operating larger commercial buildings regardless of heating system type 
5.1 There is energy flexibility potential in today's commercial buildings in New Zealand which warrants further investigation.

5.2 Shifting strategies offer greater demand reduction potential than shedding strategies 136

5.3 A refined methodology and energy modelling practice to investigate energy flexibility 136

5.4 Limitations

5.5 Future research 138

6 Conclusion

7 References

8 Appendices

8.1 Commercial building stock - The population.

8.2 Electricity end-uses of buildings in size group one and two 153

8.3 Simulation inputs for each energy flexibility test. 156

8.4 Python script to measure energy flexibility

8.5 Comfort capacity and building characteristics

8.6 Number of buildings that met the aggregation criteria

8.7 Reduction in the commercial building stock's peak demand from each energy flexibility test 176 


\section{FIGURES}

Figure 1 Proportion of Electricity Demand and Total Energy Demand.

Figure 2 Change in electricity supply sources under different future energy scenarios from 2016 to 2040 (MBIE, 2016).

Figure 3 Estimated electricity demand by sector from 2015 to 2050 (annotated by author)

(Transpower, 2018).

Figure 4 Markets mechanism for demand response at different load commitment timescales

(USDOE, 2006).

Figure 5 Price based demand response for different load commitment timescales (USDOE, 2006).

Figure 6 Electricity generation by sources, commercial sector consumption, and commercial

building consumption. Sources: Cory (2016) and EMI (2017).

Figure 7 Non-renewable electricity generation and commercial building consumption on an average summer day

Figure 8 Non-renewable electricity generation and commercial building consumption on an average winter day.

Figure 9 Energy demand and generation per month throughout a year of two example NZEBs

(Cory, 2016).

Figure 10 Energy demand and generation per hour throughout a day in summer of two example

NZEBs (Cory, 2016)

Figure 11 Energy demand and generation per hour throughout a day in winter of two example NZEBs (Cory, 2016)

Figure 12 Growth in electricity demand in 2020, 2035, and 2050 on the average winter day (Transpower, 2018)

Figure 13 Energy flexibility results from past studies (Aduda et al., 2016)................................... 25

Figure 14 Spread of commercial building across 16 locations in New Zealand (Cory, 2016) .......... 39

Figure 15 Split of commercial buildings by seven climate regions (Cory, 2016).

Figure 16 Non-renewable electricity generation and commercial building consumption on an average summer day.

Figure 17 Non-renewable electricity generation and commercial building consumption on an average winter day.

Figure 18 Average winter day electricity demand by size group and total power demand from all groups 
Figure 19 Average winter and summer day electricity demand by size and type.

Figure 20 Average winter day electricity demand for a selection of size group one and two buildings with electric heating.

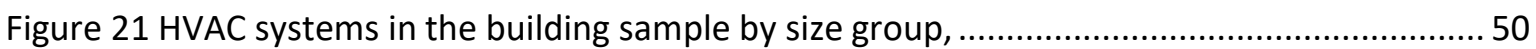

Figure 22 Number of buildings by BEM types in the sub-sample across New Zealand. 51

Figure 23 Indoor air temperatures and electricity demand from the simple BEM located in Auckland and Queenstown.

Figure 24 Heat pump load in relation to temperature differential in degree-days (Boait \& Stafford, 2011)

Figure 25 Peaking factor of real heat pumps and modelled heat pumps. 64

Figure 26 Test result from informing load shifts by changing the BEM HVAC schedule...................66

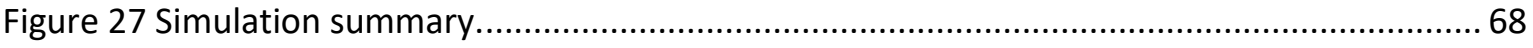

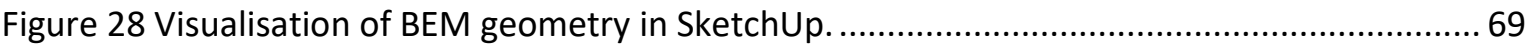

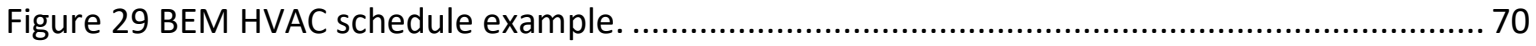

Figure 30 Visual representation of setpoints and comfort limits ................................................ 72

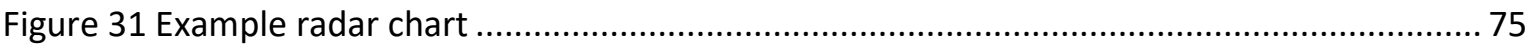

Figure 32 Process of measuring the reduction in the commercial building stock's peak demand.. 77 Figure 33 Calculating peak demand reduction from energy flexibly operating some of the commercial building stock.

Figure 34 Example of the presentation of the reduction in the commercial building stock's peak demand.

Figure 35 Evaluation framework for selecting energy flexibility tests for extrapolation.

Figure 36 Information used to extrapolate the results of two energy flexibility tests across larger commercial buildings.

Figure 37 Evaluation framework to select the best buildings to operate energy flexibly. 89

Figure 38 Evaluation framework to select the best buildings to operate energy flexibly.

Figure 39 Energy flexibility results from Short shift morning only test

Figure 40 Energy flexibility results from Short shift morning + evening test 99

Figure 41 Energy flexibility results from Long shift morning only test. 103 Figure 42 Normalised power capacity of each building from each shift in a warmer climate. * ... 105 Figure 43 Normalised power capacity of each building from each shift in a cooler climate. * .... 105 Figure 44 Increase/decreases in normalised power capacity as a proportion of total increase/decrease from a medium shift and then long shift in a warmer climate. * 107 
Figure 45 Increase/decreases in normalised power capacity as a proportion of total increase/decrease from a medium shift and then long shift in a cooler climate. ${ }^{*}$....................... 107

Figure 46 Energy flexibility results from Long shift morning + evening test............................... 109

Figure 47 Energy flexibility results from Minor shed test ............................................................ 113

Figure 48 Energy flexibility results from Major shed test ........................................................ 114

Figure 49 Daily load profiles from partly energy flexibly operating the commercial building stock.

Figure 50 Evaluating energy flexibility tests for extrapolation. ............................................... 120

Figure 51 Hour before peak hour in a warmer climate........................................................... 122

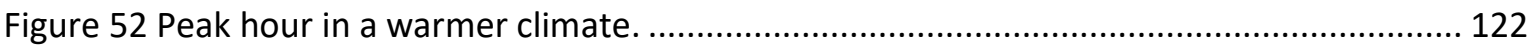

Figure 53 Hour before peak hour in a cooler climate. .............................................................. 122

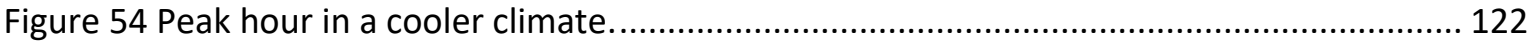

Figure 55 Non-renewable electricity generation and the commercial building stock not energy flexibly operated and partly energy flexibly operated in a High Reduction scenario..................... 128

Figure 56 Best buildings to energy flexibly operate at the individual level. ................................ 129

Figure 57 Best buildings to energy flexibly operate at the stock level. ...................................... 130

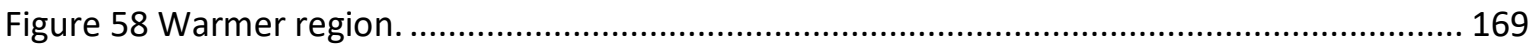

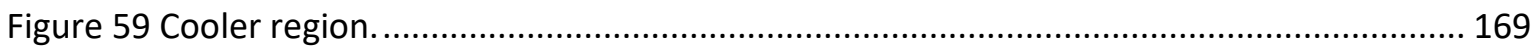

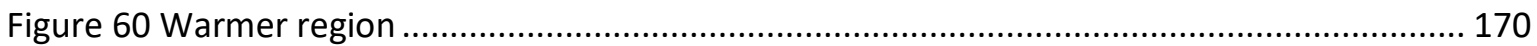

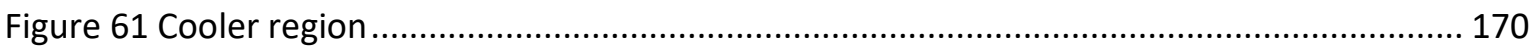

Figure 62 Daily load profile on the peak day after Long and Short shift Morning + Evening test. 176 Figure 63 Ordered daily load profile on the peak day after Long and Short shift Morning + Evening

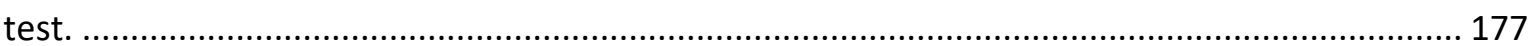

Figure 64 Daily load profile on the peak day after Minor and Major Shed test............................ 178

Figure 65 Ordered daily load profile on the peak day after Minor and Major Shed test. ............. 178 


\section{TABLES}

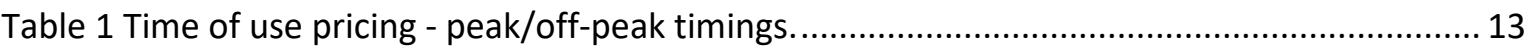

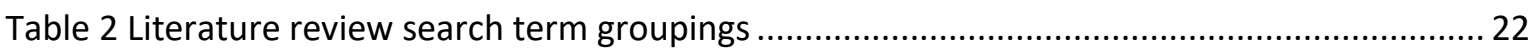

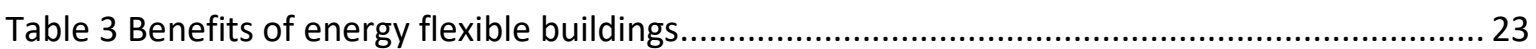

Table 4 Definitions of various flexibility terms used in literature .................................................... 28

Table 5 Two-step process to measure grid support................................................................... 31

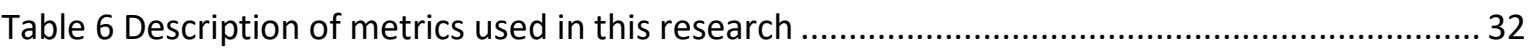

Table 7 Commercial building stock summary adapted by author (Cory, 2016) ............................... 37

Table 8 Commercial building stock stratified by size and type ...................................................... 38

Table 9 Breakdown of sample BEMs by type and size group ........................................................... 40

Table 10 Number of buildings in size group one and two by type.................................................. 45

Table 11 Categorisation of building electricity end-uses............................................................... 48

Table 12 End-use control type and the associated load commitment timescale and markets....... 49

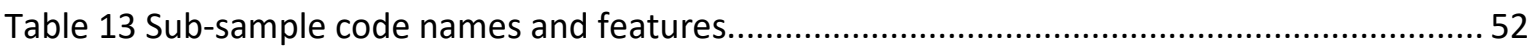

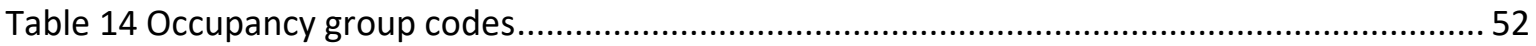

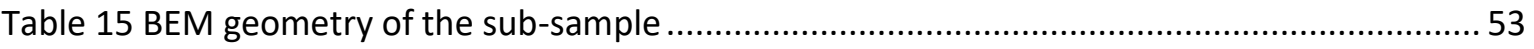

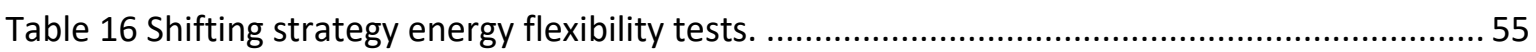

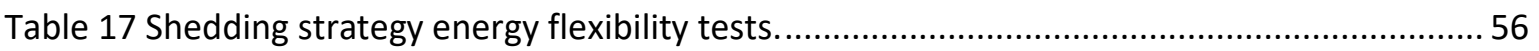

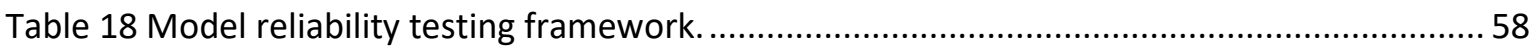

Table 19 Calculated and simulated energy demand of simple BEMs in Auckland and Queenstown.

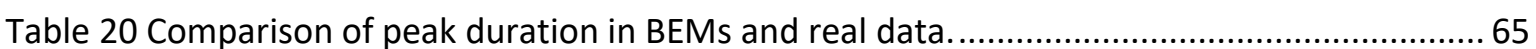

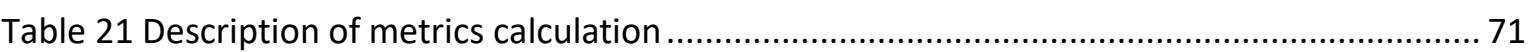

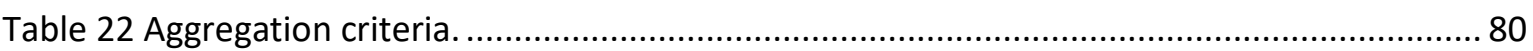

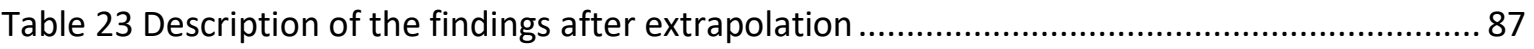

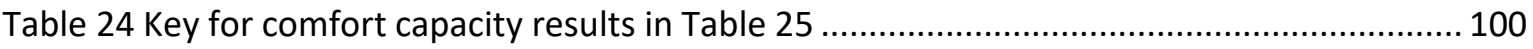

Table 25 Comfort capacity results by type, size, and lower band temperature from a Short shift

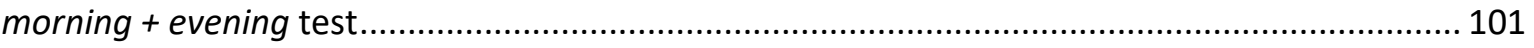

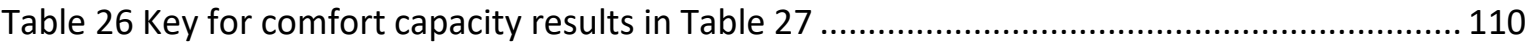

Table 27 Comfort capacity results by type, size, and lower band temperature from a Long shift morning + evening test

Table 28 Summary of results after implementing energy flexibility tests in small commercial buildings. 
Table 29 Summary of the results from energy flexibly operating larger commercial buildings with heat pumps.

Table 30 Summary of the results from energy flexibly operating larger commercial buildings regardless of heating system type. 126

Table 31 Best buildings to energy flexibly operate at the individual level. 131 



\section{INTRODUCTION}

The aim of this thesis was to establish whether energy flexible commercial buildings in New Zealand can maintain the current quality of indoor thermal comfort and achieve reductions in demand that are sufficiently large that grid operators consider them significant contributors to grid management. For this thesis, 'commercial buildings' refer to commercial office, retail, and mixed-use buildings. In New Zealand, the total number of commercial electricity consumers are far less numerous than residential electricity consumers. There are 1.7 million residential consumers but only 175,000 commercial consumers, but the total electricity use of each sector is less than $10 \%$ different $(E A, 2018)$. Much of the discussion around managing the electricity grid using buildings has focused on the residential sector (Dortans et al., 2018; Jack et al., 2016; Jack \& Suomalainen, 2018). But, considering the similar proportion of total electricity use with lower numbers of consumers, commercial buildings within the commercial sector also represent an opportunity to respond to grid needs (Aduda et al., 2018, Yin et al., 2016). By improving energy efficiency and implementing energy flexible operation in commercial buildings, it could free up generation and network capacity to support the electrification and decarbonisation of the energy and electricity system (New Zealand Productivity Commission, 2018; IEA, 2019; Jensen et al., 2017). In the context of the grid, 'energy flexibility' means the ability for a building to manage its electricity demand and generation to respond to local climate conditions and reduce grid stresses while maintaining user comfort (Jensen et al., 2017; Finck et al., 2016; Aduda et al., 2016).

\subsection{BACKGROUND AND PROBLEM}

New Zealand's national grid owner and operator, Transpower, projects that the electricity system is likely to undergo serious changes in the next thirty years (Transpower, 2018). Efforts to mitigate climate change by decarbonising the system will play a significant role and will significantly increase the amount of electricity consumed across the energy sector (Transpower, 2018). Key themes characterising the energy and electricity future includes the energy mix shifting away from non-renewable generation, increasing electricity demand, adoption of distributed energy sources, and growth in different grid management options (Transpower, 2018). To support changes in the electricity sector, it has been argued that energy flexible buildings could play a part in evening out demand and integrating more variable renewable energy sources into the grid (Jensen et al., 2017; Aduda et al., 2016; Finck et al., 2016). 
Transpower (2018) expects electricity demand to double by 2050 but daily peaks to flatten out from the growth in electric vehicles and battery storage systems. In the short term, peaks in daily, monthly and annual demand will increase distribution costs and require more expensive and nonrenewable generation (EA, 2018; ENA, 2016; Strbac, 2008). To manage this, the role of domestic building electricity patterns to reduce demand and cope with network constraints has been a strong focus (Dortans et al., 2018; Jack et al., 2016, 2017; Stephenson et al., 2018; Alzaanin, 2014). In New Zealand, studies have looked at using residential thermoelectric appliances to manage electricity on the demand-side by altering operation and providing energy flexibility (Dortans et al., 2018; Jack et al., 2016, 2017,2018a; Alzaanin, 2014). Such appliances include hot water heaters, heat pumps, and refrigerators.

When it comes to commercial buildings there is a lack of insight into the energy flexibility potential. Even though this may be the situation there are several reasons why the potential for energy flexibility in commercial buildings should be investigated. Cory's (2016) research explored the potential of Net-Zero Energy Commercial Buildings and recommended exploration of how their onsite renewable electricity generation might be integrated into the New Zealand electricity grid. Integration between the two systems in a manner that responds flexibly to grid needs as much as it responds flexibly to user needs, as well as to the availability of generation required attention.

Cory's (2016) analysis of commercial building energy use and data from the Energy Market Information (EMI) (2017) database show that the peak demand from commercial office, retail, and mixed-use buildings aligns with winter morning peaks in non-renewable electricity generation and a network peak period. During this time, demand from these commercial buildings is more than half the electricity generated from non-renewables such as gas, coal, and diesel (Cory, 2016; EMI, 2017). This suggests that energy flexible commercial buildings could be used to manage network peaks and support the decarbonisation of New Zealand's energy and electricity system. It could also be managed with fewer customers compared to residential customers (EA, 2018; Jensen, 2016; Aduda el al., 2017; Isaacs et al., 2014). 


\subsection{A DEMAND-SIDE SOLUTION IN COMMERCIAL BUILDINGS}

The New Zealand Productivity Commission (2018), the Electricity Authority (EA) (2018a), and Strbac et al. (2012) state that demand-side management can and will play a significant role in the energy and electricity future. It could reduce the use of non-renewable fuel sources during peak times, deliver electricity at lower costs, and save on significant investment costs. The International Energy Agency (IEA) (2019) adds that energy efficiency and energy flexibility will also reduce the impact of electrification.

Energy efficiency and Net-Zero Energy Buildings have been thoroughly explored by Cory (2016), therefore this thesis investigates the energy flexibility of commercial buildings. Jensen (2016) explain that energy flexibility of a building is:

"The ability to manage its demand and generation according to local climate conditions, user needs, and energy network requirements" (p. 1).

They further go on to say that energy flexibility will "allow for demand side management/load control and thereby demand response based on the requirements of the surrounding grids" (Jensen, 2016, p. 1). Jensen et al. (2017) describe energy flexible buildings as a cost-effective way to integrate more variable renewable energies such as solar and wind into a low carbon energy grids. This is achieved by consuming energy when it can be generated by changing demand to match it.

Cory (2016) demonstrated that in commercial buildings, all non-electric demand and the portion of electric demand from non-renewable sources could be eliminated or significantly reduced in size through energy efficiency measures. Any saved electricity in the commercial sector could free up capacity for the electrification of transport and increase the proportion of electricity demand that is illustrated Figure 1 (New Zealand Productivity Commission, 2018; Transpower, 2018a). Coupling energy efficiency with energy flexibility could increase the proportion of electricity demand by supporting the penetration of renewable generation, particularly variable sources such as solar and wind (Transpower, 2018a). By increasing the share of renewable generation and responding to grid and user needs, energy flexibility could manage network constraints and support the decarbonisation of New Zealand's energy and electricity system (Jensen, 2016; IEA, 2019; Stevenson et al., 2018; Transpower; 2018a). 


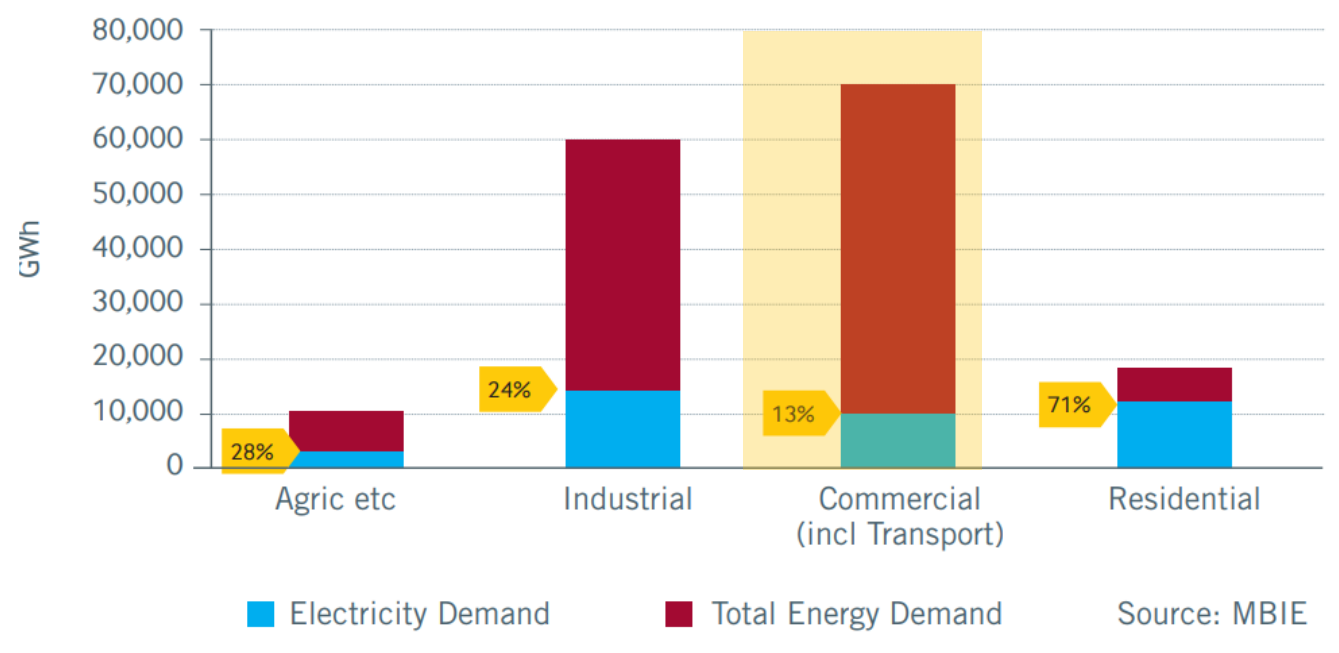

Figure 1 Proportion of Electricity Demand and Total Energy Demand.

Graphic from Transpower (2018a) and data from the Ministry of Business, Innovation, and Employment.

\subsection{RESEARCH AIM AND QUESTION}

It is anticipated that commercial buildings may have flexible demand potential. Energy flexibility is worthwhile investigating because it could help reduce non-renewable electricity demand, manage network constraints and help Net-Zero Energy Buildings respond to grid needs. However, how much energy flexibility potential exists in commercial buildings to respond to the changing energy and electricity environment, especially during times of high grid stress, has not yet been quantified. Therefore, the aim of the research is:

To establish whether energy flexible commercial buildings in New Zealand can maintain their current quality of indoor thermal comfort and achieve electricity demand reductions that are sufficiently large that grid operators consider them significant contributors for grid management.

To achieve the aim, the research question asks:

How much reduction in the commercial building stock's peak demand is possible from energy flexibly operating commercial buildings?

This question essentially asks "what if buildings were energy flexibly operated?" and therefore "how much reduction in demand is possible?" By asking this, we can then assess whether the reduction in demand is sufficiently large to be considered useful for grid management. 
To answer the main question, three key sub-questions are asked. The first set of sub-questions asks:

1. What is the energy flexibility potential of individual commercial buildings?

\section{a. What characteristics or conditions affect the potential?}

By asking this question, any energy flexibility potential in individual commercial buildings can be understood and further investigated. Therefore, the next set of sub-questions asks:

2. If there is energy flexibility potential within individual buildings, how much reduction in the commercial building stock's peak demand is possible?

a. How much reduction in the commercial building stock's peak demand is possible from energy flexibly operating small commercial buildings?

b. How much reduction in the commercial building stock's peak demand is possible from energy flexibly operating small and larger commercial buildings?

By asking these questions, the reduction in the commercial building stock's peak demand from energy flexibly operating commercial buildings can be understood at two different scales. The final question asks:

3. Which building or buildings of those investigated, are the best buildings to operate energy flexibly?

The answer of this question will indicate which building or buildings represent good opportunities to reduce the commercial building stock's peak demand. The building or buildings should be investigated in future research.

\section{Answering the research question}

To answer the research questions, a sample of commercial buildings which are representative of the New Zealand commercial building stock was investigated using their Building Energy Model (BEM) counterpart. The BEMs were originally created by Cory (2016) for both their Ph.D. thesis which investigated the feasibility of converting the commercial building stock to be Net-Zero Energy, and for the Building Research Association of New Zealand's (BRANZ) Building Energy EndUse Study (BEES) (Isaacs et al., 2014). The BEES was a nationwide survey of commercial buildings to examine their energy and water consumption. 
6| Pag e 


\section{LITERATURE REVIEW}

This chapter describes the energy and electricity context in New Zealand and the relationship between electricity consumption and commercial buildings. It also covers the evidence that exists for energy flexible buildings as a demand-side grid management resource. This section also presents a review of energy flexibility definitions and quantification methods. It also summarises how energy flexibility is defined and quantified in this thesis.

\subsection{ENERGY AND ELECTRICITY IN NEW ZEALAND}

Transpower, New Zealand's owner and operator of the high voltage transmission network, the National Grid, describes New Zealand's energy landscape as unique (Transpower, 2016). Characteristics of the National Grid include high renewable electricity generation, disconnection from international electricity grids and low levels of energy storage (Transpower, 2016). In New Zealand, $80-85 \%$ of electricity generation is from renewable resources such as hydro, geothermal and wind. The remaining generation is from gas, coal and small percentages of oil (MBIE, 2018; MBIE, 2018a). In 2017 New Zealand's total net electricity generation was 42.9 GWh. Of this generation, the industrial sector demanded $44 \%$, followed by the residential sector at $32 \%$ and the commercial sector at 24\% (MBIE, 2018; EA, 2018a).

There is a different story when it comes to national energy generation. The mix of resources to generate New Zealand's energy is less than that $40 \%$ renewable. Due to climate change and the ratification of the Paris Agreement, New Zealand is targeting a low-emissions future by aiming to achieve net-zero emissions by 2050 (MFE, 2018). Part of this will be done by electrifying major sectors to reduce the demand for non-renewable energy sources. However, electrification of sectors such as industry and transportation would have significant effects on our electricity generation, transmission and distribution systems (New Zealand Productivity Commission, 2018; Transpower, 2018). Discussions have been underway to understand how New Zealand might cope with changes in the system (Transpower, 2018; Transpower, 2018a; Transpower 2016). 


\subsubsection{WHAT IS OUR ENERGY AND ELECTRICITY FUTURE?}

Transpower has identified five key factors that will influence New Zealand's electricity future. These factors are climate change; uncertainty in the economic, political and security landscape; disruptive technologies; population growth and urbanisation; and New Zealand's unique circumstances regarding winter peaking and high renewable generation (Transpower, 2018a). This section will discuss four aspects of New Zealand's energy and electricity future that address some of the influencing factors. These aspects are important for understanding the potential use of energy flexible commercial buildings as a demand-side solution.

\section{Increases in electricity demand}

Electricity demand in New Zealand is estimated to grow on average between $0.4 \%$ and $1.3 \%$ each year up until 2050 (end of the forecasting period) (MBIE, 2016). The slow growth can be attributed to energy efficiency gains and the impact of Transmission Pricing Methodology (TPM) however, by 2050 the total electricity demand will double (Transpower, 2016a; Transpower, 2018). Contributing to the increasing electricity demand is the electrification of space heating in residential buildings, electrification in process heat in the industrial sector, and moving from combustion fuel engines to electric vehicles (EVs) in the transport sector. This will also increase peak demand especially in the evening and will "significantly impact on the utilisation of generation and network infrastructure" (Strbac et al., 2012, p. 6; Transpower 2018).

\section{Changing energy and electricity mix to decarbonise the energy system}

The Ministry of Business, Innovation and Employment (MBIE) and Transpower expects our energy mix to become more renewable in the face of local and international climate change policies (MBIE, 2016; Transpower, 2018a). Both MBIE and Transpower have conducted work to understand future energy and electricity scenarios New Zealand could go through. Figure 2 illustrates the change in electricity capacity from 2016 to 2040 under different future scenarios. Each bar represents the total change from 2016 to 2040. During this time, for all but one scenario it is expected that there will be large growth in wind and solar generated electricity (MBIE, 2016). 


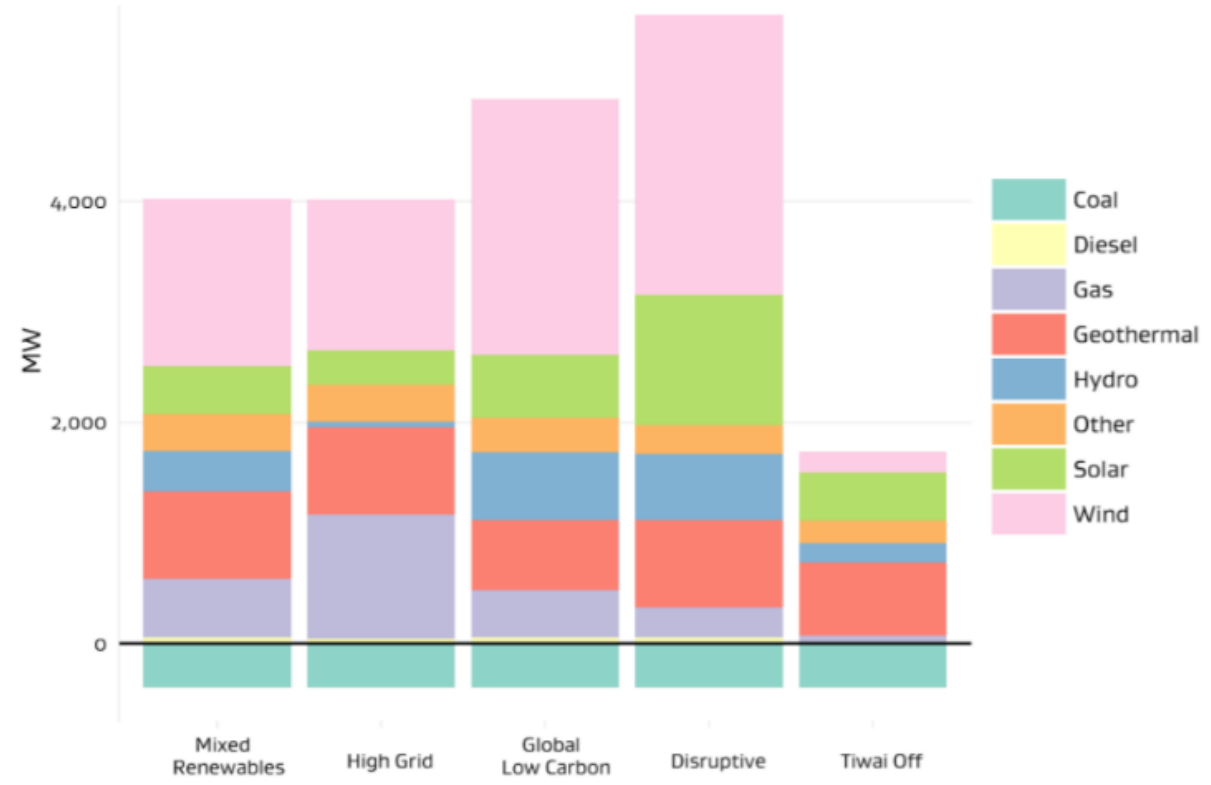

Figure 2 Change in electricity supply sources under different future energy scenarios from 2016 to 2040 (MBIE, 2016).

The uptake of wind and solar energy, and electrifying industry and transportation will play a part in decarbonising the energy mix (MBIE, 2016; Transpower 2016, Transpower, 2018, Transpower, 2018a). However, the electrification of transport will significantly increase electricity demand. Figure 3 illustrates the estimated electricity demand from different sectors in New Zealand from 2015 to 2050 and shows the substantial growth in demand from transport. To support the electrification of transport, an opportunity exists to free up generation and network capacity by improving energy efficiency and implementing energy flexible operation in buildings ( $\mathrm{New}$ Zealand Productivity Commission, 2018; IEA, 2019; Jensen et al., 2017). 


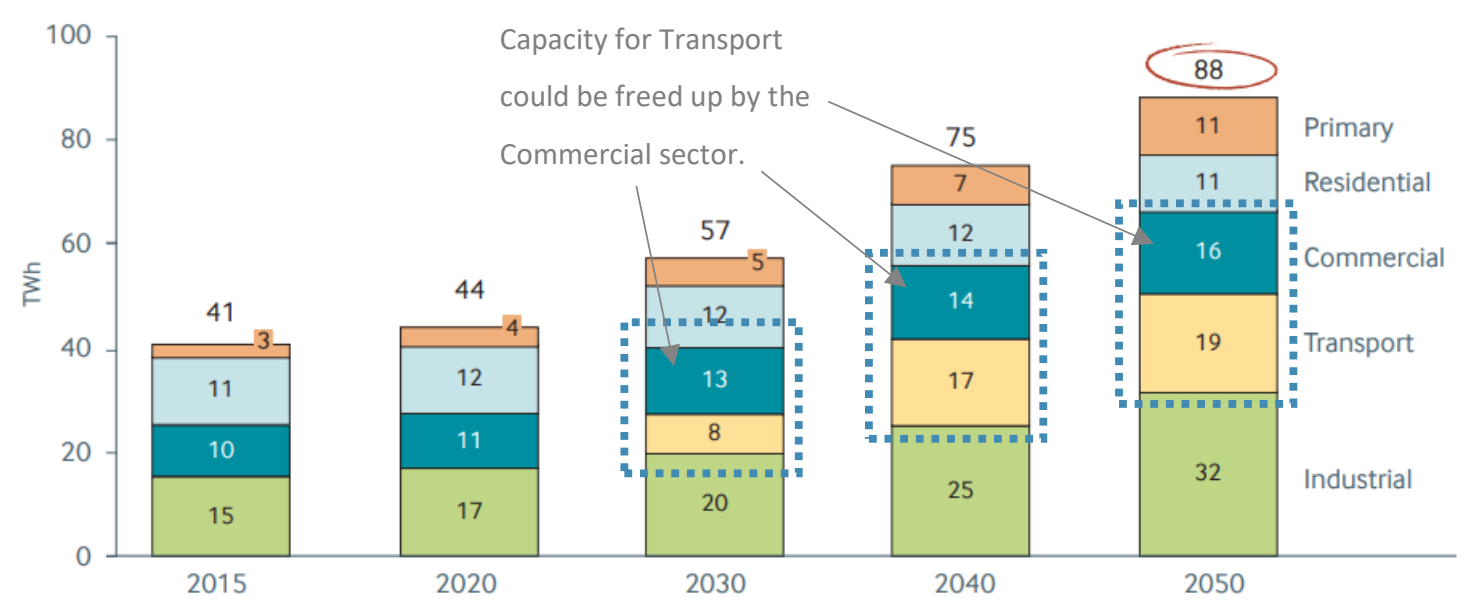

Figure 3 Estimated electricity demand by sector from 2015 to 2050 (annotated by author) (Transpower, 2018).

\section{New technologies offer more grid management options}

Transpower (2018) acknowledges that the disruptive technologies in smart homes, smart grids and markets challenge traditional utility business models. Strbac et al. (2012) conducted a feasibility study to understand the implications and opportunities of smart grid and disruptive technologies and concluded that there is a case for these technologies which presents opportunities to improve grid management. For example, smart appliances in smart homes provide services for balancing generation and demand, reducing peaks, and managing network congestion. Technologies that will enable the smart grid will encourage demand-side participation and offer significant demand response (Strbac et al., 2012). It will facilitate responsive and costeffective approaches to stabilise the grid and enable greater utilisation of existing assets (Lapthorn, 2012).

\section{Adoption of distributed energy generation}

Due to the expected growth of solar in the energy and electricity future, Transpower published a paper addressing some of the myths surrounding solar and expanded on the implications in New Zealand (Transpower, 2019; Transpower, 2018). They report that New Zealand already has over $85 \mathrm{MW}$ of distributed solar and the adoption of residential solar will continue to grow as the price of technology becomes cheaper. One of the key myths reported is that "[s]olar will make the power system unmanageable" however, the system can be made more effective if paired with battery technology to flatten daily demand fluctuations (Transpower, 2019, p. 8; Transpower, 
2016; Transpower, 2018a). Jensen et al. (2017) adds that energy flexibility could also support the integration of solar by managing variability.

\subsubsection{DEMAND RESPONSE}

\section{What is demand response?}

The Electricity Authority (EA) (2018a) in New Zealand defines demand response as:

"[I]ntentionally altering the normal electricity consumption patterns of an end-use consumer in response to an incentive" (p. 1).

A more detailed version from the United States Department of Energy (USDOE) (2006) defines demand response as:

"[A] tariff or program established to motivate changes in electric use by end-use customers in response to changes in the price of electricity over time, or to give incentive payments designed to induce lower electricity use at times of high market prices or when grid reliability is jeopardized" (p. 1).

\section{Demand response markets}

The USDOE (2006) outlines that demand response is implemented in a range of timescales and markets. This is because of two important factors of electricity generation: (1) electricity is not storable and (2) the electricity industry is capital intensive and projects can take years to construct. Due to these two factors, the balance of electricity supply, demand, and delivery must be managed at a range of timescales and markets. Figure 4 shows that there are different markets for different timescales which demand response is implemented in. For each timescale, there are varying magnitudes of load that is committed (to be reduced or changed) for the demand response. A high amount of load is committed in the system planning timescale (left) while less load is committed within 15-minutes timescales (right). At each timescale, prices of the electricity generation and delivery can be used to coordinate the commitment of load from customers (USDOE, 2006). 


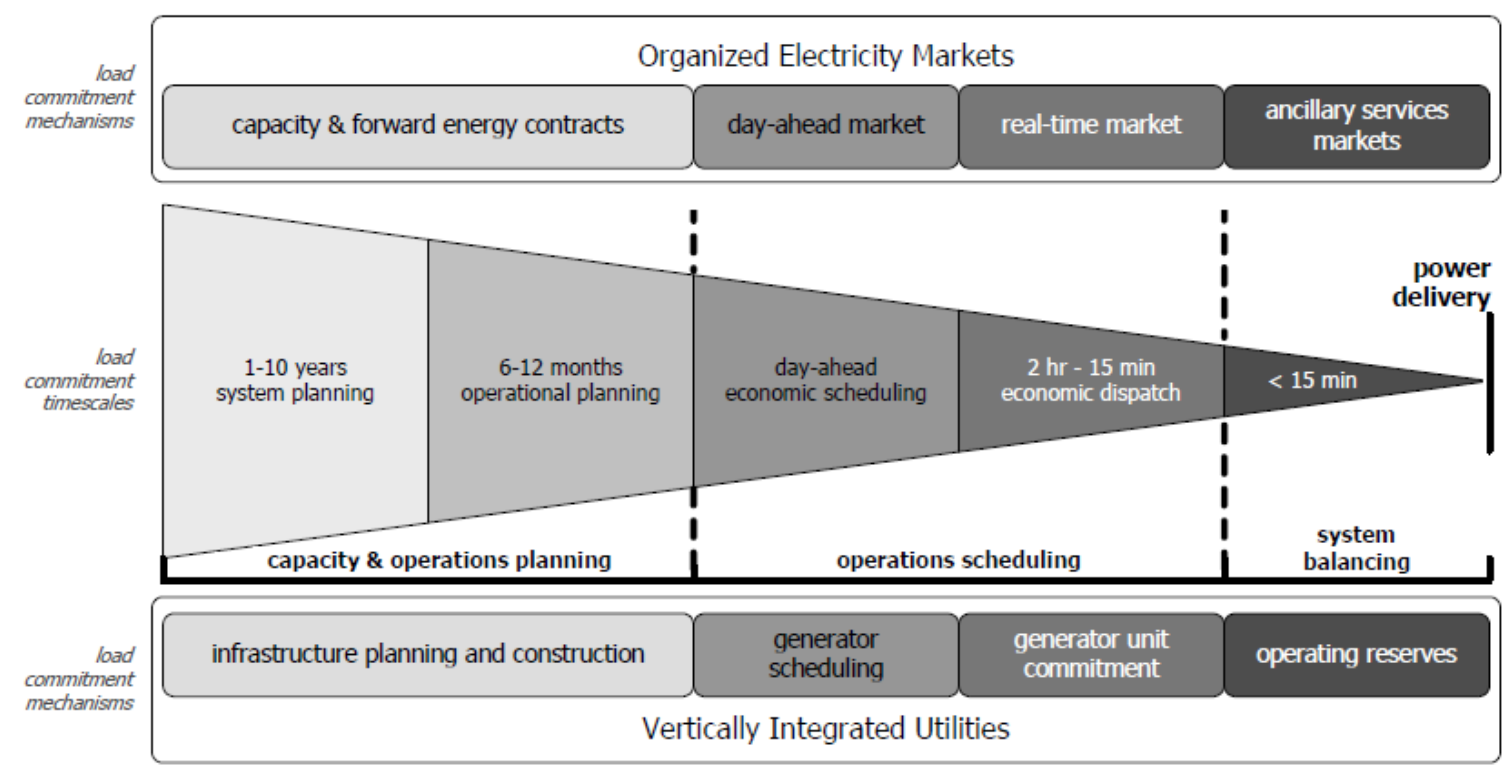

Figure 4 Markets mechanism for demand response at different load commitment timescales (USDOE, 2006).

\section{Price based demand response}

Tariffs are a price-based demand response strategy where various pricing structures reflect the cost of generating and delivering electricity at different times (USDOE, 2006). There are three key types of price-based demand response: time-of-use (TOU) pricing, real-time pricing (RTP), and critical-peak pricing (CPP). Tariffs aim to change electricity usage of the customer by enabling them to "take advantage of lower-priced periods and/or avoid consuming when prices are higher" (US DOE, 2006, p. 10). Higher price periods mean the cost of generating and delivering electricity is greater and disincentivises demand during those times (US DOE, 2006).

TOU pricing is "a rate for. .. usage during different blocks of time, usually defined for a 24-hour day. TOU rates reflect the average cost of generating and delivering power during those time periods" (US DOE, 2006, p. 9). The rates are fixed in advance to reflect the intraday and seasonal variations in the costs of distributing electricity. RTP is a "rate in which the price for electricity typically fluctuates hourly reflecting changes in the wholesale price of electricity" (USDOE, 2006, p. 9). CPP is imposed on "usage designated by the utility to be a critical peak period" (USDOE, 2006, p. 9) which could occur at any time.

The different types of tariffs are used to reflect different load commitment timescales. Figure 5 illustrates where each type of tariff fits in relation to the load commitment timescales and markets referred to in Figure 4. RTP and CPP is used for faster responses. In these events, the load is committed the day before or on the same day it is delivered (the day-ahead and real-time 
market). On the other end, TOU pricing is used for slower responses but more load can be committed (capacity and forward energy contracts).

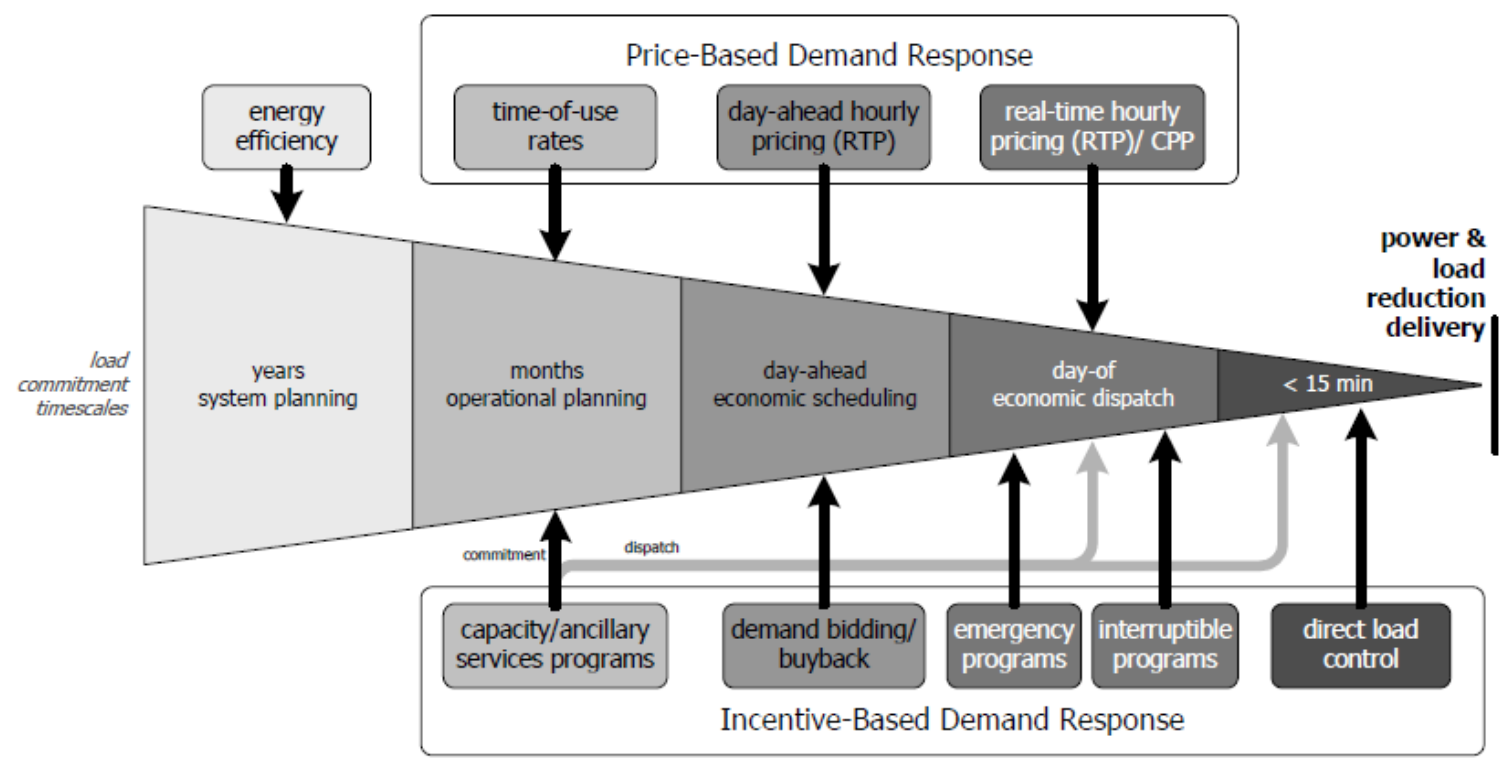

Figure 5 Price based demand response for different load commitment timescales (USDOE, 2006).

\section{Prices based demand response in New Zealand}

Some examples of TOU pricing periods of four New Zealand distribution companies is stated in Table 1. For all four distributors, the cost of generating and delivering electricity is higher during mornings (7am to $9 \mathrm{am} / 11 \mathrm{am}$ ) and evenings ( $5 \mathrm{pm}$ to $9 \mathrm{pm}$ ). During these times electricity demand is disincentivised.

Table 1 Time of use pricing - peak/off-peak timings.

\begin{tabular}{|c|c|c|c|}
\hline & $\begin{array}{l}\text { Higher charge } \\
\text { (peak time) }\end{array}$ & $\begin{array}{l}\text { Lower charge (off-peak } \\
\text { time) }\end{array}$ & Notes \\
\hline Vector & $\begin{array}{l}7 \mathrm{am} \text { to } 11 \mathrm{am} \text { and } \\
5 \mathrm{pm} \text { to } 9 \mathrm{pm}\end{array}$ & $\begin{array}{l}9 \mathrm{pm} \text { to } 7 \mathrm{am} \text { and } 11 \mathrm{am} \\
\text { to } 5 \mathrm{pm}\end{array}$ & $\begin{array}{l}\text { The TOU charges are for specific TOU } \\
\text { customers and applies for weekdays. }\end{array}$ \\
\hline Powerco & $7 a m$ to $11 p m$ & $11 p m$ to $7 a m$ & $\begin{array}{l}\text { TOU charges are dependent on the } \\
\text { network (eastern or western) and price } \\
\text { categories. }\end{array}$ \\
\hline $\begin{array}{l}\text { Wellington } \\
\text { Electricity }\end{array}$ & $\begin{array}{l}7 \mathrm{am} \text { to } 11 \mathrm{am} \text { and } \\
5 \mathrm{pm} \text { to } 9 \mathrm{pm}\end{array}$ & $\begin{array}{l}11 \mathrm{am} \text { to } 5 \mathrm{pm} \text { and } 9 \mathrm{pm} \\
\text { to } 7 \mathrm{am} \text { and weekend all } \\
\text { times. }\end{array}$ & $\begin{array}{l}\text { TOU charges are for residential customers } \\
\text { on an 'Electric Vehicle and Battery' (EVB) } \\
\text { plan. }\end{array}$ \\
\hline
\end{tabular}




\begin{tabular}{|c|c|c|c|}
\hline Orion & $\begin{array}{l}\text { 7am to } 9 \mathrm{pm} \text { and } \\
\text { peak periods* }\end{array}$ & $\begin{array}{l}\text { 9pm to 7am and } \\
\text { weekends all times. }\end{array}$ & $\begin{array}{l}\text { Information is for residential and small } \\
\text { business. For major customers, a control } \\
\text { period demand charge is charged based on } \\
\text { the customer's contribution to the peak } \\
\text { loading levels. }\end{array}$ \\
\hline
\end{tabular}

* Occurs on the coldest weekday mornings and evenings.

Source: Powerco (2017), Orion (2019), Wellington Electricity (2018) and Vector (2018).

Another type of tariff is a demand charge which is charged on a customer's maximum usage (ENA, 2016). This provides an incentive for consumers (generally large commercial) to reduce their maximum usage over a given period. This type of tariff encourages commercial building owners or tenants to lower their maximum demand regardless of the time of day.

Transpower's demand response programme

In 2013, Transpower ran a commercial demand response programme between July and December using their new Demand Response Management System (DRMS) which notifies participants of an upcoming demand response event (Transpower, 2014). The programme had eight commercial participants registering 134MW of demand response which has since grown (M. Richardson, personal communication, March 22, 2019). Throughout the programme 20 demand response events were called with the average demand response delivered being $38 \mathrm{MW}$, the largest demand response delivered was $176 \mathrm{MW}$, and the average length of the demand response events was two hours (Transpower, 2014). During the events the participants offered a range of demand response sources such as general load management, hot water for load management, and standby generators.

The programme established that there is demand response capability from commercial consumers which is more than $100 \%$ reliable due to the use of hot water control from distributors. Although a positive result from the participating commercial consumers, Transpower (2014) states that demand response beyond the established hot water load management must be encouraged. They also add that the sample of participants was not wide enough to "determine differing cost bands for a range of demand response resources" (p. 8) and that small to medium commercial consumers have potential demand response capability which is to be explored (Transpower, 2014). 


\section{Demand response and energy flexibility}

Descriptions of the relationship between energy flexibility and demand response in the literature are to some extent varied. Research by Yin et al. (2016) quantifies energy flexibility for demand response. Similarly, Ayón et al. (2017) propose that aggregated flexibility can be called upon for demand response purposes. Christantoni et al. (2016) state that building services such as heating, ventilation, and air-conditioning (HVAC) are forms of flexible loads that can be used during demand response events. While Billanes et al. (2017) define demand response as an energy flexible solution. The consensus seems to be that the energy flexibility of a building or other system enables demand response. Demand response itself is a flexible grid management strategy which represents a competitive and low-cost method to help manage New Zealand's supply and demand (EA, 2018). In this thesis energy flexibility was explored as a demand response strategy which could contribute to current demand response capability in New Zealand.

\subsection{COMMERCIAL BUILDING STOCK ELECTRICITY USE}

Figure 6 illustrates New Zealand's electricity generation from different sources and electricity consumption from the commercial sector ("commercial consumption") throughout 2016. The data is gathered from Cory (2016) and the Energy Market Information (EMI) (2017) database. The "commercial building consumption" line represents the portion of electricity consumption from the commercial building stock, which in this thesis refers to office, retail and mixed-use buildings across New Zealand. The general commercial sector includes consumption from transportation and other commercial buildings such as schools, hotels, and hospitals. In total, the commercial sector consumes $24 \%$ of the total electricity generation over a year. Of the $24 \%$, the commercial building stock only contributes to about a third of the consumption (Cory, 2016; EMI, 2017). This is only $8 \%$ of the total electricity consumption but still represents a source of electricity for energy flexibility. 


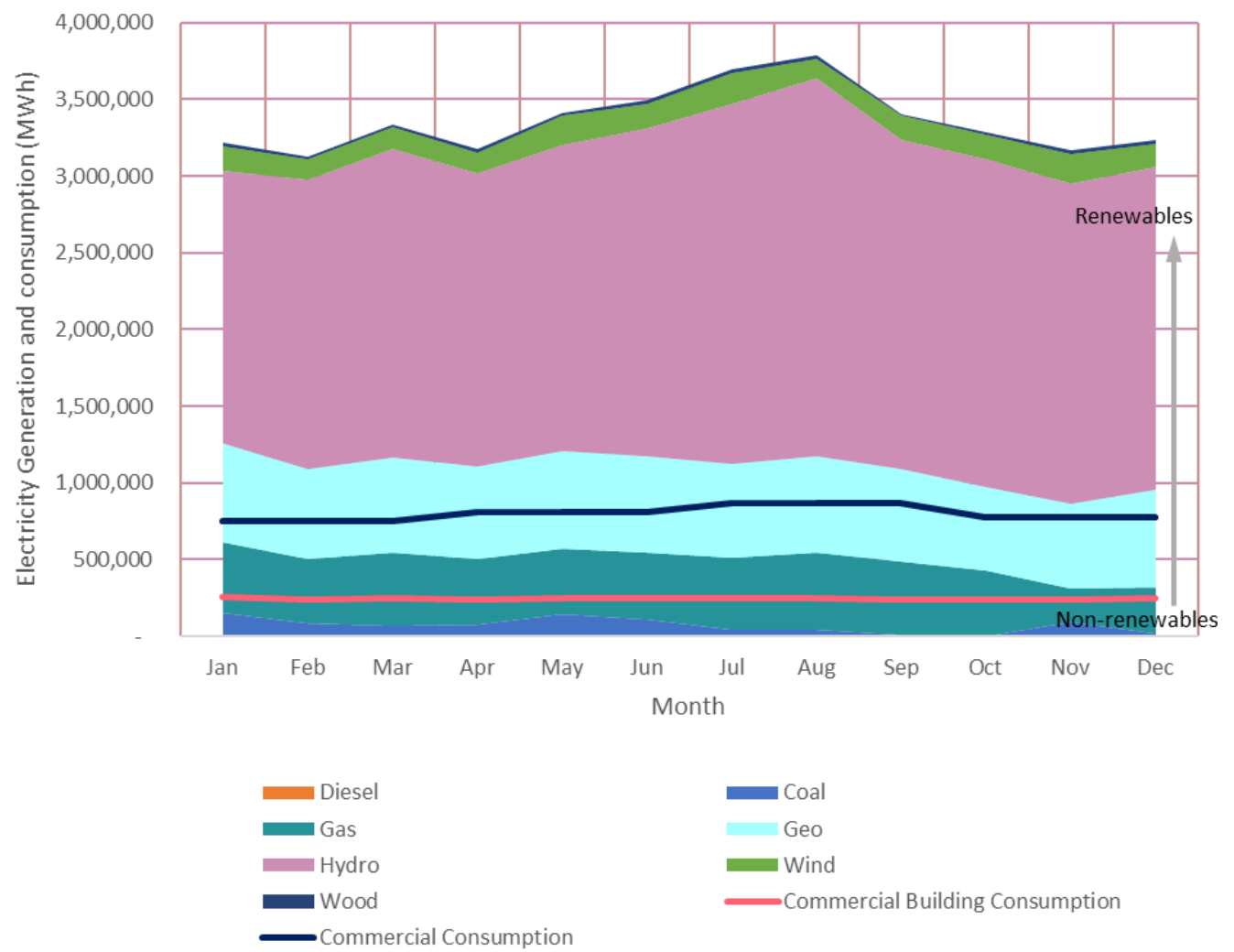

Figure 6 Electricity generation by sources, commercial sector consumption, and commercial building consumption. Sources: Cory (2016) and EMI (2017).

Figure 7 and Figure 8 shows electricity generation and consumption from the commercial building stock on an average summer and winter day. The data was also gathered from Cory (2016) and the EMI (2017) database. The data shows that consumption and generation in summer is flatter than it is in winter. There is more intraday variability in winter, and consumption just from the commercial building stock is almost as much as the generation from non-renewables in the morning. It also shows the morning peaks in consumption and the ramp-up of generation coincide with each other. Generation in the afternoon and evenings did not follow the commercial building stock consumption pattern. This is evidence of generation meeting the demand for other types of commercial buildings or sectors such as the residential sector. Reducing consumption, especially during winter mornings, represents an opportunity to reduce non-renewable generation used to meet peaks in demand. 


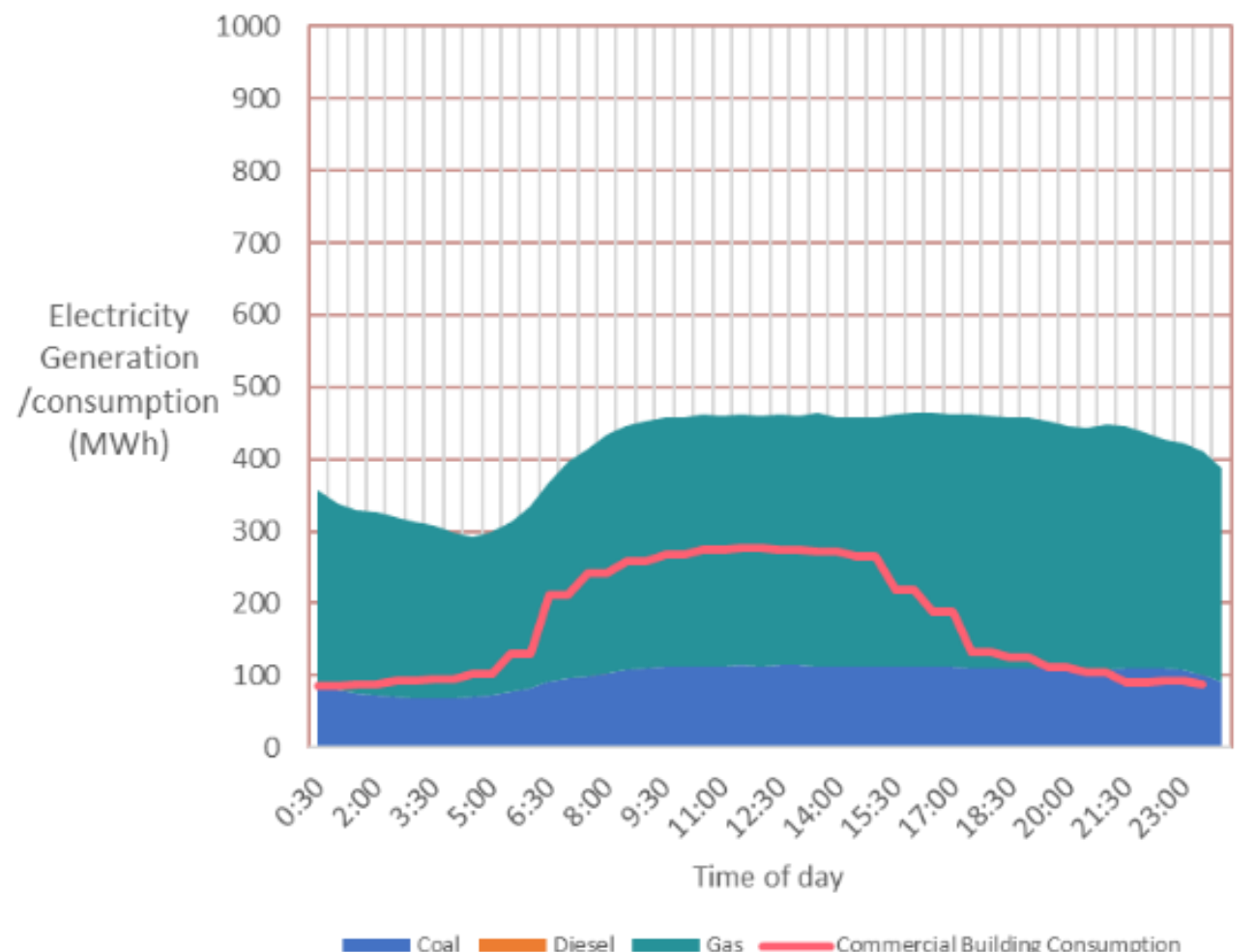

Figure 7 Non-renewable electricity generation and commercial building consumption on an average summer day.

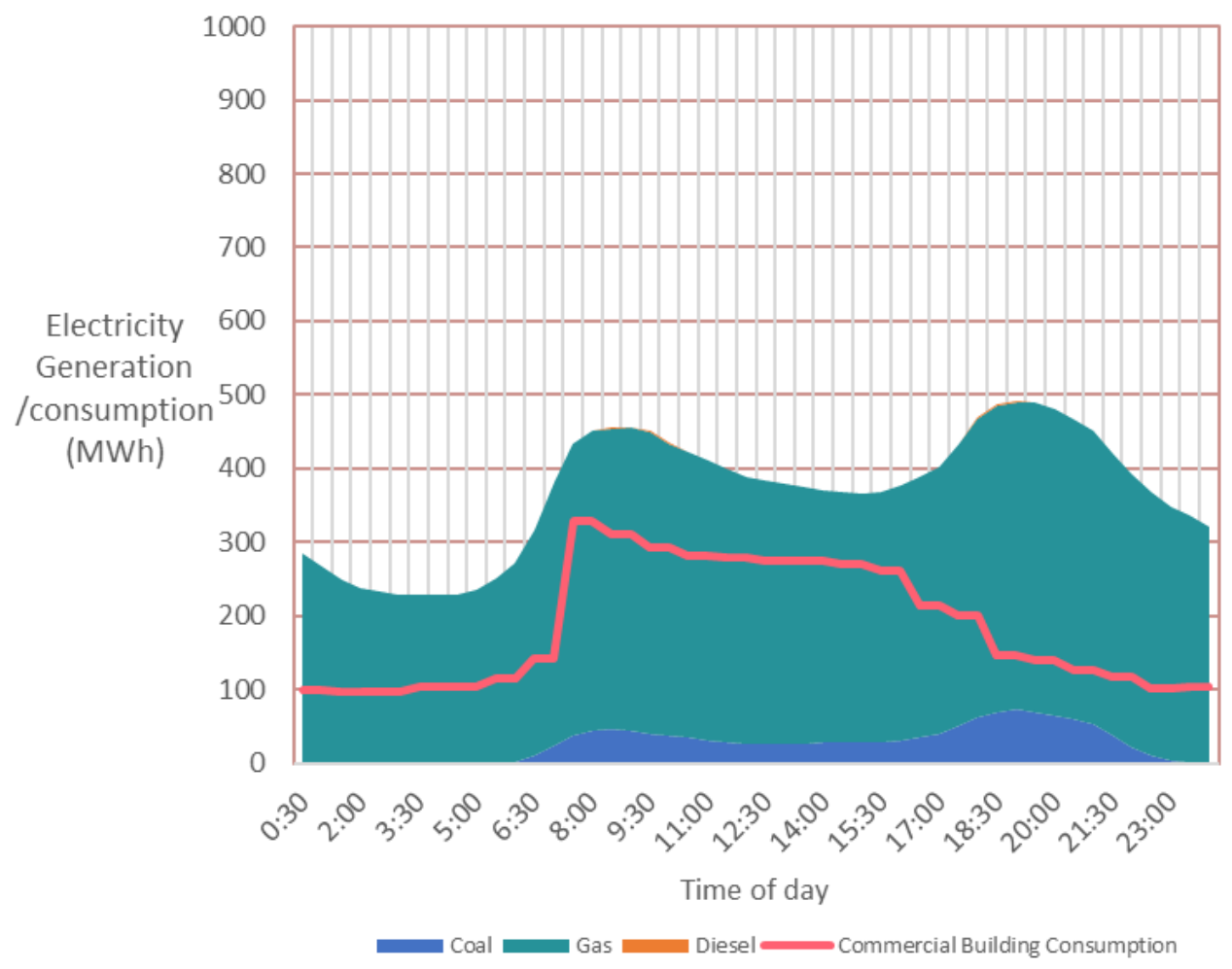

Figure 8 Non-renewable electricity generation and commercial building consumption on an average winter day.

Sources for both charts: Cory (2016) and EMI (2017). 
The commercial building stock represents a load source for demand response which could be used to reduce intraday variability and therefore peaking of non-renewable electricity generation. Different types of demand responses from the commercial building stock could be implemented at different timescales. These are discussed in the following sections. The first response is through energy efficiency improvements and converting existing commercial buildings into Net-Zero Energy Buildings. Based on the demand response framework in the previous section, this type of response will commit greater load but could take years to deliver. The second response is through energy flexibly operating buildings. This type of response will commit less load but within days of delivery.

\subsubsection{Retrofitting Net-Zero Energy Buildings.}

One option to reduce the electricity demand and consumption of commercial buildings is through building or retrofitting Net-Zero Energy Buildings (NZEB). According to Voss et al. (2010, p. 3) a NZEB "is a grid connected, energy efficient building that balances its total annual energy needs by on-site generation and associated feed-in credits." Cory (2016) examined the potential of converting New Zealand's commercial building stock into NZEBs. The research demonstrated that $96 \%$ of the NZEB goal could be achieved by way of energy demand reductions through energy conservation measures. The remaining $4 \%$ of the NZEB goal is achievable by using on-site renewable energy generation.

Cory (2016) states that retrofitting NZEBs could "negate the need for non-renewable fossil fuel energy use in buildings" and "reduce energy consumption . . . to improve energy security and reduce climate change inducing $\mathrm{CO}_{2}$ emissions" (p. 3). However, Cory (2016) found these buildings pose an issue due to the poor interaction between buildings and the grid. This is due to mismatches between on-site generation and demand. Cory (2016) uses a small and large building to demonstrate the mismatches and the effect on the grid.

Demonstrated in Figure 9 is the demand and generation from on-site renewables of a small and large building during each month over a year (inter-seasonal timescale). The graphs show demand and generation do not align for both buildings. The patterns of demand and generation over the year are so dissimilar that the curvature of demand is the opposite to that of generation. This is particularly prominent in the small building. 
Small Building: Monthly Energy Patterns

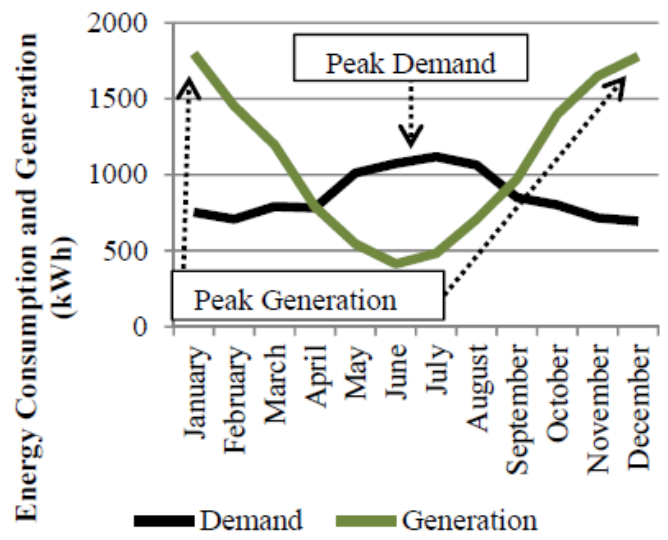

Large building: Monthly Energy Patterns

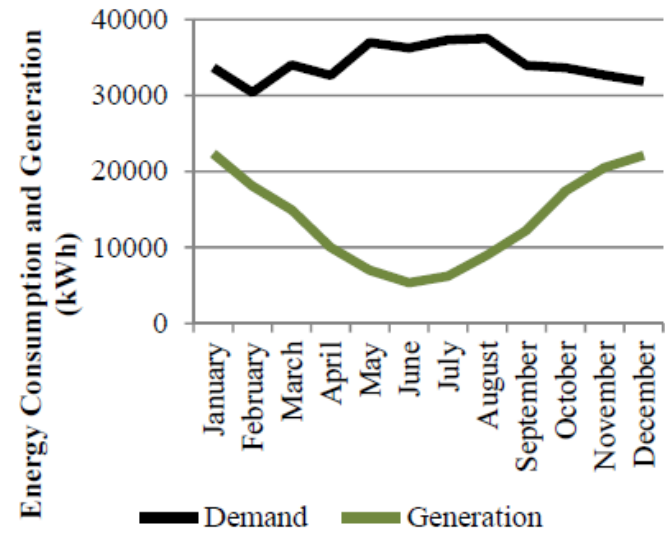

Figure 9 Energy demand and generation per month throughout a year of two example NZEBs (Cory, 2016)

Figure 10 and Figure 11 demonstrates the mismatches between demand and generation over a day in summer and winter (intraday timescale). The examples indicate that buildings have better self-consumption in summer than in winter. Self-consumption refers to the consumption of onsite generation. Poor self-consumption in winter leads buildings to rely on generation from the grid, especially in the morning (shaded area). This is undesirable for two reasons. First, at this time there is a higher proportion of non-renewable generation, as shown in Figure 8 earlier. Secondly, there is more constraint on the distribution system to deliver the generated electricity during a peak time. The constraint is reflected in higher TOU prices.

Small Building: Summer Weekday Energy Profile

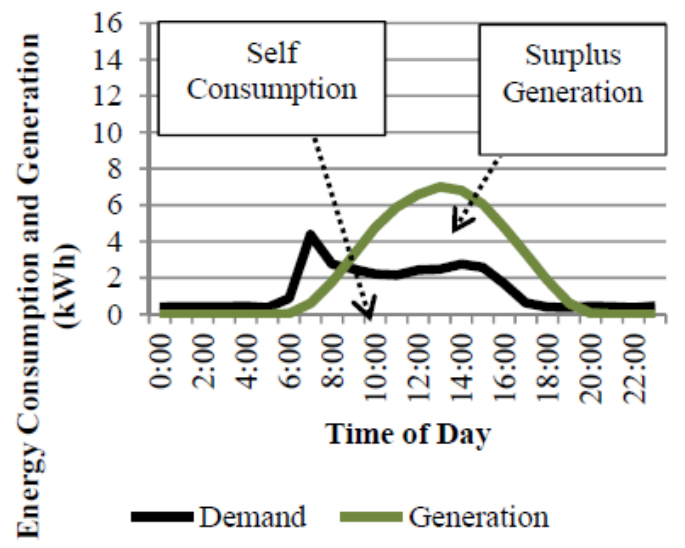

Large Building: Summer Weekday Energy Profile

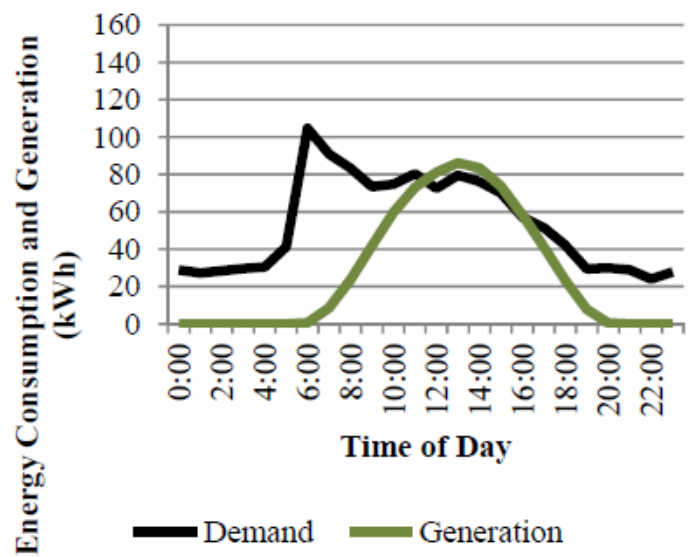

Figure 10 Energy demand and generation per hour throughout a day in summer of two example NZEBs (Cory, 2016) 
Small Building: Winter Weekday Energy Profile

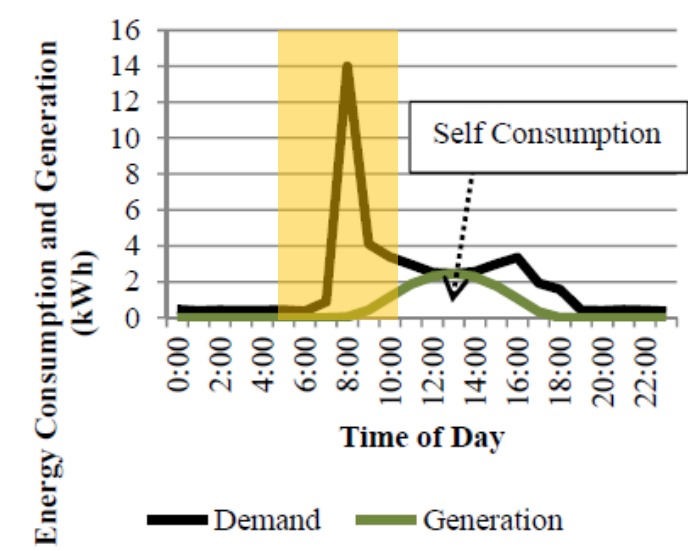

Large Building: Winter Weekday Energy Profile

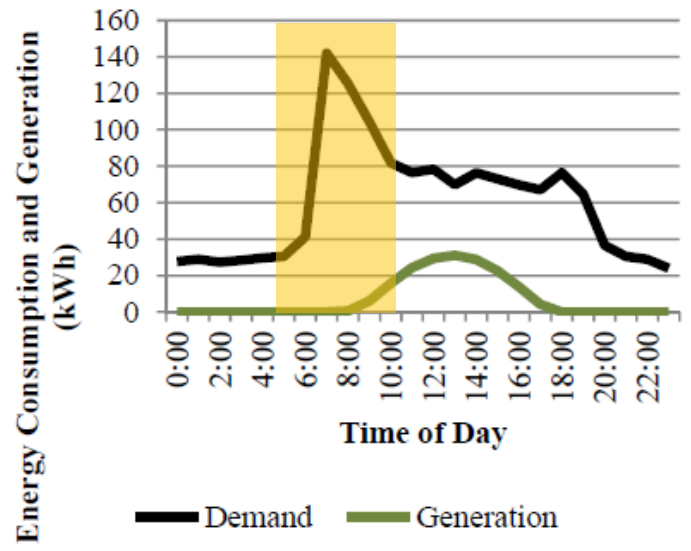

Figure 11 Energy demand and generation per hour throughout a day in winter of two example NZEBs (Cory, 2016)

Based on the temporal energy mismatches, Cory (2016) states that further work should be conducted to assess and adapt NZEBs so they can flexibly response to the needs of the grid. Cory (2016) concludes that temporal energy matches and the ability of a building to respond to grid signals, often referred to as flexibility is important, however comprehensive research of the flexibility of NZEBs in New Zealand is limited.

\subsubsection{Operating Energy FleXible Buildings}

NZEBs may be low energy buildings that balance demand and consumption over a year, however due to mismatches in demand and on-site generation they will maintain pressure on distribution systems and could continue to demand non-renewable generation (Cory, 2016). This is undesirable especially during peak times such as winter mornings. Additionally, the pressure on distribution systems and generation will be intensified by the electrification of other sectors and overall increases in demand (Transpower, 2016).

Transpower (2016) states that technology like batteries represents an opportunity to accommodate growth by flattening daily peaks and shifting loads. Figure 12 shows the growing demand from 2020 to 2050 flattening over time. Despite the flattening of peaks, pronounced intraday peaks are still evident today and in the next year. To support the grid today energy flexible buildings, described by Jensen et al. (2017), offer similar services to respond to grid signals by reducing peaks and integrating renewable energy sources into the grid. 


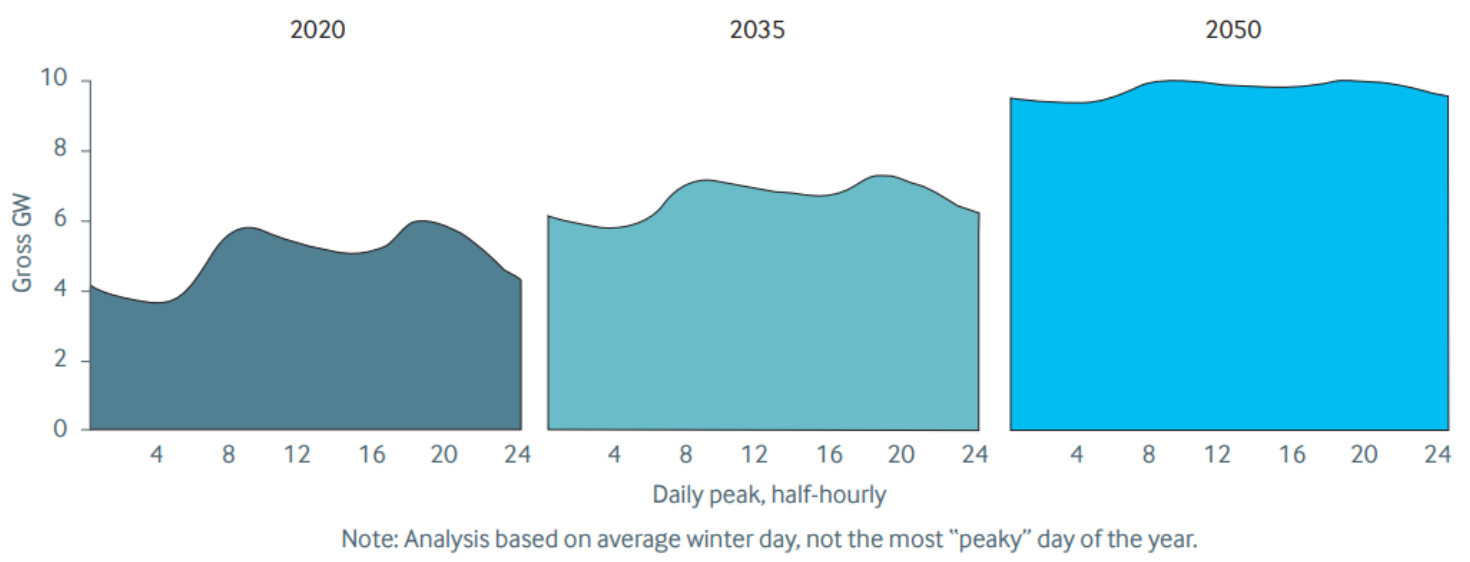

Figure 12 Growth in electricity demand in 2020, 2035, and 2050 on the average winter day (Transpower, 2018)

Based on the demand response load commitment timescales, retrofitting energy efficient commercial buildings could take years to respond. Aduda et al. (2018) suggest commercial buildings as an energy flexible resource could respond much faster compared to retrofitting, and also faster than responses from power plants on the supply side. Therefore, energy flexibly operated buildings could respond to grid needs today. Yin et al. (2016) explain that mechanical heating, ventilation, and air-conditioning (HVAC) systems and other thermostatically controlled loads found in commercial buildings provide flexibility for demand response events. These loads can be used for load shedding and shifting services and be activated within seconds to minutes.

\section{Commercial buildings versus residential buildings and industrial plants as energy flexible resources}

Several authors (Aduda et al., 2017; Beil et al., 2015; Billanes et al., 2017) argue that commercial buildings have great potential to be used as energy flexible resources in contrast to residential buildings and industrial plants. This is due to a combination of HVAC loads, the ability to control the loads through building management systems (BEMS), and high thermal inertia. Aduda et al. (2017) explain that unlike commercial buildings, residential buildings would require elaborate communication infrastructure such as a home energy management system (HEMS), the equivalent to a BEMS, and the loads from one building are small in comparison to its commercial counterpart. Loads in industrial plants may be large and provide significant demand reduction potential however, the complexities of industrial processes, the requirements to maintain safety, and avoidance of large losses make them impractical as energy flexibility resources (Aduda et al., 2017). 


\subsection{BENEFITS AND DRAWBACKS OF ENERGY FLEXIBLE BUILDINGS}

The previous sections describe New Zealand's energy and electricity context and how NZEBs and energy flexible buildings could play a role in demand response markets and the anticipated energy future. This section expands on the capabilities of energy flexible buildings by outlining some of the benefits and the evidence supporting it. It also outlines some drawbacks.

The findings in this section and the following section, section 2.4 , were both generated via a Systematic Literature Review process which follows the procedure documented by Boland et al. (2014). A key feature of the Systematic Literature Review is that the steps of the literature search must be documented so others can readily replicate it.

\subsubsection{LITERATURE REVIEW METHODOLOGY}

The literature review was conducted online in four databases:

- Science Direct, Scopus and Google Scholar for their large range of disciplines, and

- IEEE Xplore for its specialisation in power systems.

Terms used to define the searches are grouped under four headings (Who, What, Where and How) according to the Boland et al. (2014) systematic review structure, this is called the inclusion criteria. The inclusion criteria ensured the most relevant references are found. Under each heading synonyms were used to capture results that used different vocabulary. A fifth heading, Exclusion (or the exclusion criteria), was used to look more closely to identify articles relevant to the research. These terms are shown in Table 2

The article titles were screened and deemed relevant or irrelevant based on the inclusion and exclusion criteria. This process was followed for screening abstracts and full texts.

Table 2 Literature review search term groupings

\begin{aligned} \hline Who & Energy or electricity, and indoor environmental quality \\ \hline What & Energy balance or grid support \\ \hline Where & Commercial buildings \\ \hline How & Energy Flexibility, demand-side flexibility or energy scheduling \\ \hline Exclusion & Residential, industrial, policy and price \end{aligned}


The systematic approach aimed to cover almost all relevant literature in the field. However, limitations in the review process existed due to the following reasons:

- Only English articles were read therefore literature from some non-English speaking countries were excluded.

- Full texts that were not found online or physically were excluded.

- The systematic review requirement by Boland et al. (2014) for a second reviewer was not followed, but every effort was made to avoid observer bias.

\subsubsection{The Benefits Of ENERGy FLEXIBLE BUILDINGS}

Jensen et al. (2017) state that energy flexible buildings could be a potential solution to mitigate problems in low carbon energy grids by responding to grid needs and the availability of variable generation. This is due to the growth in energy generation from solar and wind which is characterised by its variability in energy supply over the period of an hour, day and year (Cory, 2016; Jensen et al., 2017; Ayón et al., 2017; Bode et al., 2017; Christantoni et al., 2016; Hurtado Munoz et al., 2015; Lopes et al., 2016).

Energy flexibility is frequently referred to in studies examining the demand response potential of buildings. This is because energy flexibility enables demand response management where buildings could potentially play a significant role in maintaining the balance of supply and demand that is often achieved on the supply side (Christantoni et al., 2016; Cui et al., 2015; Aduda et al., 2017; Lopes et al., 2016). Some of the benefits of energy flexibility are summarised in Table 3.

Table 3 Benefits of energy flexible buildings

\begin{tabular}{ll}
\hline Benefits & Reference \\
\hline $\begin{array}{l}\text { Support the integration of more renewable energy } \\
\text { and low carbon technologies. }\end{array}$ & Jensen et al. (2017), IEA (2019) \\
\hline $\begin{array}{l}\text { Support a better relationship between electricity } \\
\text { grids and NZEBs. }\end{array}$ & Cory (2016) \\
\hline $\begin{array}{ll}\text { Improve the balance between demand and supply } \\
\text { at a lower cost. }\end{array}$ & $\begin{array}{l}\text { Ayon et al. (2017), Bode et al. (2017), EA (2018), } \\
\text { Yin et al. (2016) }\end{array}$ \\
\hline Increase utilisation of electrical assets. & Hurtado Munoz (2017), Lapthorn (2012), \\
& Strbac et al. (2012) \\
\hline Defer investment costs. & Strbac et al. (2012), Aduda et al. (2017) \\
\end{tabular}




\begin{tabular}{ll}
\hline Improve transmission and distribution reliability. & Hurtado Munoz (2017), EA (2018) \\
\hline Improve power quality. & Hurtado Munoz (2017) \\
\hline Aid the roll-out of smart grids. & De Coninck \& Helsen (2013) \\
\hline
\end{tabular}

\subsubsection{THe eVIDENCE FOR ENERgy FLEXIBLE BUILDINGS}

There is no standard quantification of energy flexibility (Jensen et al. 2017, Lopes et al., 2016). The results presented in this section are therefore context specific and use different methods and methodologies. The inconsistencies made the consolidation of published energy flexibility results problematic. It is further complicated by the lack of evidence of how much energy flexibility buildings can offer energy systems (Jensen et al. 2017). Nonetheless, the following studies present some insight into the energy flexibility offered by buildings and the systems within them.

Aduda et al. (2016) conducted a review of demand-side flexibility potential focusing on three characteristics in commercial buildings. Figure 13 displays the demand-side flexibility potential as a percentage and they describe the characteristics as the following:

- Shed-ability: The "theoretical potential for load shed or shifts for a given end use which is associated with specific demand-side strategies" (p. 3).

- Controllability: The "portion of load shed or shifts for a given end use which is associated with an equipment having in place [the] required communications and controls capabilities for grid support activities" (p. 3).

- Response time: "The time lapse to full load shed" (p. 3).

The review shows that for three types of building loads (cooling, heating, and ventilation) there is about $40 \%$ to $60 \%$ shed-ability potential. For lighting loads the potential is much lower. The building loads with high shed-ability are all HVAC loads which proves the point made by Aduda et al. (2017), Beil et al. (2015), and Billanes et al. (2017) that these types of loads in commercial buildings are useful in offering energy flexibility. These loads also have a higher controllability potential than lighting but were not greater than $25 \%$. The response times of the flexibility is also presented in the last column of Figure 13 and reported in minutes and seconds. All loads can respond quickly within an hour, indicating that they could be used for demand response in the day-head and day-of markets. 


\begin{tabular}{|c|c|c|c|}
\hline Building Load & Shed-ability & Controllability & Response time \\
\hline Cooling & $\begin{array}{l}\text { 41-58\% (Olsen et al., 2014; Hummon et al., } \\
\text { 2014; D'hulst et al., 2015) }\end{array}$ & $\begin{array}{l}\text { 7-25\% (Olsen et al., 2014; Hummon et al., } \\
\text { 2014; Watson, 2013) }\end{array}$ & 1-15 min (D'hulst et al., 2015; Watson, 2013) \\
\hline Heating & $\begin{array}{l}\text { 46-64\% (Olsen et al., 2014; Hummon et al., } \\
\text { 2014; D'hulst et al., 2015) }\end{array}$ & $\begin{array}{l}\text { 7-25\% (Olsen et al., 2014; Hummon et al., } \\
\text { 2014; Watson, 2013) }\end{array}$ & 1-15 min (D'hulst et al., 2015; Watson, 2013) \\
\hline Ventilation & $\begin{array}{l}\text { 46-59\% (Olsen et al., 2014; Hummon et al., } \\
\text { 2014) }\end{array}$ & $\begin{array}{l}\text { 8-25\%(Olsen et al., 2014; Hummon et al., 2014; } \\
\text { Aduda \& Mocanu, 2014; Watson, 2013; Hao } \\
\text { et al., 2014) }\end{array}$ & $\begin{array}{l}\text { 1-15 min (Aduda \& Mocanu, 2014; Watson, } \\
\text { 2013; Hao et al., 2014) }\end{array}$ \\
\hline Lighting & $\begin{array}{l}\text { 26-28\% (Olsen et al., 2014; Hummon et al., } \\
\text { 2014) }\end{array}$ & $\begin{array}{l}\text { 7-17\% (Olsen et al., 2014; Hummon et al., } \\
\text { 2014; Watson, 2013) }\end{array}$ & 30-40s (Watson, 2013) \\
\hline
\end{tabular}

Note: The potentials on humidifiers have been excluded due to the fact that little is reported on them.

Figure 13 Energy flexibility results from past studies (Aduda et al., 2016)

Aduda et al. (2016) also conducted experiments on a case study non-residential building to assess the load reduction ability from demand-side flexibility strategies. The strategies were the cyclical operation of air supply fans and cooling systems. The study concluded that a $30 \%$ to $60 \%$ reduction in peak power over 120 minutes could be realised while maintaining indoor air quality within the local codes. Though the result represents potential to reduce peak loads and that there is some flexibility in existing office buildings, Aduda et al., (2017) acknowledged more research of other demand-side flexibility strategies should be conducted. These strategies include fixed operational schedules or modulated operation of equipment, pre-cooling, and operation of equipment at partial load.

Christantoni et al. (2015) tested the demand response potential of a multi-purpose building. They tested this by preconditioning zones to shift load, relaxing temperature setpoints, and switching equipment off and on to shed load. They found that an $8 \%$ reduction in baseline loads was possible over one hour.

Weiß et al. (2018) investigated energy flexibility but in residential buildings in Austria. A dynamic building simulation programme was used to test shifts in heating loads from a radiator system while considering the impact on occupant comfort. The results from the study showed that at least " $50 \%$ of domestic heating peak loads can be shifted to off-peak periods" (p. 15).

Similarly, Six et al. (2011) and D'hulst et al. (2015) showed that energy flexibility could be achieved in residential buildings using electrical appliances such as heat pumps, washing machines, and domestic hot water. The results are presented in different forms. Six et al. (2011) presented the result as time and stated 0.5 to 1 hour of flexibility can be achieved. D'hulst et al. (2015) stated that a 300MW decrease in demand via flexibility could be achieved and be sustained for 15 minutes, specifically at $10 \mathrm{pm}$ in the weekend, from a cluster of buildings. 


\subsubsection{THE DRAWBACKS OF ENERGY FLEXIBLE BUILDINGS}

\section{Comfort is often ignored}

Aduda et al. (2018) and Reynders et al. (2018) recognise that achieving flexibility can come at the expense of indoor environmental comfort. However, they challenge this consequence and state that it is essential for occupant comfort to be met while delivering energy flexibility. Unfortunately, it is apparent that many studies ignore comfort as a key parameter (Aduda et al., 2018; Hurtado Munoz, 2017). Parameters could include those used by Aduda et al. (2016) such as temperature, carbon dioxide concentration, and the Predicted Percentage Dissatisfied (PPD). Aduda et al. (2018) also acknowledge this is particularly tricky as many sources of flexibility are also sources of indoor environmental conditioning.

\section{Trade-off between demand reduction and energy consumption}

By energy flexibly operating buildings, there is a potential trade-off between reducing peak demand and increasing total energy consumption (Weiß et al., 2018). However, in some circumstances, a reduction in peak demand can also result in a decrease in energy consumption. The following studies presents an example of both situations.

Stafford (2017) demonstrated the trade-off between reducing peak demand with an increase in energy consumption. They tested the load-shifting potential of hybrid heat pump/gas-boiler systems and measured the energy penalty. The energy penalty was defined as the increase in total energy consumption from a load shift. The resulting energy penalty for the systems tested was a 4 to $7.5 \%$ increase of the original consumption.

Contrary to the finding by Stafford (2016), in a local study by Pollard \& Berg (2018), reducing peak loads can also reduce energy consumption. The study presented the power demand and energy consumption of a heat pump operated in two ways: 1) when it was turned on and off and 2) when it was left on continuously. The continuous operation resulted in lower peaks and less energy consumption by $13 \%$. 


\subsection{DEFINING AND MEASURING ENERGY FLEXIBILITY}

\subsubsection{HOW HAS ENERGY FLEXIBILITY BEEN DEFINED?}

There are various forms of energy flexibility and the terminology can be confusing. Often different terms are added onto the start of "flexibility" for example: "energy flexibility", "demand flexibility" and "demand-side flexibility". In many cases, different words mean similar things. Many authors suggest that there is no consistent understanding of flexibility (Christantoni et al., 2016; Cui et al., 2015; Yin et al., 2016; Hurtado Munoz, 2017; Bode et al., 2017). The International Energy Agency's (IEA) Energy in Buildings and Communities Programme also noted that there was variability in early international research work and therefore needed to derive common terminology and definition (Jensen, 2016). This section outlines the definitions and variability of "flexibility" in literature when it comes to buildings and energy specialisations. Despite the variability, the review demonstrates that there is a strong consensus on the principle of flexibility. Table 4 lists flexibility terms, the definition, and the references that use each definition. Articles that had a stronger building component were of greater interest in this thesis. The 'Building Specific?' column is ticked if it had a greater focus on buildings. Each definition is categorised by the main object or system which is energy flexible. There are six categorisations:

\section{Categorisations/key:}

\begin{tabular}{|ll}
\hline 1. & Buildings \\
\hline 2. & General Systems \\
\hline 3. & Power Systems \\
\hline 4. & Devices or Installations \\
\hline 5. & General Supply and Demand Balance \\
\hline 6. & Consumer/user \\
\hline
\end{tabular}


Table 4 Definitions of various flexibility terms used in literature

\begin{tabular}{|c|c|c|c|}
\hline Term & Definition/s & References & $\begin{array}{l}\text { Building } \\
\text { specific? }\end{array}$ \\
\hline $\begin{array}{l}\text { Energy } \\
\text { flexibility }\end{array}$ & $\begin{array}{l}\text { The ability for a building to manage its demand and } \\
\text { generation according to local climate conditions, user } \\
\text { needs, and energy network requirements. This will then } \\
\text { enable demand response management/load control of } \\
\text { the building based on the requirements of the grid. }\end{array}$ & Jensen et al. (2017) & $\checkmark$ \\
\hline $\begin{array}{l}\text { Energy } \\
\text { flexibility }\end{array}$ & $\begin{array}{l}\text { Energy flexibility refers to the thermal mass and any } \\
\text { other building integrated physical entity that can store } \\
\text { energy. The buildings energy flexibility is also associated } \\
\text { with the applied control strategy. }\end{array}$ & Finck et al. (2016) & $\checkmark$ \\
\hline $\begin{array}{l}\text { Energy } \\
\text { flexibility }\end{array}$ & $\begin{array}{l}\text { The ability of a system to respond to changes in net } \\
\text { load/demand. }\end{array}$ & $\begin{array}{l}\text { Billanes et al. (2017) } \\
\text { References to: } \\
\text { Lannoye et al. (2015); } \\
\text { Papalexopoulos et al. (2016). }\end{array}$ & $\begin{array}{l}\text { No } \\
\text { No }\end{array}$ \\
\hline $\begin{array}{l}\text { Demand } \\
\text { flexibility }\end{array}$ & $\begin{array}{l}\text { The capacity of the system to react and adapt in a } \\
\text { tolerable time to unforeseen events is known as } \\
\text { flexibility. }\end{array}$ & $\begin{array}{l}\text { Hurtado Munoz et al., (2015) } \\
\text { References to: } \\
\text { Entso-e (2004); } \\
\text { Ulbig and Andersson (2012) }\end{array}$ & $\begin{array}{l}\checkmark \\
\text { No } \\
\text { No }\end{array}$ \\
\hline $\begin{array}{l}\text { Energy } \\
\text { flexibility }\end{array}$ & $\begin{array}{l}\text { The flexibility of a specific system is the ability to shift } \\
\text { the consumption of a certain amount of electrical power } \\
\text { in time. Flexibility is measured by the number of hours } \\
\text { electricity consumption can be delayed or anticipated. }\end{array}$ & $\begin{array}{l}\text { Lopes et al. (2016) } \\
\text { References to: } \\
\text { Six et al. (2011) and } \\
\text { Nuytten et al. (2013) }\end{array}$ & $\checkmark$ \\
\hline $\begin{array}{l}\text { Demand } \\
\text { flexibility }\end{array}$ & $\begin{array}{l}\text { The changes in consumption/injection of electrical power } \\
\text { from/to the power system from their current/normal } \\
\text { patterns in response to certain signals, either voluntarily } \\
\text { or mandatory. }\end{array}$ & $\begin{array}{l}\text { Hurtado Munoz (2017) } \\
\text { References to: } \\
\text { Cenelec (2014) }\end{array}$ & $\checkmark$ \\
\hline $\begin{array}{l}\text { Operational } \\
\text { flexibility }\end{array}$ & $\begin{array}{l}\text { The technical ability of a power system unit to modulate } \\
\text { electrical power feed-in to the grid and/or power outfeed } \\
\text { from the grid over time. It may also refer to very } \\
\text { different things ranging from the quick response times of } \\
\text { generation units, e.g. gas turbines, to the degree of } \\
\text { efficiency or robustness of a given power market setup. }\end{array}$ & $\begin{array}{l}\text { Stinner et al. (2016) } \\
\text { Ulbig \& Andersson (2015) }\end{array}$ & \\
\hline $\begin{array}{l}\text { Energy } \\
\text { Flexibility }\end{array}$ & $\begin{array}{l}\text { The technical ability of electrical devices to change the } \\
\text { electricity demand from the building compared to the } \\
\text { normal operation. }\end{array}$ & $\begin{array}{l}\text { Bode et al. (2017) } \\
\text { References to: } \\
\text { De Coninck \& Helsen (2016) }\end{array}$ & $\checkmark$ \\
\hline $\begin{array}{l}\text { Demand- } \\
\text { side } \\
\text { flexibility }\end{array}$ & $\begin{array}{l}\text { The use of demand-side installations to balance power } \\
\text { demand and available supply without diminishing design } \\
\text { intended functionality. Installations include connected } \\
\text { loads and storage after the traditional power meter. }\end{array}$ & $\begin{array}{l}\text { Aduda et al. (2017) } \\
\text { References to: } \\
\text { Lund et al. (2015): } \\
\text { Ulbig \& Andersson (2015) }\end{array}$ & $\begin{array}{l}\checkmark \\
\text { No } \\
\checkmark\end{array}$ \\
\hline $\begin{array}{l}\text { Power } \\
\text { flexibility }\end{array}$ & $\begin{array}{l}\text { The ability to continually balance of electricity supply and } \\
\text { demand with negligible disruption to service for } \\
\text { connected loads often in response to variability in } \\
\text { renewable energy resources (RES) based generation. }\end{array}$ & $\begin{array}{l}\text { Aduda et al. (2018) } \\
\text { References to: } \\
\text { Ulbig \& Andersson (2015) }\end{array}$ & $\checkmark$ \\
\hline $\begin{array}{l}\text { Power } \\
\text { flexibility }\end{array}$ & $\begin{array}{l}\text { The ability to cost-effectively balance electricity supply } \\
\text { and demand continually while also maintaining } \\
\text { acceptable service quality to connected loads. }\end{array}$ & $\begin{array}{l}\text { Aduda et al. (2016) } \\
\text { References to: } \\
\text { Ulbig \& Andersson (2015); } \\
\text { Cochran et al. (2014) }\end{array}$ & $\begin{array}{l}\text { No } \\
\text { No }\end{array}$ \\
\hline $\begin{array}{l}\text { Energy } \\
\text { flexibility }\end{array}$ & $\begin{array}{l}\text { The possibility to change (more specific: adapt, deviate, } \\
\text { shift) the electricity consumption profile. Flexibility can } \\
\text { then be defined as the possibility to deviate the } \\
\text { electricity consumption from the business as usual } \\
\text { consumption at a certain point in time and during a } \\
\text { certain time span. }\end{array}$ & $\begin{array}{l}\text { Lopes et al. (2016) } \\
\text { References to: } \\
\text { De Coninck \& Helsen (2013); } \\
\text { De Coninck (2015) }\end{array}$ & $\begin{array}{l}2 \\
2 \\
2\end{array}$ \\
\hline $\begin{array}{l}\text { Demand } \\
\text { flexibility }\end{array}$ & $\begin{array}{l}\text { A customer's ability to modify their energy consumption } \\
\text { in response to an external signal. }\end{array}$ & Ayon et al., 2017 & $\checkmark$ \\
\hline
\end{tabular}

The main object of the definition is in Bold formatting. 


\section{There is no clear consistent definition}

Though definitions are clearly stated in some articles, it is evident from the literature review that many studies use the term flexibility with no consistent definition (Christantoni et al., 2016; Cui et al., 2015; Yin et al., 2016). When energy flexibility is defined, is it often inconsistent with other studies often aiming to quantify the same thing.

The definition used by Lopes et al. (2016) is about the general balance of supply and demand and in their literature review they describe two main approaches to achieve energy flexibility in buildings: (1) thermal energy storage, which could align more with the Building categorisation; and (2) appliance operation which could align more with the Devices or Installations categorisations. Both approaches aim to defer energy consumption times.

The definitions listed in Table 4 could fit within the two approaches suggested by Lopes et al. (2016). The use of 'electrical devices' and 'power system units' identified by Bode et al. (2017) and Stinner et al. (2016) are categorised as Devices or Installations, an indication of the second approach. Aduda et al. (2017) use 'demand-side installations' also categorised as Devices or Installations, but they state that the installation relates to both storage (approach 1) and connected loads (approach 2) after the traditional power meter. Finck et al. (2016) explicitly state that energy flexibility refers to "the thermal mass and any other building integrated physical entity that can store energy" (p. 1), an indication of both approaches.

The term energy flexibility is briefly discussed by Aduda et al. (2018) and is not explicitly defined due to the topic being "not entirely new" (p. 2). However, based on this review of definitions, although not entirely new as stated by Aduda et al. (2018), the definition of energy flexibility has not been entirely clear. To conclude, Reynders et al. (2018) summarise that the similarity between most definitions was that flexibility is the ability for something, whether an appliance or thermal storage, to change or adapt its energy or electricity consumption without jeopardizing technical and comfort constraints. This was clear from the review of definitions. 


\subsubsection{WHAT DOES ENERGY FLEXIBILITY MEAN IN THIS RESEARCH?}

Although each definition is the same in principle, a definition that is commonly agreed upon was needed for this research. The IEA's Energy in Buildings and Communities Programme contains a body of international researchers tasked to provide insight into energy flexible buildings. One of the aims of the programme was to develop common terminology and a consistent definition of what an energy flexible building is. Therefore, this thesis adopts that definition which states that energy flexibility is...

\section{The ability for a building to manage its demand and generation according to local climate conditions, user needs, and energy network requirements. This will then enable demand response management/load control of the building based on the requirements of the grid.}

The energy flexibility of a building is, therefore, a service to an energy system such as the surrounding electricity grid network. The service could be thought of as "the amount of power and energy within a given period that can be changed on request" (Reynders et al., 2018, p. 8). The IEA's definition was used in this thesis due to the body of contributors and because the definition has a strong focus on buildings.

\subsubsection{HOW HAS ENERGY FLEXIBILITY BEEN QUANTIFIED?}

Due to the variation in definitions, Lopes et al. (2016) state:

"The development of methodologies to quantify the energy flexibility of buildings is normally affected by the definition of flexibility followed by the respective researchers. Currently, several different definitions of energy flexibility exist, each one distinct with its own methodology for quantification" (p. 2).

Hence the next question regarded the quantification of this service. In quantifying building energy flexibility Reynders et al. (2018) states there are two main approaches based on a review of past research. The first is the indirect method and the second is the direct method. The indirect method assumes an energy system or energy market context to measure the implications of energy flexibility. Measures could include operational cost savings, $\mathrm{CO}_{2}$ emission reductions, and peak power reductions. This approach quantifies the outcome of the use of energy flexibility. The direct approach uses a bottom-up approach and aims to quantify the actual energy flexibility in buildings or an individual technology offered to an energy system - the service itself. To quantify 
energy flexibility, in many studies (Hurtado Munoz, 2017; Aduda et al., 2018, Aduda et al., 2016, Stinner et al., 2016) and as Lund et al. (2015) and De Coninck \& Helsen (2013) state, there is no one metric to measure energy flexibility but multiple.

Aduda et al. (2016) conducted a field study in a building and used eight parameters to evaluate building performance during the flexible operation of a building. The parameters were a combination of indoor environmental performance indicators (thermal comfort, indoor air quality, and acceptability), power and energy specific indicators (demand reduction and energy delivered), and indicators relating to time (availability period, comfort recovery and comfort systems response time). Many indicators were used to thoroughly understand the impact of flexibility events on buildings.

Hurtado-Munoz (2017) evaluated flexibility by simulating buildings in a building performance simulation programme. Six parameters were established to measure energy flexibility which are like those used by Aduda et al. (2016). They were: ramping up/down rate, power capacity, energy capacity, comfort capacity, and comfort recovery.

\subsubsection{HOW IS ENERGY FLEXIBILITY QUANTIFIED IN THIS RESEARCH?}

This thesis takes a direct approach to quantify energy flexibility in individual buildings. Once it was understood in individual buildings, the results were converted into a single metric of demand reduction across the commercial building stock. Quantifying the demand reduction from energy flexible buildings was a two-step process summarised in Table 5.

Table 5 Two-step process to measure grid support

\begin{tabular}{|c|c|}
\hline \multirow[t]{2}{*}{ Step one } & Measuring energy flexibility in individual buildings \\
\hline & Uses multiple metrics to measure energy flexibility of individual buildings directly. \\
\hline \multirow[t]{2}{*}{ Step two } & $\begin{array}{l}\text { Converting energy flexibility into demand reduction from an aggregate of } \\
\text { buildings }\end{array}$ \\
\hline & $\begin{array}{l}\text { Uses a single metric to measure demand reduction offered by energy flexibly } \\
\text { operating an aggregate of buildings. }\end{array}$ \\
\hline
\end{tabular}


Step one resembled part of the study conducted by Hurtado Munoz (2017) that investigated demand flexibility in buildings to support grid operations. Demand flexibility was the term used in their study and was defined as:

\section{"The changes in consumption/injection of electrical power from/to the power system from their current/normal patterns in response to certain signals, either \\ voluntarily or mandatory." (Hurtado Munoz, 2017, p. 22)}

This definition had similarities with the definition used in this research. "Changes in consumption/injection of electrical power" in their study was comparable with "managing demand and generation" in this study. Similarly, "responding to certain signals" was comparable to "management/load control of the building based on the requirements of the grid."

As uncovered in the literature, there is no single metric to measure energy flexibility and comfort is often overlooked. To measure demand flexibility, Hurtado Munoz (2017) used six metrics that measured power and energy capacity, comfort, and speed of response. Table 6 describes the metrics used by Hurtado Munoz (2017) which were adopted in this thesis.

Table 6 Description of metrics used in this research

\begin{tabular}{lll}
\hline Metric & Unit & Description \\
\hline Power Capacity & $\mathrm{kW}$ or MW & The size of the flexibility delivery. \\
\hline Energy Capacity & $\mathrm{kWh}$ or MWh & The total amount of energy that is delivered as flexibility. \\
\hline Comfort Capacity & Minutes & How long the response can be sustained before the \\
& & comfort limits are reached. \\
\hline Comfort Recovery & Minutes & How long the building requires to restore the minimal \\
& & comfort level. \\
\hline Ramping Rate (up) & $\mathrm{kW} / \mathrm{min}$ & How fast the building reacts \\
\hline Ramping Rate (down) & $\mathrm{kW} / \mathrm{min}$ & How fast the building reacts \\
\hline
\end{tabular}




\subsection{SUMMARY OF THE LITERATURE}

This chapter described the energy and electricity future in New Zealand. Some key aspects of the future include increases in electricity demand, a changing energy and electricity mix to decarbonise the energy system, new technologies for more grid management options, and the adoption of distributed generation. The changes expected in the energy and electricity future indicate that there is an opportunity to use energy flexible commercial buildings as a demand-side grid management strategy to help manage the changes.

This chapter highlighted that energy flexible operation of the commercial building stock could free up generation for the electrification of transport and industry. The electrification is also expected to have significant impacts on distribution networks. Energy flexible load could be reduced (committed) much faster than retrofitting energy efficiency measures to respond to intraday peaks and to manage both non-renewable generation and network constraints that exist today. The term energy flexibility is used widely in academic literature, however a review conducted to understand what exactly energy flexibility means resulted in a variety of different definitions. Differences in reporting the energy flexibility of building also exist but overall, the literature suggests that buildings could have energy flexibility potential. They could then enable demand response and support the energy and electricity system to transition into a low carbon system. However, insight into how much reduction in electricity demand could be achieved from energy flexibly operating commercial buildings in New Zealand is yet to be understood. 
34 | P a g e 


\section{RESEARCH METHODOLOGY}

This chapter describes the methodology used to answer the following research question:

\section{How much reduction in the commercial building stock's peak demand is possible from energy flexibly operating commercial buildings?}

The most appropriate approach to answer this question was to simulate buildings and their operation using Building Energy Models (BEMS) in a whole building simulation tool. By simulating buildings, the energy performance could be predicted over a period of time and used to answer "what if?" questions (Griffith et al., 2008). The research question essentially asked "what if buildings were energy flexibly operated?" and therefore "what is the predicted outcome?" This approach was useful to inform a change in the operation of a significant number of New Zealand commercial buildings. It was used for predicting thermal comfort and peak demand reduction to establish if the reduction is sufficiently large to be considered useful for grid management. The prediction will indicate whether it is worth undertaking further study or real-world tests.

The basic concept of the methodology was based on the following opportunities:

1. Calibrated BEMs already developed - Commercial buildings in New Zealand were studied in the BRANZ's BEES project (Isaacs et al., 2014). An outcome of the study was a selection of BEMs that were statistically representative of the commercial building stock. The BEMs were calibrated against the actual energy use records of their real-world counterparts. An advantage of using these BEMs was that it provided a statistically representative sample that could estimate the performance of New Zealand's commercial building stock. The same BEMs were also used in Cory's (2016) Ph.D. thesis and resulted in a collection of datasets containing outputs from the BEMs. These datasets were also used in this thesis.

2. Variations in the contexts and measurement of energy flexibility - Since global energy systems are different, the contexts of where and how energy flexible buildings are operated to respond to grid needs are different in New Zealand compared to other countries (Jensen, 2017a). It may also be different for each building due to different user needs and the flexible systems available. This created an opportunity to select the most meaningful methodology to evaluate energy flexibility in New Zealand to answer the research question. 
3. Access to, and experience in, free software - The BEMs could be simulated in a freely available and validated program called EnergyPlus developed by the United States Department of Energy (Witte et al., 2001; Henninger et al., 2003; Henninger et al., 2004). EnergyPlus can be used to assess buildings at national building stock level (Griffith et al., 2008; Deru et al., 2007).

As the research further develops Cory's (2016) work, and data from the thesis was available, and as time constraints limited the gathering of additional real-world data, it was logical to employ a case study methodology. Groat \& Wang (2013) state the advantages of a case study includes the use of multiple sources of evidence and the generalisability to a wider population. A case study approach was useful for achieving the aims and answering the research questions for two key reasons. The first was that a single building can be used to test whether demand can be reduced and if thermal comfort can be maintained during the energy flexible operation of a building. In this research not just one case was selected, but multiple cases were selected to represent different types of buildings and thus to test the robustness of conclusions. This leads onto the second reason where selecting multiple cases was useful to understand the demand reduction across the commercial building stock by generalising the results of few buildings across a wider population.

The case study contained 48 BEMs which was a representative sample of the whole commercial building stock. The BEMs were simulated in EnergyPlus to test and measure the energy flexibility potential of individual buildings. The types of tests implemented were based on local grid needs. The results of the sample were then extrapolated to measure the reduction of the commercial building stock's peak demand.

\subsection{THE COMMERCIAL BUILDINGS EXAMINED}

The commercial building stock was examined using a statistically representative sample of commercial buildings (Isaacs et al., 2014; Cory, 2016). The commercial building stock, as mentioned earlier, refers to commercial office, retail, and mixed-use buildings across New Zealand. Commercial buildings such as schools, hotels, and hospitals were outside the scope of this study. This commercial building stock and the case study buildings (the sample) are outlined in this section. 


\subsubsection{THE COMMERCIAL BUILDING STOCK - THE POPULATION}

Buildings in the commercial building stock are categorised into three types and five sizes. The types were office, retail, and mixed-use, with mixed-use buildings referring to those with multiple commercial uses e.g. office and retail. A breakdown of the commercial building stock by size is shown in Table 7. The total floor area of the buildings in each size group covers about $20 \%$ of the total floor area across New Zealand. While floor area coverage is similar between size groups, the number of small buildings is significantly greater than larger buildings.

Table 7 Commercial building stock summary adapted by author (Cory, 2016)

\begin{tabular}{|c|c|c|c|c|c|c|c|}
\hline & Size group & One & Two & Three & Four & Five & Total \\
\hline & Floor area size & 5 to & 650 to & 1,500 to & 3,500 to & over & \\
\hline & range & $649 m^{2}$ & $1,499 \mathrm{~m}^{2}$ & $3,499 m^{2}$ & $8,999 m^{2}$ & $9000 m^{2}$ & \\
\hline & Description & Small and & & Medium & & Large but & \\
\hline & & plentiful & & & & few & \\
\hline & & & & quantity & & & \\
\hline \multirow{7}{*}{ 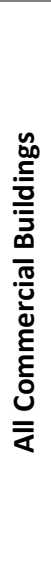 } & Approximate & & & & & & \\
\hline & number of & 19,961 & 4,680 & 1,909 & 876 & 342 & 27,768 \\
\hline & buildings & & & & & & \\
\hline & $\begin{array}{l}\text { Percentage of } \\
\text { total buildings }\end{array}$ & $72 \%$ & $17 \%$ & $7 \%$ & $3 \%$ & $1 \%$ & $100 \%$ \\
\hline & Total floor area & $5,855,000$ & $4,489,000$ & $4,230,000$ & $4,640,000$ & $5,927,000$ & $25,142,000$ \\
\hline & $\begin{array}{l}\text { Percentage of } \\
\text { total floor area }\end{array}$ & $23 \%$ & $18 \%$ & $17 \%$ & $18 \%$ & $24 \%$ & $100 \%$ \\
\hline & $\begin{array}{l}\text { Average floor } \\
\text { area }\end{array}$ & 293 & 959 & 2,216 & 5,298 & 17,330 & 905 \\
\hline
\end{tabular}


Table 8 stratifies the number of buildings in the commercial building stock by size and type. Retail buildings make up a significant proportion of the commercial building stock. A complete breakdown of buildings by size and type can be found in Appendix 8.1.

Table 8 Commercial building stock stratified by size and type

\begin{tabular}{|c|c|c|c|c|}
\hline & & Office & Retail & Mixed-use \\
\hline \multirow{2}{*}{$\begin{array}{c}\text { Size group } \\
\text { One }\end{array}$} & $\begin{array}{l}\text { Approximate number of } \\
\text { buildings }\end{array}$ & 3,709 & 12,806 & 3446 \\
\hline & Total floor area & $1,053,000$ & $3,687,000$ & $1,115,000$ \\
\hline \multirow{2}{*}{$\begin{array}{c}\text { Size group } \\
\text { Two }\end{array}$} & $\begin{array}{l}\text { Approximate number of } \\
\text { buildings }\end{array}$ & 997 & 2,365 & 1318 \\
\hline & Total floor area & 987,000 & $2,217,000$ & $1,285,000$ \\
\hline \multirow{2}{*}{$\begin{array}{c}\text { Size group } \\
\text { Three }\end{array}$} & $\begin{array}{l}\text { Approximate number of } \\
\text { buildings }\end{array}$ & 547 & 716 & 646 \\
\hline & Total floor area & $1,122,000$ & $1,572,000$ & $1,436,000$ \\
\hline \multirow{2}{*}{$\begin{array}{l}\text { Size group } \\
\text { Four }\end{array}$} & $\begin{array}{l}\text { Approximate number of } \\
\text { buildings }\end{array}$ & 314 & 224 & 338 \\
\hline & Total floor area & $1,682,000$ & $1,142,000$ & $1,817,000$ \\
\hline \multirow{2}{*}{$\begin{array}{l}\text { Size group } \\
\text { Five }\end{array}$} & $\begin{array}{l}\text { Approximate number of } \\
\text { buildings }\end{array}$ & 131 & 113 & 98 \\
\hline & Total floor area & $1,978,000$ & $2,085,000$ & $1,864,000$ \\
\hline \multicolumn{2}{|c|}{ Total number of buildings } & 5698 & 16,224 & 5,846 \\
\hline \multicolumn{2}{|c|}{ Total floor area of buildings } & $6,922,000$ & $10,703,000$ & $7,517,000$ \\
\hline
\end{tabular}

Figure 14 shows the spread of buildings by location. A third of commercial buildings are in Auckland (31\%), $17 \%$ in Wellington, and $12 \%$ in Christchurch. Although the buildings can be identified by 16 locations, Cory (2016) grouped the buildings by seven climate regions for modelling and calculations, which is demonstrated in Figure 15. 


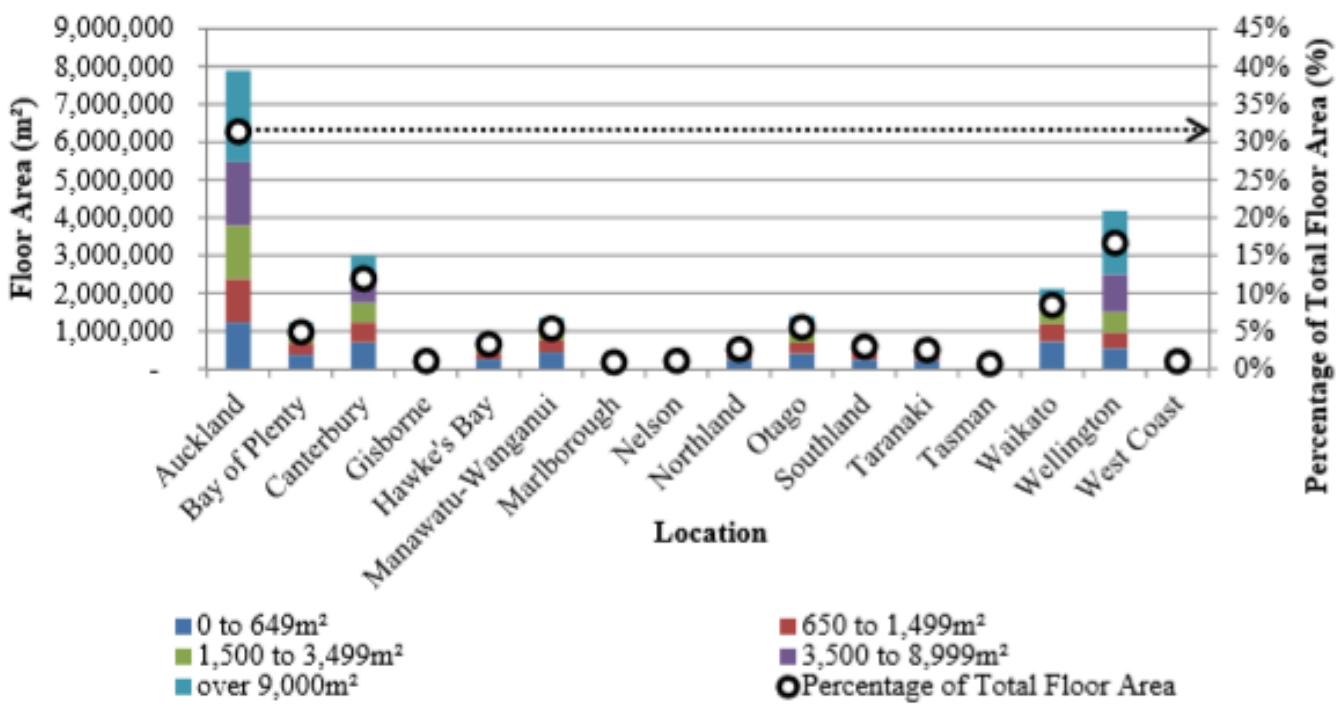

Figure 14 Spread of commercial building across 16 locations in New Zealand (Cory, 2016)

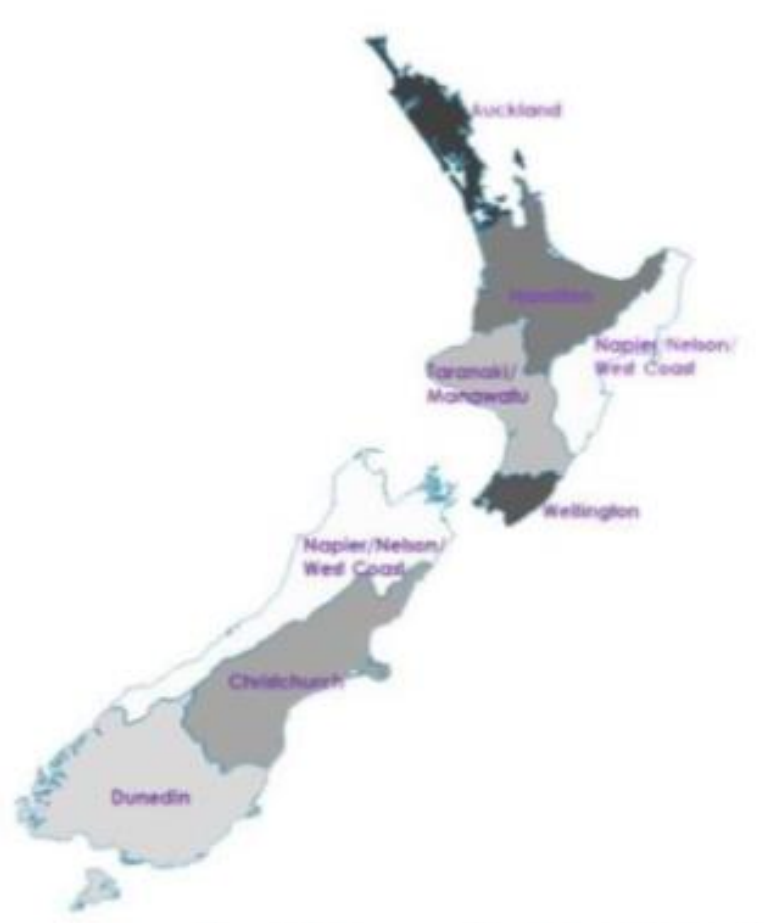

\begin{tabular}{|c|c|c|c|}
$\begin{array}{c}\text { Aggregated } \\
\text { group and } \\
\text { New Zealand } \\
\text { Commercial } \\
\text { Building } \\
\text { climates }\end{array}$ & $\begin{array}{c}\text { Weather file } \\
\text { used }\end{array}$ & $\begin{array}{c}\text { Amount } \\
\text { of floor } \\
\text { area }\left(\mathbf{m}^{2}\right)\end{array}$ & $\begin{array}{c}\% \text { of } \\
\text { floor } \\
\text { area }\end{array}$ \\
\hline $\begin{array}{c}\text { Northland / } \\
\text { Auckland }\end{array}$ & Auckland & $\begin{array}{c}12,097,86 \\
\text { Waikato / }\end{array}$ & $41 \%$ \\
\hline $\begin{array}{c}\text { Tauranga / } \\
\text { Rotorua / } \\
\text { Taupo }\end{array}$ & $\begin{array}{c}\text { Waikato } \\
\text { (Hamilton) }\end{array}$ & $2,886,308$ & $10 \%$ \\
\hline $\begin{array}{c}\text { East Coast - } \\
\text { Napier / } \\
\text { Nelson / West } \\
\text { Coast }\end{array}$ & $\begin{array}{c}\text { Napier - East } \\
\text { Coast }\end{array}$ & $1,784,312$ & $6 \%$ \\
\hline $\begin{array}{c}\text { Manawatu / } \\
\text { Taranaki }\end{array}$ & Manawatu & $1,336,576$ & $5 \%$ \\
$\begin{array}{c}\text { Wellington / } \\
\text { Waiarapa }\end{array}$ & Wellington & $7,444,195$ & $25 \%$ \\
\hline $\begin{array}{c}\text { Christchurch - } \\
\text { Canterbury } \\
\text { Dunedin / } \\
\text { Lauder / } \\
\text { Queenstown / } \\
\text { Invercargill }\end{array}$ & $\begin{array}{c}\text { Christchurch } \\
\text { Canterbury }\end{array}$ & $2,866,520$ & $10 \%$ \\
\hline Dunedin & $1,276,223$ & $4 \%$ \\
\hline
\end{tabular}

Figure 15 Split of commercial buildings by seven climate regions (Cory, 2016) 


\subsubsection{THE CASE STUDY - A SAMPLE OF 48 BUILDINGS}

In this study, a BEM counterpart was created for 48 buildings which were representative of the commercial building stock. In Cory's (2016) research, the BEMs were simulated and the results scaled and aggregated to represent the commercial building stock. The process of developing the representative sample is described in depth in Chapter 6 of Cory's (2016) Ph.D. thesis.

The sample of buildings, and thus BEMs, was selected from a pool of monitored buildings in the BEES project. This meant that real data was available to create and calibrate the BEMs to ensure accurate modelling. There were 10 BEMs in each size group, excluding size group five as only eight real buildings were monitored, and each group had a different number of building types. A breakdown of the BEMs by type is shown in Table 9.

Table 9 Breakdown of sample BEMs by type and size group

\begin{tabular}{|c|c|c|c|c|c|}
\hline & S1 & $\mathrm{S} 2$ & S3 & S4 & S5 \\
\hline & 0 & 0 & 0 & 0 & 0 \\
\hline & 0 & 0 & 0 & 0 & 0 \\
\hline & 0 & $\mathrm{R}$ & 0 & 0 & 0 \\
\hline & $\mathrm{R}$ & $\mathrm{R}$ & $\mathrm{R}$ & 0 & 0 \\
\hline & $\mathrm{R}$ & $\mathrm{R}$ & $\mathrm{R}$ & 0 & $\mathrm{R}$ \\
\hline & $\mathrm{R}$ & $\mathrm{R}$ & $R$ & $\mathrm{R}$ & $M$ \\
\hline & $\mathrm{R}$ & $\mathrm{R}$ & $\mathrm{R}$ & $\mathrm{R}$ & $M$ \\
\hline & $\mathrm{R}$ & $M$ & $M$ & $M$ & $M$ \\
\hline & $M$ & $M$ & $M$ & $\mathrm{M}$ & \\
\hline & $\mathrm{M}$ & $\mathrm{M}$ & $\mathrm{M}$ & $\mathrm{M}$ & \\
\hline Total & 10 & 10 & 10 & 10 & 8 \\
\hline
\end{tabular}

\begin{tabular}{|l|l|l|}
\hline & & Key \\
\hline & 0 & Office \\
\hline & $R$ & Retail \\
\hline & $M$ & Mixed use \\
\hline
\end{tabular}

\subsubsection{DATASET FORMAT}

Cory (2016) simulated the 48 BEMs and created an energy (electricity and gas) demand dataset. The data was collected for every hour of a typical year. In this thesis, the dataset was adapted by removing any gas demand from buildings as it was not the focus of this research, and by multiplying the results from each BEM by the number of buildings of each type and in each of the seven climate regions. The resulting dataset contained hourly electricity demand over a year from all commercial buildings across New Zealand. The dataset was comprised of the New Zealand commercial building stock where no buildings were energy flexibly operated. It represented the base case situation and is referred to as the 'base case dataset'. 


\section{Limitations in the dataset}

Each of the 48 BEMs used to create the New Zealand commercial building stock dataset was originally simulated in the climate region their real-world counterpart was located in. Therefore, simply multiplying the results by the number of buildings in each of the other six climate regions did not take into account the different performance the buildings might have when located in a different climate region.

\subsection{CREATING THE SUB-SAMPLE}

The population, represented by the sample of 48 buildings, was analysed to select a sub-sample of buildings to test and measure energy flexibility. Creating the sub-sample was done in two steps. The steps focused on selecting buildings which should and could be energy flexibly operated. The first step of the analysis was to understand which buildings might have good energy flexibility potential. These are buildings that should be tested as their demand does not align with grid signals such as peaks in non-renewable generation and network constraints. Energy flexibly operating these buildings could be beneficial and respond to grid needs (Jensen, 2016). The next step was to check that the buildings could be tested. This was based on whether the buildings have systems which could be operated in an energy flexible manner.

The analysis justified the selection of the sub-sample and, by doing this, the first research subquestion was partly answered. The sub-question was "What is the energy flexibility potential of individual commercial buildings?" It was partly answered by uncovering what opportunities for energy flexibility exists in the first instance. It then led onto which energy flexibility strategies should be applied and tested in the simulation process.

\section{Format of the dataset to select the sub-sample}

To analyse the dataset, daily load profiles (displaying demand or consumption data from 12am to $12 \mathrm{pm}$ at hourly intervals) were extracted. Daily load profiles were investigated because of the mismatches between supply and demand at the intraday timescale. The mismatches indicated the possible implementation of energy flexibility (Cory, 2016). Although variability in demand and supply can occur at other timescales (e.g., annually, monthly, and weekly (weekday/weekend)), energy flexibility can be implemented at much shorter timescales and so the intraday timescale was in focus. 


\subsubsection{GRID SIGNALS TO INFORM WHICH BUILDINGS SHOULD BE ENERGY FLEXIBLY OPERATED}

The first step was to identify when energy flexibility should be implemented in the commercial building stock based on grid signals and grid needs. To identify periods when the commercial building stock should respond better, two indicators were used. The first indicator was based on times where there are peaks in non-renewable electricity generation. The second indicator was based on network constraints.

\section{Non-renewable electricity generation as an indicator of when less electricity should be used}

Section 2.2 of the literature review illustrated the patterns of electricity generation from nonrenewable fuel sources and the commercial building stock consumption on an average summer and winter day. The charts are also copied below in Figure 16 and Figure 17 The charts showed that peaks in non-renewable electricity generation follow the ramp-up of commercial building consumption in both summer and winter. The findings of this analysis indicated that energy flexibility in the commercial building stock could be used to limit non-renewable electricity generation during morning peaks by decreasing the morning consumption. Buildings causing morning peaks were therefore chosen as candidates for the sub-sample.

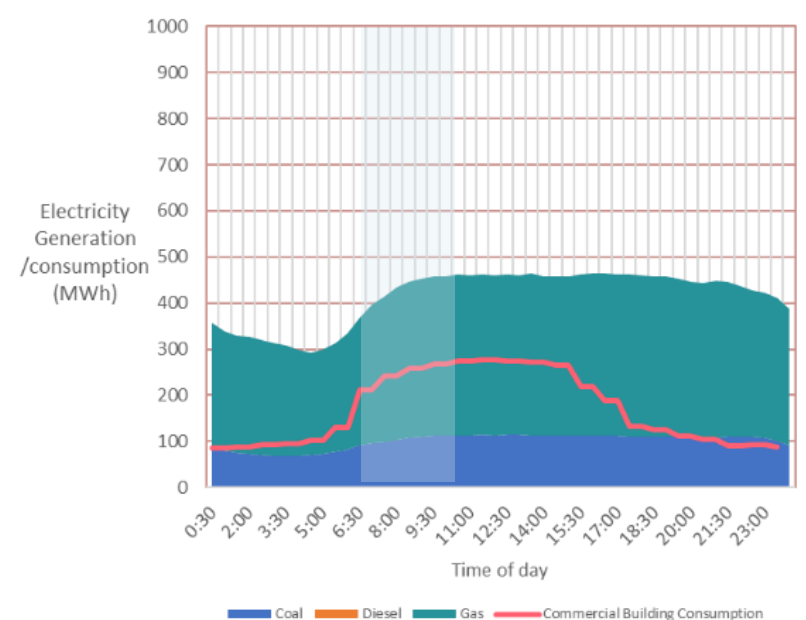

Figure 16 Non-renewable electricity generation and commercial building consumption on an average summer day.

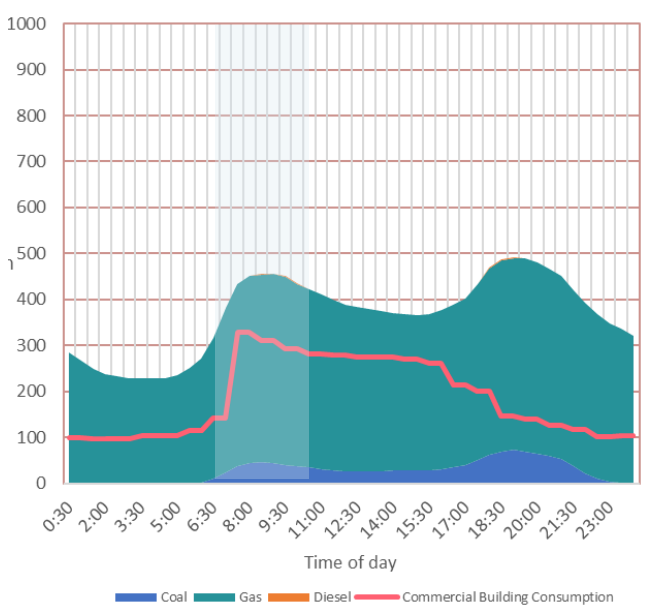

Figure 17 Non-renewable electricity generation and commercial building consumption on an average winter day. 


\section{Tariffs as an indicator of network constraint}

Based on the cost of generating and distributing electricity, shifting or shedding the demand of the commercial building stock out of peak demand periods and into off-peak periods is incentivised. This is because higher TOU prices are set in the morning and evening peak periods. This specifically means shifting or shedding demand outside of the 7am to 9am or 11am period and $5 \mathrm{pm}$ to $9 \mathrm{pm}$ period is desirable. There is also an incentive for the customer (e.g. building owners or tenants) to move demand to off-peak times to reduce costs by using lower tariffs (USDOE, 2006). Similarly, there is also an incentive to reduce peak demand based on demand changes set on the maximum usage (ENA, 2016).

Non-renewable generation and tariffs suggest that demand from the commercial building stock should be lower in the morning and afternoon peak periods.

Two indicators, non-renewable generation and TOU prices, signal that the commercial building stock should shift demand during morning and evening peak periods to non-peak periods or shed demand during these peak periods. The first indicator signals that there is a higher proportion of non-renewable generation in the morning and evening, and therefore, high demand is not desirable. The second indicator signals to the customer that there is value in reducing demand during morning and evening peak periods. This is because at these times the average cost of generating and delivering electricity is higher.

\subsubsection{BUILDINGS THAT SHOULD BE ENERGY FLEXIBLY OPERATED}

At a commercial building stock level, during the peak periods, the highest demand occurs in the winter morning. This is demonstrated in the review of the commercial building stock electricity use earlier in section 2.2 of the literature review. The winter morning peak from the commercial building stock does not respond to the grid signals as described in the previous section. Therefore, buildings selected for the sub-sample were those that were significant contributors to this peak. This section breaks down the commercial building stock demand by size group and type in order to diagnose the key contributors of this peak. 


\section{Commercial building stock winter morning electricity demand by size group}

Figure 18 shows the average winter daily demand profile of the commercial buildings stock by size group (S1-5) and the total power demand from all size groups (dashed). The graph illustrates that the ramp-up of electricity demand for buildings in all size groups is from about 6am. Size groups three to five have relatively flat demand profiles throughout the day while the smaller buildings, size group one and two, have sharp spikes between 7am and 9am. The maximum total demand from the commercial building stock was 370MW.

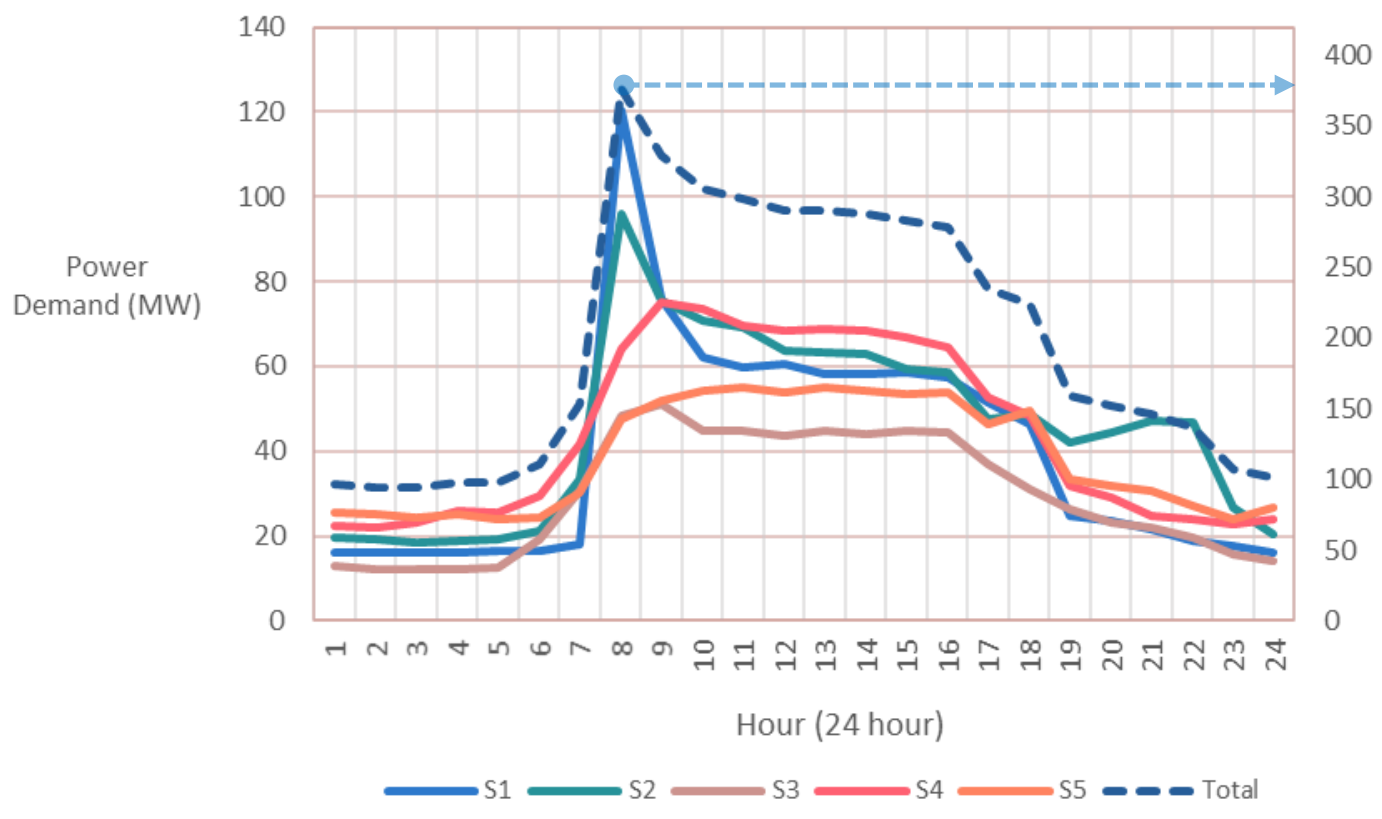

Figure 18 Average winter day electricity demand by size group and total power demand from all groups.

Buildings in the two smallest size groups were found to have much higher demand during the winter morning peak period. This analysis found that there may be an opportunity for energy flexibility and therefore energy flexibility potential in small commercial buildings. 


\section{Commercial building stock winter morning electricity demand by building type}

As shown in Figure 18 above, the smallest two building size groups have sharp winter mornings peaks. Figure 19 presents the electricity demand of the commercial building stock in size group one and size group two by type. This was done to understand if there is a type of small building that is contributing significantly to the peak. For both these sizes, retail buildings contribute the most to the morning peak demand. This was likely due to a large number of retail buildings in the commercial building stock which is more than double the number of office and mixed-use buildings. The total number of buildings by type across New Zealand is summarised in Table 10.
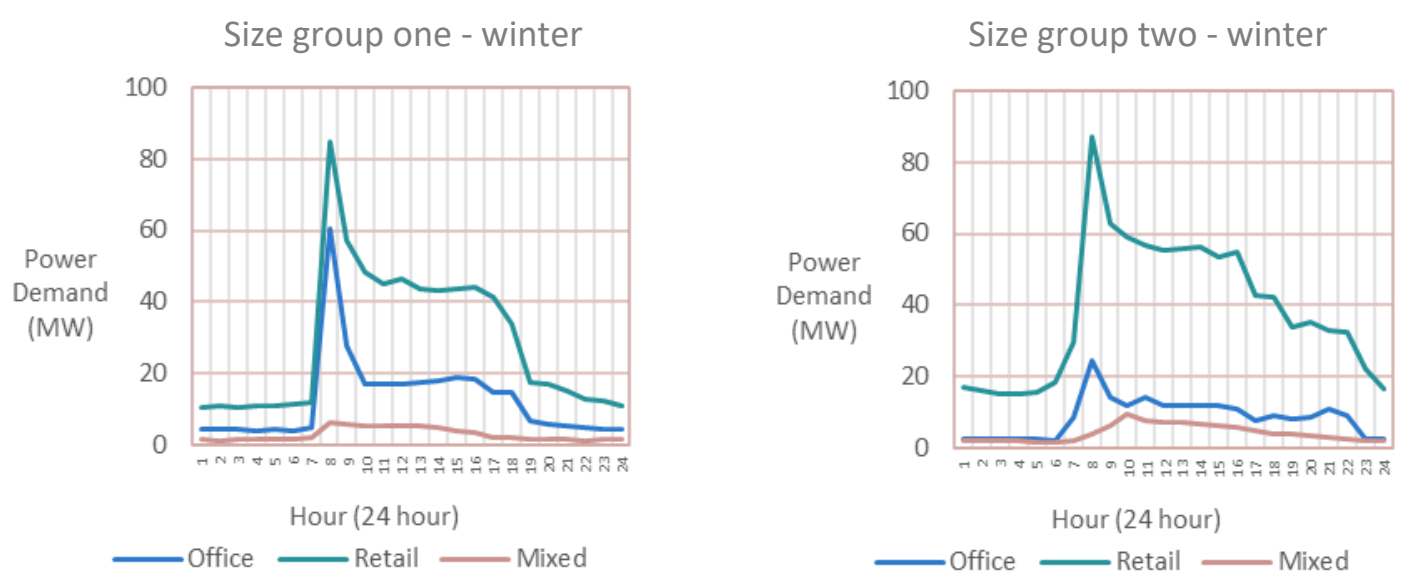

Figure 19 Average winter and summer day electricity demand by size and type.

Table 10 Number of buildings in size group one and two by type.

\begin{tabular}{rlll}
\hline & Office & Retail & Mixed \\
\hline Size group one & 3,709 & 12,806 & 3,446 \\
\hline Size group two & 997 & 2,365 & 1,318 \\
\hline Total & $\mathbf{4 , 7 0 6}$ & $\mathbf{1 5 , 1 7 1}$ & $\mathbf{4 , 7 6 4}$ \\
\hline
\end{tabular}

Buildings that should be energy flexibly operated are those that contribute to winter morning peaks.

The analysis showed that there is energy flexibility potential in small commercial buildings, particularly retail buildings, as there is an opportunity to respond better to grid signals by reducing demand during winter morning peaks. Therefore, small buildings should be energy flexibly operated and were further assessed to understand if they could be energy flexibly 
operated based on building end-uses. Although most buildings contributing to the winter morning peak were retail buildings, buildings of all types were further investigated. This was to understand if building types have different energy flexibility potential which is not influenced by the number of buildings across the commercial building stock.

\subsubsection{BUILDINGS THAT COULD BE ENERGY FLEXIBLY OPERATED}

The second step was understanding what electrical end-uses in the buildings could be used to implement energy flexible operation. These end-uses were identified based on whether they contribute to winter morning peaks and their demand response potential which was established by their load and control type. To analyse the end-uses, the BEMs in size group one and two were re-simulated at smaller time intervals.

\section{Small commercial buildings' winter morning electricity demand by end-use}

Figure 20 presents the demand profile by end-use of some buildings in size group one and two. The graphs show that the total electricity demand for each building, represented by the dotted blue line, follows the heating demand, represented by the solid blue line. Other building loads such as lighting and interior equipment remain relatively flat. It was clear that electric heating in the smallest buildings caused winter morning peaks in individual buildings during an average winter day. End-uses for all buildings in size group one and two can be found in Appendix 8.2.

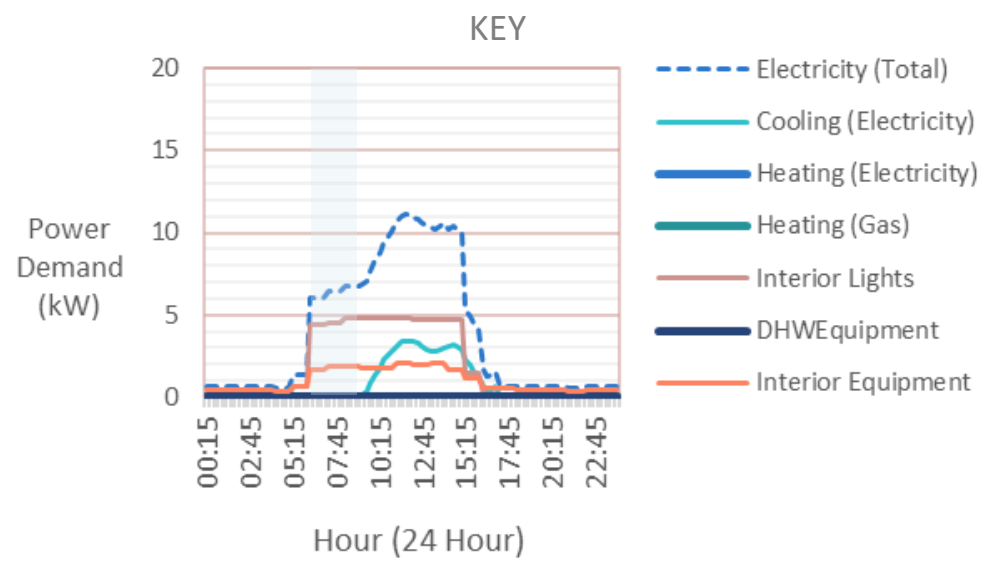



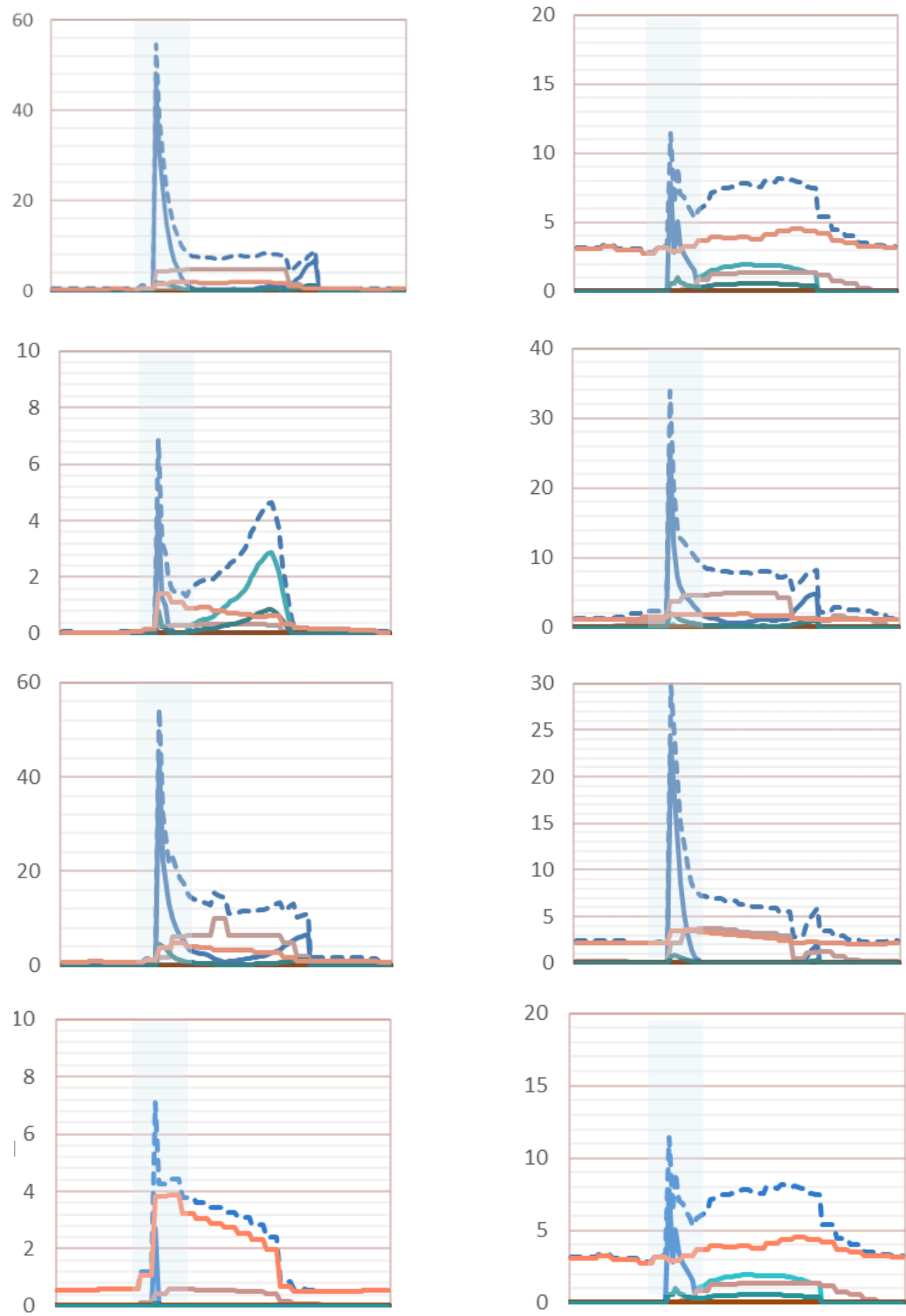

Figure 20 Average winter day electricity demand for a selection of size group one and two buildings with electric heating.

Note that y-scales are not consistent. See Appendix $\mathbf{8 . 2}$ for all profiles of buildings in size group one and two. 


\section{End-uses by control type and demand response potential}

Heating and other electrical building end-uses are grouped into four load categories. The categories are based on work in New Zealand to understand household demand management opportunities (Jack et al., 2016). Although used for household demand management, the categories also suited commercial building loads. These categories are baseline loads, userdependent loads, set-to-run loads, and autonomous loads. These categories were used to understand if heating and other end-loads could be used for energy flexible operation. They were assessed by their type of load, how the load might be controlled and therefore which demand response mechanism could be used. Table 11 defines each load categorisation and provides examples of electrical end-uses found in commercial buildings.

Some loads, such as baseline loads, must run constantly to perform tasks normally and should not be flexibly operated. However, these loads can be controlled through energy efficiency improvements. Energy efficiency improvements can take years to implement and represents a slow demand response. At the other end of the scale are autonomous loads where energy usage is separate to demand and could be controlled much faster. Electric heating loads could be categorised as user-dependent or set-to-run loads depending on the control technology. These loads could be controlled by users or be programmed to run regularly through timers and remote network control.

Table 11 Categorisation of building electricity end-uses.

\begin{tabular}{llll}
\hline Load categorisation & Definition & End-use/appliances & Type of control \\
\hline Baseline & $\begin{array}{l}\text { Appliances that must run } \\
\text { constantly to perform their } \\
\text { tasks normally. }\end{array}$ & $\begin{array}{l}\text { Wi-Fi, ICT, refrigeration, } \\
\text { computers, and printers. }\end{array}$ & $\begin{array}{l}\text { Energy efficiency } \\
\text { improvements }\end{array}$ \\
& Appliances that are turned & Computers, plug in heaters & Real-time alerts \\
oser-dependent & and fans, office kitchen & \\
& & $\begin{array}{l}\text { appliance, other plug loads, } \\
\text { lighting }\end{array}$ & \\
\hline Set-to-run & Appliances that have a delay & Heating, Ventilation and Air & Timers and remote \\
& function or are programmed & Conditioning (HVAC) & network control \\
to run regularly. & Systems, lighting, & \\
\hline Autonomous & Appliances whose usage is & Domestic hot water (DHW) & Direct load control \\
& separate to demand. & & \\
\hline
\end{tabular}


Section 2.1.2 provided an outline of demand response and different load commitment timescales and markets. Table 12 shows the control types, and therefore the load types, that are suitable for each of the different load commitment timescales and markets. Using real-time alerts or timers and remote control, heating loads could be committed at the day-ahead or day-of timescale. This means heating loads could provide energy flexibility for demand response at the intraday timescale. This means heating electricity demand could be shifted or shed to reduce winter morning peaks.

Table 12 End-use control type and the associated load commitment timescale and markets.

\begin{tabular}{lcccc}
\hline Load commitment scale & $\begin{array}{c}\text { Month } \\
\text { Operational planning }\end{array}$ & $\begin{array}{c}\text { Day-ahead } \\
\text { Economic } \\
\text { scheduling }\end{array}$ & $\begin{array}{c}\text { Day-of } \\
\text { Economic } \\
\text { dispatch }\end{array}$ & $\begin{array}{c}<15 \text { minute } \\
\text { Direct load } \\
\text { control }\end{array}$ \\
\hline $\begin{array}{l}\text { Control type } \\
\text { Capacity and forward } \\
\text { energy contracts }\end{array}$ & $\begin{array}{c}\text { Day-ahead market } \\
\text { Energy Efficiency }\end{array}$ & $\checkmark$ & & Ancillary \\
Real-time alerts & & $\checkmark$ & $\checkmark$ & \\
\hline$\underline{\text { Timers and remote }}$ & & $\checkmark$ & $\checkmark$ & \\
$\underline{\text { network }}$ & & $\checkmark$ & $\checkmark$ & $\checkmark$ \\
\hline$\underline{\text { Direct load control }}$ & & $\checkmark$ & \\
\hline
\end{tabular}

\section{Heat pumps in small commercial buildings represent an opportunity for energy flexible operation.}

Electric heating presents an opportunity to reduce winter morning peaks and to implement energy flexible operation. Heating systems across the sample included heat pumps, fan coil units (FCU), variable air volume (VAV) units, and supplementary electric and gas heaters. A breakdown of primary and secondary systems is presented for all size groups in Figure 21. In the smallest buildings, it was clear that heat pumps were the primary heating system which caused the sharp peaks in individual buildings contributing to the winter morning peaks. Therefore, heat pumps presented an opportunity for energy flexible operation. 


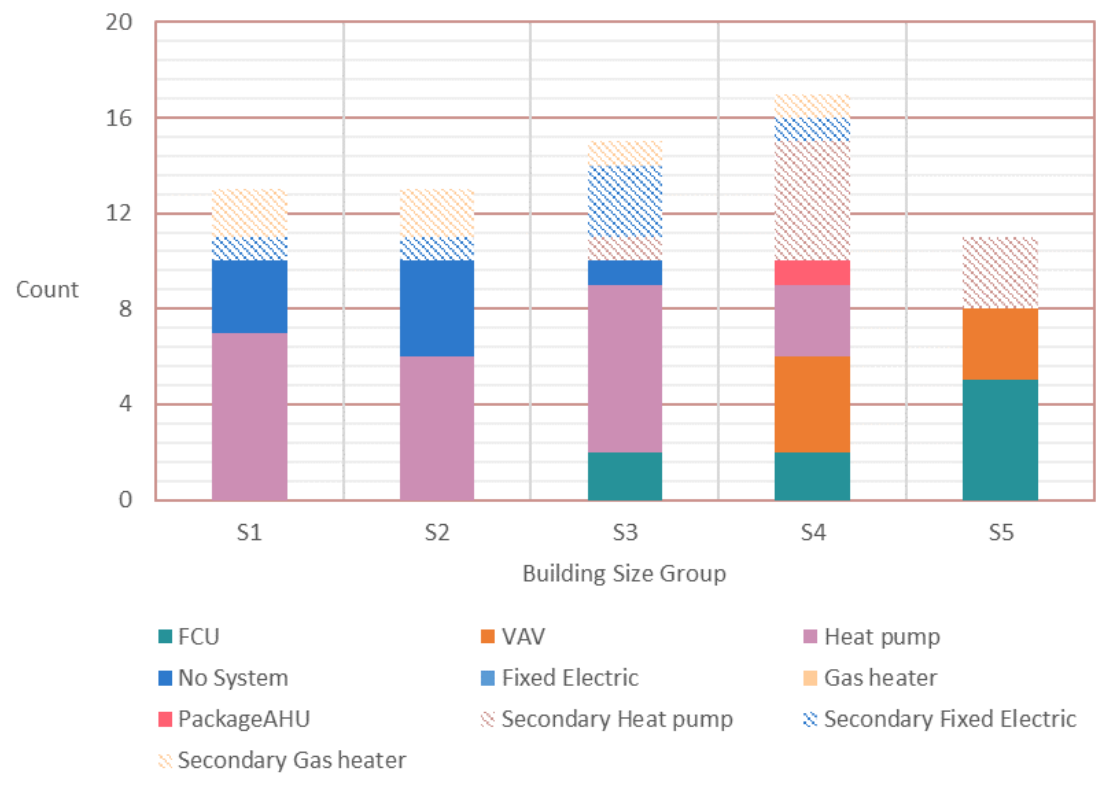

Figure $\mathbf{2 1}$ HVAC systems in the building sample by size group,

Aduda et al. (2017), Beil et al. (2015) and Billanes et al. (2017) state that commercial buildings are good energy flexibility resources due to a combination of characteristics. One of the characteristics mentioned is HVAC systems. This analysis of end-uses in New Zealand commercial buildings supports this claim. 


\subsubsection{SUMMARY OF THE SUB-SAMPLE}

To summarise, the sub-sample contained small commercial buildings between $5 \mathrm{~m}^{2}$ and $1499 \mathrm{~m}^{2}$ comprising of all building types (ORMu) and which contained heat pumps. In total there were just over 13,800 buildings which represented $53 \%$ of the total number of buildings in the commercial building stock and $24 \%$ of the commercial building stock floor area. The sub-sample is represented by 12 BEMs. Figure 22 illustrates the spread of the sub-sample across the seven climate regions.

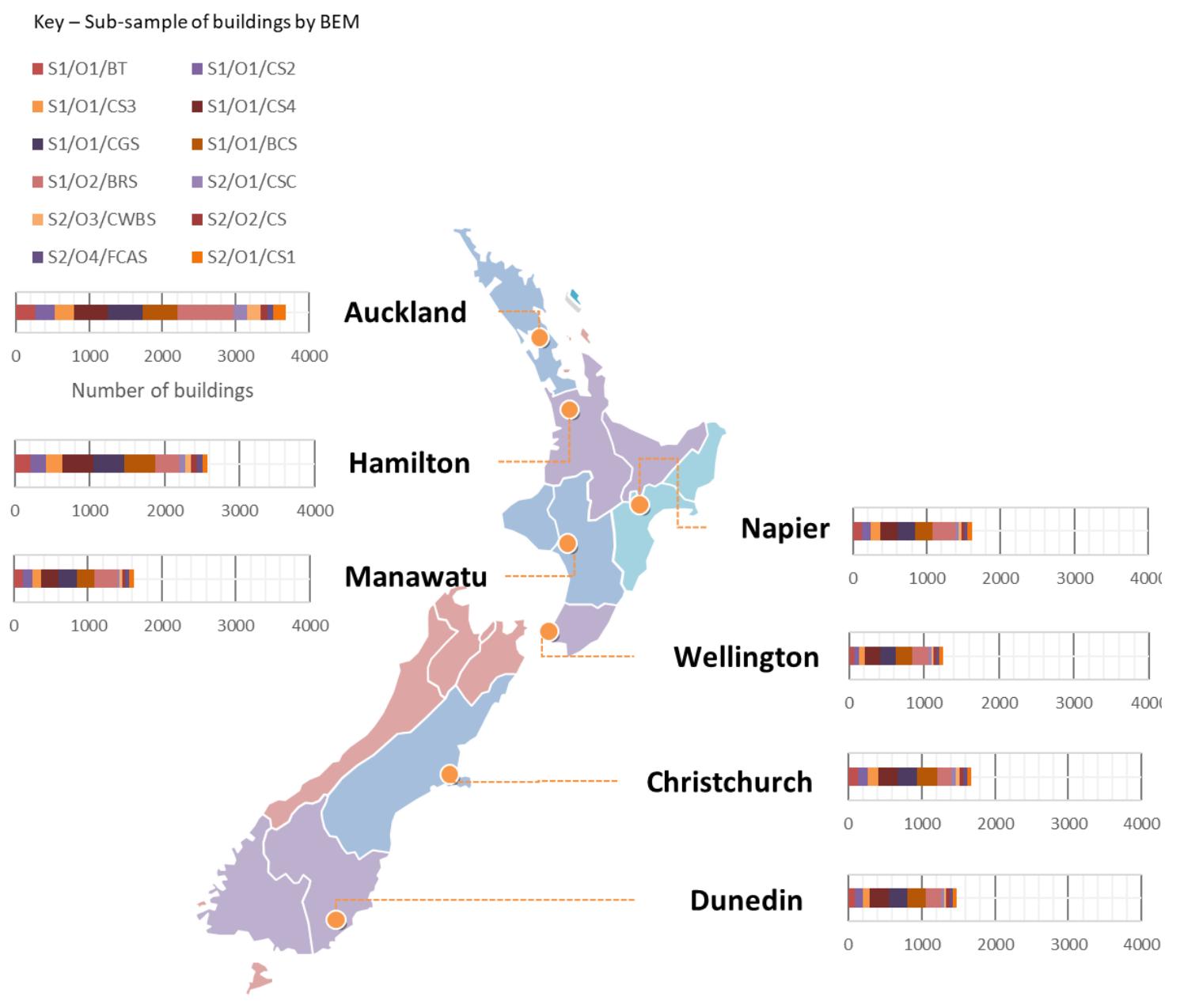

Figure 22 Number of buildings by BEM types in the sub-sample across New Zealand. 


\section{BEM code names and building descriptions}

Code names were given to each of the 12 BEMs which represented the sub-sample. A summary of the code names and a description of the buildings is presented in Table 13.

Table 13 Sub-sample code names and features

\begin{tabular}{|c|c|c|c|c|c|c|c|}
\hline Code & $\begin{array}{l}\text { Size } \\
\text { group }\end{array}$ & $\begin{array}{l}\text { Building } \\
\text { Type }\end{array}$ & Levels & Occupancy & $\begin{array}{l}\text { HVAC } \\
\text { Operation }\end{array}$ & Location & Construction \\
\hline S2/01/CS1 & 2 & $\begin{array}{l}\text { Mixed- } \\
\text { use }\end{array}$ & 2 & 2 & 9am - 5pm & Suburb & Concrete + Slab \\
\hline S1/01/BT & 1 & Office & 1 & $3-5$ & 7am - 6pm & Suburb & Brick + Timber \\
\hline S2/01/CSC & 2 & Office & 2 & $3-5$ & 10am - 10pm & City & $\begin{array}{l}\text { Concrete + Suspended } \\
\text { Concrete }\end{array}$ \\
\hline S1/01/CS2 & 1 & Office & 1 & 3-5 & $7 a m-6 p m$ & Suburb & Concrete + Slab \\
\hline S1/01/CS3 & 1 & Office & 1 & 2 & 7am - 6pm & Suburb & Concrete + Slab \\
\hline S2/02/CS & 2 & Retail & 1 & $6-10$ & 7am - 6pm & City & Concrete + Slab \\
\hline S1/01/CS4 & 1 & Retail & 1 & $3-5$ & $7 a m-6 p m$ & Suburb & Concrete + Slab \\
\hline S1/01/CGS & 1 & Retail & 1 & $3-5$ & 7am - 6pm & Suburb & $\begin{array}{l}\text { Concrete / Glass + } \\
\text { Slab }\end{array}$ \\
\hline S1/01/BCS & 1 & Retail & 1 & $3-5$ & 7am - 6pm & Suburb & Brick/Concrete + Slab \\
\hline S1/02/BRS & 1 & $\begin{array}{l}\text { Mixed- } \\
\text { use }\end{array}$ & 1 & $6-10$ & $7 a m-6 p m$ & Suburb & $\begin{array}{l}\text { Brick / Roughcast + } \\
\text { Slab }\end{array}$ \\
\hline $\begin{array}{r}\text { S2/04/FCA } \\
S\end{array}$ & 2 & Retail & 1 & $21-50$ & 7am - 6pm & & $\begin{array}{l}\text { Fibre Cement / } \\
\text { Aluminium + Slab }\end{array}$ \\
\hline $\begin{array}{r}\mathrm{S} 2 / 03 / \mathrm{CW} \\
\mathrm{BS}\end{array}$ & 2 & Office & 1 & $11-20$ & $7 a m-6 p m$ & City & $\begin{array}{l}\text { Concrete / } \\
\text { Weatherboard +Slab }\end{array}$ \\
\hline
\end{tabular}

The codes contain information about the buildings and is structured as follows:

\section{Size / Occupancy group / Construction}

There were only two sizes, 'S1' for size group one and 'S2" for size group two. There were also four occupancy groups which are outlined in Table 14 below:

Table 14 Occupancy group codes

\begin{tabular}{ccc}
\hline Occupancy group code & Occupancy & Description \\
\hline O1 & $2-5$ people & 'very few' \\
\hline O2 & $6-10$ people & 'few' \\
\hline O3 & $11-20$ people & 'medium' \\
\hline O4 & $21+$ & 'many'
\end{tabular}

The last piece of information in the code was the construction. The most common construction was concrete and a slab or 'CS'. To differentiate between buildings with the same characteristics a number was added to the end of the construction, e.g. '..CS1' and '..CS2'. Table 15 displays the BEM geometry for each building in the sub-sample. 
Table 15 BEM geometry of the sub-sample
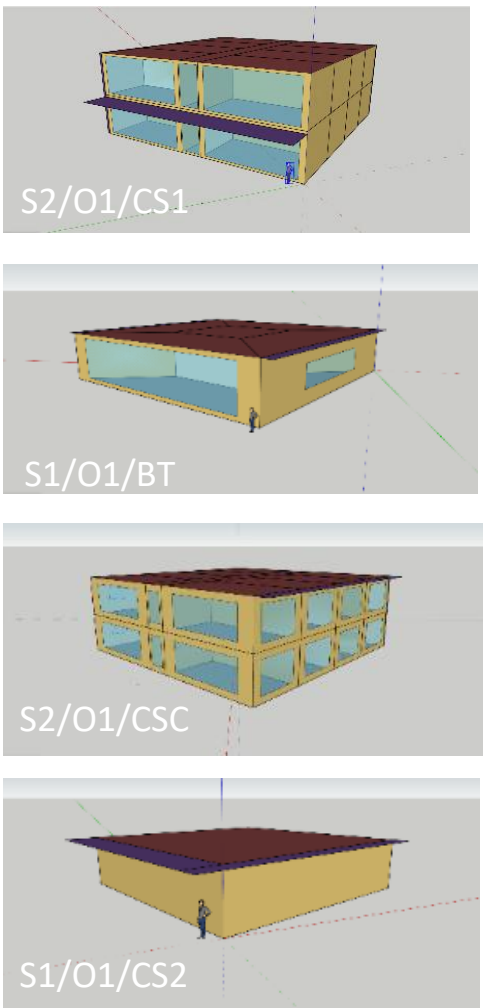
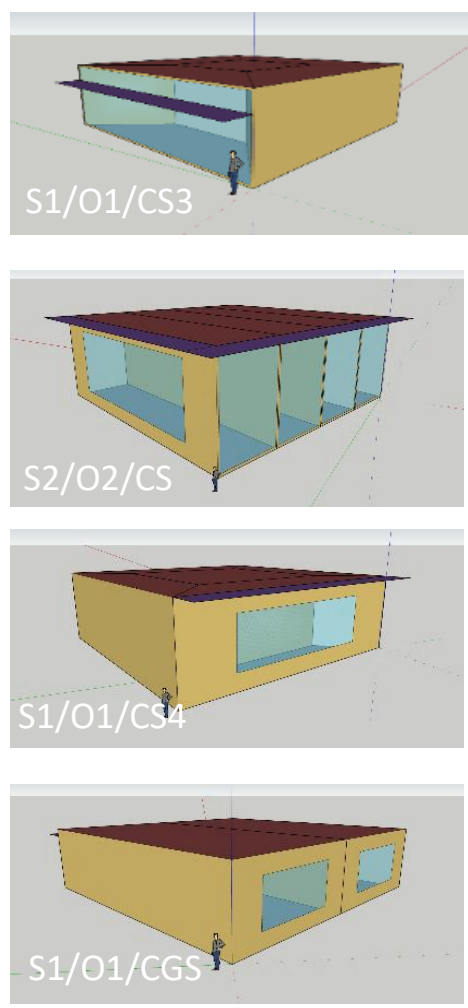
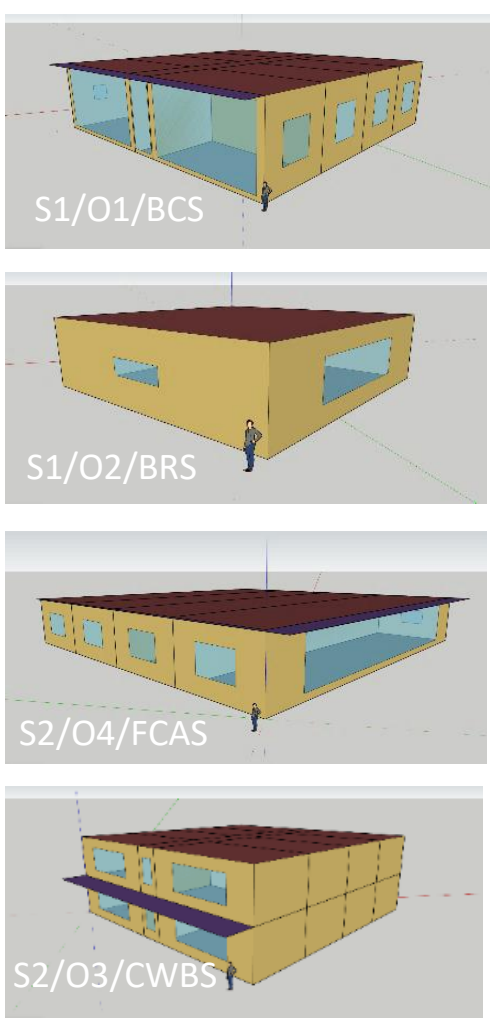

The sub-sample was selected based on buildings which could respond better to grid signals and contained useful end-uses for energy flexible operation.

The commercial building stock was analysed to select a sub-sample of buildings to test and measure energy flexibility. The sub-sample was selected based on buildings which should and could be energy flexibly operated. Buildings that should be energy flexibly operated are those that could respond better to current grid signals. These buildings are small buildings which contribute significantly to the commercial building stock demand during winter morning peak periods. For the small buildings, heat pumps were the primary cause of the winter morning peaks. The presence of heat pumps, a user-dependent or set-to-run load, indicated that there is an opportunity to energy flexibly operate heating loads. This means heating loads could be used to test energy flexibility. It also means it could be committed for demand response at the day-ahead or day-of timescale. 


\section{Justifying the selected sub-sample partly answered research sub-question 1}

Analysing the commercial building stock to create the sub-sample partly answered sub-question 1 which is "What is the energy flexibility potential of individual commercial buildings?" The analysis showed that there is energy flexibility potential in small commercial buildings that contain heat pumps. This is because they could better respond to current grid signals as there is both a sizable spike in demand and there is technical capability by which these buildings could be energy flexibly operated. This needed to be further tested.

\subsection{STRATEGIES TO MINIMISE PEAKS IN WINTER MORNING DEMAND}

The maximum demand from the commercial building stock, based on the dataset, occurred on a winter morning between 7am and 8am on the $2^{\text {nd }}$ of August of a typical year. This hour is referred to as the peak hour in this thesis. Energy flexibility strategies were selected to minimise the commercial building stock's demand in the peak hour. Only two simple energy flexibility strategies were tested. This was done to understand whether it was possible by using basic strategies to reduce demand by a large enough magnitude while maintaining comfort to see if energy flexibility is worth further investigation. The first strategy was shifting heating electricity demand away from the peak hour by preheating the building and the second strategy was shedding heating electricity demand by relaxing the setpoints during the peak hour. The strategies were tested in the subsample.

\subsubsection{THE ENERGY FLEXIBILITY STRATEGIES}

\section{Shifting demand to minimise the winter morning peak}

To minimise the winter morning peak, the electric heating demand in the sub-sample of buildings was shifted to begin earlier in the morning. This essentially preheated the building to avoid the start-up peak occurring during the peak hour. This strategy was based on Christantoni et al. (2015) where cooling of a multi-purpose building commenced three hours before the typical operation began. Christantoni et al. (2015) focused on summer operation and the energy flexibility strategy was tested in one building zone. In this thesis, all energy flexibility strategies were tested in all conditioned zones. 
Unlike Christantoni et al. (2015), who tested a single three-hour shift in cooling demand, this thesis tested four shifts of two timescales. Short shifts were conducted to test if any major or minor energy flexibility potential existed from just a small change in building operation. On the other end of the scale, long shifts were conducted to test if any additional energy flexibility potential exists by dramatically shifting demand away from the peak. The short and long shifts were grouped by two types of shifting approaches. The first approach preheated the building without any change to operation at the end of the day. The second approach preheated the building and shifted the heating demand at the end of the day. The tests are summarised in Table 16 below.

Table 16 Shifting strategy energy flexibility tests.

\begin{tabular}{clll}
\hline Approach & Test name & Morning changes & Evening changes \\
\hline \multirow{2}{*}{ Morning only } & Short shift morning only & Switch on heating 30 minutes & No changes \\
& & earlier & \\
\cline { 2 - 4 } & Long shift morning only & Switch on heating 150 minutes & No changes \\
& & earlier & \\
\hline \multirow{2}{*}{ Morning + } & Short shift morning + & Switch on heating 30 minutes & Switch heating off 30 minutes \\
& evening & earlier & earlier \\
\cline { 2 - 4 } & Long shift morning + & Switch on heating 150 minutes & Switch heating off 150 minutes \\
& evening & earlier & earlier \\
\hline
\end{tabular}

\section{Shedding demand to minimise the winter morning peak}

The second energy flexibility strategy was to shed electric heating demand during the morning peak hour. Past studies tested shedding potential by relaxing space conditioning setpoints. Christantoni et al. (2015) relaxed the air conditioning setpoint by one degree Celsius for six hours, Yin et al. (2016) relaxed the air conditioning setpoint by one, two and three degrees Celsius for an hour several times a day, and Hurtado Munoz (2017) altered the setpoints several times a day for different time durations.

In this thesis, the energy flexibility from the shedding strategy was tested by conducting a minor and major change to heating setpoints similar to Yin et al. (2016) during the peak hour. A minor and major change in setpoint was conducted to understand how much additional energy flexibility potential could be gained. The tests are summarised in Table 17. 
Table 17 Shedding strategy energy flexibility tests.

\begin{tabular}{cc}
\hline Test name & Peak hour changes \\
\hline Minor shed & Relax heating setpoint by $1^{\circ} \mathrm{C}$ \\
\hline Major shed & Relax heating setpoint by $3^{\circ} \mathrm{C}$ \\
\hline
\end{tabular}

\subsubsection{THE APPROPRIATE METHOD FOR ESTIMATING ENERGY FLEXIBILITY IN EXISTING BUILDINGS.}

The methods and tools for estimating energy flexibility had to consider the impact of thermal mass in buildings. Thermal mass will have an impact on the energy shifting capacity and therefore affect the indoor temperatures which must be suitable for the occupants and/or services (Aduda et al., 2017; Aduda et al., 2018; Hurtado Munoz et al., 2017; Reynder et al., 2018; Stinner et al., 2016; Kampelis et al. 2017; Yin et al., 2016).

The effects of thermal mass on indoor temperatures can be simulated using building performance simulation programs such as IES, DOE2.1, and EnergyPlus (Crawley et al., 2008). In these programs, BEMs are created. BEMs have a variety of uses including assessment of performance optimisation measures, comparison of the cost-effectiveness of various energy conservation measures, and building commissioning. BEMs also have the key benefit of "predict[ing] system behaviour given previously unobserved conditions" (Coakley et al., 2014, p. 3). This is particularly useful in studying the effects of energy flexibility strategies to assess building energy and thermal performance.

Given this thesis further developed the work by Cory (2016), the calibrated BEMs of real New Zealand commercial buildings were re-simulated in EnergyPlus. Using the same BEMs and program eliminated the need for extensive remodelling and avoided potential interoperability issues if another program was used. EnergyPlus was also used by Christantoni et al. $(2016,2015)$, Hurtado Munoz (2017), and Yin et al. (2016) to assess demand response and energy flexibility potential in buildings. 


\subsection{CAN THE BEMS BE TRUSTED FOR ANALYSING ENERGY FLEXIBILITY?}

The BEMs were calibrated by Cory (2016) but the models had to be checked again to ensure they could be used for the purpose of this research. There were two key parts to this process. The first part was to check that the heat pumps were modelled in a way that, under varying operating conditions, was representative of reality. To check this, a simple single-zone test BEM containing a modelled heat pump was compared against real data. The second part was to check if changes in the modelled heat pump from implementing energy flexibility strategies reflected the expected output.

\section{The importance of modelling the heat pumps correctly}

As stated by Aduda et al. (2017), Jensen et al. (2017), Christantoni et al. (2016) and Kampelis et al. (2017), HVAC in buildings can be a source of flexible load. In small commercial buildings, common HVAC systems consist of heat pumps. Heat pumps have high power demand during winter morning peaks which do not align with the grid signals from non-renewable electricity generation and network constraints. Therefore, the correct modelling of heat pumps in this research was essential to measure the potential peak demand reduction of the commercial building stock.

Gates (2013) stated "In addition to simply having a system modelled, the importance of having a matching system and correct values for the parameters modelled should be emphasised. This is because it has a significant impact on the calculated results" (p. 12) Often simplifications to BEMs are made to speed up the simulation process however, by doing this the reliability of the model can be compromised (Niemelä et al., 2016). Thus, quality assurance and calibration are important steps to accurately represent operational performance in BEMs under flexible operation (Christantoni et al., 2015a).

\subsubsection{The NeEd to QUality ASSURE THE BEMs, Again.}

Although the BEMs were calibrated by Cory (2016) and "a reasonable match [was] developed between the modelled and measured energy flows", there was a lack of evidence that the models were a good representation of the actual buildings at smaller time intervals. The BEMs were calibrated at monthly and annual intervals however Christantoni et al. (2015a) highlight that BEMs for demand response analysis requires more extensive calibration due to the timescales in which demand response is executed. They state that: 
"A building energy simulation model built for [demand response] analysis should be able to model building response to aggregator/utility request . . . in a time range from 15 minutes to several hours (usually 24 hours). For this reason, a [demand response] simulation model requires a more extensive calibration not only for the building electric power demand but also for the zone comfort parameters that are affected by [demand response] strategies. Thus, calibration using 15-minute time step data is required in order for the model to be reliable for [demand response] demonstration" (Christantoni et al., 2015a, p. 2).

Checking the trustworthiness of the BEMs at smaller intervals was essential however recalibration was not feasible due to limitations in sourcing suitable granular data from the real buildings. Real data from residential heat pumps in New Zealand was available but calibration using this data was not suitable as the operation of the commercial buildings modelled and residential buildings would not be the same. Nonetheless, the real data was used to run tests to check the trustworthiness of the modelled heat pumps.

Overall, to quality assure the models for estimating energy flexibility, three types of checks were conducted. These are summarised in Table 18.

Table 18 Model reliability testing framework.

\begin{tabular}{|c|c|c|}
\hline \multicolumn{3}{|c|}{ Testing framework to check the reliability of the model at smaller timesteps } \\
\hline $\begin{array}{l}\text { Granularity of } \\
\text { information }\end{array}$ & Check 1 & $\begin{array}{l}\text { Test if shorter timesteps in the model provided more useful } \\
\text { information. }\end{array}$ \\
\hline \multirow{2}{*}{$\begin{array}{l}\text { Heat pump } \\
\text { reliability }\end{array}$} & Check 2 & $\begin{array}{l}\text { Test if the modelled heat pumps reflect the expected energy } \\
\text { demand and temperature under different conditions. }\end{array}$ \\
\hline & Check 3 & $\begin{array}{l}\text { Test if the peaking characteristics of the modelled heat pumps are } \\
\text { reasonable. }\end{array}$ \\
\hline $\begin{array}{l}\text { Reflecting energy } \\
\text { flexibility }\end{array}$ & Check 4 & $\begin{array}{l}\text { Test if the inputs to inform energy flexible operation reflects the } \\
\text { expected shifts in electricity demand. }\end{array}$ \\
\hline
\end{tabular}

The first check was to investigate if the timesteps and reporting frequency reflected extra detail useful for investigating energy flexibility in buildings. Christantoni et al. (2015a) suggest that calibration at 15-minute intervals is necessary however, based on early test simulations, significant changes in demand can occur within 15 minutes. Simulations at 5, 15, and 60-minute intervals (which equals 12, 4 and 1 timestep respectively) were run to check how quickly electricity demand changed. From this check, a consistent timestep and reporting frequency for the subsequent simulations was selected. 
The second check was to test if the electricity demand of the modelled heat pumps responded as expected under various conditions. This was done by modelling a heat pump in a simple singlezone room, making changes to the BEM, and examining the results. The third check was to test if the peaking characteristics of the modelled heat pumps were representative of reality. To do this, the peaking factor of the BEMs was compared to real data.

The final check was to establish if the BEMs reflected the expected shift in electricity demand from implementing the shifting energy flexibility strategies.

\subsubsection{TESTING THE INFLUENCE OF SIMULATION TIMESTEPS AND REPORTING FREQUENCY}

Outputted energy data is often presented at hourly intervals however understanding energy loads at greater granularity was required for demand response analysis and therefore, for energy flexibility analysis (Crawley et al., 2008; Fumo et al., 2010; Christantoni et al., 2015a). In this test, a description of simulation timesteps, the timesteps and reporting frequency of the existing BEMs, and the results from simulations at a range of timesteps and reporting frequency is presented.

\section{Simulation timesteps in EnergyPlus}

There are two types of timesteps in EnergyPlus. The first type is used to define the time interval between heat and mass balance calculations; this is set in the 'Timestep' object of the program. EnergyPlus documentation notes that the use of more timesteps (less than 10-minute intervals) will have greater accuracy, while fewer timesteps (longer intervals) "lead to more dampened dynamic response[s]" (USDOE, 2019b). The second type is a system timestep which is set in the 'Convergencelimits' object and specifies the timesteps for HVAC system simulation. Reducing the timesteps, which means increasing the time intervals, will reduce the time of simulation at the expense of accuracy (USDOE, 2019a).

\section{Timesteps and reporting frequency of the existing BEMs}

The timestep for heat and mass balance calculations in the existing BEMs were set at four timesteps (15-minute intervals) or six timesteps (10-minute intervals). The system timestep of the existing BEMs was set to the default 12 timesteps (5-minute intervals). Although the BEMs were simulated at timesteps less than one hour, the results from the base case dataset were reported at hourly intervals. 


\section{Results from simulating and reporting at various timesteps}

A selection of BEMs containing heat pumps were simulated at 12 timesteps (5-minute intervals), four timesteps (15-minute intervals), and one timestep (60-minute intervals) and the results were reported at each of the timesteps. This was done to investigate which timestep and reporting frequency should be used to represent heating demand for accurately measuring and estimating energy flexibility. It was expected that more timesteps would represent heat pump energy demand more realistically, especially during periods with abrupt peaks. This was because "when data [is] reported at coarser frequencies such as hourly, then the results are averages or simple totals for all the timesteps that are contained within the larger bin of time" (US DOE, 2018a, p. $55)$.

The results of the tests showed that there was almost a $200 \%$ difference in energy demand between two 5-minute timesteps. This meant that simulating and reporting data to calibrate the BEM at 15-minute timesteps, as recommended by Christantoni et al. (2015a), loses information of how dramatically energy demand varies over a short period of time. This showed that increasing the timestep and reporting frequency of the simulations from the original settings was important to understand the peaking of heat pump energy demand. Therefore, the BEMs were simulated and reported at 12 timesteps, meaning at 5-minute intervals for the subsequent simulations.

\subsubsection{TESTING IF THE BEMS REFLECT ELECTRICITY DEMAND AND TEMPERATURE AS EXPECTED}

To test the trustworthiness of the modelled heat pumps, a simple BEM was created. The BEM was a single-zone $6 \mathrm{~m} \times 6 \mathrm{~m}$ building with one east-facing window and contained a heat pump which was modelled in the same way it was in the existing BEMs. The BEM had no people, light or electrical loads, therefore electricity demand and the temperature was reflective of only the heat pump and solar gains. Two checks were run to test the trustworthiness and limitations of the modelled heat pumps. The checks were (1) checking that the simulated electricity demand of the BEM reflected the type of climate it was located in and (2) checking that the simulated electricity demand was reasonable for heating the indoor air to the desired temperature.

\section{Checking that the simulated electricity demand reflected the type of climate it was located in}

The simple BEM was simulated using Typical Meteorological Year (TMY) weather data to represent the heat pump operated in two different climate regions. It was expected that electricity demand in a cooler climate would be greater than the demand in a warmer climate to 
meet the same temperature setpoint. This was based on the heat capacity formula where larger temperature differences between outdoor temperature and desired indoor temperature will require more energy. To check if this was true, the simple BEM was modelled in Auckland, a warmer climate region, and Queenstown, a cooler climate region. The thermal properties of the building envelope were not adjusted for the different climates.

Figure 23 shows the indoor air temperature and electricity demand results of the simple BEM in Auckland and Queenstown over a week in winter. Indoor air temperatures are higher in Auckland than in Queenstown during the weekends and nights. When the heating is switched on during the day indoor air temperatures are stable; this is because the modelled heat pump uses just enough electricity to maintain the specified setpoint, in this case $21.7^{\circ} \mathrm{C}$.

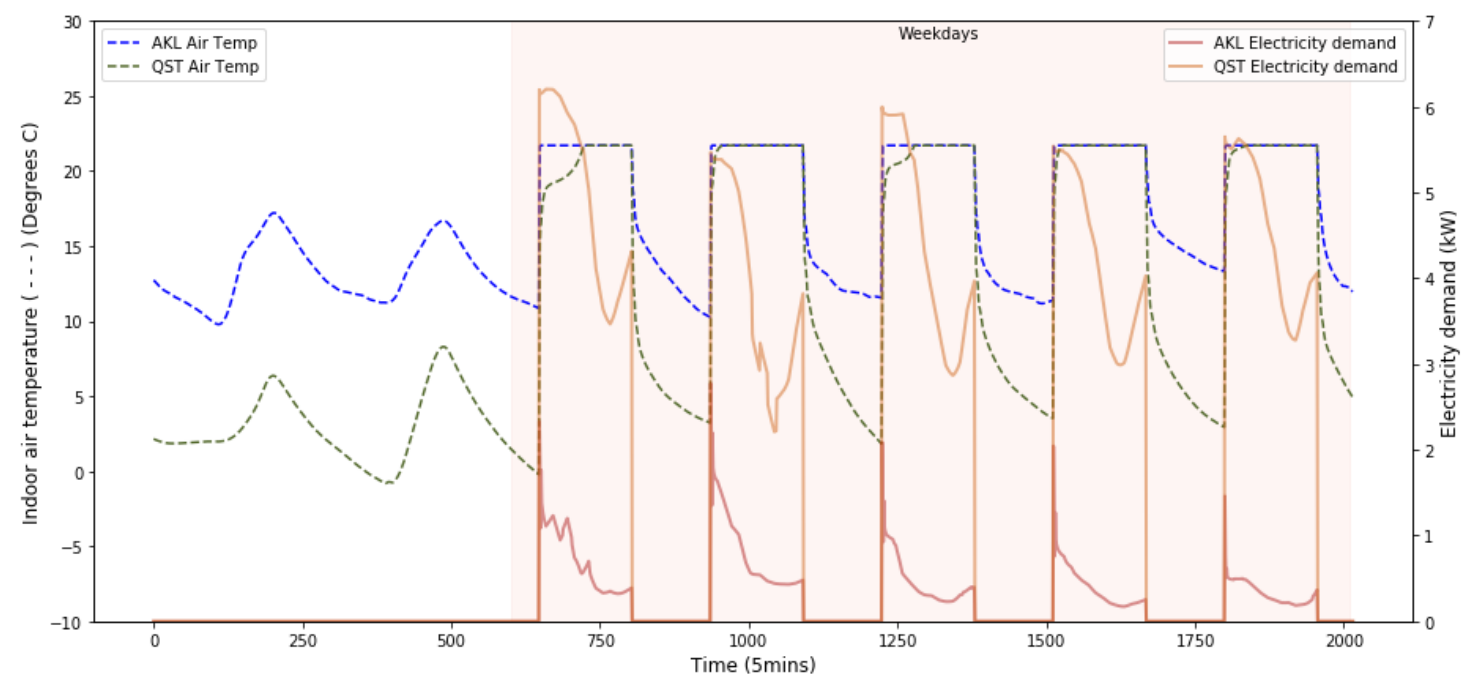

Figure 23 Indoor air temperatures and electricity demand from the simple BEM located in Auckland and Queenstown.

When the heat pumps were switched on in the morning in Queenstown, the heating setpoint was not immediately reached as it was in Auckland. This is visualised by the sags in temperature in Figure 23 and was due to much lower outdoor air temperatures requiring the outdoor unit to defrost. The outdoor air temperature at its lowest was $-5^{\circ} \mathrm{C}$, and defrost was set to occur when temperatures were below $5^{\circ} \mathrm{C}$. During defrost, electricity was used to reverse-cycle the heat pump to effectively heat the outdoor unit to remove ice build-up (USDOE, 2018b).

The graph also shows that to reach the same temperature setpoint, more electricity was required to heat the air in Queenstown than in Auckland. This was expected as it takes more energy to 
heat air when the temperature difference is greater. The test showed that the air temperatures and electricity demand reflected what would be expected in reality.

The findings in the simple BEMs were similar to those from a UK study which used real heat pump data and showed that the increase in heating energy demand is related to the temperature difference between the desired indoor temperature and low outdoor air temperature (Boait \& Stafford, 2011). Figure 24 shows the increase in average energy input as the temperature difference, in degree-days, widens.

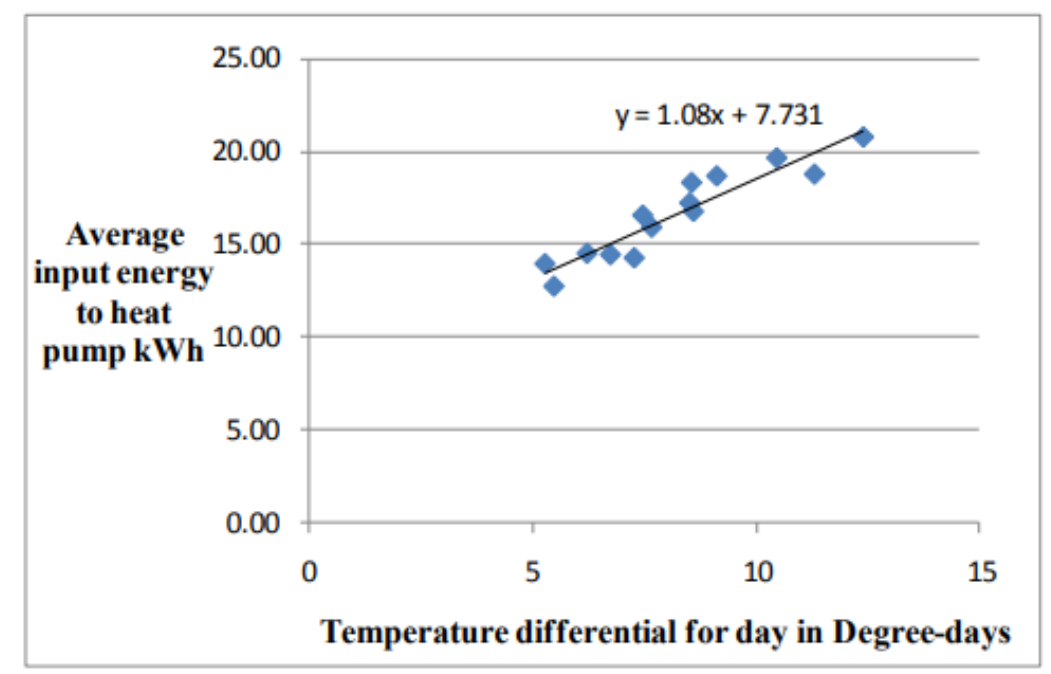

Figure 24 Heat pump load in relation to temperature differential in degree-days (Boait \& Stafford, 2011).

\section{Checking that the simulated electricity demand was reasonable for heating the indoor air to the desired temperature}

The heat capacity formula was used to calculate the energy required to meet the desired indoor air temperature. The formula is:

$$
Q=m c \Delta T
$$

Where $Q$ is the energy required to change the temperature (heat capacity), $m$ is the mass of air, $c$ is the specific heat capacity of the air, and $\Delta T$ is the change in temperature between $T_{s}$ (start temperature) and $T_{e}$ (end temperature). This equation assumes that the energy input is equal to the energy output.

Table 19 shows the energy demanded in the simulations and energy required to raise the temperature from the $T_{s}$ to $T_{e}$ as calculated using the heat capacity formula. 
Table 19 Calculated and simulated energy demand of simple BEMs in Auckland and Queenstown.

\begin{tabular}{|c|c|c|}
\hline Units in $\mathrm{KJ}$ & $\begin{array}{l}\text { Auckland } A T_{s}=11, \\
T_{e}=21.7\end{array}$ & $\begin{array}{l}\text { Queenstown B (with defrost) } \\
\mathrm{T}_{s}=0, T_{e}=18\end{array}$ \\
\hline Energy demanded in the BEM at start-up & 1,589 & 11,095 \\
\hline Difference & 370 & 9,045 \\
\hline Difference (\%) & $23 \%$ & $82 \%$ \\
\hline
\end{tabular}

The results show the energy required in the BEM was greater than the energy needed based on the heat capacity formula. This was expected as the formula does not account for energy losses through the thermal envelope, inefficiencies of the heat pump or energy used for defrosting. It was also expected that the energy required in the Queenstown BEM would be greater than in Auckland due to a greater temperature difference between the indoor air temperature and outdoor air temperature. The results suggest that in Queenstown more than $80 \%$ of the energy demanded was not consumed to heat the indoor air during start-up. It was expected that energy was required for defrosting the outdoor unit in colder temperatures before heating the indoor air. Modelling the simple BEM in a warmer and cooler region and comparing the energy results of the simple BEM with the results of the heat capacity calculation provided a clear indication that the results from heat pump models could be expected in reality.

\subsubsection{TESTING IF THE PEAKING CHARACTERISTICS OF THE BEMS ARE REASONABLE}

Simulations at greater timesteps highlighted that peaks in the BEMs can occur abruptly (within 15 minutes). Therefore, the aim of this check was to understand if the heat pumps in the BEMs produced peaks in electricity demand that were believable and representative of real heat pumps. To check this, the peaking factor and time of peaking of three BEMs with heat pumps and a singlezone BEM was compared against the peaking factor and time of peaking of real heat pump data.

\section{The modelled heat pumps in the existing BEMs:}

Three BEMs with heat pumps were selected for comparison with real data. A simple single-zone BEM with a heat pump was also created and compared with the real data. All BEMs were simulated in three climate regions; Auckland, Queenstown and New Plymouth. Auckland and Queenstown were selected to represent heat pumps in a warmer and cooler region, and New 
Plymouth was selected as the real data was collected from buildings located there. All heat pumps in the BEMs were simulated from 6am to $7 \mathrm{pm}$ and then again for 24-hours. The BEMs were simulated in different locations and for different periods to match the potential conditions the real buildings may have been operating in.

\section{The real heat pump data}

Four sets of real heat pump data were used to check the reliability of heat pump peaking in the BEMs. The first set of data was collected every five minutes over a week in August from a commercial office building in New Plymouth (Anonymous, 2018). Another three datasets were selected from the New Zealand GREEN grid household electricity demand study (Anderson et al., 2018). These datasets contained residential demand data for every one-minute over a four month period covering winter in New Plymouth.

\section{Peaking factor}

The peaking factor (PF) in this test was the ratio of the average demand to the peak demand. Peaks in this research were defined as demand in the highest $98^{\text {th }}$ percentile. Low PFs mean there is greater difference between the peak demand and average demand which indicates abrupt or exaggerated peaks. The PFs of the BEMs were calculated over the same season and length of time the real data was collected for. Figure 25 shows the PFs of the real heat pumps as red triangles and the modelled heat pumps as green dots. The PFs of all the modelled heat pumps were no lesser nor greater than the highest and lowest PF of the real heat pumps. The simple comparisons suggested that the peaking of heat pumps in the BEMs were reasonable however, the real heat pump PFs were significantly spread.

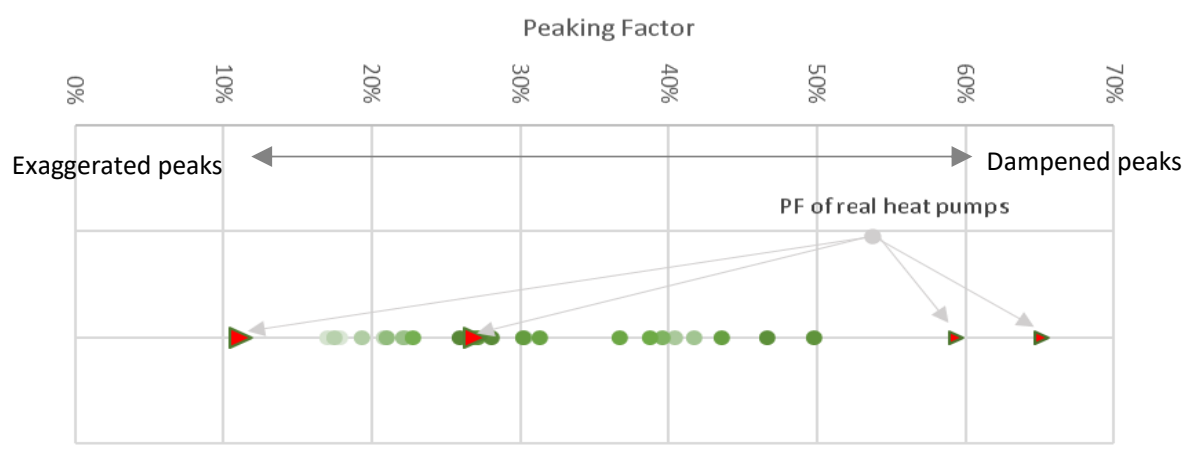

Figure 25 Peaking factor of real heat pumps and modelled heat pumps.

Red triangles represent the PF of real heat pumps and green dots represent the PF of the modelled heat pumps. 


\section{Time of peaking}

The electricity demand from heat pumps in the BEMs had single abrupt peaks during winter mornings which only lasted for short periods. Real data was again used to check if the short existence of single peaks was representative of reality. In this check the duration of peaks was measured. For each BEM and dataset from real buildings, two durations were measured; the first being the duration of the maximum measured peak and the second being the duration of the longest lasting peak.

The duration of peaks from each BEM and each real building is summarised in Table 20. The results of the test showed that the duration of the maximum measured peak in the BEMs was comparable to the real commercial and residential data. The longest lasting peak of the simulated data was comparable to the real commercial building data, however they were significantly longer for real residential heat pumps. The analysis concluded that the duration of the highest measured peaks in the BEMs reflects real data however, the longest lasting peaks in the BEMs only reflect the real commercial building data.

Table 20 Comparison of peak duration in BEMs and real data.

\begin{tabular}{lll}
\hline Building & Peak & Longest lasting peak \\
\hline Model 1 & 5 minutes & 10 minutes \\
\hline Model 2 & 5 minutes & 15 minutes \\
\hline Model 3 & 10 minutes & 10 minutes \\
\hline Real commercial & 5 minutes & 15 minutes \\
\hline Real residential 1 & 4 minutes & 35 minutes \\
\hline Real residential 2 & 20 minutes & 35 minutes \\
\hline Real residential 3 & 23 minutes & 98 minutes \\
\hline
\end{tabular}

The smallest time interval of the BEMs was 5 minutes. Shorter peaking times may have occurred.

\subsubsection{TESTING IF THE OUTPUTS REFLECT THE INPUTS FOR ENERGY FLEXIBLE OPERATION}

This section checks if the outputs of the BEMs from a shift in heating demand, informed by changing the HVAC schedule, reflects the expected results. A shed in demand was not checked as changes in setpoints have been clearly demonstrated in research by Hurtado Munoz (2017), Yin et al. (2016) and Christantoni et al. (2015). 


\section{Shifting heating demand in the BEMs}

Figure 26 illustrates a daily load profile during an average winter day after a change to the HVAC schedule was made. The on and off times of the HVAC schedule were changed to start and end 150 minutes earlier. The graph shows that electricity for heating reflects the changes made to the schedule as it peaks earlier in the morning. Flow-on effects from this simple change are also reflected in the output.

The results show that electricity for heating is required earlier and therefore the indoor air temperature also rises earlier. Also shown in the graph is a kink in heating demand from 6am to 7am. This kink occurred because a greater level of electricity was required to raise the indoor air temperature while outdoor air temperatures were still low. The dashed yellow line represents the electricity demand for heating when it was shifted only 30 minutes earlier. In this situation the kink was not pronounced as outdoor air temperatures were higher.

The result of this test demonstrated that simple changes to the HVAC schedule to inform a shifting strategy reflects the results that would be expected.

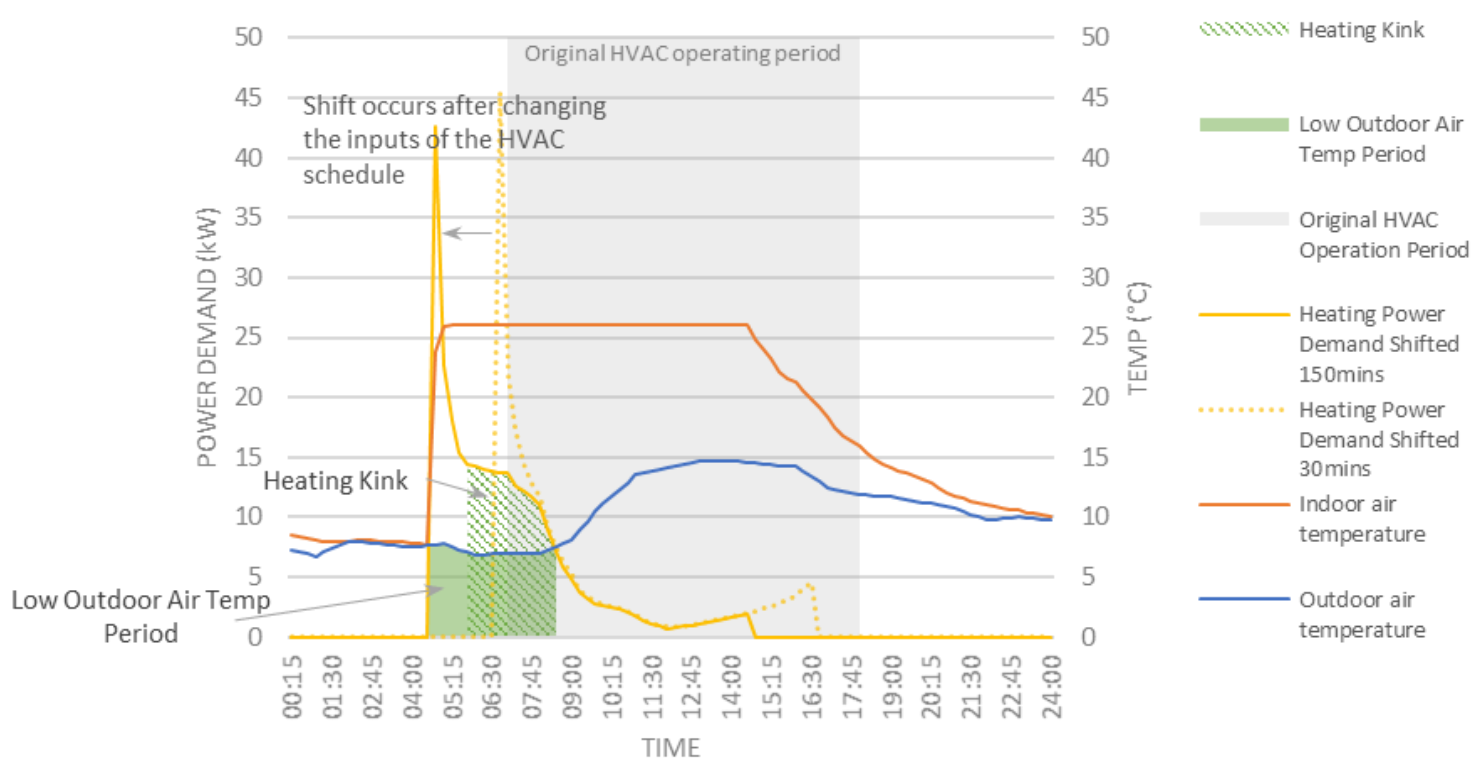

Figure 26 Test result from informing load shifts by changing the BEM HVAC schedule. 


\subsubsection{SUMMARY OF THE TESTS}

Although the existing BEMs were calibrated, Christantoni et al. (2015a) stated that calibrating BEMs for demand response analysis and therefore energy flexibility analysis should be done in much smaller time intervals than traditional calibration. Real data was not available to recalibrate the BEMs, hence a variety of tests were conducted to ensure that the reported data from the BEMs at smaller time intervals could be trusted and represent the operation of heat pumps in reality. The results from the tests in this section showed:

- Simulating BEMs at shorter timesteps reflected more useful information for evaluating energy flexibility.

- The modelled heat pumps reflect the expected electricity demand and temperature under different conditions.

- Peaking of heat pumps occurred abruptly which was consistent with real data.

- Changes to the BEMs to inform energy flexible operation is reflected in the outputs.

This section demonstrated that investigating energy flexibility using EnergyPlus was possible. The following sections describe how energy flexibility was tested and calculated in individual buildings and how the reduction in the commercial building stock's peak demand was calculated.

\subsection{ESTIMATING ENERGY FLEXIBILITY OF AN INDIVIDUAL BUILDING}

To estimate the energy flexibility potential of small commercial buildings, 12 BEMs representative of the sub-sample were re-simulated in EnergyPlus. The re-simulated BEMs had energy flexibility strategies implemented within them. For each BEM, four energy flexibility tests were implemented using the shifting strategy, and two energy flexibility tests were implemented using the shedding strategy. Each BEM was simulated in seven climate regions over the course of a year at five-minute intervals (12 timesteps). The outputted data was also reported at five-minute intervals. The result was a total of 504 annual simulations. Figure 27 illustrates the relationship between the tests, BEMs, and climate regions. 
Each test was conducted on 12 BEMs
Each BEM was simulated in 7

different climate regions

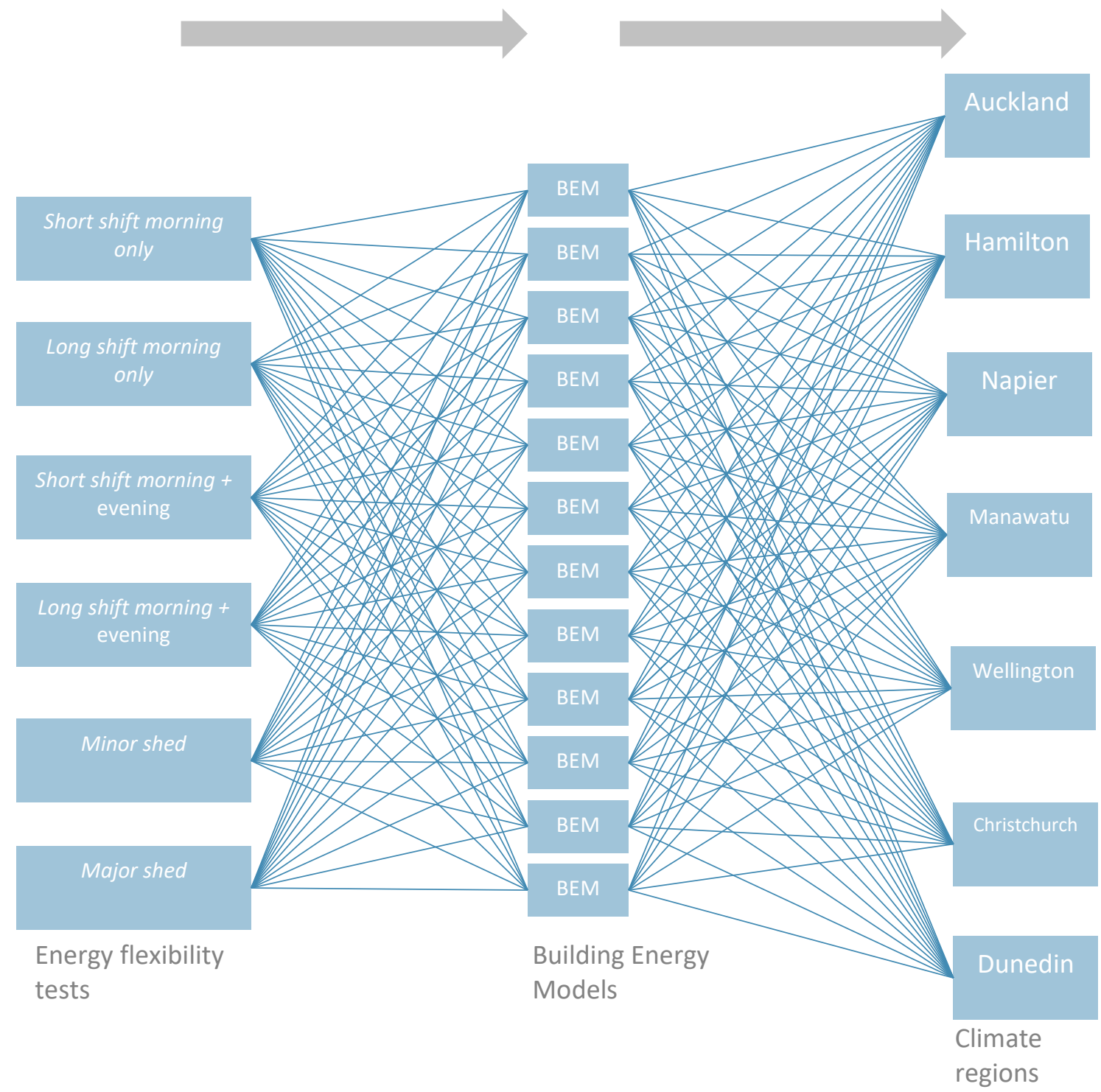

Figure 27 Simulation summary.

\subsubsection{THE EXISTING BEMS}

The BEMs were built from templates containing New Zealand specific materials, constructions and loads (Cory, 2016). They also contained EnergyPlus HVAC system templates which simplified the inputs and node connections when a new system is created. The BEMs, built from the templates, were modified using real data to match what was found in reality as closely as possible. 


\section{BEM HVAC}

The buildings in the sub-sample did not contain any complex plant. The BEMs contained autosized single speed heat pumps. The efficiencies of the HVAC system templates were assumed based on a survey conducted by Gates (2013). The survey was completed by HVAC engineers on commonly installed systems in New Zealand commercial buildings.

Ten of the BEMs operated HVAC from 7am to $6 \mathrm{pm}$. The remaining two buildings operated HVAC from $9 \mathrm{am}$ to $5 \mathrm{pm}$ and $10 \mathrm{am}$ to $10 \mathrm{pm}$. About half the BEMs had fixed heating and cooling setpoints. The other half had setpoints that varied across the year. No two BEMs had the same temperature setpoints.

\section{BEM geometry}

The geometry of the BEMs can be visualised in SketchUp, a 3D modelling program. The geometry of two BEMs is shown in Figure 28. The BEMs include floors, walls, roofs/ceilings and windows which are all assigned constructions and materials. There are also objects to represent shading surfaces from adjacent buildings and window overhangs. These are represented by the purple elements.

The BEMs are broken down into thermal zones. All thermal zones of all BEMs in the sub-sample were conditioned by a heat pump (with the exception of one building which only conditioned some zones). Outlines of the thermal zones can be seen on the roof/ceiling of the BEMs in the figures.
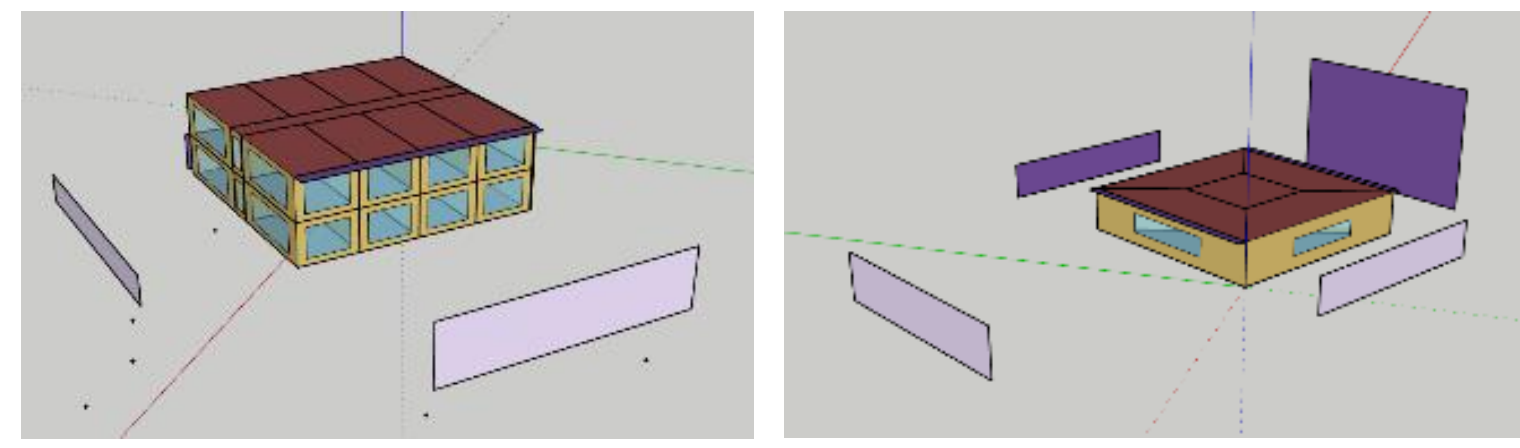

Figure 28 Visualisation of BEM geometry in SketchUp. 


\subsubsection{SIMULATION INPUTS}

\section{Implementing a shifting strategy}

To implement energy flexibility using a shifting strategy, changes were made to the HVAC schedule in all BEMs. The HVAC schedule sets out the HVAC on and off time throughout a day and a year. Figure 29(a) shows the format of an EnergyPlus HVAC schedule for a BEM that normally turns the HVAC on at 7am and off at 6pm. Figure 29 (b) shows the schedule for the same building operating under a short shift morning + evening test where the HVAC is turned on 30 minutes earlier at the beginning of the day and turned off 30 minutes earlier at the end of the day.

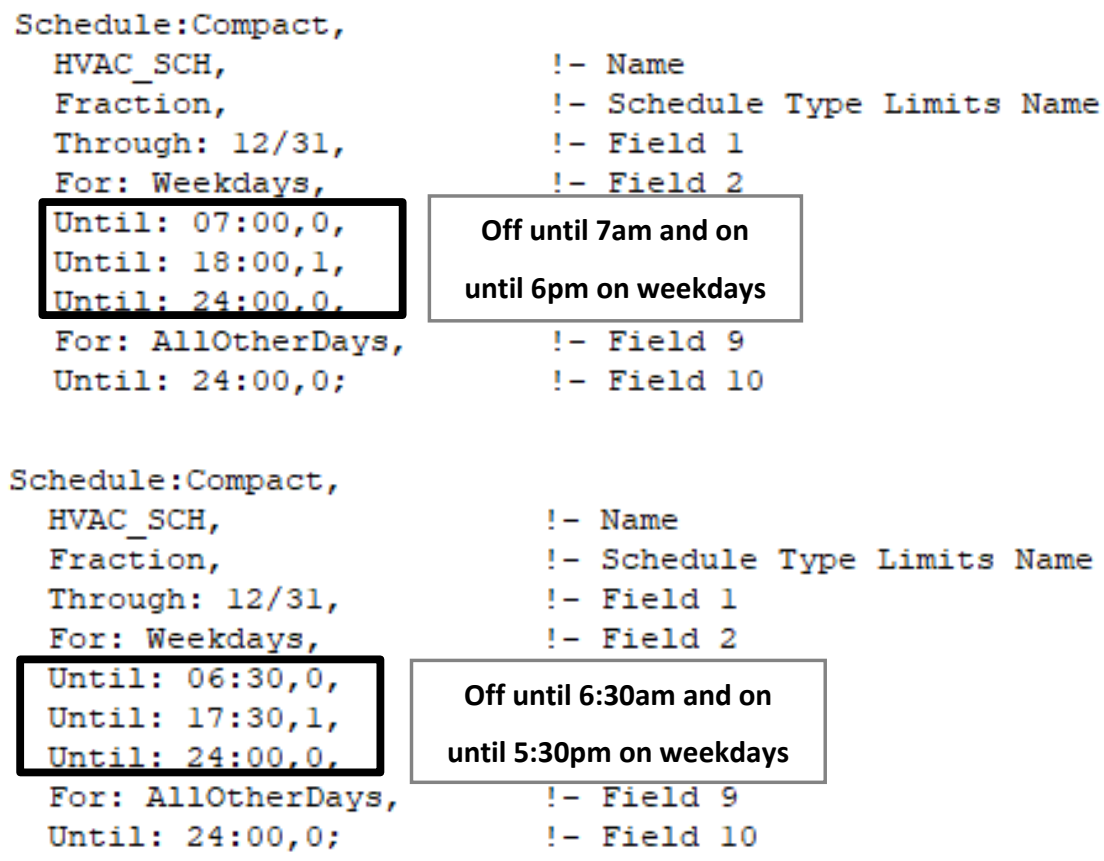

Figure 29 BEM HVAC schedule example.

\section{Implementing a shedding strategy}

To implement energy flexibility using a shedding strategy, changes were made to the thermostat setpoints. The heating setpoints for all buildings in all climate regions were reduced by 1 degree Celsius and 3 degrees Celsius to represent the Minor Shed and Major Shed tests, respectively. This was done in a similar fashion to changing the HVAC schedule. All inputs to the schedules are listed in Appendix 8.3. 


\subsubsection{SIMULATION OUTPUTS AND PROCESSING TO MEASURE ENERGY FLEXIBILITY}

The output of each simulation resulted in a .csv file which contained heating electricity data, total building electricity data, and indoor air temperatures of each thermal zone for every five minutes of a typical year. The .csv files were processed by a python script to calculate the energy flexibility metrics. The script was created based on (1) the defined period that energy flexibility was calculated for, (2) the defined comfort limits for each building, and (3) the average temperature of all thermal zones. These details are described below, and the full python script can be found in Appendix 8.4.

\section{Calculations of each energy flexibility metric}

A description of the calculations for energy flexibility each metric is provided in Table 21 . The calculations were based on the descriptions given by Hurtado Munoz (2017) but were adapted to suit the conditions of the shifting and shedding tests in this study. The calculations were translated into the python script.

Table 21 Description of metrics calculation

\begin{tabular}{|c|c|c|}
\hline Metric & Unit & Calculation formula and conditions \\
\hline $\begin{array}{l}\text { Power } \\
\text { capacity } \\
\text { (max and } \\
\min \text { ) }\end{array}$ & kW & $\begin{array}{l}\text { Shifting and shedding: The maximum and minimum difference in power } \\
\text { between the base case BEM and energy flexible BEM between the hours of } \\
\text { 7am to } 8 \mathrm{am} \text {. }\end{array}$ \\
\hline $\begin{array}{l}\text { Energy } \\
\text { capacity }\end{array}$ & kWh & $\begin{array}{l}\text { Shifting and shedding: The resulting energy consumption from subtracting } \\
\text { the energy consumption between 7am to 8am of the energy flexible BEM } \\
\text { from the energy consumption between 7am to 8am of the base case BEM. }\end{array}$ \\
\hline $\begin{array}{l}\text { Comfort } \\
\text { capacity }\end{array}$ & Minutes & $\begin{array}{l}\text { Shifting: The time from when the heating turned off until the time the } \\
\text { indoor temperatures exceed the comfort limit which is not beyond the } \\
\text { normal building operation hours. } \\
\text { Note: Comfort capacity was only calculated for tests when evening heating } \\
\text { demand was shifted to turn off earlier. } \\
\text { Shedding: Not calculated for this strategy. }\end{array}$ \\
\hline $\begin{array}{l}\text { Comfort } \\
\text { recovery }\end{array}$ & Minutes & $\begin{array}{l}\text { Shifting: Not calculated for this strategy. } \\
\text { Shedding: The time from when the setpoint returns to the original } \\
\text { setpoint, to the time when the indoor temperatures reach the } \\
\text { temperature it should have been without any changes to the operation. }\end{array}$ \\
\hline $\begin{array}{l}\text { Ramp-rate } \\
\text { (down) }\end{array}$ & $\mathrm{kW} / \mathrm{min}$ & $\begin{array}{l}\text { Shifting: The maximum power capacity delivered, divided by the time from } \\
\text { when the heating was turned on to the time the maximum power capacity } \\
\text { is delivered. }\end{array}$ \\
\hline
\end{tabular}




\begin{tabular}{|c|c|c|}
\hline & & $\begin{array}{l}\text { Shedding: The maximum power capacity delivered divided by the time } \\
\text { from when the setpoints widen to the time maximum power capacity is } \\
\text { reached. }\end{array}$ \\
\hline $\begin{array}{l}\text { Ramp-rate } \\
\text { (up) }\end{array}$ & $\mathrm{kW} / \mathrm{min}$ & $\begin{array}{l}\text { Shifting and shedding: The maximum power capacity delivered divided by } \\
\text { the time from when the maximum power capacity was reached to the time }\end{array}$ \\
\hline
\end{tabular}

Minimum energy demand in the ramp-rate (up) calculation was the minimum energy demand until the point of any increase in energy demand. Ramp-rate (down) was calculated when the heating was turned on because by turning the system on earlier, energy flexibility was provided between 7am to 8am.

\section{The defined period energy flexibility was calculated for}

The energy flexibility potential of each building was calculated during the peak hour, which was between $7 \mathrm{am}$ and $8 \mathrm{am}$ on the $2^{\text {nd }}$ of August. The peak hour was selected because the energy flexibility strategies were implemented to reduce the winter morning peaks. The day of the peak hour was referred to as the peak day $\left(2^{\text {nd }}\right.$ August). The maximum demand from the commercial building stock during the peak hour was $986 \mathrm{MW}$. The peak demand was the $98^{\text {th }}$ percentile of demand throughout the peak day and was $887 \mathrm{MW}$ in the base case scenario.

\section{Comfort limits of the buildings}

The comfort capacity was the time from when the heating was turned off until the comfort limit was reached, only during the normal operating hours of the building. Comfort limits were set to indicate when the indoor air temperatures were no longer comfortable. The comfort limit was set $5^{\circ} \mathrm{C}$ higher than the original cooling setpoint, and $5^{\circ} \mathrm{C}$ lower than the original heating setpoint. The comfort limit varied for each BEM due to the variation of the original setpoints. A visual representation of the setpoints (lower and upper band) and comfort limits are shown in Figure 30.

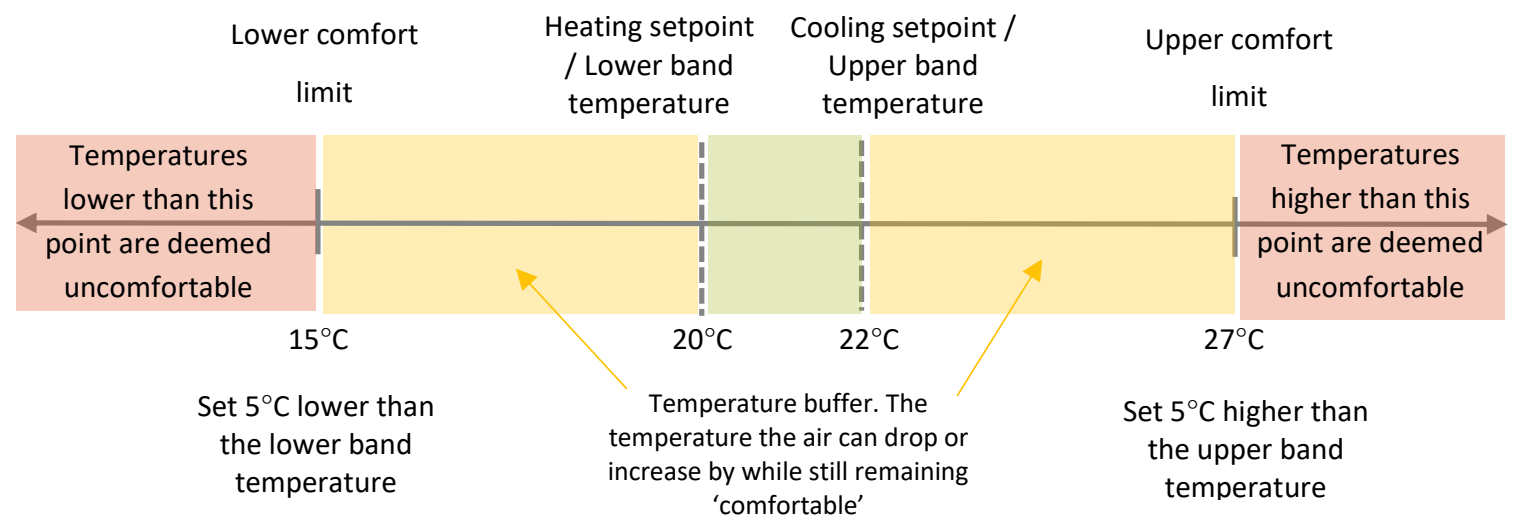




\section{Indoor air temperature of BEMs}

The simulation outputted indoor air temperatures for each thermal zone of the BEMs. For BEMs with more than one thermal zone, some thermal zones may be comfortable for longer or temperatures may recover faster in some thermal zones than others. This meant that there could be different levels of comfort capacity and comfort recovery in one BEM. To measure the comfort capacity and comfort recovery for the entire BEM regardless of the number of thermal zones, the indoor air temperatures of each conditioned thermal zone were averaged.

\subsubsection{EVALUATING ENERGY FLEXIBILITY OF INDIVIDUAL BUILDINGS}

Each of the buildings in the sub-sample were different in their designs, construction, occupancy, size, peak demand, energy consumption, and other factors. To evaluate the energy flexibility potential between different buildings, the results of the metrics were normalised. Depending on the metric, it was normalised by either the maximum power demand, energy consumption, time of shift, or timestep. By doing this, the energy flexibility results for each metric could be compared between buildings relative to how the building originally operated, or to a point of reference which was the same for all buildings (e.g. time of shift or timestep). A description of how each metric was normalised is as follows:

- Normalised power capacity was the fraction of the maximum power capacity between $7 \mathrm{am}$ and 8am over the maximum power demand of the base case. For example, if a building's base peak demand was $20 \mathrm{~kW}$ (the total available power demand that could potentially be dropped) and had a power capacity of $10 \mathrm{~kW}$, then the normalised power capacity would be $50 \%$.

- Normalised energy capacity was the fraction of energy capacity between 7am and 8am over the energy consumption of the base case between 7am and 8am. For example, if a building's base energy consumption was $40 \mathrm{kWh}$ (the total available energy consumption that could potentially be dropped) had an energy capacity of $10 \mathrm{~kW}$, then the normalised energy capacity would be $25 \%$.

- Normalised comfort capacity was only calculated for shifting strategies where heating was turned off earlier in the evening. The normalised comfort capacity was the fraction of time that was comfortable out of the total time of shift. For example, when the heating was shifted earlier by 30 minutes, a comfort capacity of 15 minutes resulted in a 
normalised comfort capacity of 50\%. A comfort capacity of 150 minutes when the heating was shifted earlier by 150 minutes would result in a normalised comfort capacity $100 \%$.

- Normalised comfort recovery was only calculated for shedding strategies as shifting strategies do not have a recovery period since temperatures were not changed during the day. To calculate the normalised comfort recovery, the timestep (equal to 5-minutes intervals) was divided by the comfort recovery time. For example, if the comfort recovery was 5 minutes, then the normalised comfort recovery would be $100 \%$. High percentages mean the temperature recovers quickly. Low percentages mean it takes a longer time for the air temperatures to achieve what it should have been under normal conditions.

- Normalised ramp-rate (down). For this normalisation, the ramp-rate was converted from $\mathrm{kW} / \mathrm{min}$ to $\mathrm{kW} / 5$ mins (timescale adjustment), this meant that for a ramp rate of $2 \mathrm{~kW} / \mathrm{min}$ would equal $10 \mathrm{~kW} / 5 \mathrm{~min}$. The normalised ramp-rate (down) was the fraction of the change in power over maximum demand. For example, if the ramp-rate was $10 \mathrm{~kW} / 5 \mathrm{~min}$ and a maximum demand was $10 \mathrm{~kW}$, the outcome would be $100 \%$. Lower rates mean slower responses and higher rates mean faster responses. The normalised ramp rate could be greater than $100 \%$. In these situations, any fractions greater than $100 \%$ were capped at $100 \%$. By scaling the rate to from 1 minute to 5 minutes, $100 \%$ means that within one simulation timestep, the maximum demand was reached.

- Normalised ramp-rate (up) was normalised in the same way ramp down was. 


\section{Presenting the results}

The normalised energy flexibility results for buildings were presented in radar charts similar to those found in Hurtado Munoz's (2017) study. Figure 31 shows an example radar chart used in this thesis. The radar charts provided a useful visual assessment of a range of energy flexibility metrics for several buildings. Each corner/axis of the radar chart refers to a normalised metric. Each coloured line represents a building. For each metric, 100\% (the outer edge) was 'good' and $0 \%$ (the inside) was 'poor'. Good overall energy flexibility meant each line was spread towards the outside of the radar.

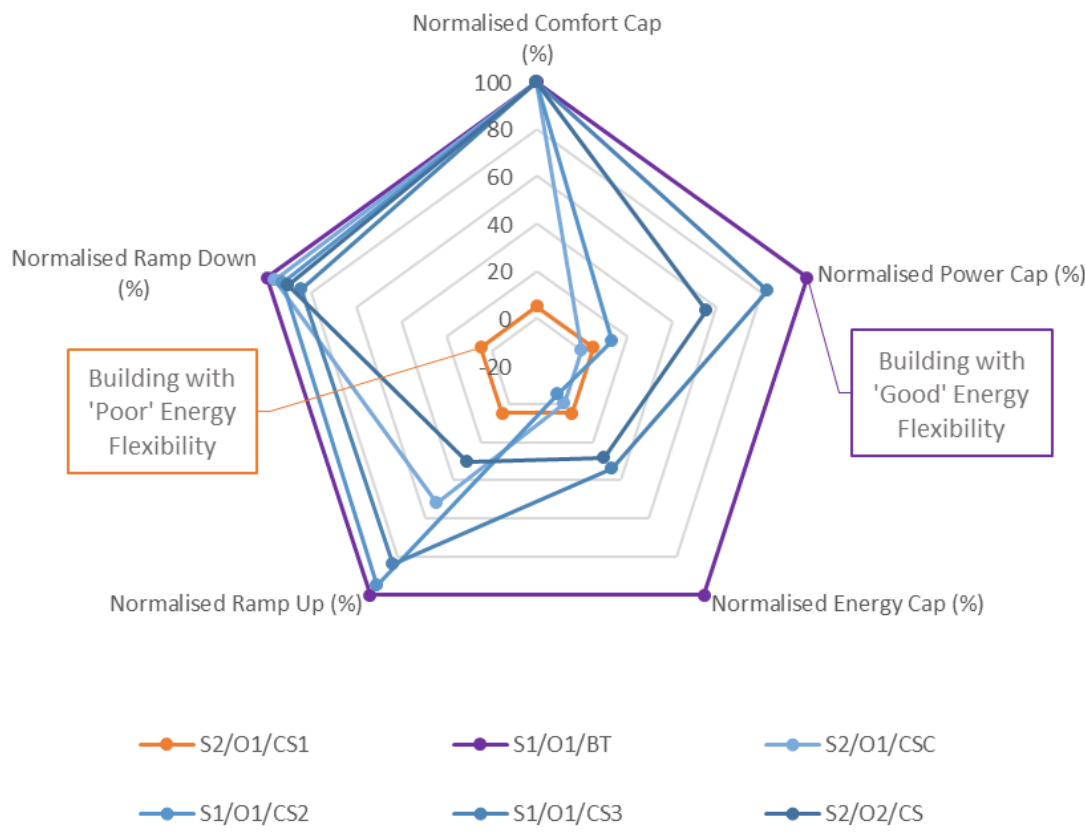

Figure 31 Example radar chart

A single radar chart contained the results of $12 \mathrm{BEMs}$ and was repeated for each of the six energy flexibility tests. The energy flexibility potential of all BEMs from all tests and in all climate regions was not evaluated due to the sheer number of comparisons that could be made. Instead, the results in a warmer climate (Auckland) and a cooler climate (Dunedin) were presented as these regions represent the two extremes of the New Zealand climate. 


\subsection{CONVERTING ENERGY FLEXIBILITY OF INDIVIDUAL BUILDINGS INTO AN AGGREGATED UNIT TO MEASURE THE REDUCTION IN PEAK DEMAND}

This part of the methodology assumes energy flexibility potential within individual buildings exists. It outlines how the energy flexibility potential within individual buildings was aggregated to calculate a reduction in the commercial building stock's peak demand. Therefore, conducting this part of the methodology answered research sub-question 2 which is "If there is energy flexibility potential within individual buildings, how much reduction in the commercial building stock's peak demand is possible?"

There were two parts to this sub-question. The first part, sub-question 2(a), was "How much reduction in the commercial building stock's peak demand is possible from energy flexibly operating small commercial buildings?" The reduction in the commercial building stock's peak demand was calculated based on the energy flexibility estimated from the simulation results. The simulation results were representative of small buildings with heat pumps. The detailed process used to answer sub-question 2(a) is outlined in this section.

The second part of the sub-question, sub-question 2(b) asked "How much reduction in the commercial building stock's peak demand is possible from energy flexibly operating small and larger commercial buildings?" To answer this question the results from answering sub-question 2(a) were extrapolated. The extrapolation process is outlined in section 3.7.

\subsubsection{OVERVIEW OF THE PROCESS}

The process of measuring the reduction in the commercial building stock's peak demand comprised of multiple components. An overview of the process and results are presented in the flow diagram in Figure 32. Component (1) in the shaded box describes the core calculation used to measure the reduction in peak demand. Within that component is an 'aggregated unit' which is made from three other components, this is labelled component (2). Two of those components were based on simulated energy flexibility results from implementing an energy flexibility test. The process was repeated six times for each energy flexibility test. The process is described in detail in the following sections. 


\begin{tabular}{|c|}
\hline Energy \\
flexibility test
\end{tabular}
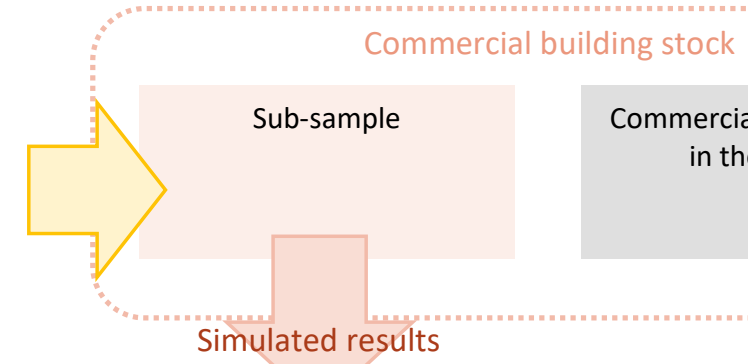

Sub-sample

Commercial building stock not in the sub-sample

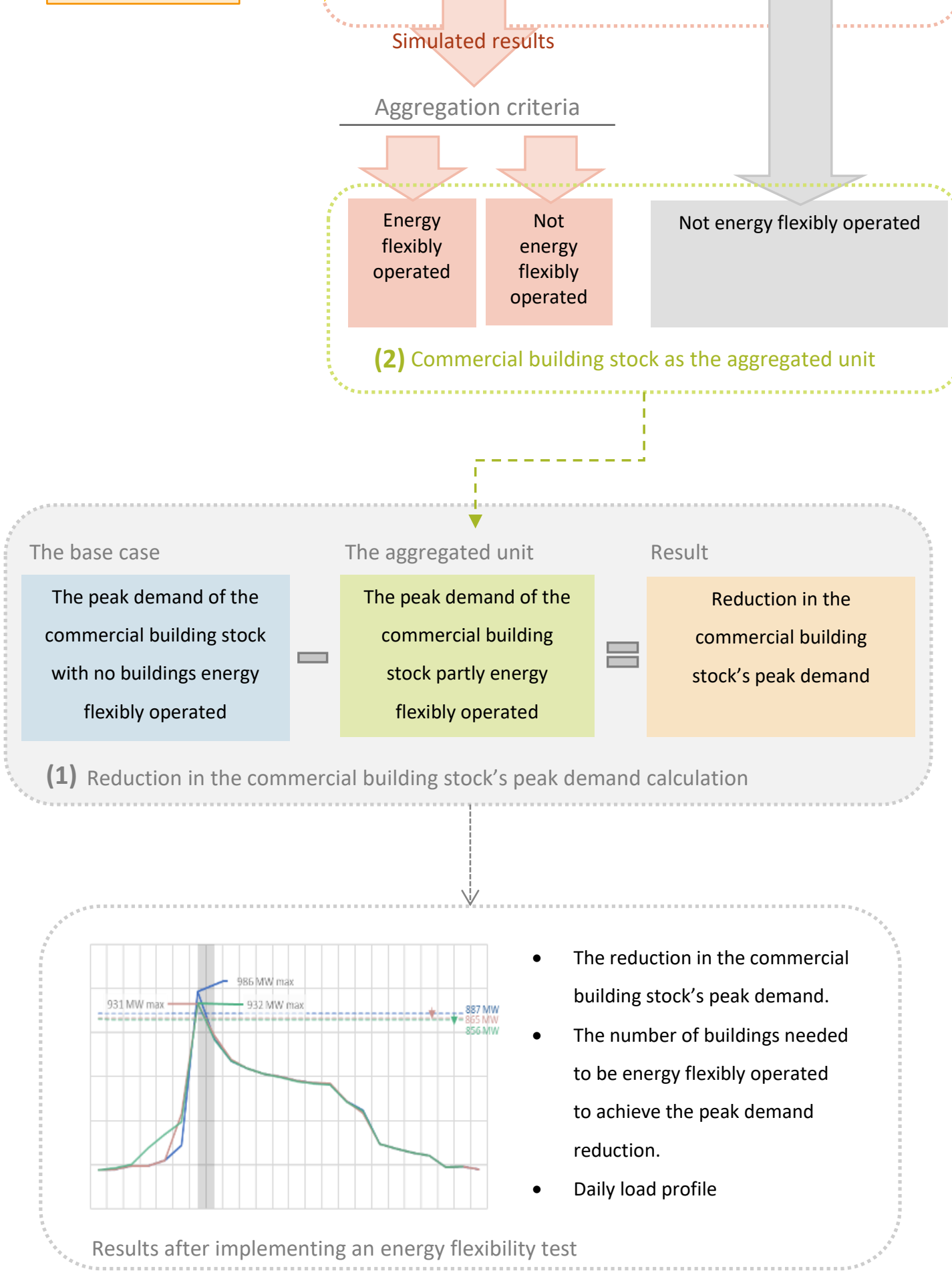

Figure 32 Process of measuring the reduction in the commercial building stock's peak demand 


\subsubsection{MEASURING THE REDUCTION IN THE COMMERCIAL BUILDING STOCK'S PEAK DEMAND}

There were two components required to measure the reduction in the commercial building stock's peak demand:

1. The peak demand of the commercial building stock with no buildings energy flexibly operated, the base case.

2. The peak demand of the commercial building stock partly energy flexibly operated, the aggregated unit.

The difference between the two components was the resulting peak demand reduction from energy flexibly operating some buildings in the commercial building stock. The calculation is summarised below:

\begin{tabular}{|c|c|c|c|c|}
\hline $\begin{array}{l}\text { The peak demand of the } \\
\text { commercial building stock with no } \\
\text { buildings energy flexibly operated }\end{array}$ & Minus & $\begin{array}{l}\text { The peak demand of the } \\
\text { commercial building stock } \\
\text { partly energy flexibly operated }\end{array}$ & Equals & $\begin{array}{l}\text { Reduction in the } \\
\text { commercial building } \\
\text { stock's peak demand }\end{array}$ \\
\hline The base case & & The aggregated unit & & Result \\
\hline
\end{tabular}

Figure 33 Calculating peak demand reduction from energy flexibly operating some of the commercial building stock.

This calculation was repeated for each of the six energy flexibility tests conducted. This was because each energy flexibility test was used to inform the energy flexible operation of the subsample in the aggregated unit. The sub-sample of buildings within the aggregated unit was not energy flexibility operated by conducting more than one energy flexibility test. Therefore, combinations of energy flexibility tests were not allowed.

The peak demand was the highest $98^{\text {th }}$ percentile of demand throughout the peak day. The peak day was selected based on the hour of the highest demand, this occurred on the $2^{\text {nd }}$ of August between 7am and 8am.

\section{Converting the BEM demand data reported at 5-minute intervals into hourly demand data}

The demand data from the BEMs and the base case dataset were reported at different frequencies. The demand data from the BEMs was reported at every 5 minutes and the base case dataset contained demand data at every hour. To compare the data from the BEMs with the base case dataset, every 12 data points was averaged to generate demand at the hour. Averaging the data points dampened the peaks in the simulation. Due to this, the difference between the maximum and minimum, and the average 5-minute demand is presented in the results. 


\subsubsection{THE BASE CASE}

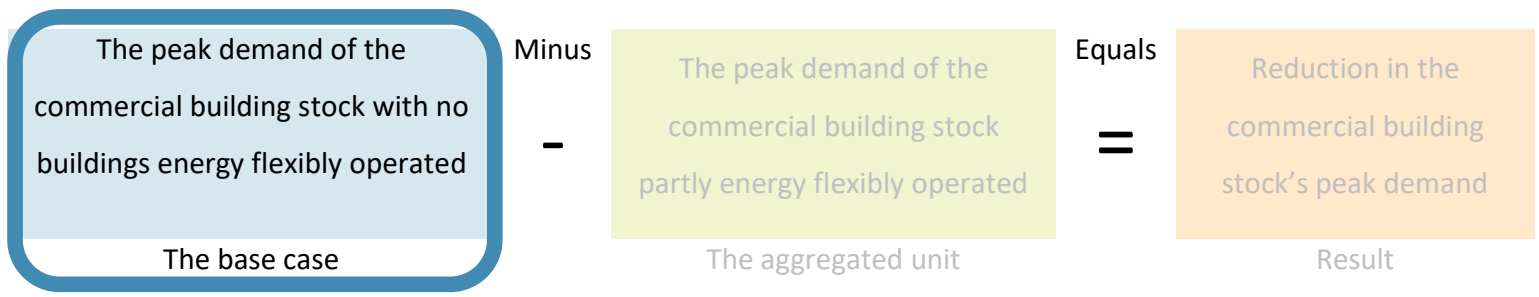

The base case was the commercial building stock with no buildings energy flexibly operated. It was the population of the study which was detailed in section 3.1. The peak demand of the base case was measured from the base case dataset. The dataset was also detailed earlier in section 3.1.3.

\subsubsection{THE AGGREGATED UNIT}

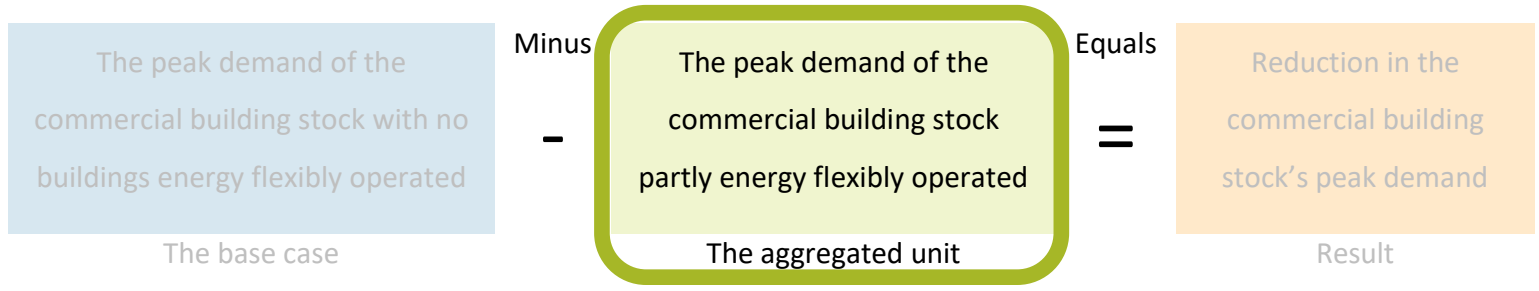

The aggregated unit contained three components:

1. Buildings in the sub-sample that were energy flexibly operated.

2. Buildings in the sub-sample that were not energy flexibly operated.

3. Buildings in the rest of the commercial building stock that were not included in the subsample and were not energy flexibly operated.

The simulations of individual buildings indicated which buildings in the sub-sample had good energy flexibility after conducting each of the six energy flexibility tests. Based on those results, a selection of small buildings in the sub-sample was energy flexibly operated. This resulted in the first component of the aggregated unit. The buildings in the sub-sample that did not have good energy flexibility were not operated energy flexibly. This resulted in the second component of the aggregated unit. All buildings that were not in the sub-sample resulted in the third component. The sum of all components created the aggregated unit. The aggregated unit represented the commercial building stock which was partly energy flexibly operated. The peak demand of the 
aggregated unit was used to calculate the reduction in the commercial building stock's peak demand.

Buildings in the sub-sample that were energy flexibly operated - the first component of the aggregated unit.

Buildings in the sub-sample were energy flexibly operated if they, under energy flexible operation from each energy flexibility test, met an aggregation criterion. Assessing the energy flexibility of individual buildings in the sub-sample against the aggregation criterion was a form of simple optimisation. It ensured buildings were only energy flexibly operated if they had good energy flexibility potential. This meant buildings that met the aggregation criterion represented good potential to reduce the commercial building stock's peak demand without diminishing the quality of indoor thermal comfort.

\section{The aggregation criterion}

The energy flexibly operated buildings from conducting each energy flexibility test had to meet three criteria: (1) the building must be comfortable throughout the day, (2) the demand between $7 a m$ and $8 a m$ must be reduced, and (3) the peak demand on the peak day must also be reduced.

Two energy flexibility metrics were used for the assessment. The first metric was the normalised comfort capacity which represented the percentage of time the indoor air temperature was comfortable. The second metric was the normalised power capacity which represented the power demand reduction during the peak hour. Peak demand on the peak day was the third metric but was not considered an energy flexibility metric. The criteria, metrics, and performance criteria are presented in Table 22.

Table 22 Aggregation criteria.

\begin{tabular}{lll}
\hline Criteria & Metric & Performance criteria \\
\hline The building must be comfortable throughout the day. & Normalised comfort capacity & $100 \%$ \\
\hline Demand between 7am and 8am must be reduced. & Normalised power capacity & Greater than zero \\
\hline Peak demand on the peak day must be reduced. & Peak demand & Greater than zero. \\
\hline
\end{tabular}


Buildings in the sub-sample that were not energy flexibly operated - the second component of the aggregated unit.

Buildings in this component were simply those in the sub-sample that did not meet the aggregation criterion when they were energy flexibly operated.

Buildings in the rest of the commercial building stock that were not included in the sample and were not energy flexibly operated - the third component of the aggregated unit.

Buildings in this component were those that were not selected for the sub-sample. These buildings included larger buildings that were in size groups three to five and small buildings that did not contain heat pumps.

\subsubsection{REPORTING THE RESULTS}

Calculation of the reduction in the commercial building stock's peak demand was repeated for each of the six energy flexibility tests. This was because each test was used to implement the energy flexible operation of the sub-sample of buildings in the aggregated unit. Each calculation had two key results, they were (1) the reduction in the commercial building stock's peak demand and (2) the number of buildings needed to be energy flexibly operated to achieve the peak demand reduction. A daily load profile such as the ones shown in Figure 34, was also generated for each calculation.

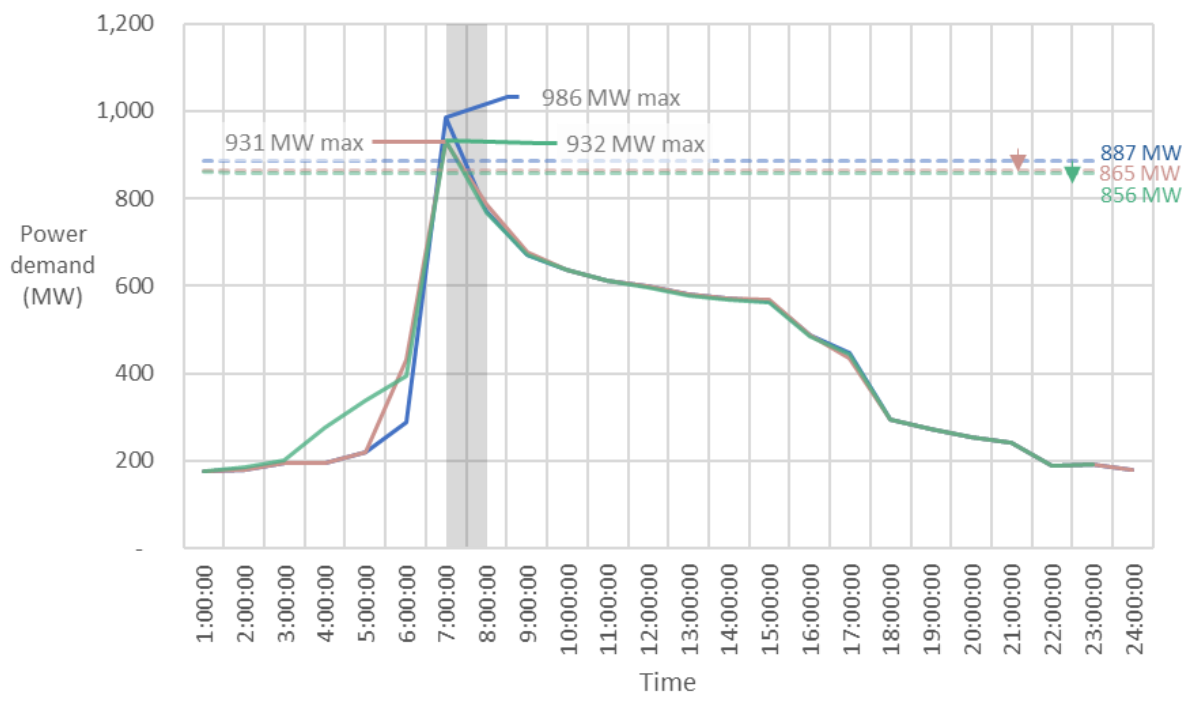

Figure 34 Example of the presentation of the reduction in the commercial building stock's peak demand. 


\subsubsection{EVALUATING THE PEAK DEMAND REDUCTION FROM EACH TEST}

The next step was to select two energy flexibility tests to implement in larger commercial buildings to answer sub-question 2(b). The tests were selected based on an evaluation framework which is shown in Figure 35. The framework is based on two findings. The first was the reduction in the commercial building stock's peak demand (y-axis). The second was the number of buildings needed to be energy flexibly operated to achieve the peak demand reduction ( $x$-axis). The two tests that were selected results in:

1. The highest peak demand reduction - a High Reduction scenario. Tests that achieved this were scattered in the top half of the framework, outlined in the dashed green line.

2. A reduction in peak demand by operating the least number of buildings energy flexibly - a Minimal Flexible Operation scenario. Tests that achieved this were scattered towards the left of the framework, outlined in the dashed blue line.

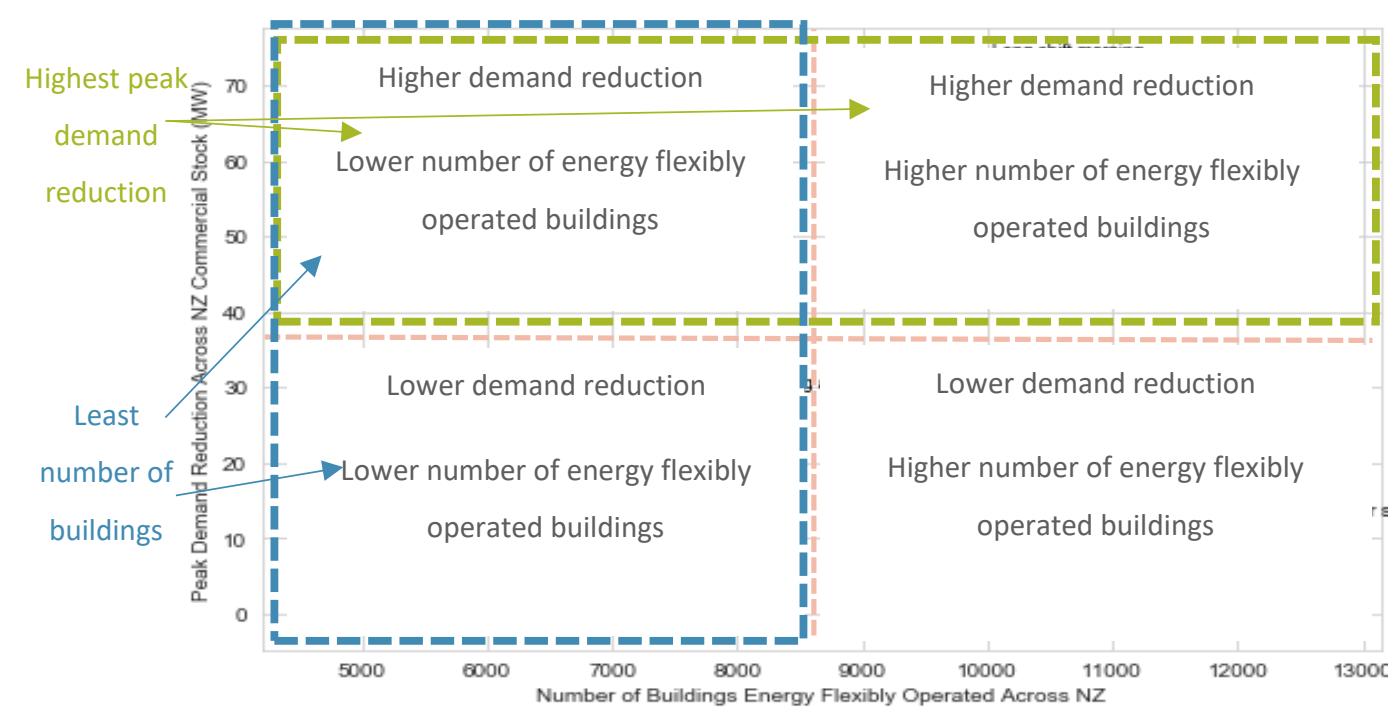

Figure 35 Evaluation framework for selecting energy flexibility tests for extrapolation. 


\subsection{EXTRAPOLATING THE ENERGY FLEXIBILITY RESULTS OF THE SUB-SAMPLE ACROSS LARGER BUILDINGS}

The second part of sub-question 2 (sub-question 2(b)) was "How much reduction in the commercial building stock's peak demand is possible from energy flexibly operating small and larger commercial buildings?" Unlike the process to answer sub-question 2(a), simulations to estimate the energy flexibility of larger buildings were not conducted. Instead, the results from answering sub-question 2(a), which were based on simulations, were extrapolated across larger commercial buildings.

The BEMs used in the simulations were representative of the sub-sample, but they were not representative of larger commercial buildings. Therefore, the extrapolated energy flexibility results were not representative of the rest of the commercial building stock. Despite the nonrepresentativeness of the results, the findings from the extrapolation still provided some indication of the potential reduction in commercial building peak demand. The indication was based on the key assumption that most buildings have energy flexibility potential.

This section outlines how the results from two energy flexibility tests were extrapolated across larger commercial buildings. The tests that were selected achieved the highest peak demand reduction and demand reduction from energy flexibly operating the least number of buildings. Both results were at the commercial building stock level.

For each of the energy flexibility tests, two extrapolations were conducted. They were conducted to answer:

1. How much reduction in the commercial building stock's peak demand is possible if small and larger buildings containing heat pumps are energy flexibly operated?

2. How much reduction in the commercial building stock's peak demand is possible if small and larger buildings containing different types of heating systems are energy flexibly operated? 


\subsubsection{OVERVIEW OF THE PROCESS}

The results from two energy flexibility tests were extrapolated across larger commercial buildings in two steps. The steps are as follows:

1. Extrapolating the percentage of energy flexibly operated buildings in the sub-sample to the larger buildings in the commercial building stock. This was done to calculate the number of larger buildings that should be energy flexibly operated.

2. Extrapolating the peak demand reduction results across the number of larger buildings selected to be energy flexibly operated.

Both steps were conducted using results extracted from the previous process which was outlined in section 3.6. The results that were extracted are highlighted in Figure 36. The first result was the percentage of energy flexibly operated buildings in the sub-sample which did and did not meet the aggregation criteria. This is number (1) in the diagram. The second result was the percentage of reduction in peak demand which is number (2) in the diagram. Both results were extrapolated across larger commercial buildings of two types to calculate the potential reduction in the commercial building stock's peak demand. 


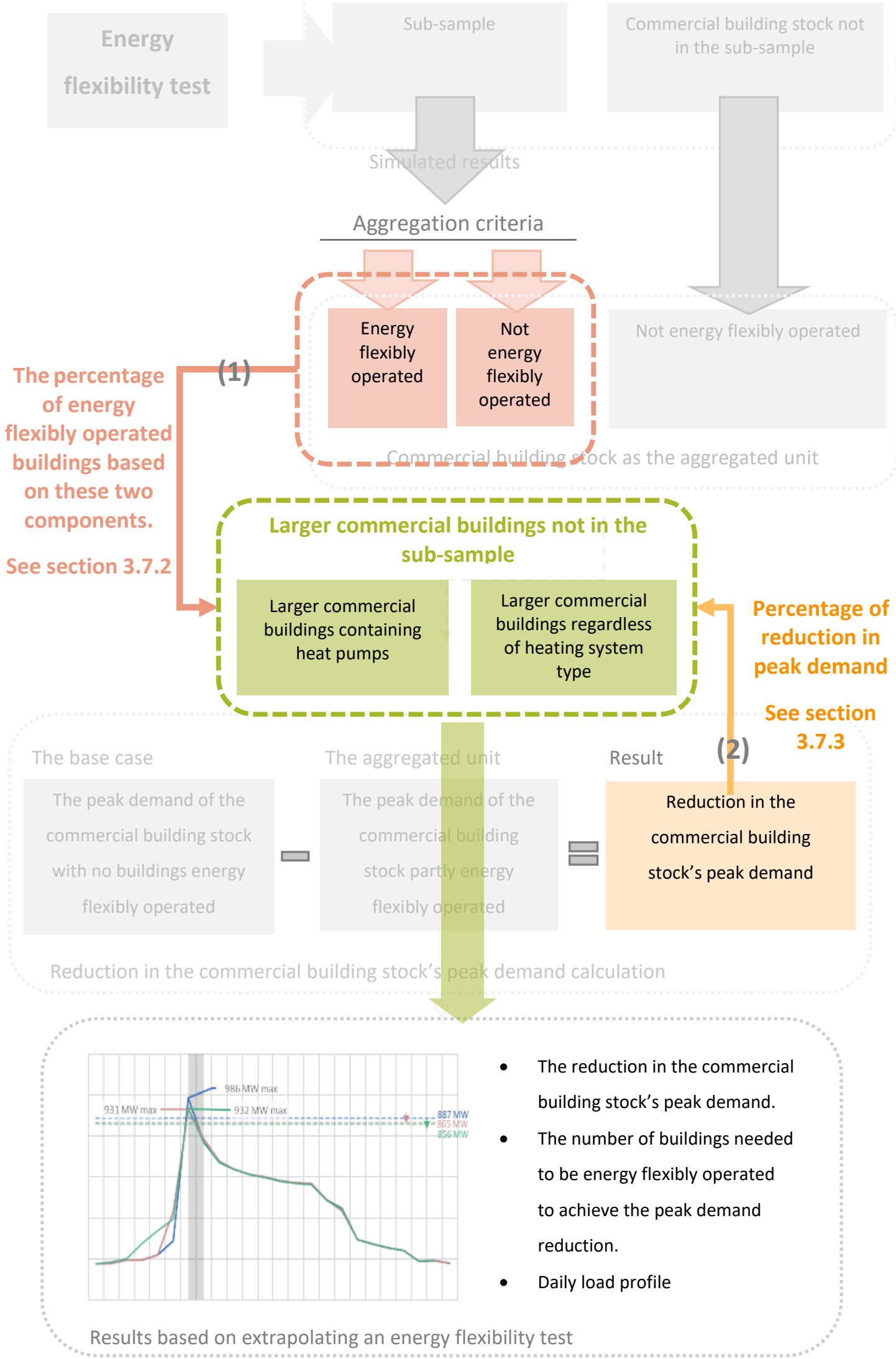

Figure 36 Information used to extrapolate the results of two energy flexibility tests across larger commercial buildings. 


\subsubsection{THE PERCENTAGE OF ENERGY FLEXIBLY OPERATED BUILDINGS}

In answering sub-question 2(a), an aggregated unit was formed to calculate the peak demand reduction from partly energy flexibly operating the commercial building stock. Two components of the aggregated unit were used to calculate the number of large buildings that were energy flexibly operated in the extrapolation. The two components were used by calculating a percentage of energy flexibly operated buildings in the sub-sample. The same percentage was then applied to larger commercial buildings. The components were:

1. Buildings in the sub-sample that were energy flexibly operated.

2. Buildings in the sub-sample that were not energy flexibly operated.

If $A=$ the number of buildings in the sub-sample that were energy flexibly operated, and $B=$ the number of buildings in the sub-sample that were not energy flexibly operated. Then the percentage of buildings that was energy flexibly operated was: $[A /(A+B)] * 100$. This percentage was multiplied by the larger buildings in the commercial building stock which the results were to be extrapolated across.

For each extrapolation, a percentage of buildings was not energy flexibly operated. This was due to some buildings which were expected not to meet each of the aggregation criteria.

\subsubsection{EXTRAPOLATING THE RESULTS OF THE PEAK DEMAND REDUCTION}

Once the number of larger buildings to be energy flexibly operated was calculated, the reduction in the commercial building stock's peak demand from the tests were extrapolated. The peak demand reduction results were extrapolated by reducing the peak demand of the groups of larger buildings by the same percentage. After the extrapolation, the reduction in the commercial building peak demand from energy flexibly operated larger buildings was measured.

Following the extrapolation of the reduction in peak demand, the increase in energy consumption specifically from shifting strategies was extrapolated. The increase in consumption was based on the percentage decrease in peak demand. 


\subsubsection{EXTRAPOLATING THE RESULTS ACROSS TWO GROUPS OF LARGER BUILDINGS}

\section{Extrapolating the results across larger commercial buildings with heat pumps}

The results from the two energy flexibility tests were first extrapolated across larger buildings that contained heat pumps. This was done as heat pumps were the source of energy flexibility in the sub-sample. It was assumed that larger buildings with heat pumps behaved similarly to smaller buildings with heat pumps and therefore the results were to some extent representative.

\section{Extrapolating the results across larger commercial buildings regardless of heating system type}

Next, the results from two tests were extrapolated across larger buildings regardless of heating system type. In this extrapolation, energy flexibility was assumed to exist in most large commercial buildings. It was assumed that a reduction in the commercial building stock's peak demand could be achieved by way of energy flexibly operating different heating systems or other commercial building end-uses.

\subsubsection{REPORTING THE RESULTS}

The reduction in the commercial building stock's peak demand from energy flexibly operating larger buildings is presented in the results section. Alongside the peak demand, four other findings were presented to contextualise in the results. A description of each finding is presented in Table 23.

Table 23 Description of the findings after extrapolation

\begin{tabular}{|c|c|}
\hline Findings & Description \\
\hline Total peak demand reduction & $\begin{array}{l}\text { The reduction in the commercial building stock's peak demand. This was the } \\
\text { difference between the commercial building stock with no buildings energy } \\
\text { flexibly operated and the commercial buildings stock that was partly energy } \\
\text { flexibly operated. }\end{array}$ \\
\hline Additional peak demand reduction & The additional reduction in peak demand from a stated reference point. \\
\hline$\%$ of peak demand reduction & The percentage of the original peak demand that was reduced. \\
\hline $\begin{array}{l}\text { \% of energy flexibly operated } \\
\text { buildings in NZ }\end{array}$ & $\begin{array}{l}\text { The percentage of commercial buildings in New Zealand that were energy } \\
\text { flexibly operated to achieve the reduction in peak demand. }\end{array}$ \\
\hline $\begin{array}{l}\% \text { of energy flexibly operated } \\
\text { floor area in NZ }\end{array}$ & $\begin{array}{l}\text { The percentage of the commercial building floor area in New Zealand that is } \\
\text { energy flexibly operated to achieve the total peak demand reduction. }\end{array}$ \\
\hline Increase in energy consumption & $\begin{array}{l}\text { The increase in energy consumption of the commercial building stock from } \\
\text { energy flexible operation. }\end{array}$ \\
\hline
\end{tabular}




\subsection{SELECTING THE BEST BUILDINGS TO OPERATE ENERGY FLEXIBLY}

This section outlines the frameworks used to select individual buildings from the sub-sample which were the best buildings to operate energy flexibly. The buildings were analysed after an energy flexibility test was implemented. The energy flexibility test that was implemented achieved the greatest reduction in the commercial building stock's peak demand. The best buildings were selected based on two categories:

1. Best buildings to energy flexibly operate on the individual level.

2. Best buildings to energy flexibly operate at the commercial building stock level.

The result of this selection process indicated which building types, represented by BEMs, should be further investigated based on the opportunity to greatly reduce demand. By conducting this part of the methodology, research sub-question 3 was answered. Sub-question 3 asked "Which building or buildings of those investigated, are the best buildings to operate energy flexibly?" The frameworks to assess the buildings outlined in this section were similar to the framework outlined earlier in section 3.6.6.

\section{Best buildings based on peak hour demand reduction of individual buildings}

The framework to assess the best buildings to energy flexibly operate on an individual level is shown in Figure 37. Buildings on an individual level that would be the best to energy flexibly operate, were those that originally had high peak hour demand and high normalised power capacity. This indicated that buildings which may have poorly responded to grid signals due to their high demand during peak times had greater opportunity to reduce demand and respond better to grid signals. 


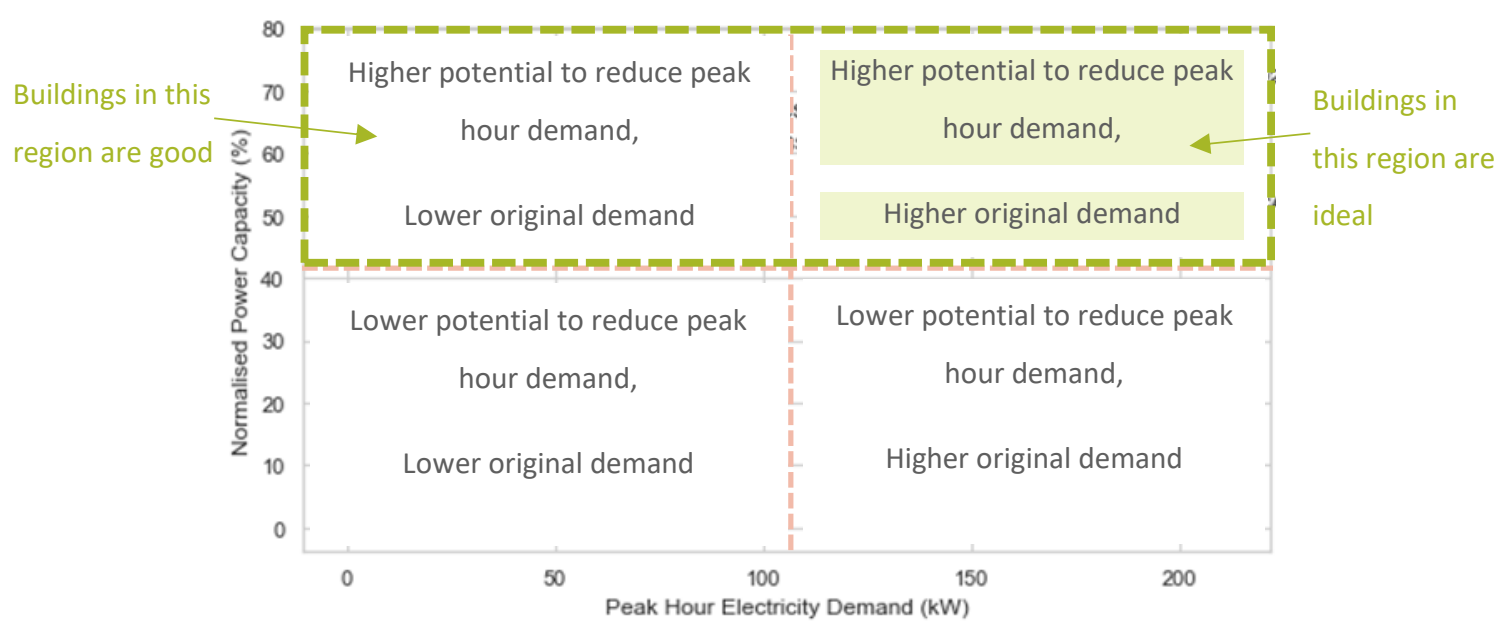

Figure 37 Evaluation framework to select the best buildings to operate energy flexibly.

Based on demand reduction at an individual level.

\section{Best buildings based on the demand reduction across the commercial building stock}

The framework to assess the best buildings to energy flexibly operate at a commercial building stock level is shown in Figure 38. At a stock level, the best buildings to energy flexibly operate were those that had higher potential to reduce peak hour demand as an aggregate across New Zealand. This could either be achieved by energy flexibly operating many buildings, or ideally fewer buildings.

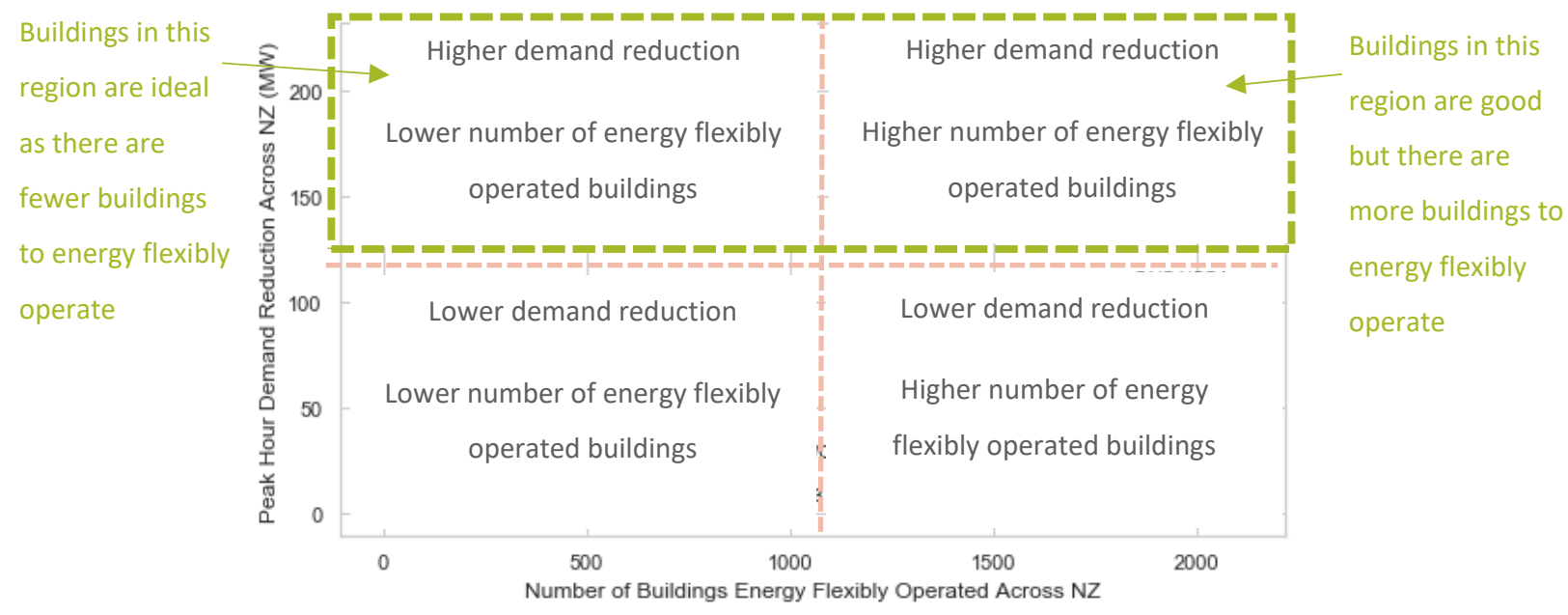

Figure 38 Evaluation framework to select the best buildings to operate energy flexibly. Based on peak demand reduction at the commercial building stock level. 


\subsection{LIMITATIONS IN THE METHODOLOGY}

\section{Peaking information from granular simulation data was lost in the aggregation and extrapolation process}

The testing of the heat pump models in EnergyPlus clearly showed that shorter time intervals and greater granularity of simulated data represented important peaking information. Peaking information was not represented in the base case dataset as it contained data reported at every hour. The simulations in this thesis were reported at every 5 minutes and were used to calculate the energy flexibility metrics. However, the data was later averaged in the aggregation and extrapolation process for comparison with the base case dataset. By averaging the 5-minute data the representation of the peaks from the heat pumps were dampened.

\section{Overly simple optimisation}

The aggregation criterion was created to run a simple optimisation of the aggregated unit. It was created to ensure buildings that were energy flexibly operated had good potential to reduce the commercial building stock's peak demand without diminishing the quality of the indoor thermal comfort within the building. The simplicity and lack of flexibility in the aggregation criteria was a key limitation. A limitation of the aggregation criterion was that buildings which did not achieve all three criteria were not included in the aggregated unit. This meant there was no room for flexibility in the aggregation process. For example, if an energy flexibility test was implemented where the heating was turned off for 150 minutes, and the building remained comfortable for 145 minutes, the comfort capacity was $95 \%$. Because the comfort capacity was not $100 \%$, the building was not included in the aggregated unit and was not energy flexibly operated. This limitation in the aggregation criteria and methodology meant there was no room for adjustments in the energy flexible operation. Taking the same case, if the heating was shifted by only 130-miniutes, the building may have achieved $100 \%$ comfort criteria.

Additionally, the simple optimisations did not provide the ability to create solution sets of energy flexibility strategies to apply across the commercial building stock. Mixing two or more energy flexibility tests was not allowed. All buildings in the sub-sample and in the extrapolation were operated under the same energy flexibility test (given that they met the aggregation criterion). 


\section{Limitations in the extrapolation process}

The extrapolated results were based on the energy flexibility potential of small commercial buildings with heat pumps. Therefore the results that were extrapolated were not representative of the larger buildings. Due to this limitation, when extrapolating to estimate the energy flexibility potential across all commercial buildings, an assumption that larger buildings have some level of energy flexibility regardless of the end-use was made.

Another limitation of the extrapolation process was that it was limited to calculating the peak demand reduction. Because of this, the effects of energy flexible operation on the pattern of demand across the day were not reflected in the results of the extrapolation. Due to this limitation, an assumption was made on the pattern of the daily load profile based on the percentage reduction of the commercial building stock's peak demand. 
92 | P a g e 


\section{RESULTS}

The previous chapter outlined the methodology used to answer the research questions. The general concept of the methodology was to run six energy flexibility tests, based on two types of strategies, in a sub-sample of the commercial buildings stock. The sub-sample contained small commercial buildings that used heat pumps. For each energy flexibility test in each building and climate region, the energy flexibility was measured. Based on a simple aggregation criterion, the energy flexibility results of the sub-sample were converted into an aggregated unit to measure the potential reduction in the commercial building stock's peak demand. The peak demand reduction results from an aggregated unit were then extrapolated across larger buildings in the commercial building stock. This was done to estimate the total reduction in the commercial building stock's peak demand if buildings of different types and sizes had some level of energy flexibility.

This chapter presents the findings in four sections. These sections are summarised below:

\section{Section one: Energy flexibility potential of individual buildings.}

This section answers sub-question 1 which is "What is the energy flexibility potential of individual commercial buildings?" Which further asked, "What characteristics or conditions affect the potential?" The results present the effect of minor and major operational changes to buildings in a warmer and cooler climate region. This section was the result of conducting section 3.5 of the methodology.

\section{Section two: Reduction in the commercial building stock's peak demand from energy flexibly} operating small commercial buildings.

This section partly answers sub-question 2 which is If there is energy flexibility potential within individual buildings, how much reduction in the commercial building stock's peak demand is possible? The results present the answer to sub-question 2(a), which was the reduction in the commercial building stock's peak demand from energy flexibly operating small commercial buildings. This section was the result of conducting section 3.6 of the methodology. 
Section three: Reduction in the commercial building stock's peak demand from energy flexibly operating small and larger commercial buildings.

This section completes the answer to sub-question 2 by presenting the answer to sub-question 2(b), which was the reduction in the commercial building stock's peak demand from energy flexibly operating small and larger commercial buildings. This section was the result of conducting section 3.7 of the methodology.

\section{Section four: Best buildings to operate energy flexibly}

This section answers sub-question three which is Which building or buildings of those investigated, are the best buildings to operate energy flexibly? The results indicate which buildings in the sub-sample represent good opportunities to reduce individual demand and demand at a stock level. This section was the result of conducting section 3.8 of the methodology.

\subsection{ENERGY FLEXIBILITY OF INDIVIDUAL BUILDINGS}

\section{Energy flexibility potential of commercial buildings based on the sub-sample justification}

The justification of the selected sub-sample which was outlined in section 3.2 partly answered the first research sub-question. Buildings that had energy flexibility potential were those that have poor responses to grid signals, therefore had potential to respond better by way of energy flexibility. The justification and selection of the sub-sample showed buildings that contributed to sharp winter morning peaks in demand were buildings which had an opportunity to be energy flexibly operated. These buildings were characterised as small commercial buildings that used heat pumps. The control type of heating loads also suggested that any energy flexibility potential could be committed at short time scales and reduce intraday peaks. 


\section{Energy flexibility potential of commercial buildings based on simulations}

The small commercial buildings in the sub-sample were represented by 12 BEMs. The BEMs were simulated in EnergyPlus to estimate the energy flexibility potential. The results from each BEM from the same energy flexibility test and same climate region are presented in one pentagonal or hexagonal radar chart. The radar charts present normalised energy flexibility metrics (refer to section 3.5.4 for calculation method). In all cases, $100 \%$ is 'good' and $0 \%$ is 'poor'. High percentages for power capacity and energy capacity meant more demand/energy can be shifted or shed away from the grid. High comfort capacity meant the building was comfortable for most of the time the heating was switched off. High comfort recovery meant the indoor air temperatures recovered to the temperature it should have been under normal conditions faster. Finally, high ramp rates meant the building responds faster to changes.

Of the buildings in the sample, it was important to note that two buildings (codes: S2/O1/CS1 and $\mathrm{S} 2 / 01 / \mathrm{CSC}$ ) did not operate during the traditional 7am to $6 \mathrm{pm}$ period. Power and energy capacity were normalised by the maximum demand between 7am and 8am as outlined in the methodology. This caused the normalised results to be zero. Shifting demand from these two buildings into the peak hour was undesirable and the energy flexibility results were skewed as the metric calculations were designed around the peak hour. Therefore, the power and energy capacity were not reported for these two buildings, and the metrics defaulted to zero. 


\subsubsection{ENERGY FLEXIBILITY FROM SHIFTING STRATEGIES}

There were two types of shifting tests. The first type was shifting heating demand at the beginning of the day only, and the second type was shifting heating demand the beginning and end of the day. For both types of tests, a short shift (30 minutes) and long shift (150 minutes) were conducted.

\section{Results from a Short shift morning only test}

Figure 39 presents the results from a Short shift morning only test where the heating demand was switched on 30 minutes earlier at the beginning of the day and the switch off time was unchanged. This test aimed to understand how a small shift in heating demand would affect the energy flexibility of a building.

The test showed average indoor air temperatures were always comfortable for all buildings in both a warm and cool climate. This is represented by all normalised comfort capacities being $100 \%$ and at the outer edge of the diagram. The result was likely due to the heat pump being available for space conditioning throughout the time the building was in use. This meant the range of power capacities could be achieved without any cost to comfort.

By simply shifting the heating demand 30 minutes earlier at the beginning of the day, the normalised power capacity reached $90 \%$ of the potential. The normalised energy capacity for all buildings was no more than $40 \%$ of the potential. This suggested that a small change in operation has good potential to reduce peaks in demand, but only some benefit in reducing energy consumption.

The key difference between a short shift of heating demand in a warmer climate versus a cooler climate was the ramping rates. Two buildings (codes: S1/O2/BRS and S2/O1/CS1) took longer to reach the maximum demand in a warmer climate. The normalised ramp down rates for S1/O2/BRS of $26 \%$ meant the building took four times the timestep (a total of 20 minutes) to reach the maximum demand. For building S2/O1/CS1, it took twice the timestep (a total of 10 minutes) to reach the maximum demand. 


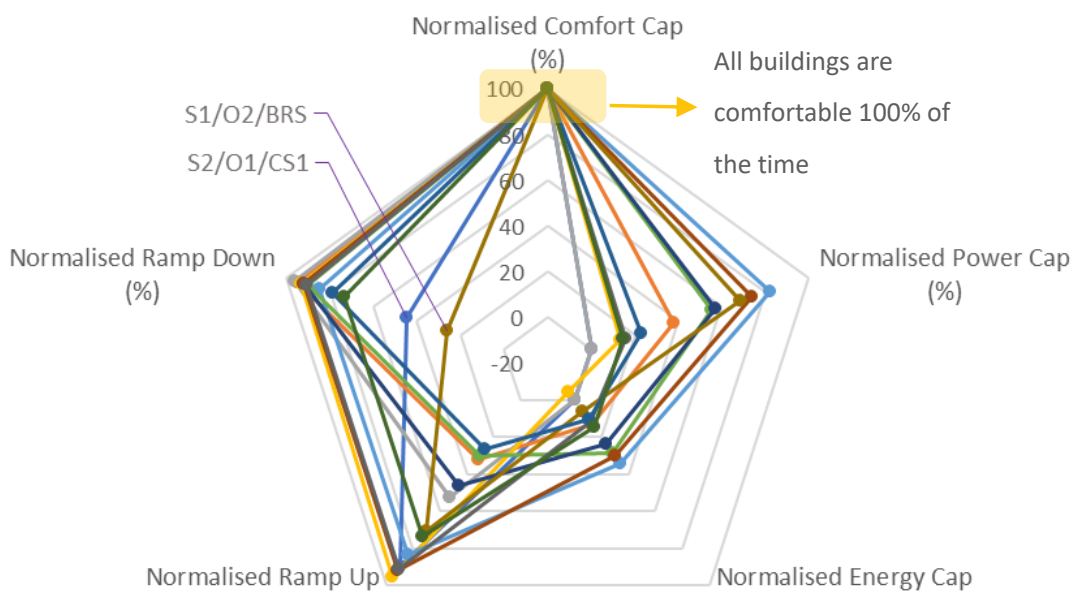

(\%)

(\%)
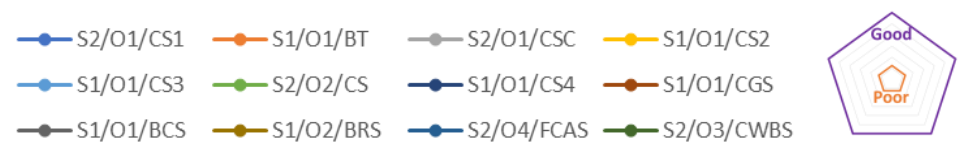

Warmer climate

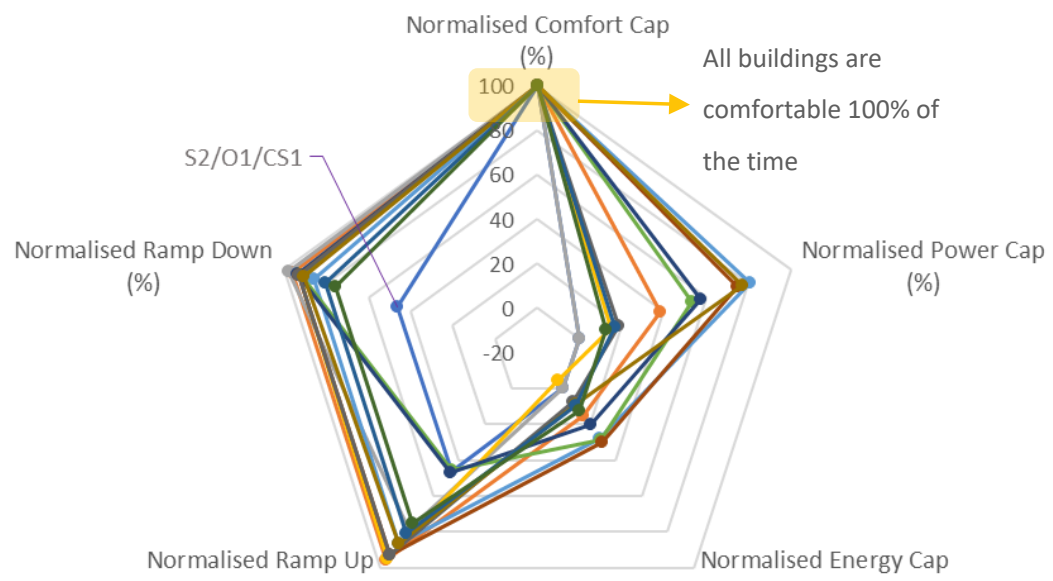

(\%)

(\%)

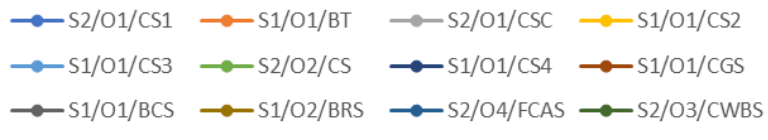

Cooler climate

Figure 39 Energy flexibility results from Short shift morning only test 


\section{Results from a Short shift morning + evening test}

This test had three aims: (1) to test a small shift in heating demand, while (2) keeping the heating on for the same length of time that it would normally be on for, and (3) to shift demand away from the evening peak. This was done by shifting heating demand to start 30 minutes earlier at the beginning of the day and switch off 30 minutes earlier at the end of the day.

The key difference between shifting heating demand at the beginning and end of the day, versus the beginning of the day only, was that comfort in the evenings was not always achieved $100 \%$ of the time. When the operation was changed in this way, comfort capacity was the cost of achieving the power capacity and energy capacity. Comfort capacity reduced in more buildings in a cooler climate than in a warmer climate. There was a high cost to comfort for two buildings in a warmer climate and six buildings in a cooler climate. 


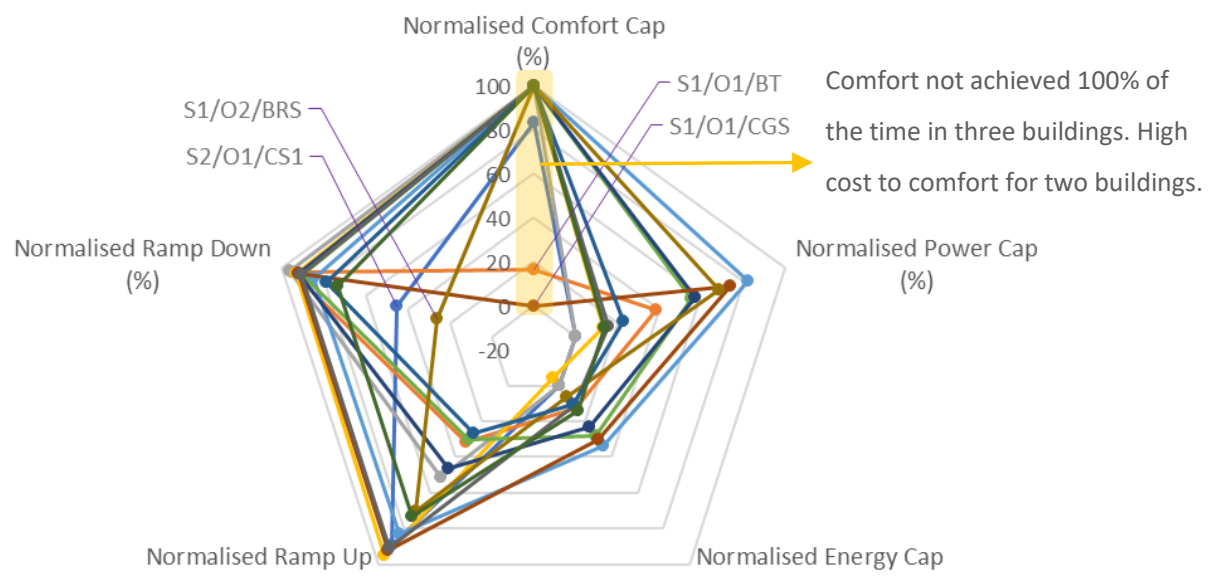

(\%)

(\%)

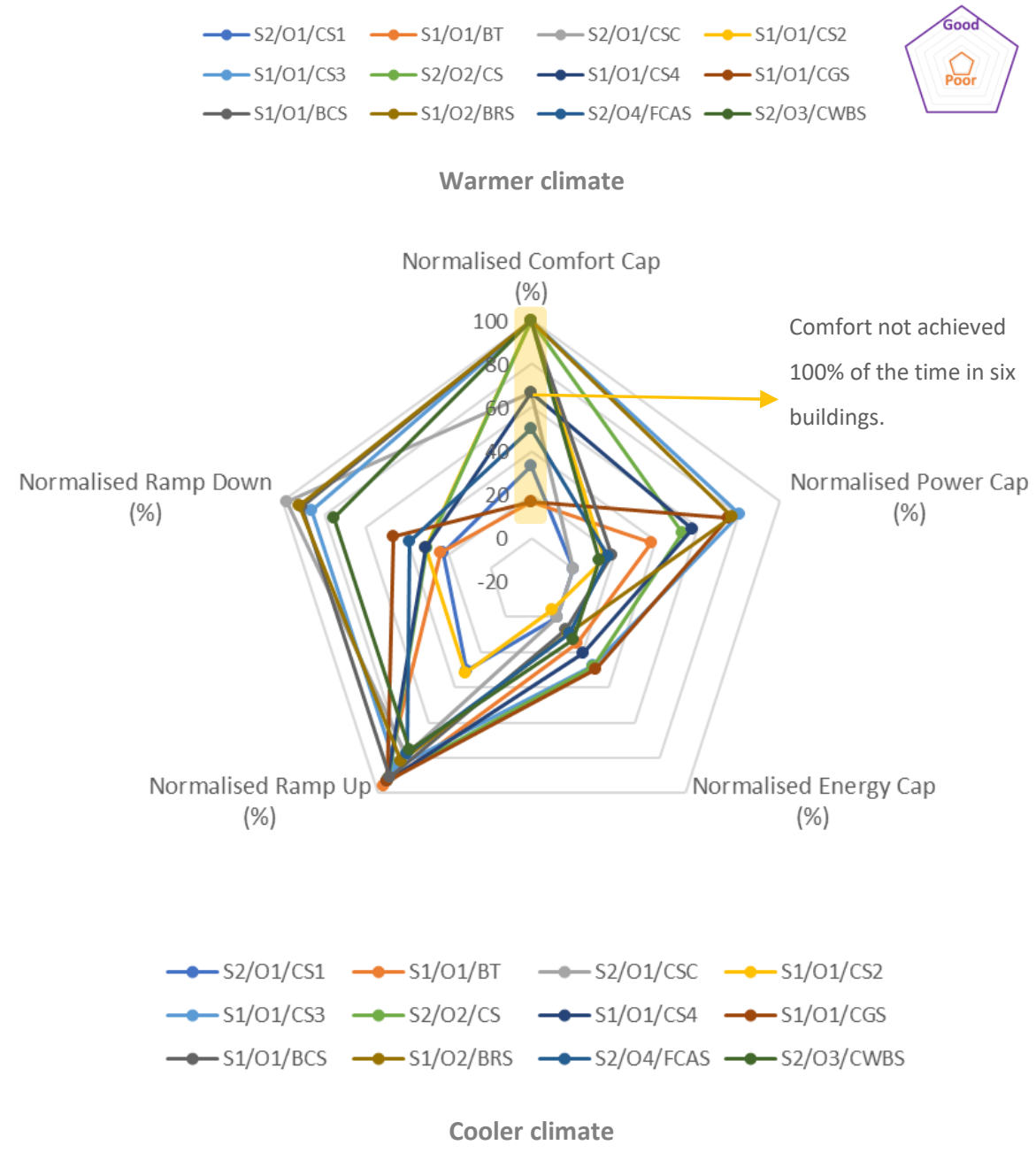

Figure 40 Energy flexibility results from Short shift morning + evening test 


\section{The comfort capacity, and physical and operational building characteristics}

Various physical and operational building characteristics were examined against the comfort capacities to understand if any relationship could be drawn between better or worse results. The characteristics examined included: concrete volume, concrete volume per square meter of floor area, conditioned floor area, window-to-wall ratios, and the lower comfort band. The results from the analysis are presented in appendix 8.5.

The result of the analysis showed no obvious correlation between the physical characteristics examined and better or worse comfort capacities. However, there was some correlation with low comfort capacities and the lower band temperature. The lower band temperature is the minimum temperature a heating system must condition to. The point where the indoor air temperature was deemed uncomfortable was set 5 degrees Celsius lower than the lower band temperature. It indicated that buildings which had high lower band temperatures caused buildings to be "uncomfortable" sooner. This was likely because there was less of a buffer for temperatures to drop. (Refer back to section 3.5.3 for description of comfort bands and lower band temperatures.)

Table 25 presents a graphical representation of the buildings as BEM geometry in a matrix which groups them by type, size, and the lower band temperature. The matrix highlights three buildings that were not comfortable $100 \%$ of the time in a warmer climate using blue borders. These buildings were of different types and size group, but all were in the same lower comfort band group. Two of the same buildings and three different buildings were not comfortable $100 \%$ of the time in a cooler climate. These buildings were highlighted using black borders. The matrix illustrates that there was some correlation between comfort capacities less than $100 \%$ and high lower comfort bands. It also showed that the geometry of the building had no significantly different features that indicated better or worse comfort capacities.

Table 24 Key for comfort capacity results in Table 25

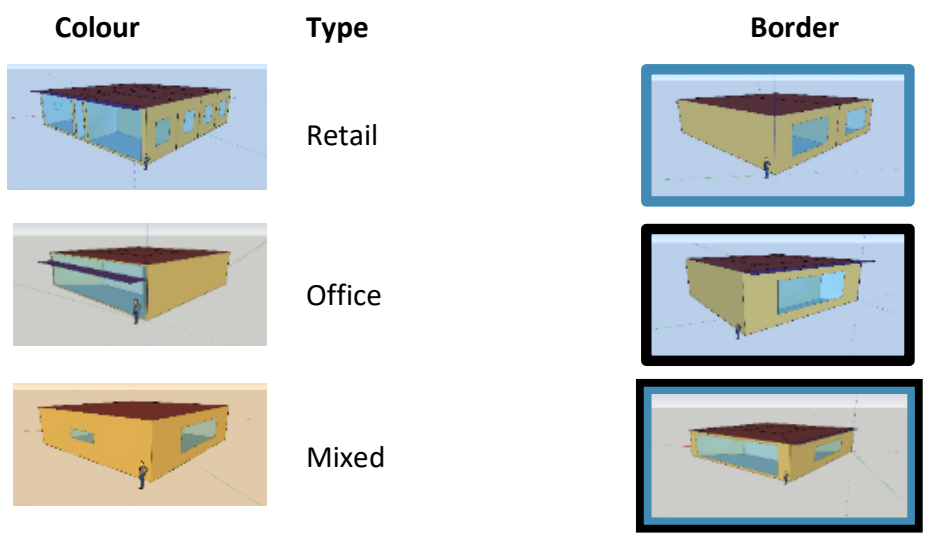

Meaning Low comfort capacity in a warmer climate Low comfort capacity in a cooler climate

Low comfort capacity in a warmer and cooler climate 
Table 25 Comfort capacity results by type, size, and lower band temperature from a Short shift morning + evening test Refer to key in Table 24. Lower band temperature was split by the median value of the sub-sample.

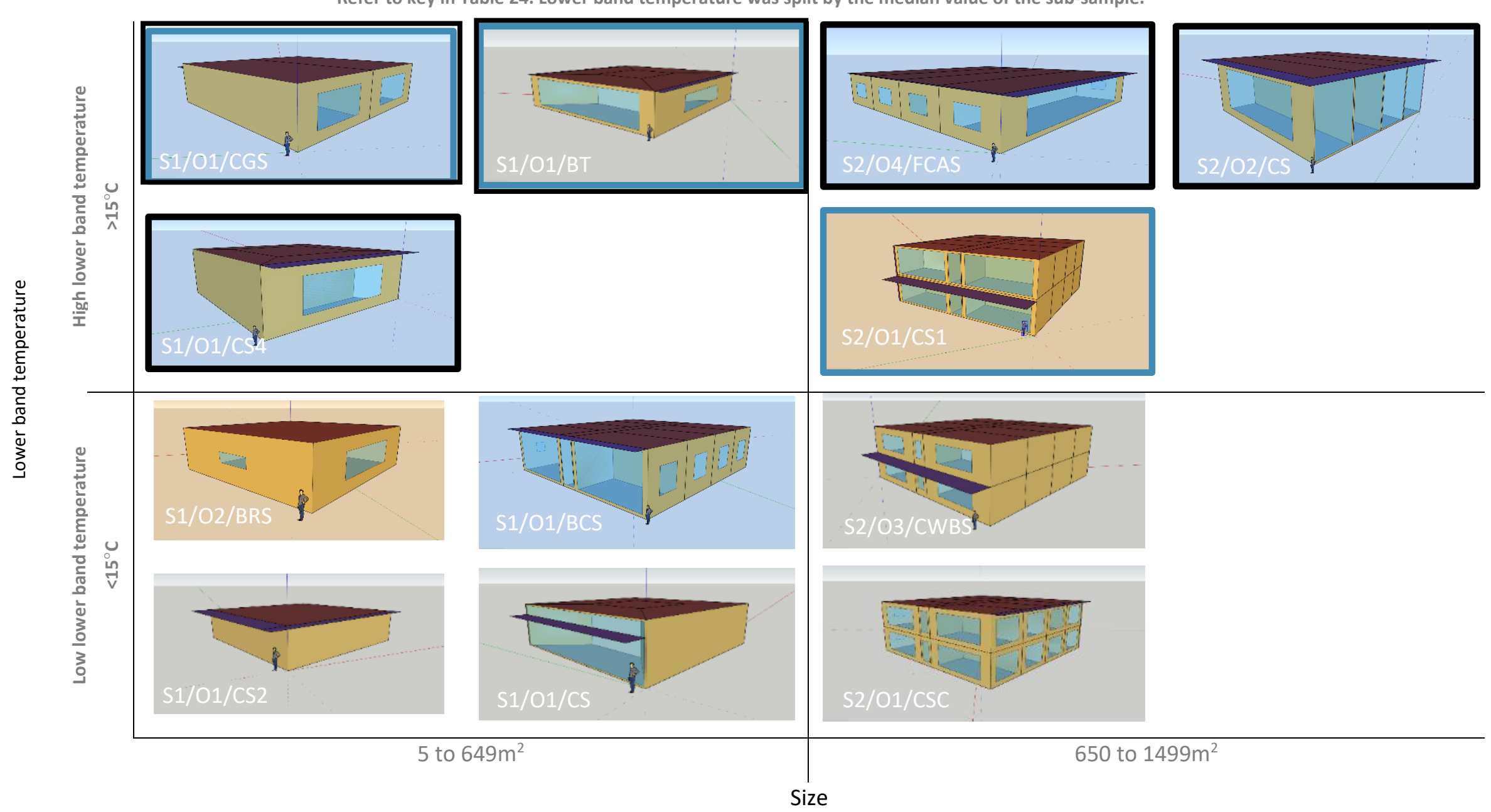

101 | P a g e 


\section{Results from a Long shift morning only test}

Figure 41 displays the results from a Long shift morning only test. In this test, the heating was switched on 150 minutes earlier at the beginning of the day only. This test aimed to understand how much additional benefit there was, if any, when heating demand was shifted significantly away from the peak hour. The results of the test showed that normalised energy capacity of most buildings increased in both warmer and cooler climates. Power capacity of all buildings in a warmer climate increased or remained relatively stable however, in a cooler climate it decreased for half the buildings. 


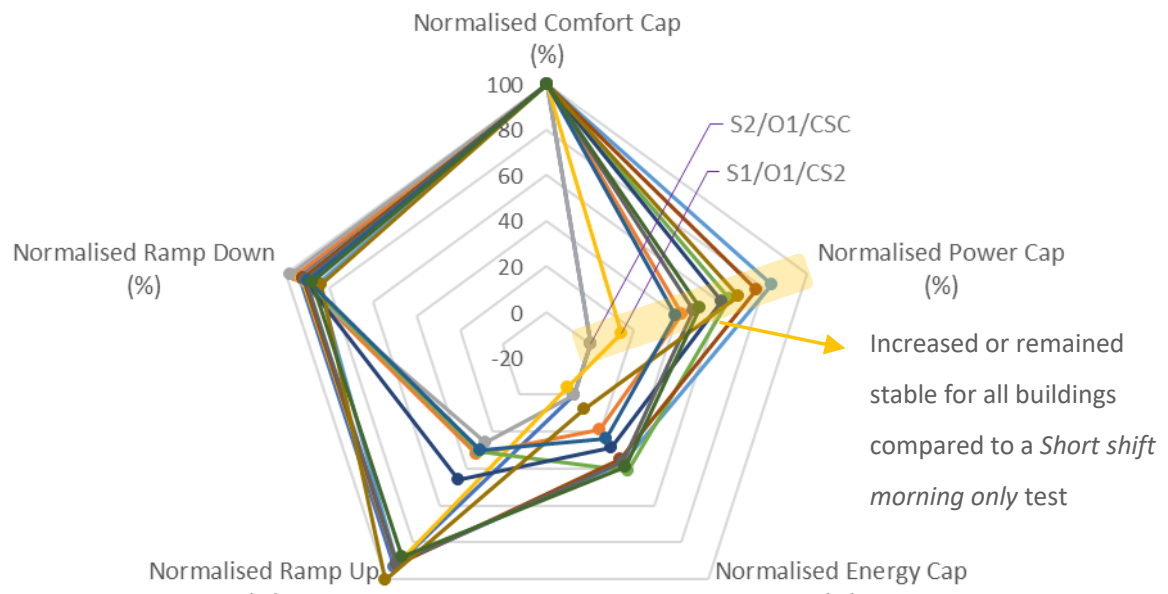

(\%)
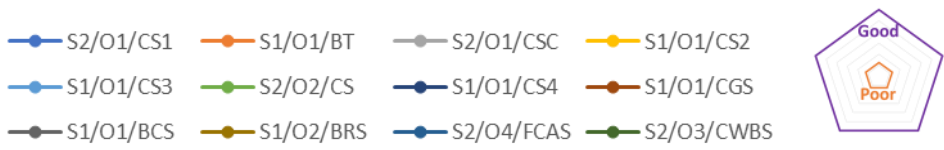

Warmer climate

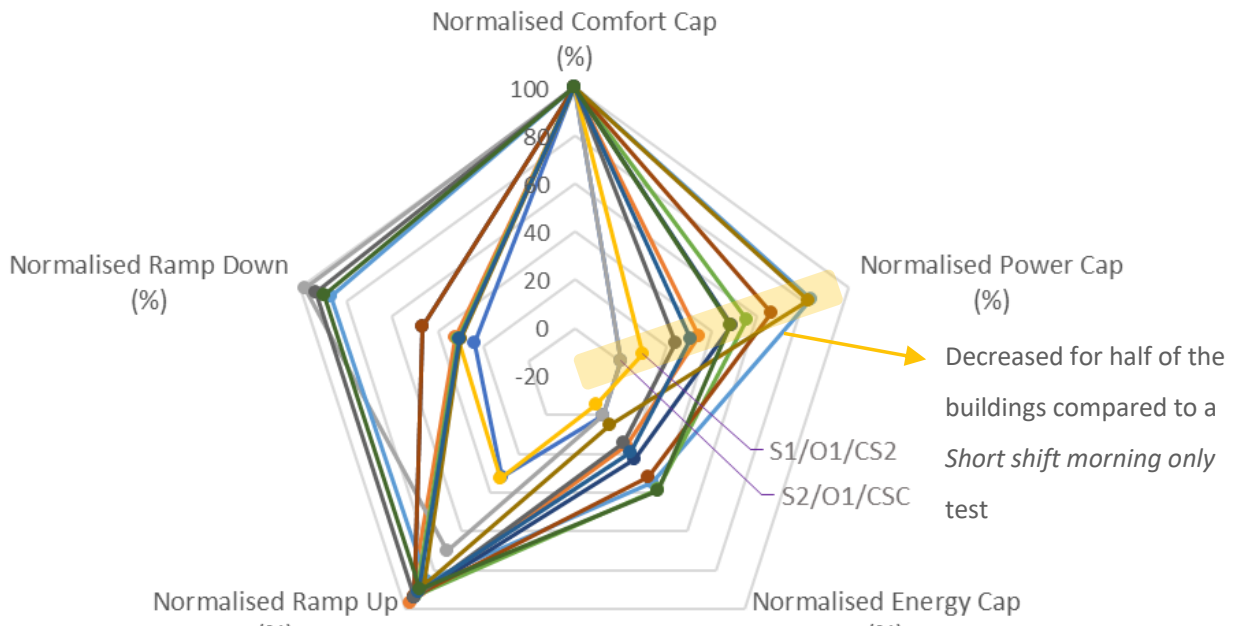

(\%)

(\%)

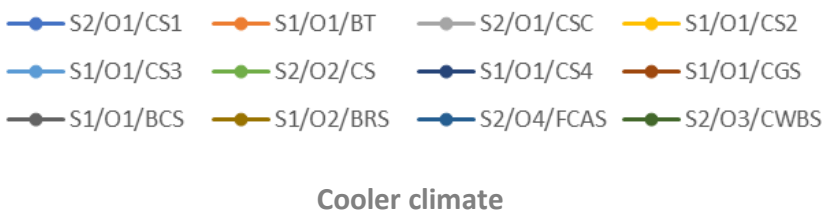

Figure 41 Energy flexibility results from Long shift morning only test 


\section{Improvements in power capacity from a short to a long shift}

By shifting the heating demand earlier at the beginning of the day, the normalised power capacity increased or remained stable for buildings located in a warmer climate. However, for the same buildings located in a cooler climate, power capacity for half the buildings decreased. Figure 42 and Figure 43 plots the normalised power capacity of each building after shifting the heating demand earlier at the beginning of the day by a short and long shift. It also plots a medium shift (90 minutes). All buildings had comfort capacities of $100 \%$.

In a warmer climate, buildings which had relatively high power capacities after conducting a short shift had slightly higher power capacities after conducting a long shift. The improvements were no more than a $15 \%$ increase. These buildings are shown the pink shaded area at the top of Figure 42. Buildings which had lower power capacities after a short shift had greater improvements in power capacity after a long shift. The improvements were between a $70 \%$ to $250 \%$ increase. These are shown in the blue shaded area in the middle of the chart.

The results suggested that conducting longer shifts in heating demand in buildings which already had high power capacity after a short shift, will not significantly increase power capacity. Buildings that had relatively low power capacity after a short shift can significantly increase power capacity after conducting longer shifts. Figure 42 also shows the increase in power capacity from a short shift to medium shift is much greater than the increase from a medium shift to a long shift. This is discussed in the following section.

Figure 43 represents the power capacity in a cooler climate. By just conducting a medium shift in heating demand after a short shift, power capacity for around half of the buildings in the subsample decreased. It suggested that for many buildings located in cooler climates, conducting short shifts will achieve the greatest power capacity, and longer shifts will have little to no additional benefit. Interestingly for one building, S2/O3/CWBS, power capacity increased significantly when heating was switched on earlier in the morning. 


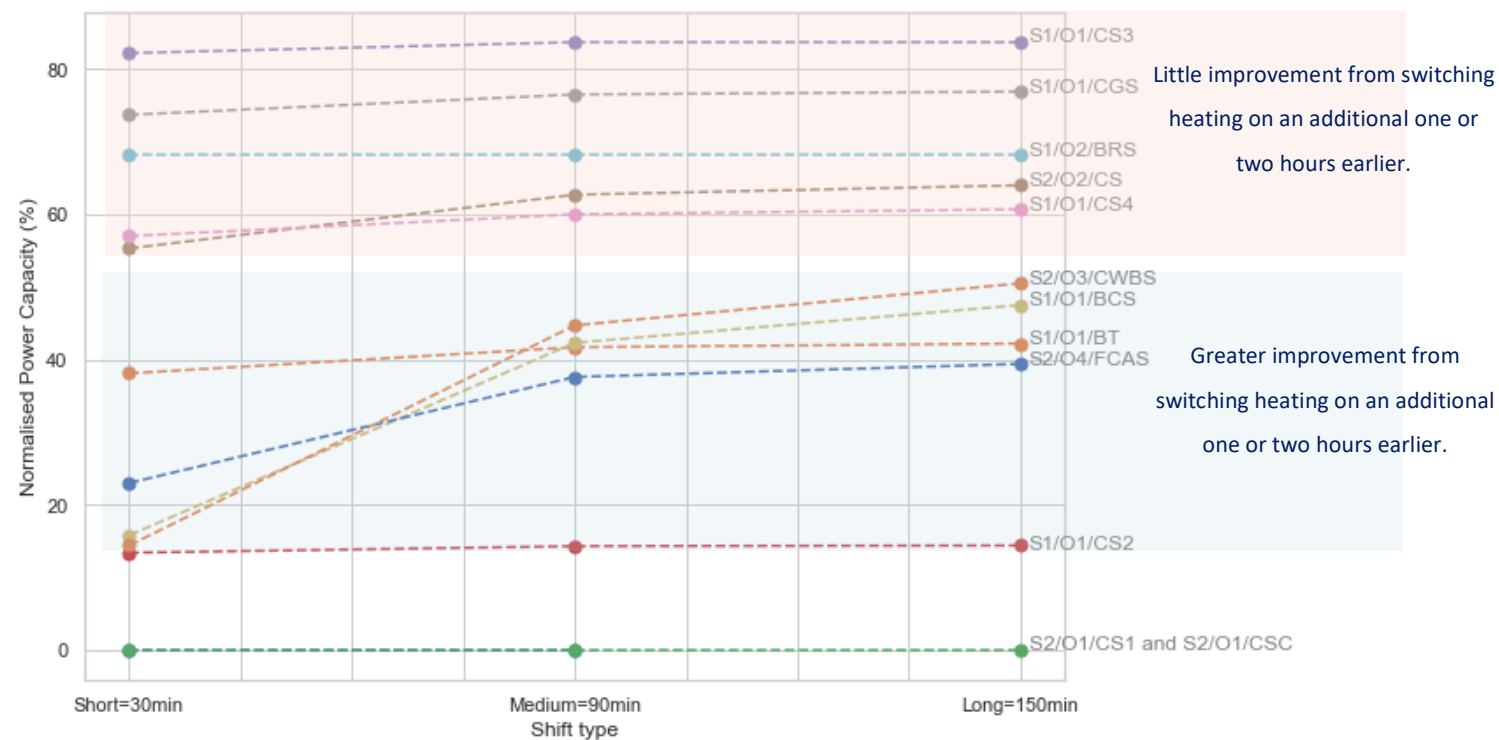

Figure 42 Normalised power capacity of each building from each shift in a warmer climate. *

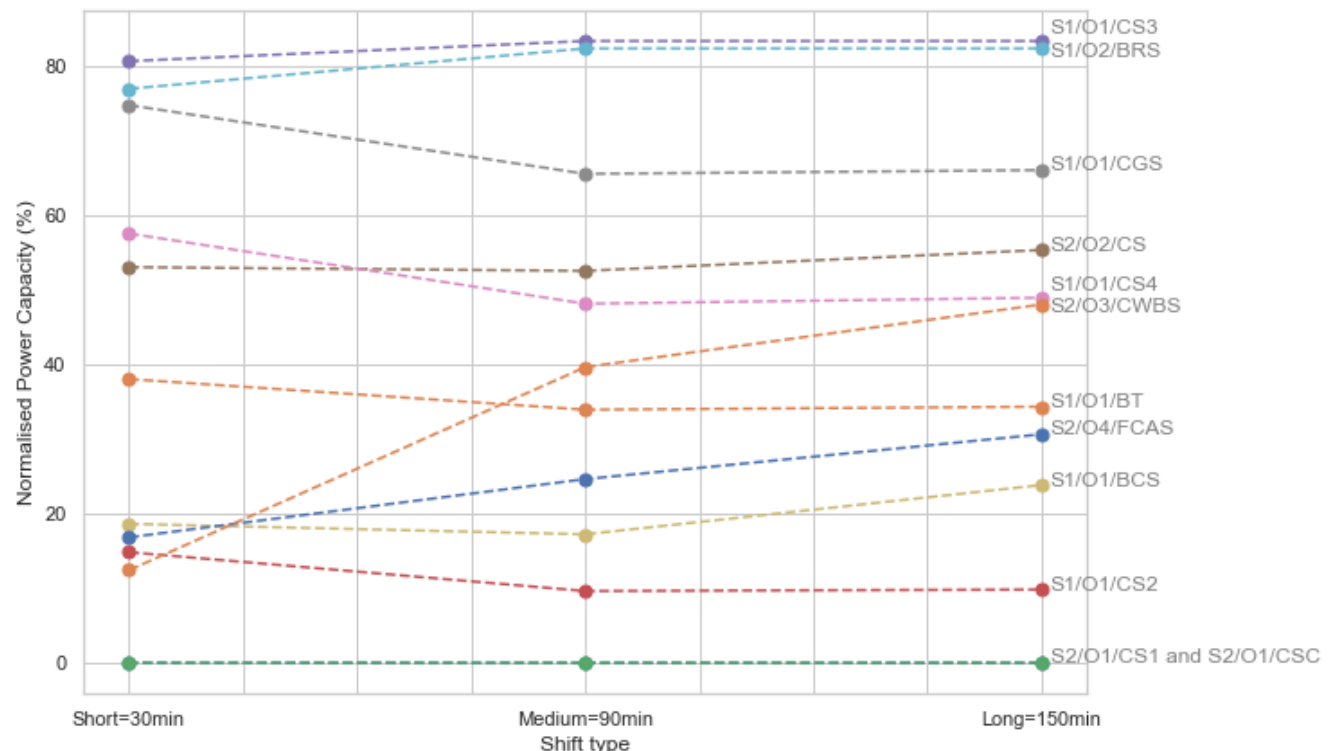

Figure 43 Normalised power capacity of each building from each shift in a cooler climate. *

* For two buildings the power capacity defaulted to zero as the original operation did not operate during the peak hour. 


\section{The additional power capacity from a long shift after a medium shift}

By plotting the results of a medium shift, the findings emphasised the small additional improvement in power capacity from conducting long shifts. Figure 44 shows the increase in power capacity in a warmer climate from a short to medium shift (blue) and a medium to long shift (pink) as a percentage of the overall increase. Of the overall increase in power capacity, a longer shift has the additional benefit of less than $20 \%$. It shows that the additional power capacity from a long shift does not have the same magnitude of improvement as a medium shift. For three buildings there were no additional improvements in power capacity. Two of those buildings were buildings that did not operate during the peak hour.

Power capacity after longer shifts did not improve for all buildings in a cooler climate. Figure 45 reflects the decreases in power capacity after a medium shift as negative improvements. The pink and positive component reflects the increase in power capacity from a long shift after the medium shift. 


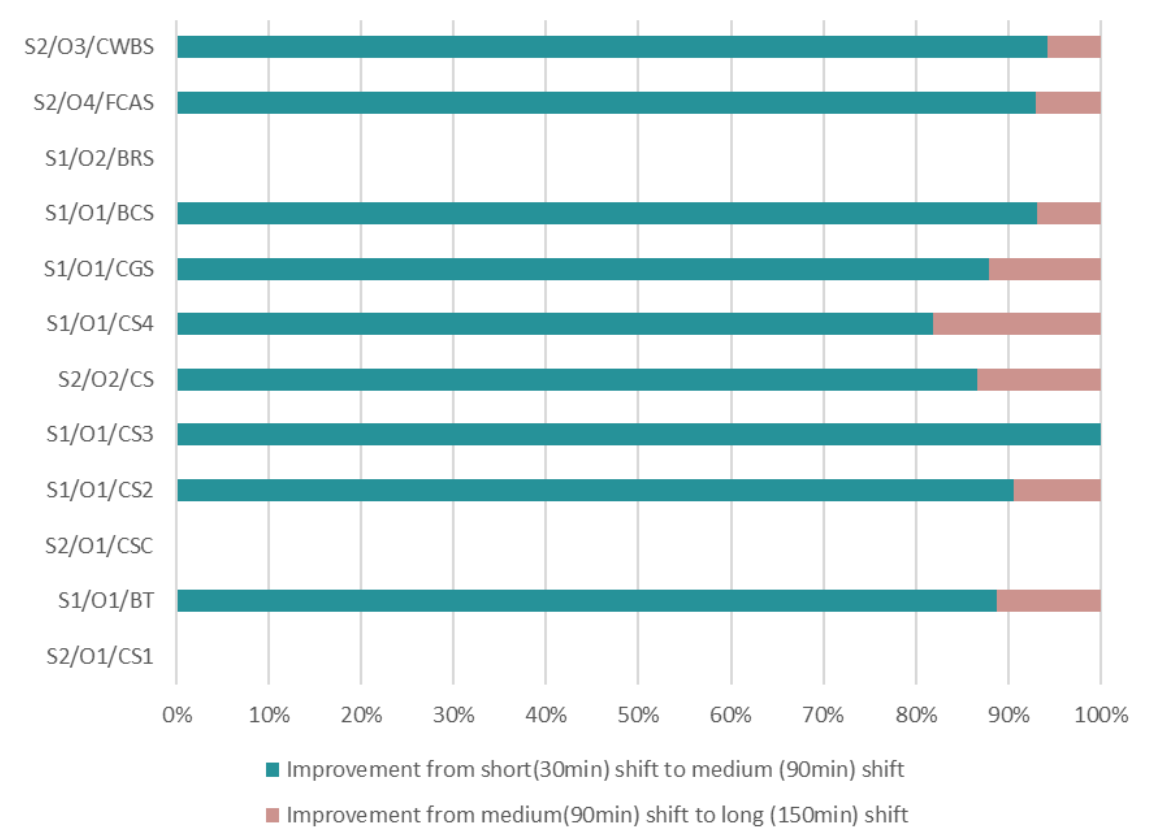

Figure 44 Increase/decreases in normalised power capacity as a proportion of total increase/decrease from a medium shift and then long shift in a warmer climate. *

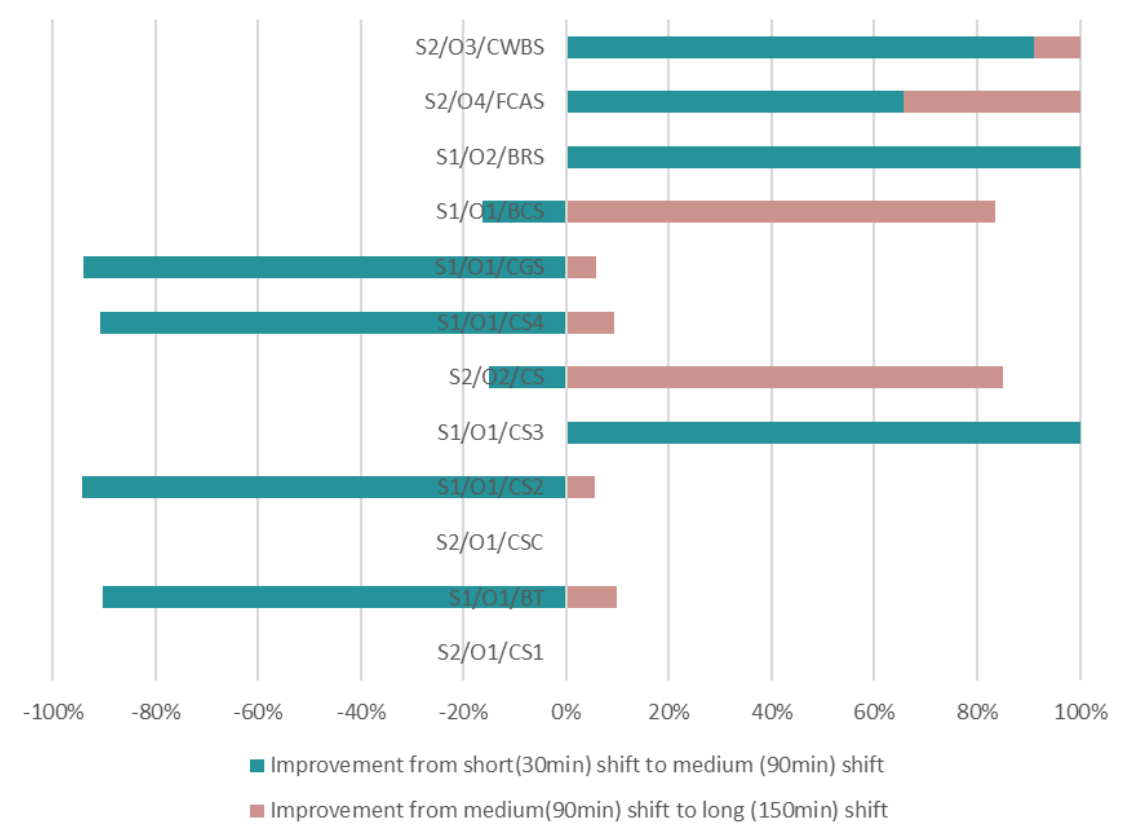

Figure 45 Increase/decreases in normalised power capacity as a proportion of total increase/decrease from a medium shift and then long shift in a cooler climate. *

*Two buildings were defaulted to zero as they did not operate during the peak hour. 


\section{Results from a Long shift morning + evening test}

When heating was shifted 150 minutes earlier at the beginning of the day and switched off 150 minutes earlier at the end of the day, there were significant changes to the comfort capacity. In a warmer climate, five of the twelve buildings did not maintain desirable temperatures $100 \%$ of the time. In a cooler region, seven of the twelve buildings did not maintain desirable temperatures $100 \%$ of the time. Similar to the results from a shorter shift at the beginning and end of the day, there was a link between lower comfort capacities and the high lower band temperature. As shown in Table 27, the buildings which had comfort capacities less than $100 \%$ had high lower comfort bands. Only two building of the low lower band temperature group had a comfort capacity of less than $100 \%$. These two buildings were both in size group two. The analysis of the relationship between comfort capacities and various other physical characteristics from conducting this test can be found in Appendix 8.5. 


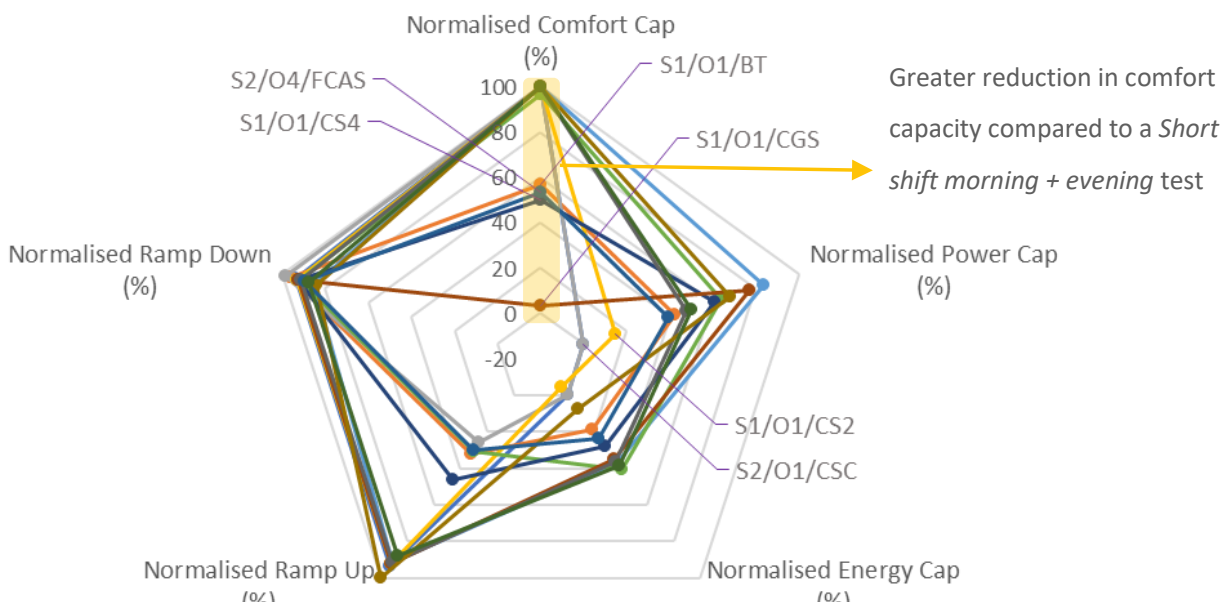

(\%)

(\%)

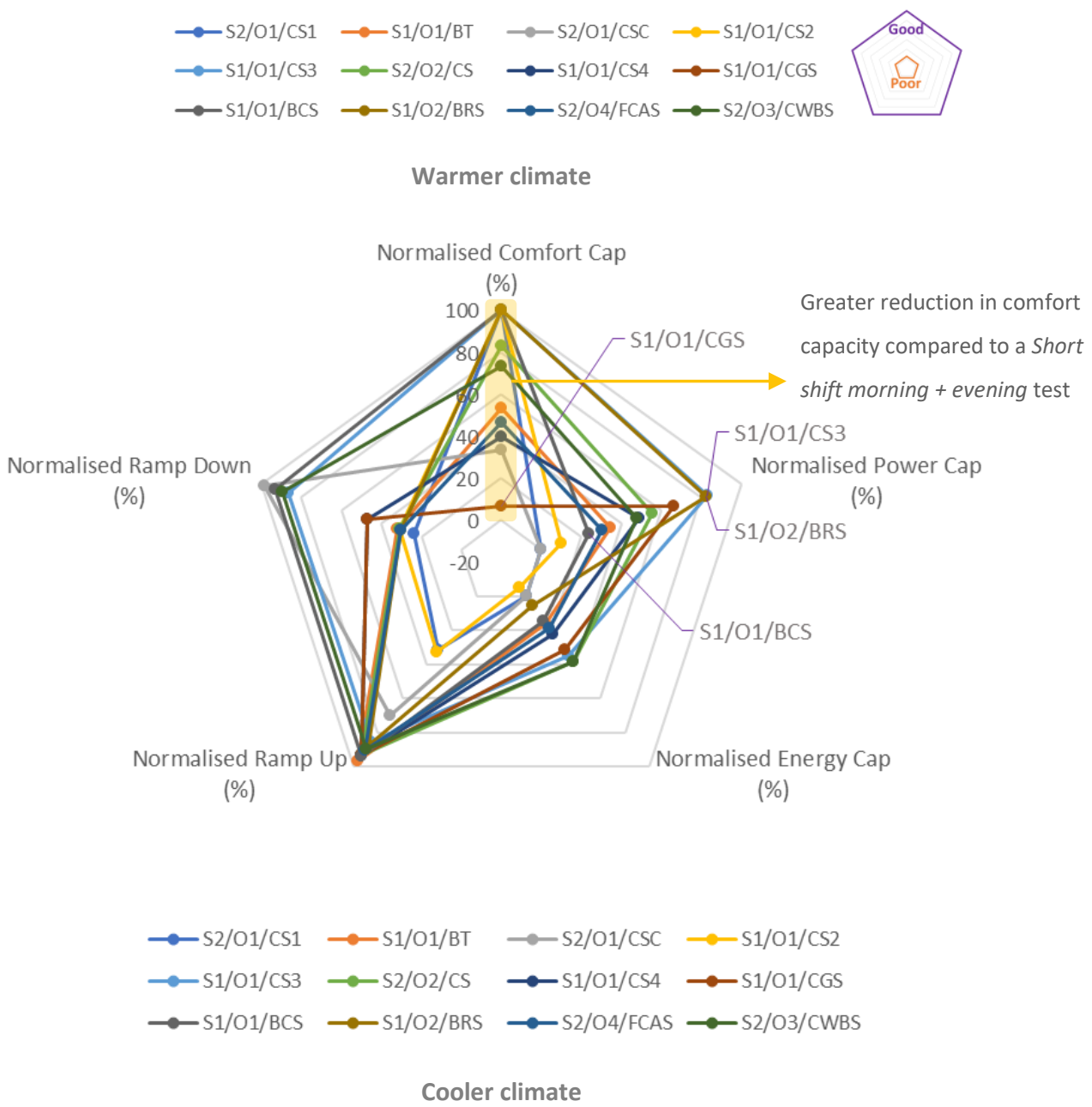

Figure 46 Energy flexibility results from Long shift morning + evening test 
Table 26 Key for comfort capacity results in Table 27

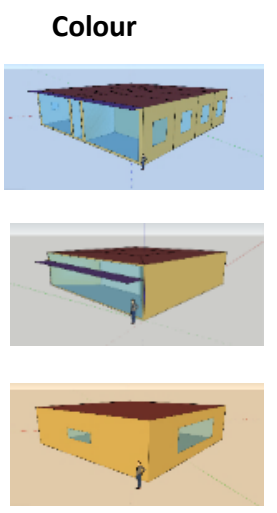

Type

Border

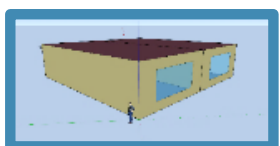

Office

Mixed
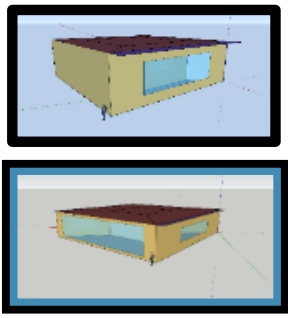

Meaning

Low comfort capacity in a

warmer climate

Low comfort capacity in a cooler climate

Low comfort capacity in a

warmer and cooler climate 
Table 27 Comfort capacity results by type, size, and lower band temperature from a Long shift morning + evening test

Refer to key in Table 26. Lower band temperature was split by the median value of the sub-sample.

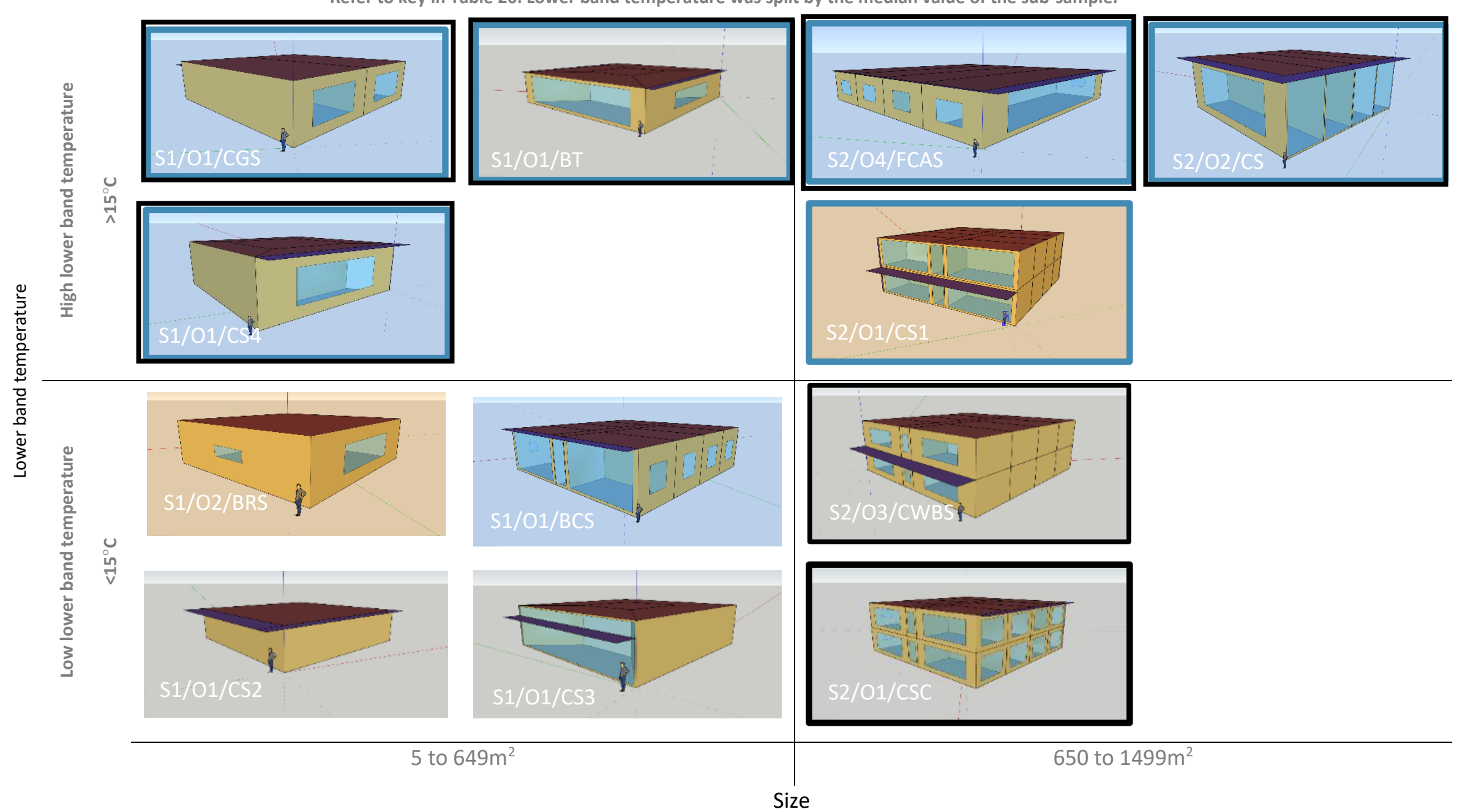

111 | $\mathrm{P}$ a g e 


\subsubsection{ENERGY FLEXIBILITY FROM SHEDDING STRATEGIES}

In the previous tests, energy flexible operation was introduced into buildings by shifting heating demand. In the following tests, changes in setpoints to stimulate a shed in heating demand during the peak hour was introduced. Reducing the setpoint by $1^{\circ} \mathrm{C}$ represented a Minor shed, and $3^{\circ} \mathrm{C}$ represented a Major shed. The energy flexibility results from both tests in a warmer and cooler climate are presented on the following page.

The results from the shedding tests included the comfort recovery metric. When the setpoints were changed back to the normal settings, the temperatures of under half the buildings in a warmer and cooler climate recovered instantly after a minor setpoint change. When a major setpoint change was implemented, the temperatures of more buildings in a warmer and cooler climate recovered faster.

Power capacity from conducting these tests did not come at the cost of comfort. But, for all but one building, the power capacities were less than $20 \%$. This was significantly lower than the power capacities from conducting shifts in heating demand. When shifts were conducted, around half the buildings had power capacities greater than $20 \%$.

Energy capacity from a minor setpoint change was much less than the energy capacity from conducting short shifts in heating demand. Energy capacity from a major setpoint change resulted in about the same energy capacity from short shifts in heating demand. 


\section{Results from a Minor shed}

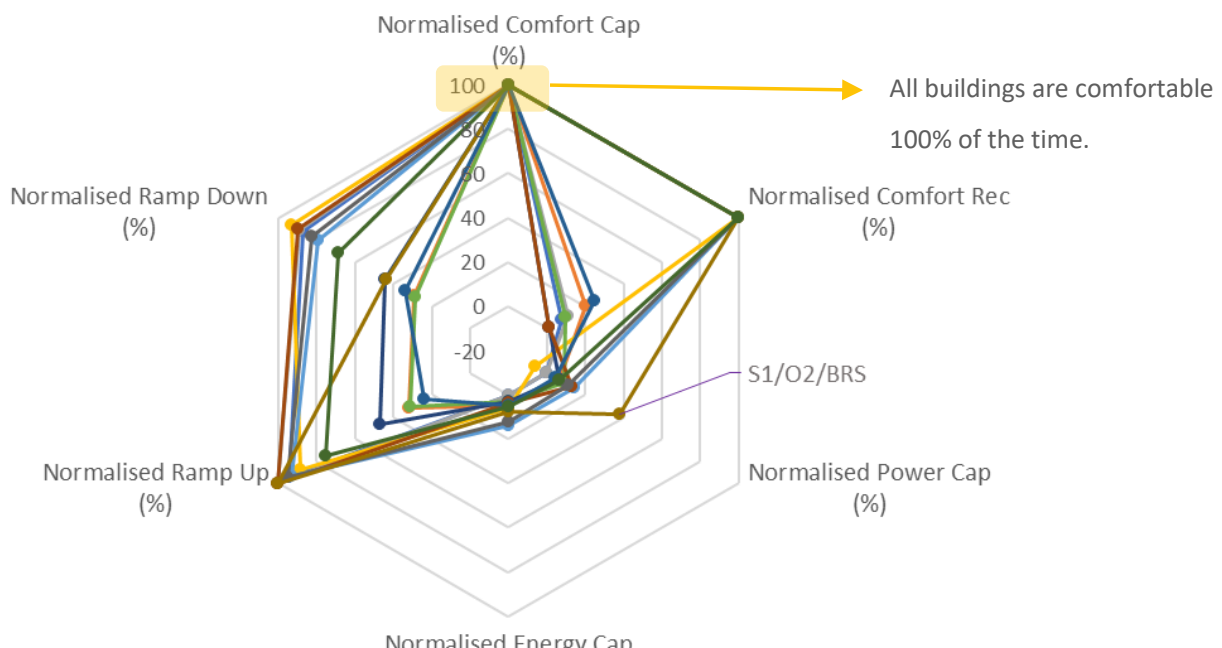

(\%)
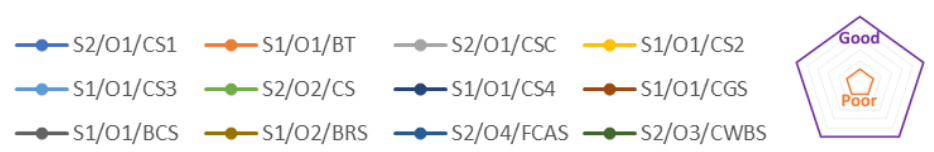

Warmer climate

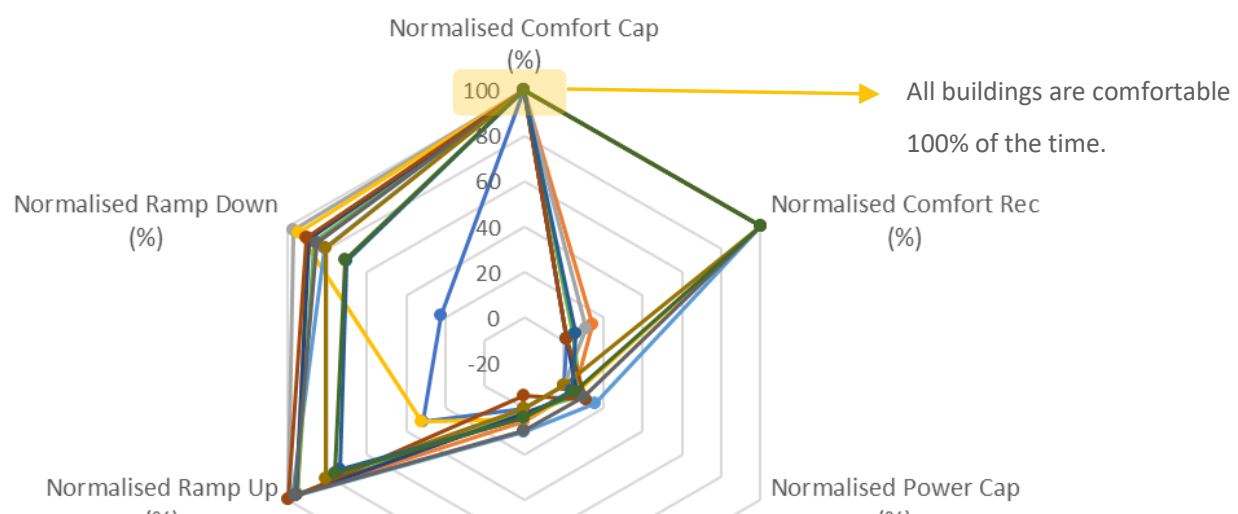

(\%)

(\%)

Normalised Energy Cap

(\%)

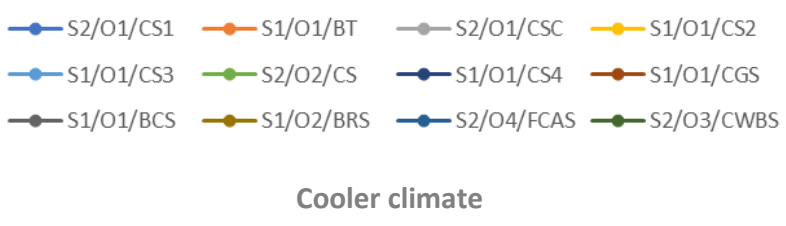

Figure 47 Energy flexibility results from Minor shed test 


\section{Results from a Major shed}

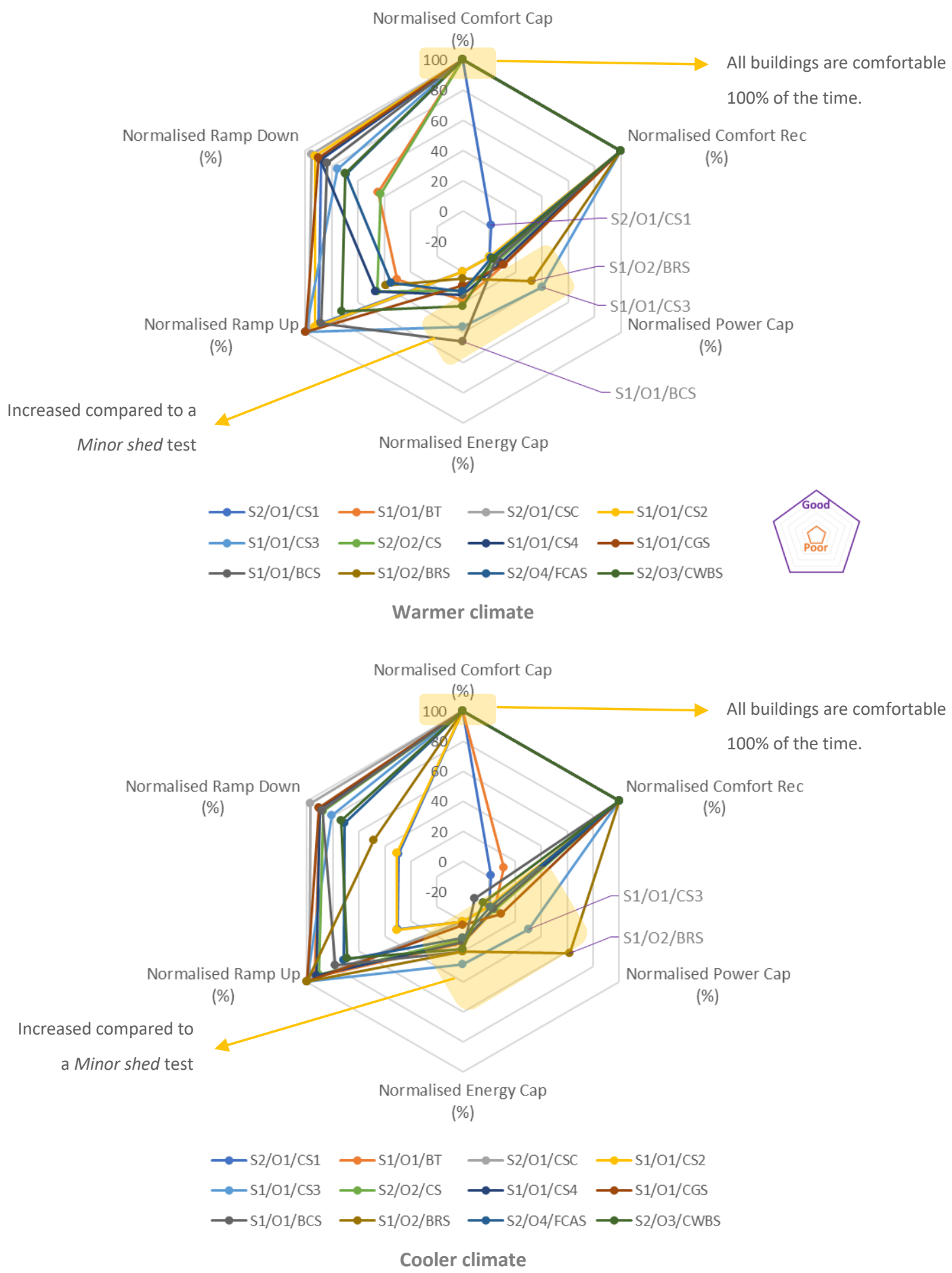

Figure 48 Energy flexibility results from Major shed test 


\subsubsection{SUMMARY OF FINDINGS}

Small commercial buildings with heat pumps have energy flexibility potential due to their winter morning electricity demand.

The justification of the sub-sample showed that small commercial buildings with heat pumps contributed to the winter morning peak. This indicated that energy flexibility potential exists in these buildings as they should and could be energy flexibly operated to respond better to grid signals. Simulating the buildings demonstrated that there is energy flexibility potential with measured results.

\section{Shifting strategies offer more reduction in peak hour demand than shedding strategies.}

Two types of energy flexibility strategies were tested. Four of the tests shifted heating demand and two tests shed heating demand. Based on the buildings' ability to reduce peak hour demand, the energy flexibility potential was $73 \%$ to $90 \%$ worse under shedding strategies than under shifting strategies. Although a greater reduction in demand was achieved from shifting heating demand, in two of the shifting tests, reductions in power and energy came at the cost of comfort.

\section{Buildings in a warmer climate region were better at remaining comfortable after the heating was switched off.}

All buildings remained comfortable when heating demand was shifted earlier at the beginning of the day only and when the temperature setpoints were relaxed. Comfort was only compromised when heating was turned off earlier at the end of the day. When heating was turned off earlier at the end of the day for a short and long period of time, more than half of the buildings in a warmer climate maintained comfortable indoor air temperatures. In a cooler climate, half the buildings were comfortable in a short shift, but less than half were comfortable in a long shift. This indicated that buildings in a warmer climate were better at remaining comfortable than buildings in a cooler climate.

This was the opposite result of what was found by Hurtado Munoz's (2017) research where buildings in a cooler climate performed better when it came to staying comfortable for longer. Hurtado Munoz (2017) stated that this was due to better insulation in buildings in a cooler climate. The difference in the results may have been caused by simulating the same buildings of the same construction in both warmer and cooler regions. This was a limitation in the research 
methodology and means that buildings in a cooler region could have better performance than what has been presented.

\section{The lower comfort band affects buildings' ability to remain comfortable.}

There were no physical characteristics of the those examined that clearly affected the buildings' ability to stay comfortable for longer. However, the lower comfort band, an operational characteristic, indicated that buildings which maintained comfortable temperatures for longer had low lower comfort bands. This meant that there was a larger buffer for indoor air temperatures to drop before the building was deemed 'uncomfortable'.

\section{Long shifts did not reduce peak hour demand significantly more than medium shifts in a warmer} climate.

In a warmer climate, long shifts in heating demand achieved a greater reduction in peak hour demand than short shifts. However, long shifts had little additional reduction in demand compared to medium shifts. The additional reduction in demand was less than $20 \%$. In a cooler climate region, for half the buildings, the reduction in peak hour demand from long shifts was less than the demand reduction from short shifts.

\subsection{REDUCTION IN DEMAND FROM ENERGY FLEXIBLY OPERATING SMALL COMMERCIAL BUILDINGS}

The previous section presented the energy flexibility results of a sub-sample of commercial buildings from conducting six energy flexibility tests. The results were used to calculate the potential reduction in the commercial building stock's peak demand. In this section, the results from two energy flexibility tests are presented. Those tests achieved the highest reduction in peak demand. The tests are: (1) Short shift morning only, and (2) a Long shift morning only. The peak demand reduction results of the four other tests are briefly discussed.

For all energy flexibility tests conducted, the reduction in the commercial building stock's peak demand was based on energy flexibly operating buildings in the sub-sample. These buildings were small commercial buildings between $5 \mathrm{~m}^{2}$ to $1499 \mathrm{~m}^{2}$ that used heat pumps and they were only energy flexibly operated if they met the aggregation criterion. As described in the methodology, 
the criterion required buildings to remain comfortable throughout the day, reduce peak hour demand, and reduce peak demand on the peak day.

\subsubsection{BUILDINGS WHICH MET THE AGGREGATION CRITERION}

For each energy flexibility test implemented in the sub-sample, the number of buildings which met the aggregation criterion was varied. In energy flexibility tests where heating was shifted earlier at the beginning of the day only, $70 \%$ to $80 \%$ of the sub-sample met the criteria and was energy flexibly operated. These buildings were comfortable throughout the day however, some of the buildings did not reduce the peak demand on the peak day and therefore were not included in the aggregation. In the energy flexibility tests where heating was shifted earlier at the beginning and end of the day, comfort in the buildings could be compromised. The results from these tests demonstrated fewer buildings met the aggregation criterion as only $30 \%$ to $50 \%$ of the subsample was energy flexibly operated. The two buildings which did not operate during the peak hour were excluded, therefore did not meet the aggregation criterion.

Energy flexibility tests of the shedding strategy resulted in $70 \%$ to $90 \%$ of the sub-sample meeting the aggregation criteria. In shedding tests, all buildings were comfortable therefore buildings which did not meet the aggregation criterion had higher peak hour demand or higher peak demand on the peak day.

The number of buildings in each climate region and each energy flexibility test which met the criterion can be found in Appendix 8.6. 


\subsubsection{REDUCTION IN THE COMMERCIAL BUILDING STOCK'S PEAK DEMAND}

The reduction in the commercial building stock's peak demand was measured on the day of the peak hour (the 'peak day'). The following chart presents the results in a daily load profile. Figure 49 contains three daily load profiles of the commercial building stock. One load profile (blue) represents the commercial building stock with no energy flexibly operated buildings. The second load profile (pink) represents the commercial building stock partly energy flexibly operated. In this load profile, energy flexibility was implemented in the sub-sample of buildings by conducting the Short shift morning only test. The third load profile (green) also shows the commercial building stock partly energy flexibly operated. However, in this load profile, energy flexibility was implemented in the sub-sample of buildings by conducting the Long shift morning only test.

The reduction in peak demand from conducting the short shift in heating demand was $52 \mathrm{MW}$. An additional $22 \mathrm{MW}$ could be reduced after conducting the long shift in heating demand. Therefore, the total reduction in the commercial building stock's peak demand was 74MW. This was a reduction of just over $8 \%$ of the original peak demand. The reduction was a small percentage, yet $38 \%$ of commercial buildings had to be energy flexibly operated to achieve the result. This was a reasonable percentage which was the equivalent of around 10,000 buildings.

The reduction in maximum demand which occurred during the peak hour was much greater. By conducting the short shift in heating demand, the maximum demand reduction was $111 \mathrm{MW}$. This could be reduced by a further $41 \mathrm{MW}$ if the longer shift in heating demand was conducted. The total reduction was $152 \mathrm{MW}$ which was just over a $15 \%$ reduction in maximum demand.

Energy flexibly operating part of the commercial building stock demonstrated flattening of the daily load profile and therefore lowered the intraday peak. The implication of this was that demand increased earlier in the morning. It also increased energy consumption by $8 \%$ when a long shift in heating demand was conducted. 


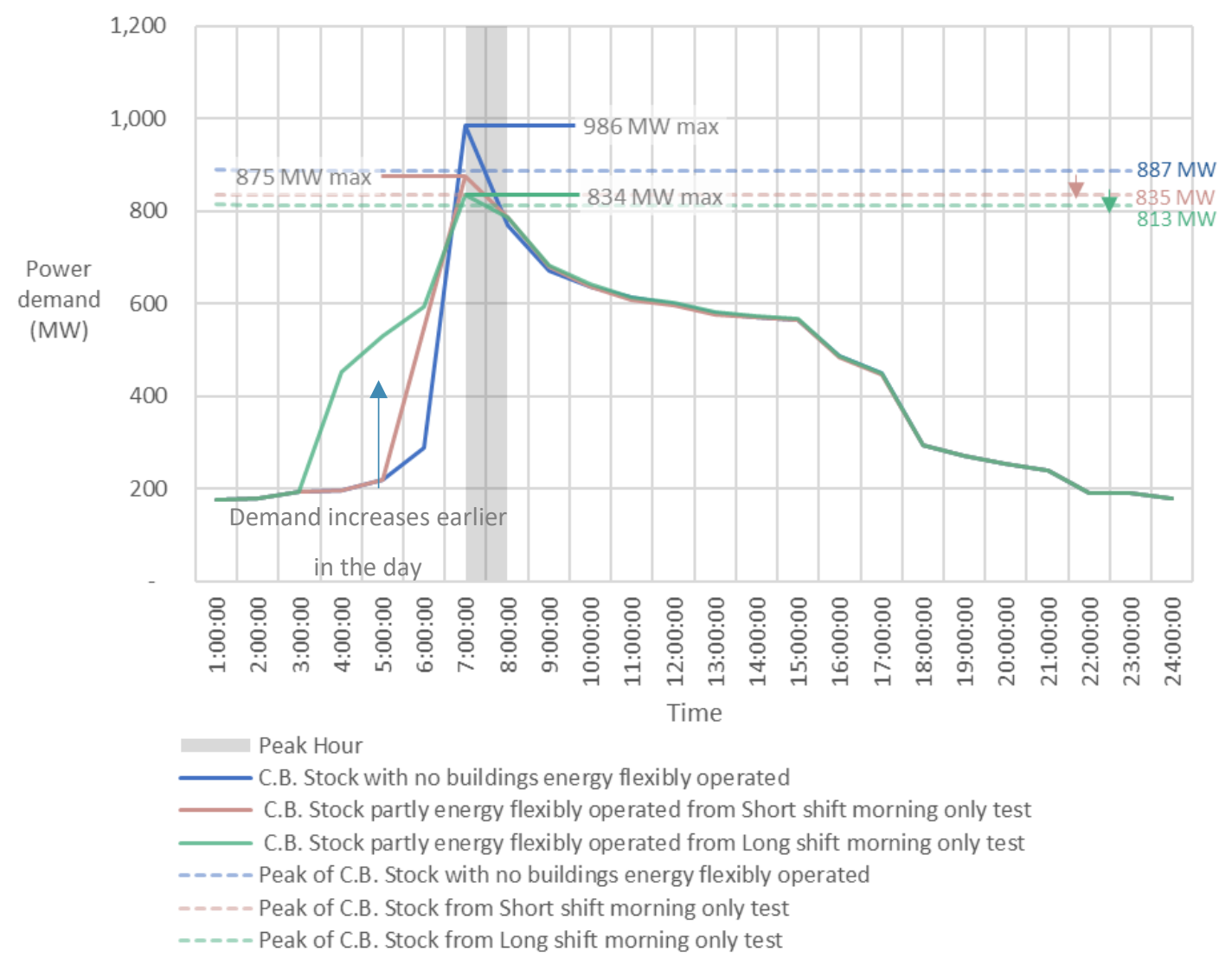

Figure 49 Daily load profiles from partly energy flexibly operating the commercial building stock.

The maximum demand is marked at 7am as the data forward facing. This means demand at 7am represents the averaged data between 7:05am and 8:00am.

“C.B." stands for 'Commercial building'.

\section{Peak demand reduction from other energy flexibility tests}

When the sub-sample was operated so that the heating would turn off earlier at the end of the day, the potential reduction in the commercial building stock's peak demand was less than $74 \mathrm{MW}$. At best, the result was a 30MW peak demand reduction from conducting a short shift in heating demand. This was just over a $3 \%$ reduction. The low reduction potential was due to fewer buildings meeting the comfort requirements of the aggregation criteria. When the heating setpoints were relaxed in sub-sample, the greatest reduction in peak demand was $13 \mathrm{MW}$. This was only a $2 \%$ reduction. The charts of daily load profiles for each energy flexibility test can be found in Appendix 8.7. 


\subsubsection{ENERGY FLEXIBILITY RESULTS TO BE EXTRAPOLATED}

Based on the results discussed in the previous section, section 0 , two of the six energy flexibility tests were selected and implemented across the rest of the commercial building stock. The tests that were selected had the highest peak demand reduction - a High Reduction scenario, and peak demand reduction from energy flexibly operating the least number of buildings - a Minimal Flexible Operation scenario. Figure 50 uses the evaluation framework set out in the methodology to select the two tests. The framework plots each test by peak demand reduction across the commercial building stock against the number of buildings that are energy flexibly operated to achieve the peak demand reduction.

Tests that were scattered at the top of the framework indicate the best tests for the High Reduction scenario. The test that achieved this goal was the Long shift morning only test. Tests that were scattered at the left side of the framework indicate the best tests for the Minimal Flexible Operation scenario. The test that achieved this goal was the Long shifting morning + evening test. These two tests were selected and implemented in the extrapolation process.

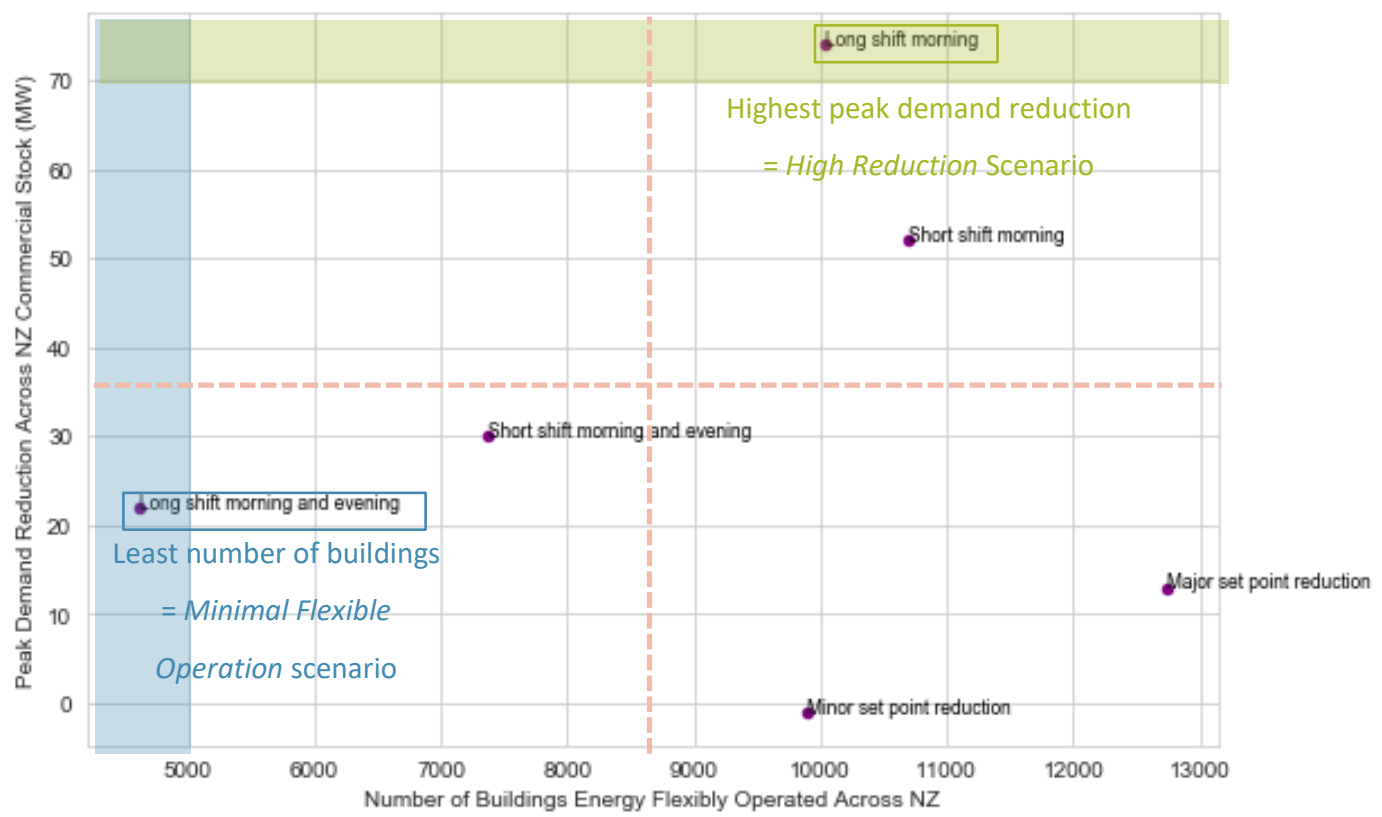

Figure 50 Evaluating energy flexibility tests for extrapolation. 


\subsubsection{DISTRIBUTION OF 5-MINUTE DEMAND DATA WITHIN AN HOUR}

The energy modelling outputs resulting in the base case dataset were reported at hourly intervals, while the outputs from each BEM used to calculate energy flexibility were reported at 5-minute intervals. A smaller time interval was used in the BEMs to understand the peaks in demand in greater detail and reflect the real operation of heat pumps. To compare the energy flexibility data with the base case dataset, the demand at every 5 minutes (5-minute demand) within each hour was averaged. By averaging the results, the maximum 5-minute demand within each hour was dampened. These dampened results were presented in the daily load profiles. To understand how representative the average demand was of the maximum and minimum demand, the distribution of 5-minute demand was examined for each BEM during the hour of heat pump start-up and during an hour of continuous heat pump operation.

For every hour there were twelve 5-minute demand data points. Figure 52 to Figure 55 shows the distribution of the 5-minute demand during the hour preceding the peak hour (6:00am to 6:55am) and the peak hour (7:00am to 7:55am). The data represents the demand from a Short shift morning only test where the heating demand in each building was shifted to start 30 minutes earlier at the beginning of the day. The data for the hour preceding the peak hour contains the demand data during the start-up of the heat pump where significant peaking occurred. The peak hour data contains the demand data of continuous heat pump operation. The distribution shown is for each building in a warmer and cooler climate. The data was not normalised.

Figure 51 and Figure 53 show that the 5-minute demand during the hour before the peak hour was more distributed than 5-minute demand during the peak hour shown in Figure 52 and Figure 54. This signified greater misrepresentation of the peaks in heating demand during the hour when the heating was switched on. This means that the results displayed in the daily load profiles did not reflect the potential sharp and short-lived peaks in demand which were likely to occur. This was a key limitation but averaging the data was necessary to compare the results with the base case dataset. 
Distribution of 5-minute demand

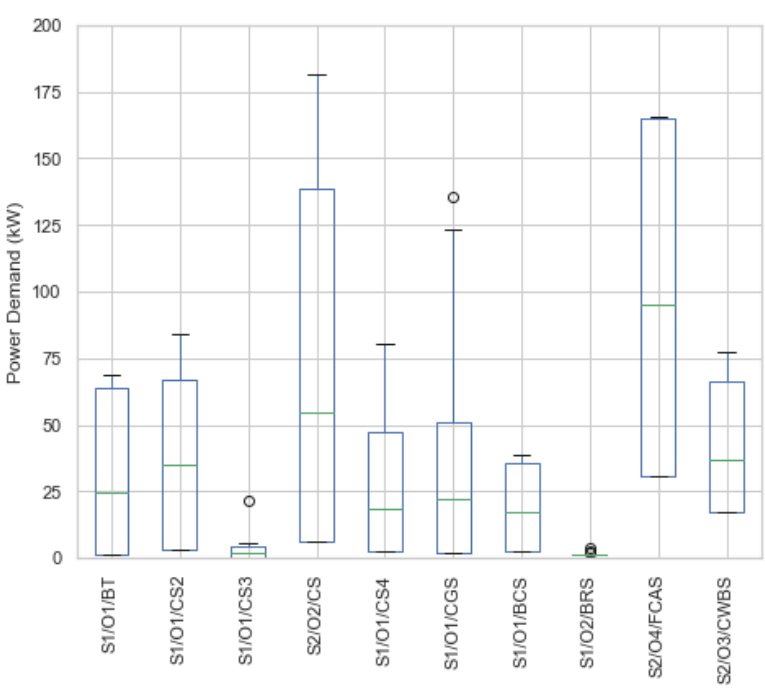

Figure $\mathbf{5 1}$ Hour before peak hour in a warmer climate.

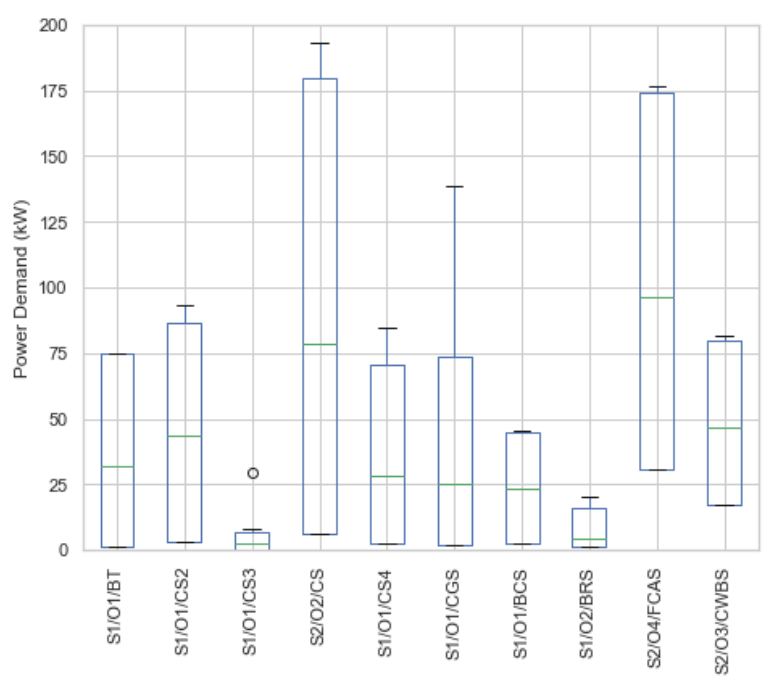

Figure 53 Hour before peak hour in a cooler climate.

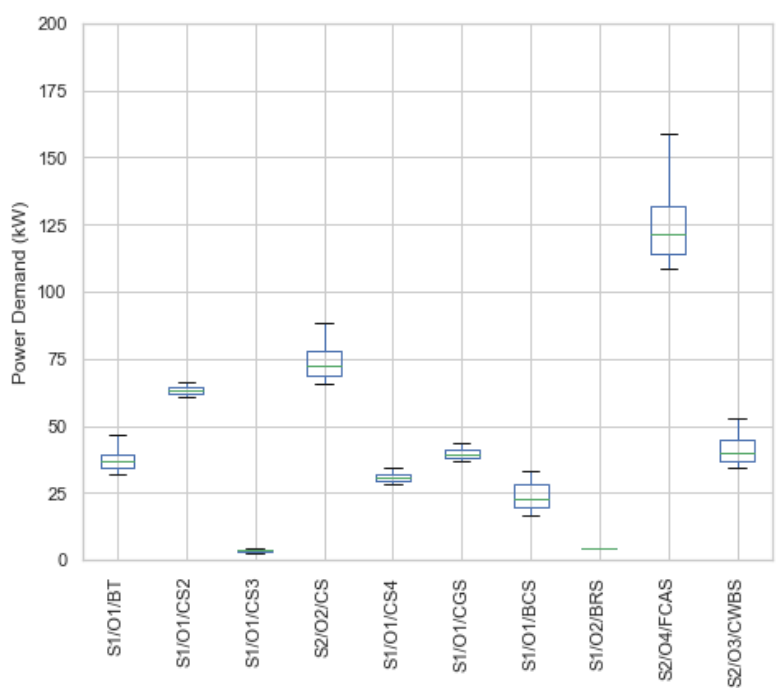

Figure 52 Peak hour in a warmer climate.

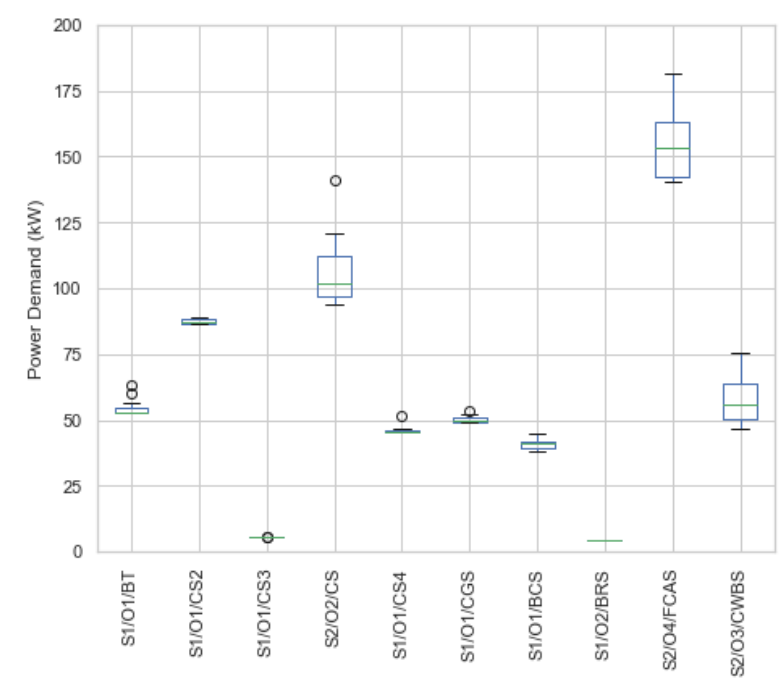

Figure 54 Peak hour in a cooler climate.

Two buildings were excluded as they did not operate during the peak hour. 


\subsubsection{SUMMARY OF FINDINGS}

Energy flexibly operating small commercial buildings reduced the commercial building stock's peak demand by 74MW.

Energy flexibly operating small commercial buildings reduced the commercial building stock's peak demand by just over $8 \%$ at best. This was a $74 \mathrm{MW}$ reduction. The reduction was achieved by energy flexibly operating around 10,000 small commercial buildings. The energy flexible operation was implemented by conducting the Long shift morning only test.

For most energy flexibility tests, more than half of the sub-sample was energy flexibly operated for the aggregation.

More than half the buildings in the sub-sample were energy flexibly operated in order to achieve the reductions in the commercial building stock's peak demand. These were energy flexibly operated with no loss of comfort, with reduced peak hour demand, and with reduced peak demand on the peak day.

The results from shifting strategies were selected for extrapolation.

To examine the energy flexibility potential across the whole commercial building stock, two energy flexibility tests were selected to apply across larger commercial buildings. Both these tests shifted heating demand. The two tests were:

1. Long shift morning only - This test was selected as it resulted in the greatest reduction in the commercial building stock's peak demand when implemented only in the sub-sample.

2. Long shift morning + evening - This test was selected as it resulted in a reduction in peak demand with the least number of energy flexibly operated buildings when implemented only in the sub-sample. 


\subsection{REDUCTION IN DEMAND FROM ENERGY FLEXIBLY OPERATING SMALL AND LARGER COMMERCIAL BUILDINGS}

The previous section presented the reduction in the commercial building stock's peak demand from implementing six energy flexibility tests in small commercial buildings. Two tests were selected based on the results in the previous section and were also implemented in larger commercial buildings. This was done to measure the reduction in the commercial building stock's peak demand if small and larger buildings were energy flexibly operated. The tests were not implemented by simulating the energy flexibility of larger buildings. Instead, the reduction was calculated by extrapolating the results from the previous section.

The two energy flexibility tests implemented in larger commercial buildings were:

1. Long shift morning only which resulted in a High Reduction scenario.

2. Long shift morning + evening which resulted in a Minimal Flexible Operation scenario.

The results from implementing the two energy flexibility tests in small commercial buildings are summarised in Table 28. These results were extrapolated across two groups of larger commercial buildings. The two groups were:

- Larger commercial buildings with heat pumps

- Larger commercial buildings regardless of heating system type

Table 28 Summary of results after implementing energy flexibility tests in small commercial buildings.

\begin{tabular}{lrrrrr}
\hline Scenarios & $\begin{array}{r}\text { Total Peak } \\
\text { demand } \\
\text { reduction }\end{array}$ & $\begin{array}{r}\text { \% of peak } \\
\text { demand } \\
\text { reduction }\end{array}$ & $\begin{array}{r}\text { \% of energy } \\
\text { flexibly operated } \\
\text { buildings in NZ }\end{array}$ & $\begin{array}{r}\text { \% of energy } \\
\text { flexibly operated } \\
\text { floor area in NZ }\end{array}$ & $\begin{array}{r}\text { Increase in } \\
\text { energy } \\
\text { consumption }\end{array}$ \\
\hline $\begin{array}{l}\text { High } \\
\text { Reduction }\end{array}$ & $74 \mathrm{MW}$ & $8 \%$ & $38 \%$ & $16 \%$ & $8 \%$ \\
\hline $\begin{array}{l}\text { Minimal } \\
\text { Flexible } \\
\text { Operation }\end{array}$ & $22 \mathrm{MW}$ & $2 \%$ & $18 \%$ & $7 \%$ & $2 \%$ \\
\hline
\end{tabular}




\subsubsection{REDUCTION FROM ENERGY FLEXIBLY OPERATING LARGER COMMERCIAL BUILDINGS WITH HEAT PUMPS}

The results were first extrapolated across larger commercial buildings that contain heat pumps. The main assumption made in this extrapolation was that large buildings and small buildings that contain heat pumps behaved similarly when energy flexibly operated.

Table 29 summarises the results. In a High Reduction scenario, the total peak demand reduction was $89 \mathrm{MW}$. This was an additional reduction of $15 \mathrm{MW}$ and was achieved by energy flexibly operating an additional $6 \%$ of the commercial building stock. In a Minimal Flexible Operation scenario, the total peak demand reduction was $24 \mathrm{MW}$. This was an additional reduction of only $2 \mathrm{MW}$ and was achieved from energy flexibly operating an additional $2 \%$ of the commercial building stock.

The additional number of buildings which were energy flexibly operated was small. This was because there were few buildings greater than $1499 \mathrm{~m}^{2}$ that contained heat pumps. Of those few buildings, not all were energy flexibly operated as some buildings were assumed not to meet the aggregation criterion.

Table 29 Summary of the results from energy flexibly operating larger commercial buildings with heat pumps.

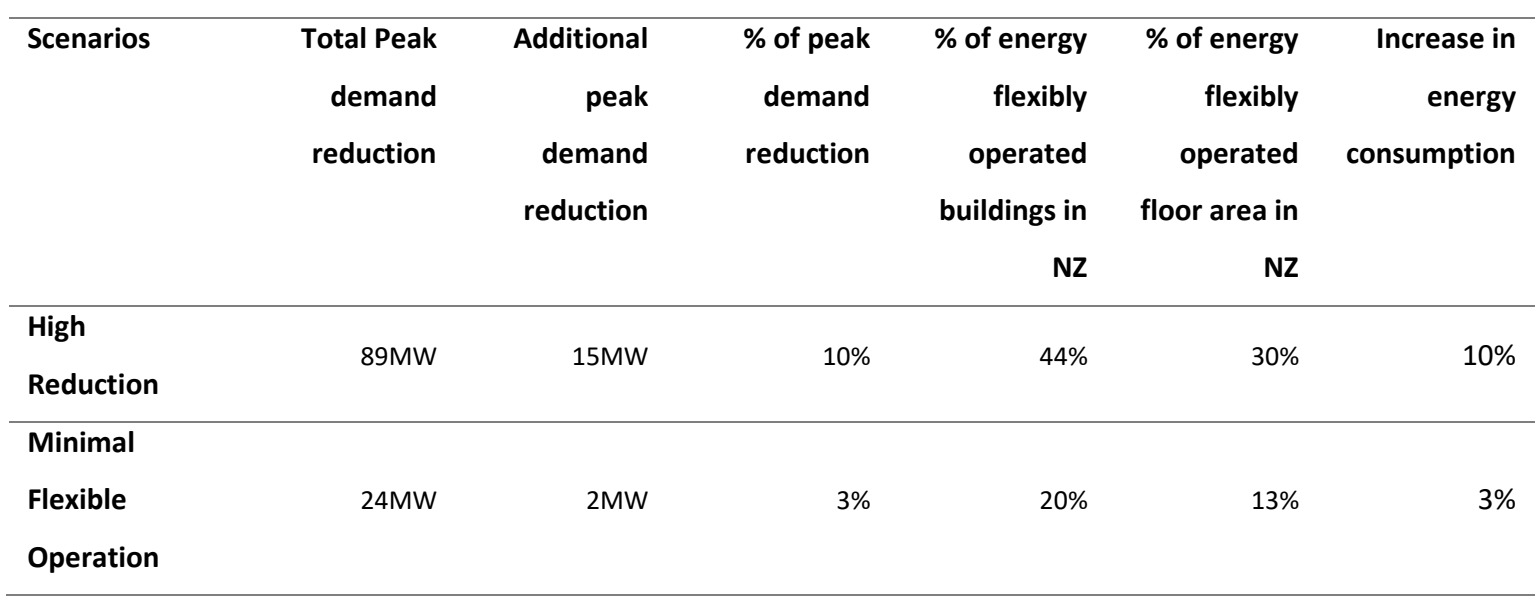




\subsubsection{REDUCTION FROM ENERGY FLEXIBLY OPERATING LARGER COMMERCIAL BUILDINGS REGARDLESS OF HEATING SYSTEM TYPE}

The results were then extrapolated across larger commercial buildings regardless of their heating system type. In this extrapolation, the main assumption made was that the results from small energy flexibly operated buildings were representative of the potential performance in larger energy flexibly operated buildings. Regardless of the heating system, the larger buildings were assumed to have energy flexibility potential. Another assumption was that if the heating systems in larger buildings were inappropriate for energy flexible operation, then other energy end-uses provided the energy flexibility.

Table 30 summarises the reduction in the commercial building stock's peak demand if larger buildings, regardless of their heating system, were energy flexibly operated. In a High Reduction scenario, the total peak demand reduction was $177 \mathrm{MW}$. This was an additional reduction of $88 \mathrm{MW}$ compared to the result of energy flexibly operating buildings with heat pumps only. The reduction was achieved by energy flexibly operating an additional $1 \%$ of the commercial building stock. The additional number of buildings was low as there were few larger buildings across the stock. In total, $45 \%$ of the commercial building stock was energy flexibly operated to achieve the reduction. In a Minimal Flexible Operation scenario, the reduction in the commercial building stock's peak demand was $66 \mathrm{MW}$. This was an additional $42 \mathrm{MW}$ reduction. In total, $28 \%$ of the commercial building stock was energy flexibly operated to achieve the reduction.

Table 30 Summary of the results from energy flexibly operating larger commercial buildings regardless of heating system type.

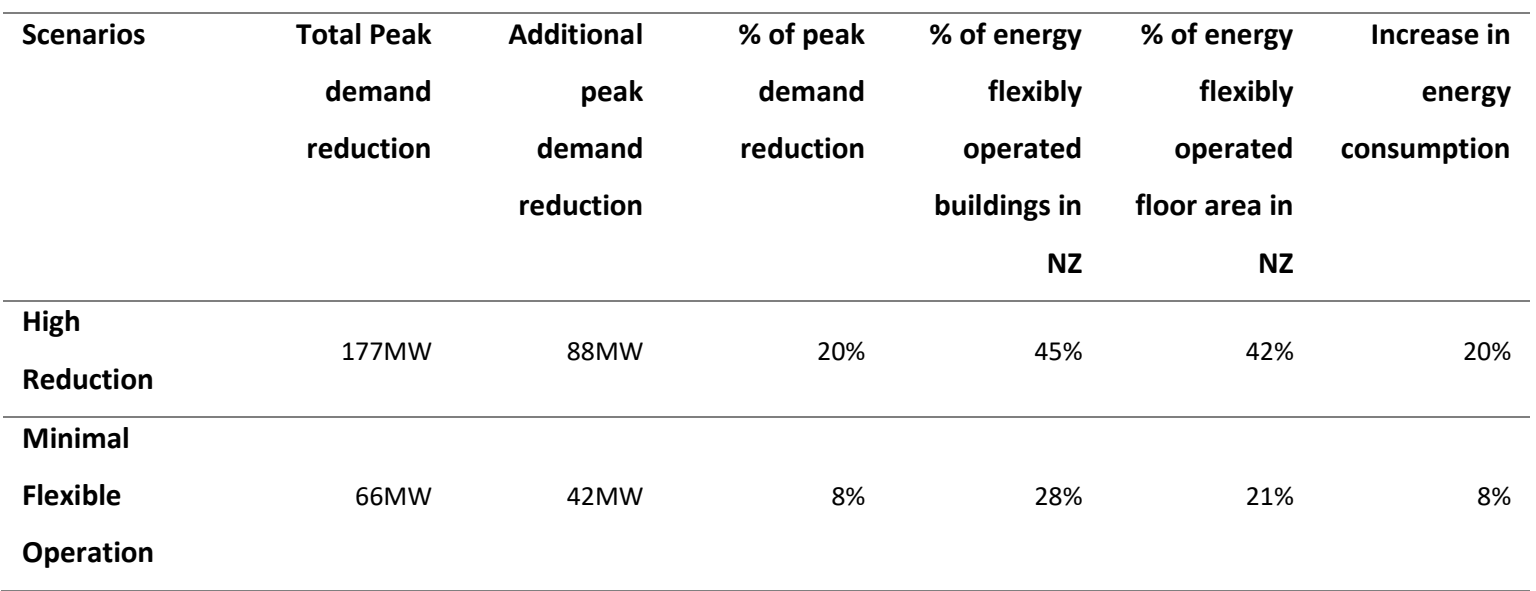




\section{The reduction in the commercial building stock's peak demand in perspective}

In comparison to residential buildings, the demand reduction potential of commercial buildings is small. Dortans et al. (2018) estimated that changes to residential loads such as heat pumps, hot water, and refrigeration could reduce winter morning peak demand by a maximum of 1,600MW, this is nine times greater than the demand reduction from the commercial building stock from a simple energy flexibility strategy. However, the number of households required to achieve the demand reduction is significantly more than the number of commercial buildings that could be energy flexibly operated to achieve the same result. Using data from BRANZ and Statistics New Zealand, Dortans et al. (2018) stated around 500,000 households have heat pumps and 1.3 million households have electric hot water systems which could be used to reduce demand. If the demand reduction from commercial buildings were scaled up to achieve the same demand reduction as from residential buildings, only 100,000 buildings would need to be energy flexibly operated.

While 177MW may be small in comparison to the total demand reduction capable from residential buildings during winter morning peaks, it represents significant load reduction potential as it could double Transpower's 2013 demand response capacity of 134MW (Transpower, 2014).

$177 \mathrm{MW}$ was also greater than the electricity generation from coal during an average winter morning peak period which was about 80MW (EMI, 2017). The relationship between coal and other non-renewable electricity generation and the commercial building stock is presented in Figure 55. The chart shows the commercial building stock flattening during the winter morning peak between 7am and 8am.

Also shown in Figure 55 is a drawback of achieving the reduction. The chart shows an increase in demand earlier in the morning. The increase in demand was due to the type of energy flexibility strategy implemented in the commercial building stock. 


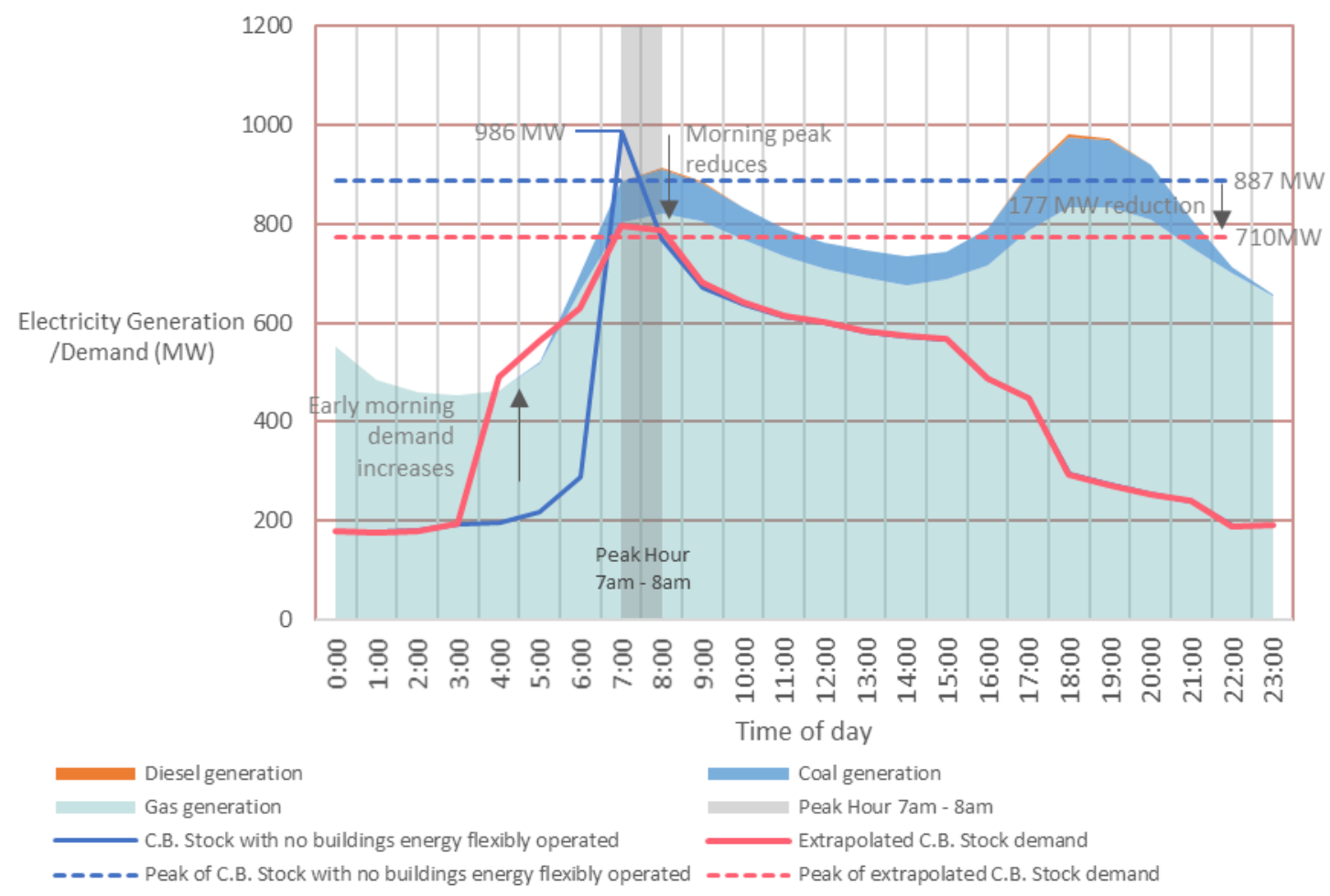

Figure 55 Non-renewable electricity generation and the commercial building stock not energy flexibly operated and partly energy flexibly operated in a High Reduction scenario.

"C.B" stands for 'Commercial building'

\subsubsection{SUMMARY OF FINDINGS}

\section{Energy flexibly operating small and large commercial buildings could reduce the commercial} building stock's peak demand by 177MW.

In a High Reduction scenario, energy flexibly operating small and large commercial buildings could reduce the commercial building stock's peak demand by $177 \mathrm{MW}$. This was a $20 \%$ reduction. It could double Transpower's 2013 demand response capability and the reduction is more than the electricity generation from coal.

\section{$45 \%$ of the commercial building stock must be energy flexibly operated to achieve the peak demand reduction.}

To achieve the $177 \mathrm{MW}$ reduction, $45 \%$ of the commercial building stock must be energy flexibly operated. This is equivalent to 11,700 individual buildings where over $80 \%$ of them are small buildings between $5 \mathrm{~m}^{2}$ to $1400 \mathrm{~m}^{2}$. The number of commercial buildings needed to be energy flexibly operated would be significantly less than the number of households required to achieve the same level of demand reduction. 


\subsection{BEST BUILDINGS TO OPERATE ENERGY FLEXIBLY}

This section highlights which buildings in the sub-sample were the best buildings to operate energy flexibly. The selection was based on two categories:

1. Best buildings to energy flexibly operate on the individual level.

2. Best buildings to energy flexibly operate at the commercial building stock level.

The buildings were evaluated after the Long shift morning only energy flexibility test was implemented.

\section{Best buildings based on the peak hour demand reduction of individual buildings}

Figure 56 plots the base case peak hour demand of each of the 12 types of buildings in the subsample against their normalised power capacity (the reduction in peak hour demand) when energy flexibly operated. Three buildings (S1/O1/CGS, S2/O2/CS and S2/O4/FCAS) at the top right corner of the chart had high peak hour demand and high potential to reduce demand during the peak hour. These buildings represented the best buildings to energy flexibly operate at the individual level. These three buildings are described in Table 31.

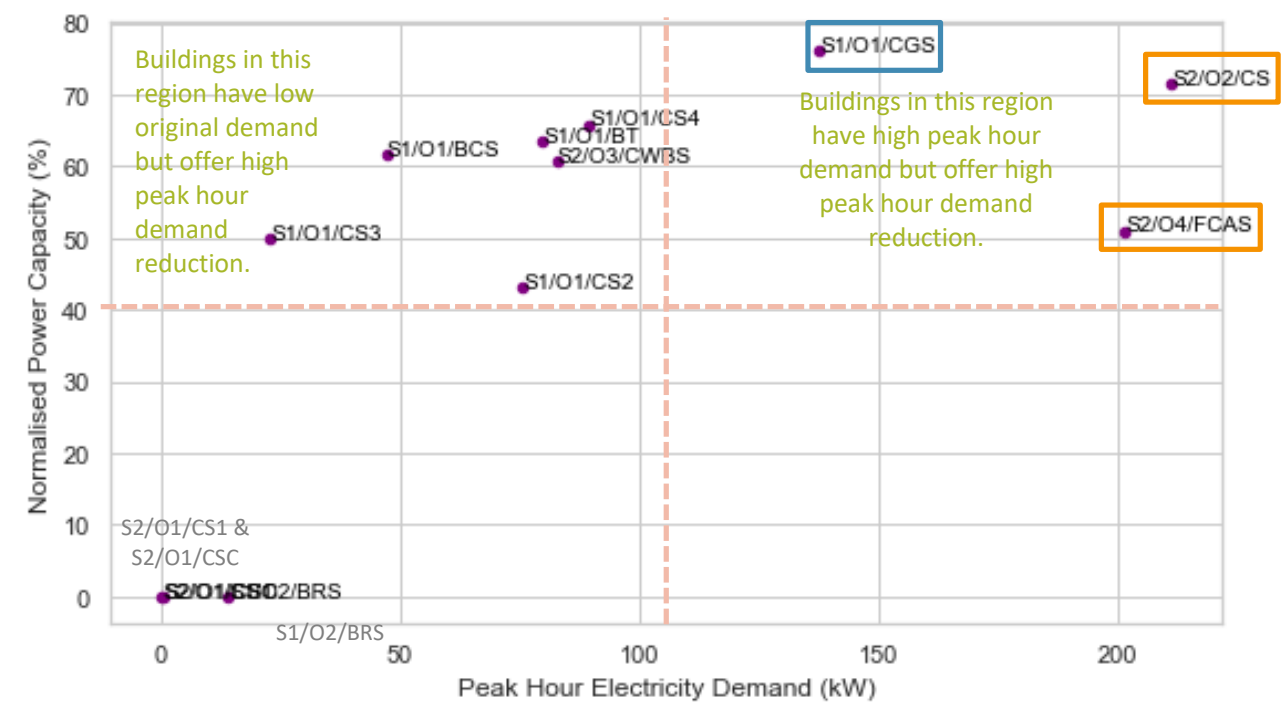

Figure 56 Best buildings to energy flexibly operate at the individual level.

The chart plots each building in the sub-sample by normalised power capacity of energy flexibly operated building and their original peak hour electricity demand. 


\section{Best buildings based on demand reduction across the commercial building stock}

One of the three buildings (S1/O1/CGS) described above also offers a high reduction in demand during the peak hour at the stock level. In Figure 57, this building is at the top right of the chart. This meant the sum of the demand reduction during the peak hour from all buildings of this type across each climate region was high. To achieve the reduction, many buildings must be energy flexibly operated. Energy flexibly operating this building type would have the greatest ability to reduce demand during the peak hour at the stock level. This building was shaded in Table 31.

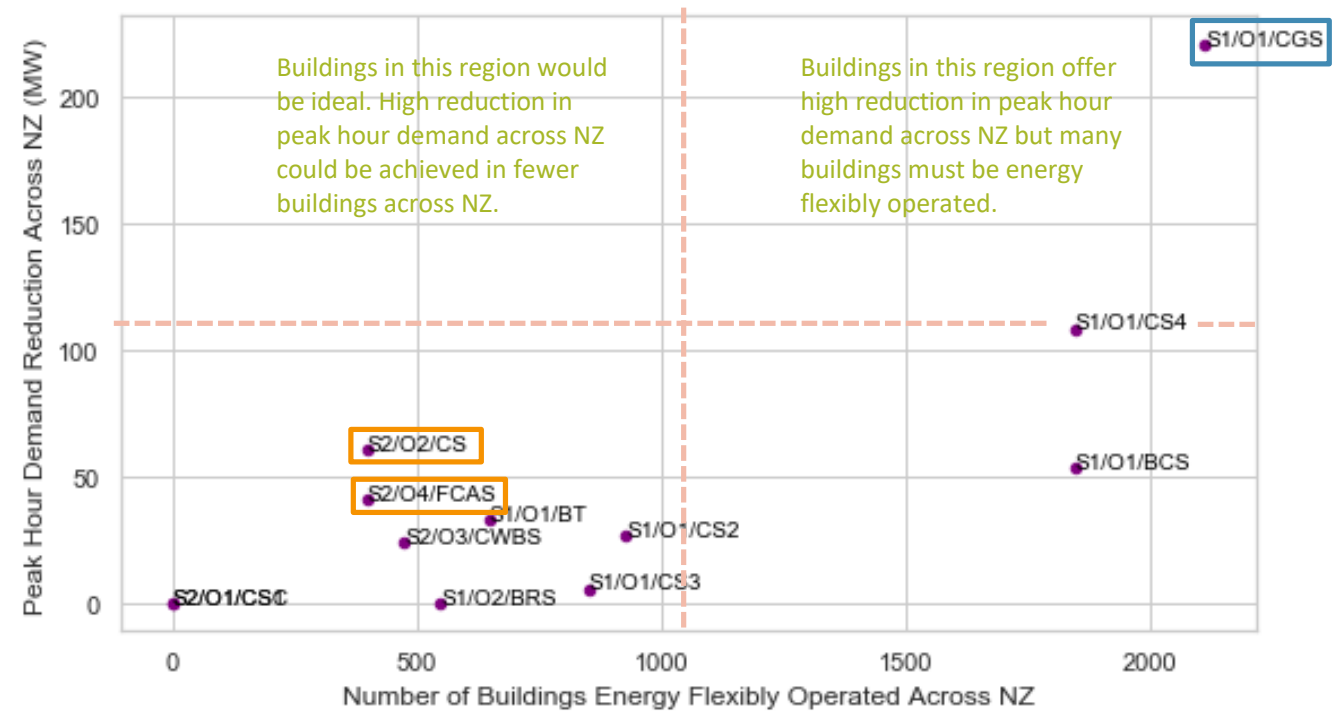

Figure 57 Best buildings to energy flexibly operate at the stock level.

The chart plots each building in the sub-sample by the total peak hour demand reduction and the number which must be energy flexibly operated. 
Table 31 Best buildings to energy flexibly operate at the individual level.

The best building to energy flexibly operate at the stock level is highlighted in blue.

\begin{tabular}{|c|c|c|c|}
\hline & S2/04/FCAS & S2/02/CS & S1/01/CGS \\
\hline Size group & 2 & 2 & 1 \\
\hline Type & Retail & Retail & Retail \\
\hline Levels & 1 & 1 & 1 \\
\hline Occupancy & $21-50$ & $6-10$ & $3-5$ \\
\hline $\begin{array}{l}\text { HVAC } \\
\text { Operation }\end{array}$ & $7 a m-6 p m$ & $7 a m-6 p m$ & $7 a m-6 p m$ \\
\hline Location & Suburb & City & Suburb \\
\hline Construction & $\begin{array}{c}\text { Fibre Cement / Aluminium + } \\
\text { Slab }\end{array}$ & Concrete + Slab & Concrete / Glass + Slab \\
\hline
\end{tabular}

Building S1/O1/CGS is not extraordinarily different to other buildings in the sub-sample. Based on this evaluation, it is likely to be considered the best building to energy flexibly operate due to this building being a common building across New Zealand. This means there are lots of these buildings scattered across the country. 
132 | P a g e 


\section{DISCUSSION}

This thesis aimed to establish whether energy flexible commercial buildings in New Zealand could maintain their current quality of indoor thermal comfort and achieve electricity demand reductions that are sufficiently large enough that grid operators consider them significant contributors for grid management. Simulations and the extrapolation of results were conducted to achieve the aim and answer the primary research question and subsequent sub-questions. This section presents three key findings and their implications. The first key finding was that energy flexibility potential exists in today's commercial buildings by using simple strategies which could make a significant contribution to grid management and can be achieved without seriously jeopardising the current quality of indoor thermal comfort. A second finding was that shifting heating demand offers a greater reduction in peak demand rather than shedding heating demand. A third finding was a refined methodology and energy modelling practice to evaluate energy flexibility which was demonstrated in this study.

\subsection{THERE IS ENERGY FLEXIBILITY POTENTIAL IN TODAY'S COMMERCIAL BUILDINGS IN NEW ZEALAND WHICH WARRANTS FURTHER INVESTIGATION}

\section{Commercial buildings could play a role in supporting the decarbonisation of New Zealand's energy and electricity system.}

This finding was demonstrated by a 177MW reduction in the commercial building stock's peak demand after implementing a single simple energy flexibility strategy. The reduction could play a role in decarbonising the energy and electricity system by reducing winter morning peak demand and intraday variability. The reduction in demand could contribute to New Zealand's demand response capability which could then substitute the use of gas and diesel peakers (Stevenson et al., 2018). It could also contribute significantly to Transpower's demand response capability by doubling it (Transpower, 2013). The results also demonstrated the potential of energy flexible commercial buildings to reduce electricity generation from coal due to the demand reduction being greater than the generation at the same time. The reduction in demand could also free up capacity for the electrification of transport. This finding demonstrates the importance of energy flexible commercial buildings and opens questions around how much more of a role it could play in decarbonising New Zealand's energy and electricity system. 
Commercial buildings could provide energy flexibility without seriously jeopardizing the current quality of thermal comfort.

Conducting simple tests demonstrated that there is energy flexibility potential in New Zealand commercial buildings which could play a role in managing grid constraints and decarbonising New Zealand's energy and electricity system. This could be done without causing any serious loss of indoor thermal comfort which supports the claims made by Jensen et al. (2017). The result means $45 \%$ of the commercial building stock or 11,700 commercial buildings, could be energy flexibly operated without seriously jeopardising thermal comfort. This finding demonstrates that commercial buildings could be used for grid management without causing major disruptions to building users and represents a source of flexibility which warrants further investigation.

\section{Commercial buildings could offer different levels of energy flexibility if different energy} flexibility strategies are implemented.

Even with a limited set of energy flexibility strategies, energy flexibility could contribute significantly to reducing the commercial building stock's peak demand. However, the narrow focus of this thesis on two simple strategies and electric heat pumps leaves many other avenues yet to be explored. It also opens up questions around what combinations of strategies could be tested to improve the energy flexibility potential of commercial buildings in New Zealand.

\section{Commercial buildings could support networks by reducing peak loading.}

This was also demonstrated by the demand reduction of 177MW. It demonstrated that energy flexible commercial buildings could support networks by reducing network peaks as the reduction in demand coincides with the morning peak period. This indicated that there is energy flexibility potential in commercial buildings which could respond to the needs of the surrounding grid. This finding was based only on one simple energy flexibility strategy and focused only on the winter morning peak demand, this means further investigation of the different ways commercial buildings could respond to grid needs should be conducted. 


\section{Commercial buildings offer a manageable number of energy flexible opportunities.}

The analysis showed that $45 \%$ of the commercial building stock must be operated flexibly to achieve the maximum demand reduction of $177 \mathrm{MW}$. This is the equivalent to around 11,700 commercial buildings. A high proportion of those buildings were no larger than $1499 \mathrm{~m}^{2} .11,700$ buildings are a small fraction of the domestic buildings that need to be operated to achieve the same results. Even though the number of commercial buildings is less numerous than domestic buildings, 11,700 buildings still represent a substantial number of opportunities for energy flexible building operation. This means if buildings or building owners or tenants cannot or do not wish to participate in offering energy flexibility, there will still plenty of other participants to fall back on. This finding also adds knowledge to Transpower's understanding of demand response capability from small to medium commercial consumers. This could help Transpower to determine the cost bands of demand response resources and represents an opportunity for further investigation (Transpower, 2014).

\section{Commercial buildings could implement energy flexibility in the day-of or day-ahead market.}

Energy flexibility could be implemented in the day-ahead or day-of demand response market based on the type of load and controls available in commercial buildings. Energy flexibility could also be implemented today by using technologies that are currently available in commercial buildings and by using simple energy flexibility strategies. The speed of response was demonstrated by the ability of energy flexible commercial buildings to respond to grid needs within a day and resulted in a reduction in intraday variability. This supports statements made by Aduda et al. (2018) and Yin et al. (2016) that energy flexibility could respond to grid needs within shorter timescales. It highlights the ability of energy flexible commercial buildings to support grid needs in the short-term. The result was based on only one type of building load, which presents an opportunity for different building loads to be investigated for their energy flexibility potential. 


\subsection{SHIFTING STRATEGIES OFFER GREATER DEMAND REDUCTION POTENTIAL THAN SHEDDING STRATEGIES}

\section{Commercial building owners or tenants could reduce electricity costs.}

Commercial building owners or tenants who pay for the electricity costs could benefit from paying less by shifting demand from peak to off-peak periods where lower tariffs are charged. Shedding demand could also benefit commercial building owners or tenants by demanding less electricity during peak periods and therefore paying less. During the peak period, specifically the peak hour defined in this research as 7am to 8am on a winter morning, shifting demand could reduce costs much more than shedding demand and therefore provide greater value to the building owner or tenant. However, the implication of shifting demand could increase overall electricity consumption and could end up increasing costs. This finding highlights that there could be value for commercial building owners and tenants by operating energy flexible buildings to better respond to price signals.

\subsection{A REFINED METHODOLOGY AND ENERGY MODELLING PRACTICE TO INVESTIGATE ENERGY FLEXIBILITY}

The methodology presented in this thesis could be used by other researchers.

The methodology in this thesis could be used by other researchers to establish the scale of the energy flexibility potential of different building types. This means researchers could use this methodology to gain an understanding of whether energy flexibility of different building types is worth further investigation in the first instance without the need to recreate a new methodology.

\section{Energy flexibility of buildings could be investigated where calibrated Building Energy Models have already been made.}

Testing of Building Energy Models (BEMs) was conducted to check if they could be used to investigate energy flexibility. It demonstrated that BEMs made for annual energy analysis could also be used to evaluate energy flexibility. The tests showed that in order to use BEMs to generate useful results, the timesteps and reporting frequency must be more granular. This was important to accurately represent the occurrence of short-lived peaks. When a calibrated BEM is made, simple changes to simulation settings could enable it to be used for energy flexibility analysis. For 
example, BEMs could be used for energy flexibility analysis during the early stage where BEMs are made to predict building performance (Griffith et al., 2008).

\subsection{LIMITATIONS}

\section{Limitation in understanding the impact of energy flexibility on inter-seasonal variability.}

In this thesis, the energy flexibility offered by commercial buildings focused on reducing intraday variability while inter-seasonal variability was not investigated. The New Zealand energy and electricity system faces significant security of supply issues in dry-years when hydro lakes are low (Transpower, 2018, 2018a; New Zealand Productivity Commission, 2018).

\section{Limitation in understanding energy flexibility in reality.}

The methodology used simulations to evaluate energy flexibility and testing the reality of operating energy flexible commercial was outside of the scope of this thesis. Bode et al. (2017) note that energy flexibility potential is less than expected in a real case scenario than in theory. Extending this work to test the real potential using the lessons from Bode et al. (2017) should be conducted. This could be followed up with real-world field tests to understand the differences and the issues that arise in the process of implementing energy flexibility.

\section{Limitation in BEM calibration for investigating energy flexibility}

Some caution is warranted when using BEMs to investigate the energy flexibility potential of buildings. This is because Christanatoni et al. (2015a) suggested that BEMs used to investigate demand response and therefore energy flexibility should be calibrated at 15-minute intervals. Due to limitations in the availability of granular real data for re-calibration, the BEMs were only compared against real data of different types of buildings to check if they could be trusted and were representative of real building operation. The BEMs used in this research were re-simulated at 5-minutes intervals but originally calibrated at monthly and annual intervals. The outputted data was deemed trustworthy and representative in this instance, but this may not be the case in other studies. Further testing of the trustworthiness and representativeness of BEMs for investigating energy flexibility should be conducted. 


\subsection{FUTURE RESEARCH}

\section{Test more energy flexibility strategies and different scenarios.}

Due to the scope of this research, only two types of energy flexibility strategies were tested in winter and both strategies were targeted to respond to a specific issue. Implementing different energy flexibility strategies in different scenarios should be tested to understand how much more energy flexibility potential exists. A limitation of the research was the lack of knowledge on the effect energy flexibility might have on inter-seasonal variability. This could be improved by testing more strategies for different scenarios. Different scenarios could include testing energy flexibility in dry-years, during summer, and testing energy flexibility in summer and winter with on-site solar energy generation. The issue of dry-years, shortfalls in generation, and growth in solar suggests that there is a need for this future research (Transpower, 2018, 2019; New Zealand Productivity Commission).

The same energy flexibility strategies tested in this research could be tested in small and large buildings of different types that were not within the scope of this research. Different building types could include schools, hotels, and hospitals. They could also be tested using different energy flexibility strategies. Testing of flexibility strategies could be conducted by simulation using the same methodology and modelling practice developed in this research.

\section{Conduct real-world tests}

A limited number of real-world tests could be conducted to confirm and quantify the difference between the simulated performance and real performance of energy flexibly operated buildings. Real-world tests could also be used to understand the complexities and constraints of operating energy flexible buildings in reality. The simple energy flexibility strategies tested in this research could be tested in today's buildings by manually adjusting setpoints and on/off times of heat pumps. In these real tests, a survey of end-user comfort and ease of implementation could also be conducted to gain an understanding of user acceptance. 


\section{CONCLUSION}

This thesis examined the energy flexibility potential of commercial buildings as a demand-side solution to support the electricity grid and respond to the anticipated changes in New Zealand's energy and electricity system. Key themes characterising the energy and electricity future includes shifting the energy mix away from non-renewable generation, increasing electricity demand, adoption of distributed energy sources, and growth of different grid management options. Research around using buildings for grid management in New Zealand has focused on the residential sector, but this thesis provides evidence for further study on the use of energy flexible commercial buildings. Energy flexible commercial buildings could respond to grid needs and support the transition to a renewable energy and electricity future. The remainder of this thesis summarises the key contributions of this research.

There is energy flexibility potential in today's commercial buildings that should be explored.

The achievable demand reduction from operating energy flexible commercial buildings across New Zealand is sufficiently large that it could be considered a significant contribution to grid management. This could be achieved in today's existing buildings without seriously jeopardizing the current quality of indoor thermal comfort. Energy flexible commercial buildings could provide significant value to grid operators and managers to manage network constraints and support the decarbonisation of New Zealand's energy and electricity system. There could also be value for building owners and tenants by potentially lowering costs. The energy flexibility potential was demonstrated in this thesis from testing only two simple energy flexibility strategies. From the two simple strategies the results showed that there is value in energy flexible commercial buildings and that this strategy should be further explored to uncover the full additional value it could provide to the energy and electricity system.

\section{Greater reductions in electricity demand are achieved through shifting strategies.}

Shifting strategies were conducted by preheating buildings while shedding strategies were conducted by relaxing temperature setpoints. The strategies could provide value to commercial building owners and tenants by lowering costs, and value to grid managers by managing network constraints. However, shifting strategies resulted in greater reductions in demand which could flatten daily demand and reduce non-renewable generation much more than shedding strategies. 
Shifting strategies were conducted by preheating buildings while shedding strategies were conducted by relaxing temperature setpoints. The strategies could provide value to commercial building owners and tenants by lowering costs, and value to grid managers by managing network constraints. However, shifting strategies resulted in greater reductions in demand which could flatten daily demand and reduce non-renewable electricity generation much more than shedding strategies.

\section{A refined methodology and energy modelling practice to evaluate flexibility using building performance simulation.}

In addition to responding to the research aim and answering the research question, a refined methodology and energy modelling practice to investigate energy flexibility was presented. The methodology and modelling practice were refined for the aim of establishing the scale of the energy flexibility potential to understand whether energy flexibility is worth further investigation. This could be adopted and adapted by other researchers to avoid the need to recreate the same methodology. 


\section{REFERENCES}

Aduda, K., Labeodan, T., Zeiler, W., Boxem, G., \& Zhao, Y. (2016). Demand side flexibility: Potentials and building performance implications. Sustainable Cities and Society, 22, 146163.

Aduda, K., Labeodan, T., Zeiler, W., \& Boxem, G. (2017). Demand side flexibility coordination in office buildings: a framework and case study application. Sustainable Cities and Society, 29, 139-158.

Aduda, K., Labeodan, T., \& Zeiler, W. (2018). Towards critical performance considerations for using office buildings as a power flexibility resource-a survey. Energy and Buildings, 159, 164-178. https://doi:10.1016/j.enbuild.2017.10.096

Alzaanin, H. (2014). The Potential of Utilising Residential Demand Response to Balance the Fluctuation of Wind Power in New Zealand (Masters Thesis). Victoria University of Wellington.

Anderson, B., Eyers, D., Ford, R., Giraldo Ocampo, D., Peniamina, R., Stephenson, J., Suomalainen, K., Wilcocks, L., \& Jack, M. (2018). NZ GREEN Grid Household Electricity Demand Study: 1 minute electricity power (version 1.0), Centre for Sustainability (http://www.otago.ac.nz/centre-sustainability/), University of Otago: Dunedin.

Anonymous. (2018). [Real heat pump data from office building in New Plymouth]. Unpublished raw data.

Ayón, X., Gruber, J., Hayes, B., Usaola, J., \& Prodanović, M. (2017). An optimal day-ahead load scheduling approach based on the flexibility of aggregate demands. Applied Energy, 198, 1-11. https://doi.org/10.1016/j.apenergy.2017.04.038

Beil, I., Hiskens, I., \& Backhaus, S. (2015). Round-trip efficiency of fast demand response in a large commercial air conditioner. Energy and Buildings, 97, 47-55. https://doi.org/10.1016/j.enbuild.2015.03.028

Billanes, J., Ma, Z., \& Jørgensen, B. (2017). Consumer Central Energy Flexibility in Office Buildings. Journal of Energy and Power Engineering, 2017(11), 621-630.

Boait, P., \& Stafford, A. (2011). Electrical load characteristics of domestic heat pumps and scope for demand side management. Paper presented at the 21st International Conference on Electricity Distribution, Frankfurt. 
Bode, G., Behrendt, S., Fütterer, J., \& Müller, D. (2017). Identification and utilization of flexibility in non-residential buildings. Energy Procedia, 122, 997-1002. https://doi.org/10.1016/j.egypro.2017.07.461

Boland, A., Cherry, M., \& Dickson, R. (2014). Doing a systematic review: a student's guide. London: SAGE.

Cenelec. (2014). SG-CG / M490 / L Flexibility Management Overview of the main concepts of flexibility management.

Christantoni, D., Flynn, D., \& Finn, D. P. (2015). Modelling of a Multi-purpose Commercial Building for Demand Response Analysis. Energy Procedia, 78, 2166-2171. https://doi.org/10.1016/j.egypro.2015.11.308

Christantoni, D., Oxizidis, S., Flynn, D., \& Finn, D. (2015a). Calibration of a commercial building energy simulation model for demand response analysis. Paper presented the 14th International Conference of the International Building Performance Simulation Association: Building Simulation, Hyderabad, India, 07-09 December 2015.

Christantoni, D., Oxizidis, S., Flynn, D., \& Finn, D. (2016). Implementation of demand response strategies in a multi-purpose commercial building using a whole-building simulation model approach. Energy and Buildings, 131, 76-86. https://doi.org/10.1016/j.enbuild.2016.09.017

Coakley, D., Raftery, P., \& Keane, M. (2014). A review of methods to match building energy simulation models to measured data. Renewable and Sustainable Energy Reviews, 37(C), 123-141. doi:10.1016/j.rser.2014.05.007

Cochran, J., Miller, M., Zinaman, O., Milligan, M., Arent, D., Palmintier, B., . . Soonee, S. (2014). Flexibility in 21st century power systems. Retrieved from https://www.nrel.gov/docs/fy14osti/61721.pdf

Cory, S. (2016). An exploration of the feasibility of converting the New Zealand commercial building stock to be Net Zero Energy (Ph.D. Thesis). Victoria University of Wellington.

Crawley, D. B., Hand, J. W., Kummert, M., \& Griffith, B. T. (2008). Contrasting the capabilities of building energy performance simulation programs. Building and Environment, 43(4), 661 673. doi:10.1016/j.buildenv.2006.10.027

Cui, B., Wang, S., Yan, C., \& Xue, X. (2015). Evaluation of a fast power demand response strategy using active and passive building cold storages for smart grid applications. Energy 
Conversion and Management, 102, 227-238.

https://doi.org/10.1016/j.enconman.2014.12.025

D’hulst, R., Labeeuw, W., Beusen, B., Claessens, S., Deconinck, G., \& Vanthournout, K. (2015). Demand response flexibility and flexibility potential of residential smart appliances: Experiences from large pilot test in Belgium. Applied Energy, 155, 79-90. https://doi.org/10.1016/j.apenergy.2015.05.101

De Coninck, R. (2015). Grey-Box Based Optimal Control for Thermal Systems in Buildings Unlocking Energy Efficiency and Flexibility. (PhD Thesis). Arenberg Doctoral School.

De Coninck, R., \& Helsen, L. (2013). Bottom-up quantification of the flexibility potential of buildings. Paper presented at the Building Simulation 2013, Chambéry.

De Coninck, R., \& Helsen, L. (2016). Quantification of flexibility in buildings by cost curves Methodology and application. Applied Energy, 162, 653. doi:10.1016/j.apenergy.2015.10.114

Deru, M., Torcellini, P., Judkoff, R., Crawley, D., \& Ryan, J. (2007). Assessment of the Technical Potential for Achieving Net Zero-Energy Buildings in the Commercial Sector.

Dortans, C., Anderson, B., Jack, M., \& Stephenson, J. (2018). Estimating the Technical Potential for Residential Demand Response in New Zealand. Retrieved from https://ourarchive.otago.ac.nz/bitstream/handle/10523/8579/Dortans_2018_TechnicalP otentialDemandResponseHouseholdsNZ.pdf?sequence=1\&isAllowed=y

EA. (2018). Electricity in New Zealand. Retrieved from https://www.ea.govt.nz/dmsdocument/20410-electricity-in-new-zealand

EA. (2018a). Guiding regulatory principles for demand response-2018 update. Retrieved from https://www.ea.govt.nz/dmsdocument/23654-guidelines-guiding-regulatory-principlesfor-demand-response-2018-update

EMI. (2016). [Generation output by plant]. Retrieved from https://www.emi.ea.govt.nz/Wholesale/Datasets/Generation/Generation_MD

ENA. (2016). Pricing guidelines for electricity distributors. Retrieved from https://www.ena.org.nz/dmsdocument/39

Entso-e (2004). P1 - Policy 1: Load-Frequency Control and Performance [C]. Retrieved from https://www.entsoe.eu/fileadmin/user_upload/_library/publications/entsoe/Operation_ Handbook/Policy_1_final.pdf 
Finck, C., Li, R., Kramer, R., \& Zeiler, W. (2018). Quantifying demand flexibility of power-to-heat and thermal energy storage in the control of building heating systems. Applied Energy, 209, 409-425. https://doi.org/10.1016/j.apenergy.2017.11.036

Fumo, N., Mago, P., \& Luck, R. (2010). Methodology to estimate building energy consumption using EnergyPlus Benchmark Models. Energy and Buildings, 42(12), 2331-2337. https://doi.org/10.1016/j.enbuild.2010.07.027

Gates, A. (2013). Determining the modelling input parameters for heating, ventilation, air conditioning systems in New Zealand commercial (Master's Thesis). Victoria University of Wellington.

Griffith, B., Long, N., Torcellini, P., \& Judkoff, R. (2008). Methodology for Modeling Building Energy Performance across the Commercial Sector Retrieved from: https://www.nrel.gov/docs/fy08osti/41956.pdf

Groat, L., \& Wang, D. (2013). Architectural Research Methods. Retrieved from https://ebookcentral.proquest.com

Henninger, R., Witte, M., \& Crawley, D. (2003). Experience testing EnergyPlus with the IEA HVAC BESTEST e100-e200 series. Paper presented at the $8^{\text {th }}$ IBPSA Conference, 467-74. Eindhoven, Netherlands: IBPSA.

Henninger, R., Witte, M., \& Crawley, D. (2004). Analytical and Comparative Testing of EnergyPlus Using IEA HVAC BESTEST E100-E200 Test Suite. Energy and Buildings 36(8), 855-63. doi:10.1016/j.enbuild.2004.01.025.

Hurtado Munoz, L. (2017). Uncovering demand flexibility in buildings: a smart grid inter-operation framework for the optimization of energy and comfort. Technische Universiteit Eindhoven.

Hurtado Munor, L., Rhodes, J., Nguyen, P., Kamphuis, I., \& Webber, M. (2017). Quantifying demand flexibility based on structural thermal storage and comfort management of nonresidential buildings: A comparison between hot and cold climate zones. Applied Energy, 195, 1047-1054. doi:https://doi.org/10.1016/j.apenergy.2017.03.004

IEA. (2019). Perspectives for the Clean Energy Transition - The Critical Role of Buildings. Retrieved from https://webstore.iea.org/perspectives-for-the-clean-energy-transition

Isaacs, N., Saville-Smith, K., Donn, M., Camilleri, M., Pollard, A., Babylon, M., . . Cory, S. (2014). Building Energy End-Use Study (BEES) Part 1: Final Report. Retrieved from 
http://www.branz.co.nz/cms_show_download.php?id=182d3ae296d4d92be905477582a e2453c0671d58

Jack, M., Ford, R., \& Dew, J. (2016). Household Demand and Demand Management Opportunities. Presented at the Gren Grid Conference 2016, Wellington.

Jack, M., Dew, J., Suomalainen, K., \& Williams, N. (2017). Residential demand management with thermo-electric appliances. Presented at the Gren Grid Conference 2017, Wellington.

Jack, M., \& Suomalainen, K. (2018). Potential future changes to residential electricity load profiles - findings from the GridSpy dataset. Presented at the Green Grid Conference 2018, Christchurch.

Jack, M., Suomalainen, K., Dew, J., \& Eyers, D. (2018a). A minimal simulation of the electricity demand of a domestic hot water cylinder for smart control. Applied Energy, 211, 104-112. https://doi.org/10.1016/j.apenergy.2017.11.044

Jensen, S. (2016). Energy Flexible Buildings. Retrieved from http://www.annex67.org/media/1058/ebc_annex_67_factsheet.pdf

Jensen, S. (2017a). Energy Flexible Buildings. Retrieved from http://www.annex67.org/media/1057/ebc_annex_67_annex_text.pdf

Jensen, S., Marszal-Pomianowska, A., Lollini, R., Pasut, W., Knotzer, A., Engelmann, P., Stafford, A., \& Reynders, G. (2017). IEA EBC Annex 67 Energy Flexible Buildings. Energy and Buildings, $155,25-34$.

Kampelis, N., Ferrante, A., Kolokotsa, D., Gobakis, K., Standardi, L., \& Cristalli, C. (2017). Thermal comfort evaluation in HVAC Demand Response control. Energy Procedia, 134, 675-682. doi:https://doi.org/10.1016/j.egypro.2017.09.587

Lannoye, E., Flynn, D., \& O'Malley, M. (2015). Transmission, Variable Generation, and Power System Flexibility. IEEE Transactions on Power Systems, 30(1), 57-66. doi:10.1109/TPWRS.2014.2321793

Lapthorn, A. (2012). Smart Grid in a New Zealand Context. Retrieved from https://ir.canterbury.ac.nz/bitstream/handle/10092/10716/12644631_SmartGrids\%20in \%20a\%20New\%20Zealand\%20Context.pdf?sequence=1\&isAllowed=y

Lopes, R., Chambel, A., Neves, J., Aelenei, D., \& Martins, J. (2016). A Literature Review of Methodologies Used to Assess the Energy Flexibility of Buildings. Energy Procedia, 91, 1053-1058. ttps://doi.org/10.1016/j.egypro.2016.06.274 
Lund, P. D., Lindgren, J., Mikkola, J., \& Salpakari, J. (2015). Review of energy system flexibility measures to enable high levels of variable renewable electricity. Renewable and Sustainable Energy Reviews, 45, 785-807.

MBIE. (2016). Electricity demand and generation scenarios. Retrieved from https://www.mbie.govt.nz/dmsdocument/2809-electricity-demand-and-generationscenarios-2016-pdf

MBIE. (2018). Data tables for electricity [XLSX, 425 KB]. Retrieved from https://www.mbie.govt.nz/assets/Data-Files/Energy/energy-quarterlystatistics/d7ea66674f/electricity-statistics.xlsx

MBIE. (2018a). Energy in New Zealand. Retrieved from https://www.mbie.govt.nz/assets/d7c93162b8/energy-in-nz-18.pdf

MFE. (2018). The transition to a low-emissions and climate-resilient Aotearoa New Zealand. Retrieved from http://www.mfe.govt.nz/climate-change/climate-change-andgovernment/climate-change-programme

New Zealand Productivity Commission. (2018). Low-emissions economy Final report. Retrieved from Wellington www.productivity.govt.nz/low-emissions

Niemelä, T., Vuolle, M., Kosonen, R., Jokisalo, J., Salmi, W., \& Nisula, M. (2016). Dynamic simulation methods of heat pump systems as a part of dynamic energy simulation of buildings. Retrieved from https://pdfs.semanticscholar.org/accc/6c03084ffefa689b0c55c35269d809fb9261.pdf?_ga $=2.137991664 .1797228735 .1555749533-1470001424.1555749533$

Nuytten, T., Claessens, B, Paredis, K., Van Bael, J., \& Six, D. (2013). Flexibility of a combined heat and power system with thermal energy storage for district heating. Applied Energy, 104, 583-591.

Orion. (2019) Orion Pricing Guide 2019/2020. Retrieved from http://www.oriongroup.co.nz/assets/Company/Corporate-publications/Orion-PricingGuide2019-FINAL.pdf

Papalexopoulos, A., Hansen, C., Frowd, R., Tuohy, A., \& Lannoye, E. (2016). Impact of the Transmission Grid on the Operational System Flexibility. Paper presented in the 2016 Power Systems Computation Conference (PSCC), 1-10.

Pollard, A., \& Berg, B. (2018). Heat Pump Performance. Retrieved from 
https://www.branz.co.nz/cms_show_download.php?id=eb79815390797f30c880990fc717 b574c349791e

Powerco. (2017). Pricing Guide 2017. Retrieved from https://www.powerco.co.nz/media/1605/pricing-guide-2017.pdf

Reynders, G., Amaral Lopes, R., Marszal-Pomianowska, A., Aelenei, D., Martins, J., \& Saelens, D. (2018). Energy flexible buildings: An evaluation of definitions and quantification methodologies applied to thermal storage. Energy \& Buildings, 166, 372-390. doi:10.1016/j.enbuild.2018.02.040

Richardson, M. (2019, May 22). Personal Email.

Six D., Desmedt J., Vanhoudt D., \& Van Bael J. (2011). Exploring the flexibility potential of residential heat pumps combined with thermal energy storage for smart grids. Present in the 21st International conference on electricity distribution; 2011. p. 0442-0442.

Stafford, A. (2017). An Exploration of Load-shifting Potential in real in-situ Heat-pump/gas-boiler Hybrid Systems. 38(4). doi:10.1177/0143624416688727

Stephenson, J., Ford, R., Nair, N.-K., Watson, N., Wood, A., \& Miller, A. (2018). Smart grid research in New Zealand - A review from the GREEN Grid research programme. Renewable and Sustainable Energy Reviews, 82, 1636-1645. doi:https://doi.org/10.1016/j.rser.2017.07.010

Stevenson, T., Batstone, S., Reeve, D., Poynton, M., \& Comendant, C. (2018). Transitioning to zero net emissions by 2050: moving to a very low-emissions electricity system in New Zealand. Retrieved from https://www.productivity.govt.nz/sites/default/files/Transitioning\%20to\%20zero\%20net \%20emissions\%20by\%202050.pdf

Stinner, S., Huchtemann, K., \& Müller, D. (2016). Quantifying the operational flexibility of building energy systems with thermal energy storages. Applied Energy, 181, 140-154. https://doi.org/10.1016/j.apenergy.2016.08.055

Strbac, G., Pudjianto, D., Djapic, P., Aunedi, M., Stanojevic, V., Castro, M., . . McDonald, J. (2012). Smart New Zealand Energy Futures: A Feasibility Study. Retrieved from https://www.meridianenergy.co.nz/assets/Investors/Reports-andpresentations/Industry-reports/31f8014edf/Smart-Enegy-Futures-Summary-ReportJan2012-2759757-1.PDF 
Transpower. (2014). 2013 Demand Response Programme Report. Retrieved from:

https://www.transpower.co.nz/sites/default/files/plain-

page/attachments/Demand\%20Response\%20Programme\%20Report\%20Summary_0.pdf

Transpower. (2016). Transmission Tomorrow. Retrieved from

https://www.transpower.co.nz/sites/default/files/plain-

page/attachments/Transpower\%20-\%20Transmission\%20Tomorrow26052016_0.pdf

Transpower (2016a). Electricity Peak Demand Forecasts. Retrieved from

https://www.transpower.co.nz/sites/default/files/plain-

page/attachments/Transpower\%20National-

Regional\%20Peak\%20Demand\%20Forecasts\%20Jul-

2016\%20Information\%20Document_0.pdf

Transpower (2018). Te Mauri Hiko. Retrieved from

https://www.transpower.co.nz/sites/default/files/publications/resources/TP\%20Energy\% 20Futures\%20-\%20Te\%20Mauri\%20Hiko\%2011\%20June\%2718.pdf

Transpower (2018a). Transmission Tomorrow - Our Strategy. Retrieved from

https://www.transpower.co.nz/sites/default/files/plain-

page/attachments/TP\%20Transmission\%20Tomorrow\%20-\%200ur\%20Strategy\%20-

\%20Published_0.pdf

Transpower (2019). The Sun Rises on a Solar Energy Future. Retrieved from

https://www.transpower.co.nz/sites/default/files/plain-

page/attachments/Te\%20Mauri\%20Hiko\%20\%E2\%80\%93\%20the\%20sun\%20rises\%20-

\%20published.pdf

Ulbig, A. \& Andersson, G. (2012). On Operational Flexibility in Power Systems. Presented in the IEEE Power and Energy Society General Meeting, IEEE, San Diego.

Ulbig, A., \& Andersson, G. (2015). Analyzing operational flexibility of electric power systems. International Journal of Electrical Power \& Energy Systems, 72, 155-164. doi:https://doi.org/10.1016/j.ijepes.2015.02.028

USDOE. (2006). Benefits of demand response in electricity markets and recommendations for achieving them. Retrieved from https://eetd.Ibl.gov/sites/all/files/publications/reportIbnl-1252d.pdf

USDOE. (2019a). Engineering Reference. Retrieved from 
https://energyplus.net/sites/all/modules/custom/nrel_custom/pdfs/pdfs_v9.1.0/Enginee ringReference.pdf

USDOE. (2019b). Input Output Reference. Retrieved from

https://energyplus.net/sites/all/modules/custom/nrel_custom/pdfs/pdfs_v9.1.0/InputOu tputReference.pdf

Vector. (2018). Vector Price Schedule. Retrieved from https://blobstatic.vector.co.nz/blob/vector/media/vector-regulatory-disclosures/180201_priceschedule-1_apr-2018_1.pdf

Voss, K, Sartori, I., Napolitano, A., Geier, S., Gonzalves, H., Hall, M., . . Torcellini, P. (2010). Load Matching and Grid Interaction of Net Zero Energy Buildings. Paper presented in the EuroSun 2010. Graz, Austria: IEA-SHC.

Weiß, T., Fulterer, A. M. \& Knotzer, A. (2017). Energy flexibility of domestic thermal loads - a building typology approach of the residential building stock in Austria. Advances in Building Energy Research, 1-16.

Wellington Electricity. (2018). Wellington Electricity Network Pricing Schedule. Retrieved from https://www.welectricity.co.nz/dmsdocument/170

Witte, M., Henninger, R., Glazer, J., \& Crawley, D. (2001). Testing and validation of a new building energy simulation program. Paper presented in the $7^{\text {th }}$ IBPSA Conference, 353-60. Rio de Janeiro, Brazil: IBPSA.

Yin, R., Kara, E., Li, Y., DeForest, N., Wang, K., Yong, T., \& Stadler, M. (2016). Quantifying flexibility of commercial and residential loads for demand response using setpoint changes. Applied Energy, 177, 149-164. https://doi.org/10.1016/j.apenergy.2016.05.090 
$150 \mid \mathrm{P}$ a g e 


\section{APPENDICES}

\subsection{COMMERCIAL BUILDING STOCK - THE POPULATION}

Commercial building stock breakdown by size, type, floor area, and number of buildings. Adapted from Cory (2016).

\begin{tabular}{|c|c|c|c|c|c|c|c|}
\hline $\begin{array}{l}\text { Building } \\
\text { type }\end{array}$ & $\begin{array}{l}\text { Floor area size } \\
\text { ranges }\end{array}$ & $\begin{array}{c}5 \text { to } \\
649 \mathrm{~m}^{2}\end{array}$ & $\begin{array}{c}650 \text { to } \\
1,499 \mathrm{~m}^{2}\end{array}$ & $\begin{array}{l}1,500 \text { to } \\
3,499 \mathrm{~m}^{2}\end{array}$ & $\begin{array}{l}3,500 \text { to } \\
8,999 \mathrm{~m}^{2}\end{array}$ & $\begin{array}{c}\text { over } \\
9000 \mathrm{~m}^{2}\end{array}$ & Total \\
\hline \multirow{5}{*}{ 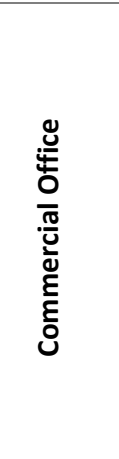 } & $\begin{array}{l}\text { Approximate } \\
\text { number of buildings }\end{array}$ & 3,709 & 997 & 547 & 314 & 131 & 5698 \\
\hline & $\begin{array}{l}\text { Percentage of } \\
\text { buildings }\end{array}$ & $65 \%$ & $17 \%$ & $10 \%$ & $6 \%$ & $2 \%$ & $100 \%$ \\
\hline & Total floor area & $1,053,000$ & 987,000 & $1,122,000$ & $1,682,000$ & $1,978,000$ & $6,922,000$ \\
\hline & $\begin{array}{l}\text { Percentage of total } \\
\text { floor area }\end{array}$ & $15 \%$ & $14 \%$ & $18 \%$ & $24 \%$ & $29 \%$ & $100 \%$ \\
\hline & Average floor area & 284 & 990 & 2,234 & 5,357 & 15,099 & 1,215 \\
\hline $\begin{array}{l}\text { Building } \\
\text { type }\end{array}$ & $\begin{array}{l}\text { Floor area size } \\
\text { ranges }\end{array}$ & $\begin{array}{c}5 \text { to } \\
649 m^{2}\end{array}$ & $\begin{array}{c}650 \text { to } \\
1,499 \mathrm{~m}^{2}\end{array}$ & $\begin{array}{l}1,500 \text { to } \\
3,499 \mathrm{~m}^{2}\end{array}$ & $\begin{array}{l}3,500 \text { to } \\
8,999 \mathrm{~m}^{2}\end{array}$ & $\begin{array}{c}\text { over } \\
9000 \mathrm{~m}^{2}\end{array}$ & Total \\
\hline \multirow{5}{*}{ 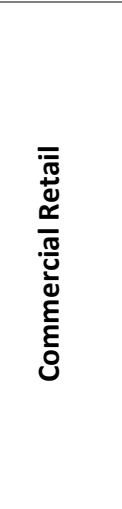 } & $\begin{array}{l}\text { Approximate } \\
\text { number of } \\
\text { buildings }\end{array}$ & 12,806 & 2,365 & 716 & 224 & 113 & 16,224 \\
\hline & $\begin{array}{l}\text { Percentage of } \\
\text { buildings }\end{array}$ & $79 \%$ & $15 \%$ & $4 \%$ & $1 \%$ & $1 \%$ & $100 \%$ \\
\hline & Total floor area & $3,687,000$ & $2,217,000$ & $1,572,000$ & $1,142,000$ & $2,085,000$ & $10,703,000$ \\
\hline & $\begin{array}{l}\text { Percentage of total } \\
\text { floor area }\end{array}$ & $34 \%$ & $21 \%$ & $15 \%$ & $11 \%$ & $19 \%$ & $100 \%$ \\
\hline & Average floor area & 288 & 937 & 2,196 & 5,098 & 18,451 & 660 \\
\hline
\end{tabular}




\begin{tabular}{|c|c|c|c|c|c|c|c|}
\hline $\begin{array}{l}\text { Building } \\
\text { type }\end{array}$ & $\begin{array}{l}\text { Floor area size } \\
\text { ranges }\end{array}$ & $\begin{array}{c}5 \text { to } \\
649 m^{2}\end{array}$ & $\begin{array}{c}650 \text { to } \\
1,499 \mathrm{~m}^{2}\end{array}$ & $\begin{array}{l}1,500 \text { to } \\
3,499 \mathrm{~m}^{2}\end{array}$ & $\begin{array}{l}3,500 \text { to } \\
8,999 \mathrm{~m}^{2}\end{array}$ & $\begin{array}{c}\text { over } \\
9000 \mathrm{~m}^{2}\end{array}$ & Total \\
\hline \multirow{5}{*}{ 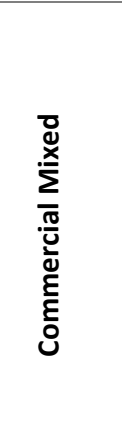 } & $\begin{array}{l}\text { Approximate } \\
\text { number of buildings }\end{array}$ & 3,446 & 1,318 & 646 & 338 & 98 & 5,846 \\
\hline & $\begin{array}{l}\text { Percentage of } \\
\text { buildings }\end{array}$ & $59 \%$ & $23 \%$ & $11 \%$ & $6 \%$ & $2 \%$ & $100 \%$ \\
\hline & Total floor area & $1,115,000$ & $1,285,000$ & $1,436,000$ & $1,817,000$ & $1,864,000$ & $7,517,000$ \\
\hline & $\begin{array}{l}\text { Percentage of total } \\
\text { floor area }\end{array}$ & $15 \%$ & $17 \%$ & $19 \%$ & $24 \%$ & $25 \%$ & $100 \%$ \\
\hline & Average floor area & 324 & 975 & 2,223 & 5,376 & 19,020 & 1,286 \\
\hline
\end{tabular}




\subsection{ELECTRICITY END-USES OF BUILDINGS IN SIZE GROUP ONE AND TWO}

Electricity end-uses of buildings in size group one and two on an average winter day.
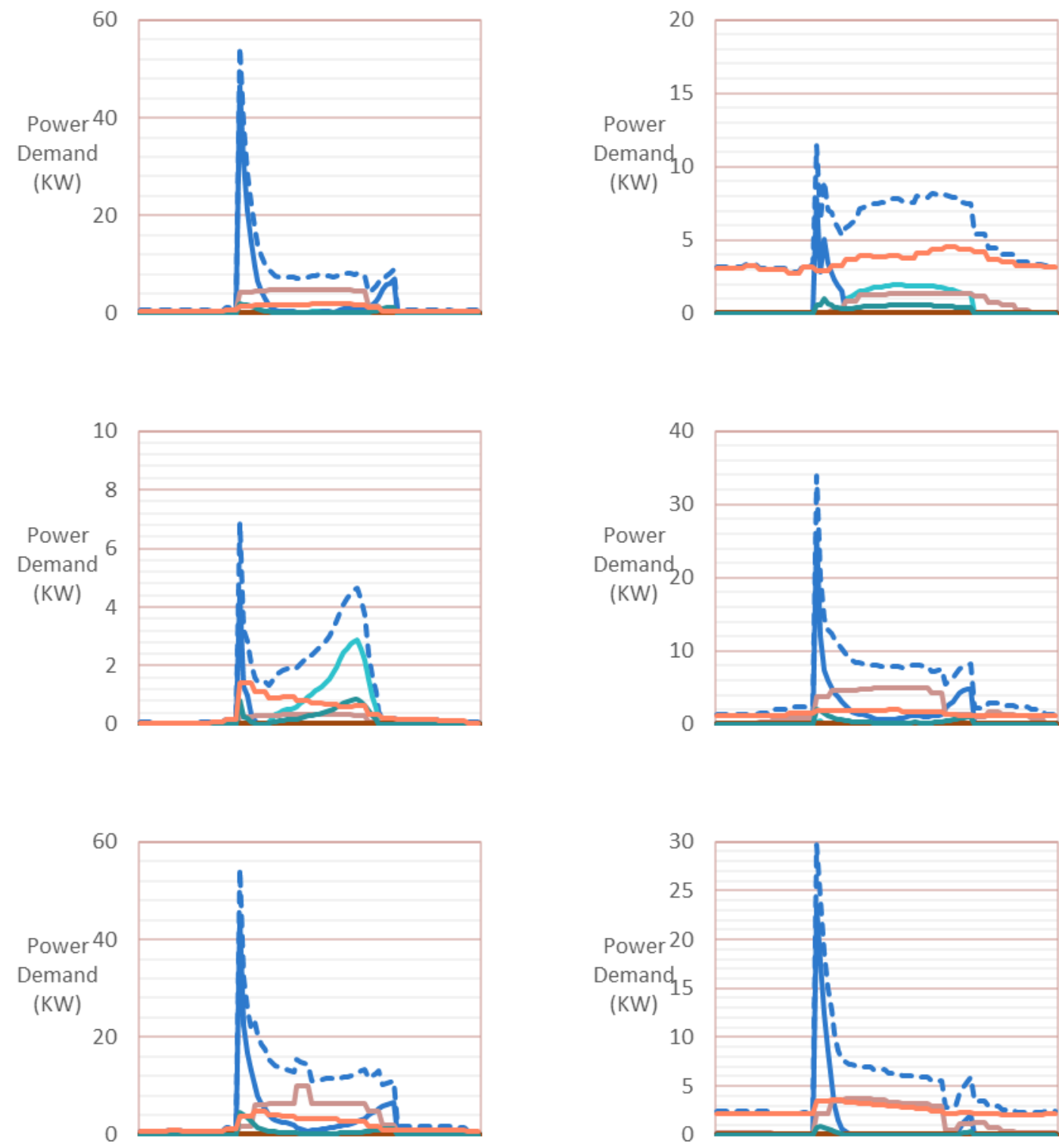

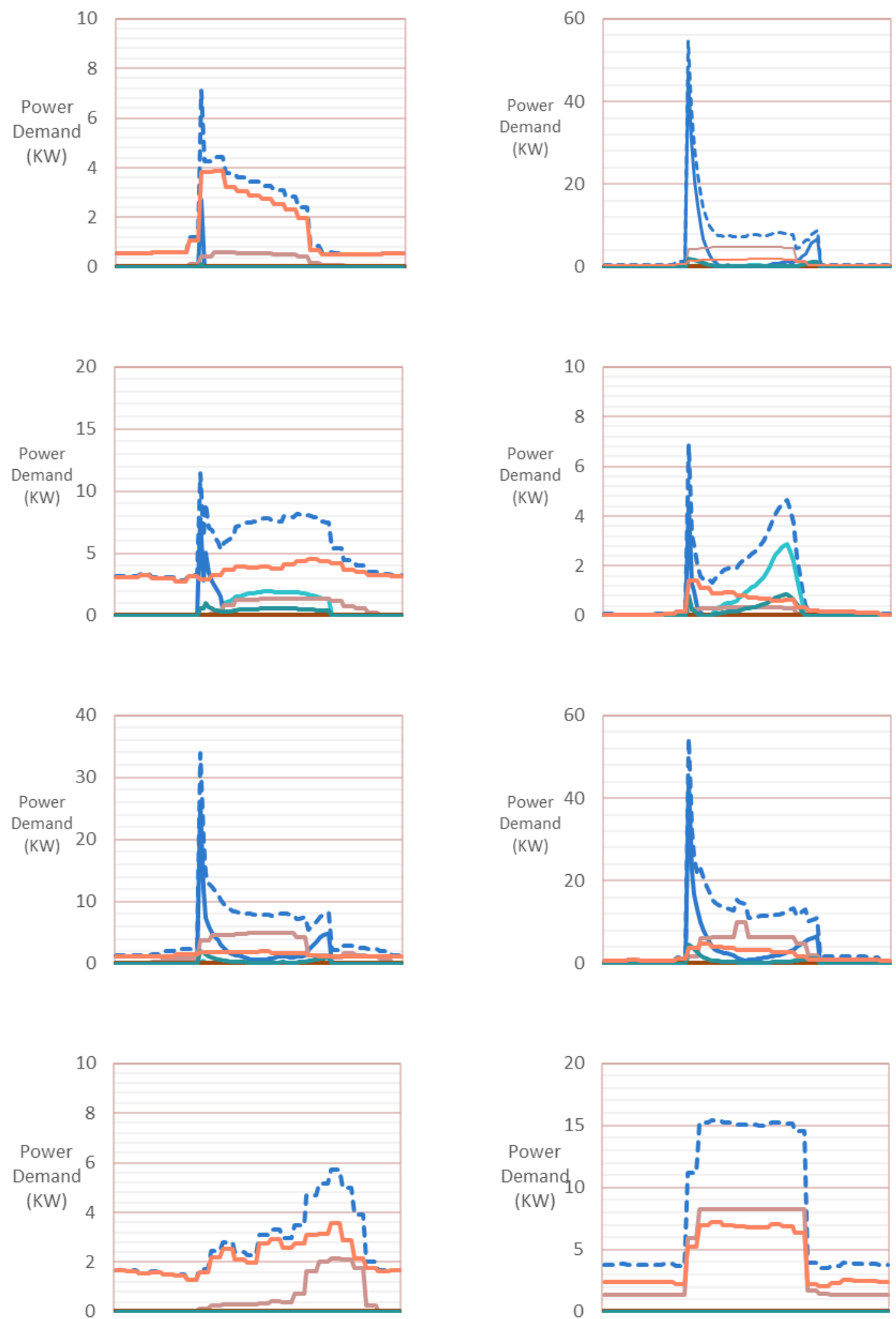

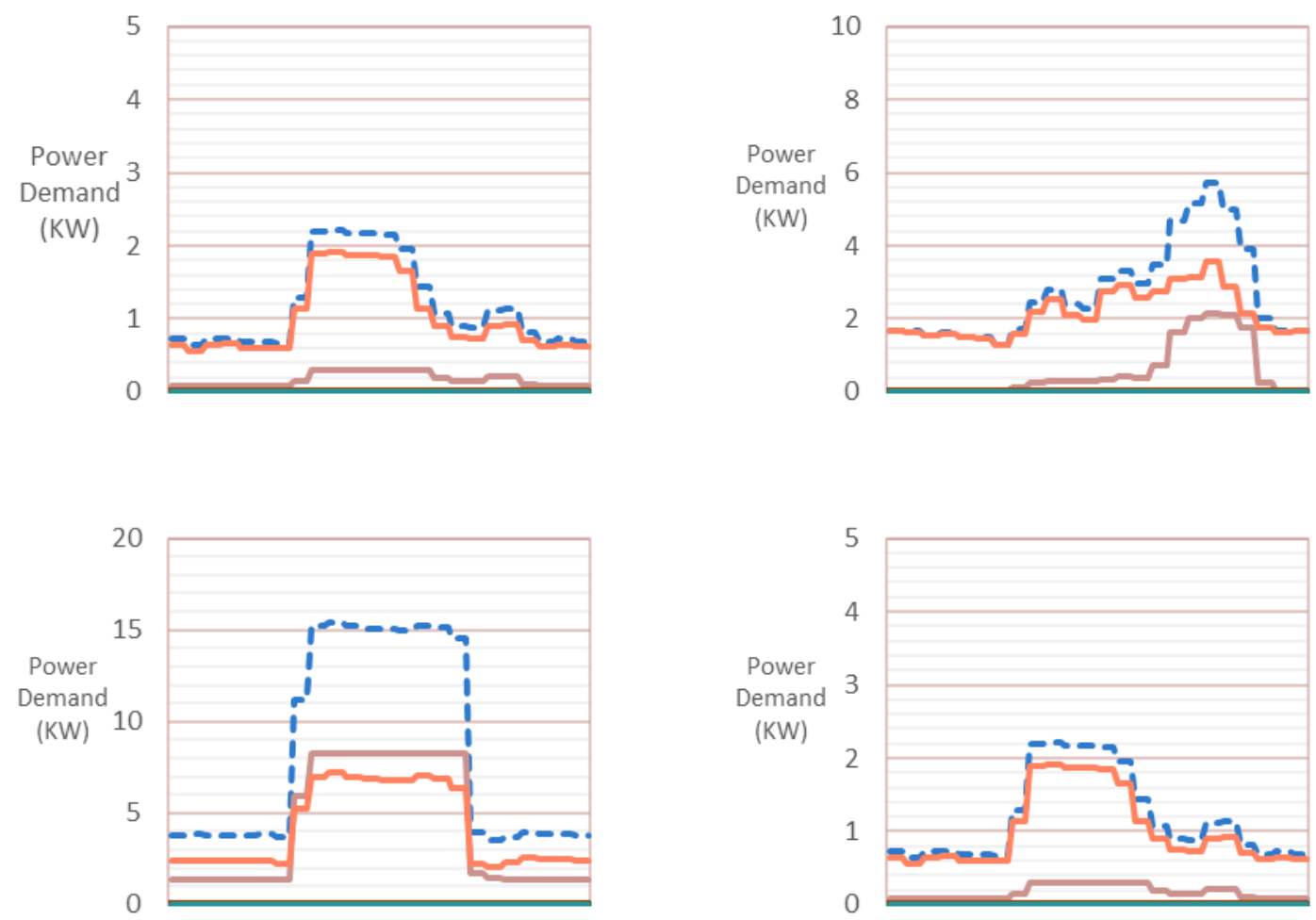
8.3 SIMULATION INPUTS FOR EACH ENERGY FLEXIBILITY TEST

\begin{tabular}{|c|c|c|c|c|c|c|c|c|c|c|}
\hline \multirow[b]{2}{*}{ Building code } & \multirow[b]{2}{*}{$\begin{array}{l}\text { Base case } \\
\text { HVAC } \\
\text { schedule }\end{array}$} & \multirow[b]{2}{*}{$\begin{array}{l}\text { Short shift } \\
\text { morning only }\end{array}$} & \multirow{2}{*}{$\begin{array}{l}\text { Medium } \\
\text { shift } \\
\text { morning } \\
\text { only }\end{array}$} & \multirow[b]{2}{*}{$\begin{array}{l}\text { Long shift } \\
\text { morning } \\
\text { only }\end{array}$} & \multirow[b]{2}{*}{$\begin{array}{l}\text { Short shift } \\
\text { morning + } \\
\text { evening }\end{array}$} & \multirow[b]{2}{*}{$\begin{array}{l}\text { Long shift } \\
\text { morning + } \\
\text { evening }\end{array}$} & \multicolumn{2}{|c|}{ Minor shift } & \multicolumn{2}{|c|}{ Mojor shift } \\
\hline & & & & & & & $\begin{array}{l}\text { Heating } \\
\text { setpoint }\end{array}$ & $\begin{array}{l}\text { Cooling } \\
\text { setpoint }\end{array}$ & $\begin{array}{l}\text { Heating } \\
\text { setpoint }\end{array}$ & $\begin{array}{l}\text { Cooling } \\
\text { setpoint }\end{array}$ \\
\hline S2/04/FCAS & $9 a m-5 p m$ & $\begin{array}{l}\text { 8:30am - } \\
4: 30 \mathrm{pm}\end{array}$ & $\begin{array}{l}7: 30 \mathrm{am}- \\
3: 30 \mathrm{pm}\end{array}$ & $\begin{array}{l}\text { 6:30am - } \\
2: 30 \mathrm{pm} \\
\end{array}$ & $\begin{array}{l}\text { 8:30am - } \\
5: 00 \mathrm{pm}\end{array}$ & $\begin{array}{l}6: 30 \mathrm{am} \mathrm{-} \\
3: 00 \mathrm{pm}\end{array}$ & 20.7 & 26 & 18.7 & 28 \\
\hline $\mathrm{S} 2 / 01 / \mathrm{CS} 1$ & $7 a m-6 p m$ & $\begin{array}{l}\text { 6:30am - } \\
\text { 5:30pm }\end{array}$ & $\begin{array}{l}\text { 5:30am - } \\
\text { 4:30pm }\end{array}$ & $\begin{array}{l}\text { 4:30am - } \\
\text { 3:30pm }\end{array}$ & $\begin{array}{l}\text { 6:30am - } \\
\text { 6:00pm }\end{array}$ & $\begin{array}{l}\text { 4:30am - } \\
\text { 6:00pm }\end{array}$ & 18 & 31 & 16 & 33 \\
\hline S2/O3/CWBS & $10 a m-10 p m$ & $\begin{array}{l}\text { 9:30am - } \\
\text { 9:30pm }\end{array}$ & $\begin{array}{l}\text { 8:30am - } \\
\text { 8:30pm }\end{array}$ & $\begin{array}{l}\text { 7:30am - } \\
7: 30 \mathrm{pm}\end{array}$ & $\begin{array}{l}\text { 9:30am - } \\
12: 00 \mathrm{pm}\end{array}$ & $\begin{array}{l}\text { 7:30am - } \\
12: 00 \mathrm{pm}\end{array}$ & 17.7 & 25 & 15.7 & 27 \\
\hline S1/O1/BT & $7 a m-6 p m$ & $\begin{array}{l}\text { 6:30am - } \\
\text { 5:30pm }\end{array}$ & $\begin{array}{l}\text { 5:30am - } \\
\text { 4:30pm }\end{array}$ & $\begin{array}{l}\text { 4:30am - } \\
3: 30 \mathrm{pm}\end{array}$ & $\begin{array}{l}\text { 6:30am - } \\
\text { 6:00pm }\end{array}$ & $\begin{array}{l}\text { 4:30am - } \\
\text { 6:00pm }\end{array}$ & 19 & 25 & 17 & 27 \\
\hline $\mathrm{S} 2 / 01 / \mathrm{CSC}$ & $7 a m-6 p m$ & $\begin{array}{l}\text { 6:30am - } \\
5: 30 \mathrm{pm}\end{array}$ & $\begin{array}{l}\text { 5:30am - } \\
\text { 4:30pm }\end{array}$ & $\begin{array}{l}\text { 4:30am - } \\
3: 30 \mathrm{pm}\end{array}$ & $\begin{array}{l}\text { 6:30am - } \\
\text { 6:00pm }\end{array}$ & $\begin{array}{l}\text { 4:30am - } \\
\text { 6:00pm }\end{array}$ & 9 & 18 & 7 & 20 \\
\hline $\mathrm{S} 1 / 01 / \mathrm{CS} 2$ & $7 a m-6 p m$ & $\begin{array}{l}\text { 6:30am - } \\
\text { 5:30pm }\end{array}$ & $\begin{array}{l}\text { 5:30am - } \\
4: 30 \mathrm{pm}\end{array}$ & $\begin{array}{l}\text { 4:30am - } \\
3: 30 \mathrm{pm}\end{array}$ & $\begin{array}{l}\text { 6:30am - } \\
\text { 6:00pm }\end{array}$ & $\begin{array}{l}\text { 4:30am - } \\
\text { 6:00pm }\end{array}$ & 23 & 25.5 & 21 & 27.5 \\
\hline S1/O1/CS3 & $7 a m-6 p m$ & $\begin{array}{l}\text { 6:30am - } \\
\text { 5:30pm }\end{array}$ & $\begin{array}{l}\text { 5:30am - } \\
4: 30 \mathrm{pm}\end{array}$ & $\begin{array}{l}\text { 4:30am - } \\
3: 30 \mathrm{pm}\end{array}$ & $\begin{array}{l}\text { 6:30am - } \\
\text { 6:00pm }\end{array}$ & $\begin{array}{l}\text { 4:30am - } \\
6: 00 \mathrm{pm}\end{array}$ & 14 & 22.5 & 12 & 24.5 \\
\hline $\mathrm{S} 2 / \mathrm{O} 2 / \mathrm{CS}$ & $7 a m-6 p m$ & $\begin{array}{l}\text { 6:30am - } \\
\text { 5:30pm }\end{array}$ & $\begin{array}{l}\text { 5:30am - } \\
\text { 4:30pm }\end{array}$ & $\begin{array}{l}\text { 4:30am - } \\
\text { 3:30pm }\end{array}$ & $\begin{array}{l}\text { 6:30am - } \\
\text { 6:00pm }\end{array}$ & $\begin{array}{l}\text { 4:30am - } \\
\text { 6:00pm }\end{array}$ & 29 & 31 & 27 & 33 \\
\hline S1/01/CS4 & $7 a m-6 p m$ & $\begin{array}{l}\text { 6:30am - } \\
\text { 5:30pm }\end{array}$ & $\begin{array}{l}\text { 5:30am - } \\
\text { 4:30pm }\end{array}$ & $\begin{array}{l}\text { 4:30am - } \\
\text { 3:30pm }\end{array}$ & $\begin{array}{l}\text { 6:30am - } \\
\text { 6:00pm }\end{array}$ & $\begin{array}{l}\text { 4:30am - } \\
\text { 6:00pm }\end{array}$ & 14 & 31 & 12 & 33 \\
\hline S1/01/CGS & $7 a m-6 p m$ & $\begin{array}{l}\text { 6:30am - } \\
5: 30 \mathrm{pm}\end{array}$ & $\begin{array}{l}5: 30 \mathrm{am}- \\
4: 30 \mathrm{pm}\end{array}$ & $\begin{array}{l}\text { 4:30am - } \\
3: 30 \mathrm{pm}\end{array}$ & $\begin{array}{l}\text { 6:30am - } \\
\text { 6:00pm }\end{array}$ & $\begin{array}{l}\text { 4:30am - } \\
\text { 6:00pm }\end{array}$ & 9 & 21 & 7 & 23 \\
\hline S1/01/BCS & $7 a m-6 p m$ & $\begin{array}{l}\text { 6:30am - } \\
5: 30 \mathrm{pm}\end{array}$ & $\begin{array}{l}\text { 5:30am - } \\
\text { 4:30pm }\end{array}$ & $\begin{array}{l}\text { 4:30am - } \\
\text { 3:30pm }\end{array}$ & $\begin{array}{l}\text { 6:30am - } \\
\text { 6:00pm }\end{array}$ & $\begin{array}{l}\text { 4:30am - } \\
\text { 6:00pm }\end{array}$ & 25 & 28 & 23 & 30 \\
\hline S1/O2/BRS & $7 a m-6 p m$ & $\begin{array}{l}\text { 6:30am - } \\
\text { 5:30pm }\end{array}$ & $\begin{array}{l}5: 30 \mathrm{am}- \\
4: 30 \mathrm{pm}\end{array}$ & $\begin{array}{l}\text { 4:30am - } \\
3: 30 \mathrm{pm}\end{array}$ & $\begin{array}{l}\text { 6:30am - } \\
6: 00 \mathrm{pm}\end{array}$ & $\begin{array}{l}\text { 4:30am - } \\
6: 00 \mathrm{pm}\end{array}$ & 20 & 25 & 18 & 27 \\
\hline
\end{tabular}

156 | P a g e 


\subsection{PYTHON SCRIPT TO MEASURE ENERGY FLEXIBILITY}

In the script, the dates were changed depending different analyses conducted. Similarly, the script was changed slightly depending on the energy flexibility test. 


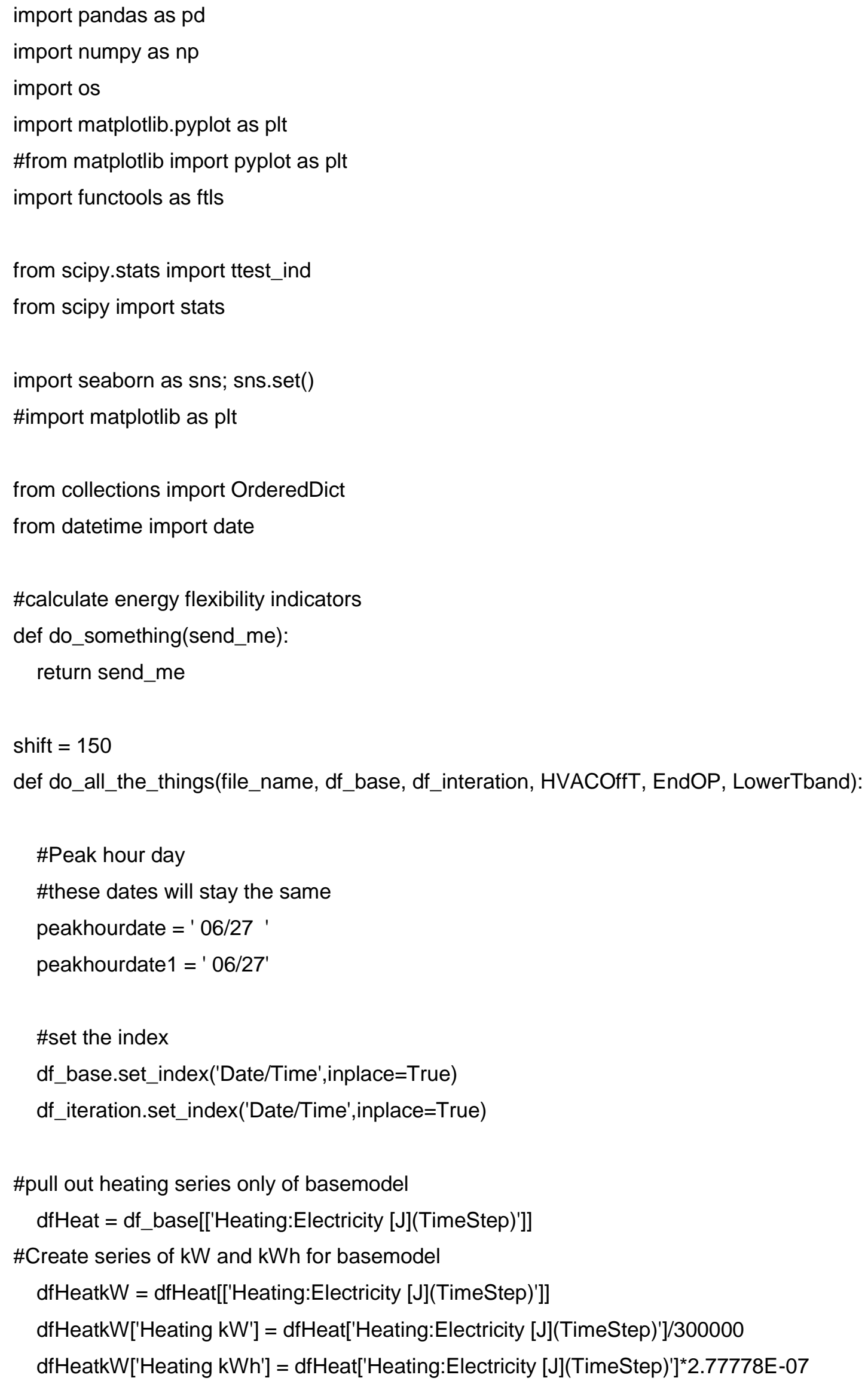




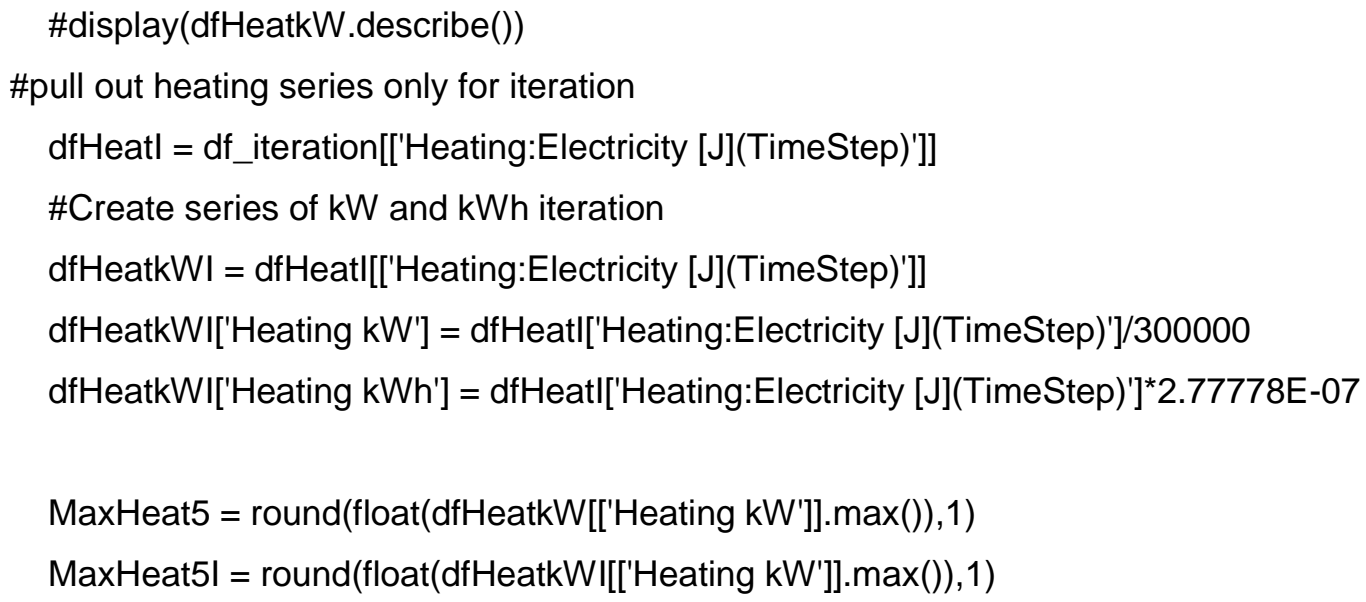

\#Average the zone temperatures for all buildings except for R0007 - R0007 is include as long as the columns are deleted from the csv.

\#Get only the zone air temperatures

df_baseTempzone $=[\mathrm{col}$ for col in df_base.columns if 'Zone Air Temperature [C](TimeStep)' in $\mathrm{col}]$

df_iterationTempzone $=[$ col for col in df_iteration.columns if 'Zone Air Temperature

[C](TimeStep)' in col]

temps $=$ df_base[[col for col in df_base.columns if 'Zone Air Temperature [C](TimeStep)' in coll]

tempsl = df_iteration[[col for col in df_iteration.columns if 'Zone Air Temperature

[C](TimeStep)' in col]]

temps['Average Zone Temperature'] = temps[temps.columns].mean(axis=1)

tempsI['Average Zone Temperature'] = tempsI[tempsl.columns].mean(axis=1)

\# Calc Max heating $\mathrm{kW}$ time annual ( $\mathrm{H}$ stands for heating)

MaxHeat5T $=\max (\mathrm{dfHeatkW[['Heating} \mathrm{kW']].idxmax())}$

MaxHeat5TI $=\max ($ dfHeatkWI[['Heating kW']].idxmax ()$)$

\# Winter heating Energy Consumption

WinHeatT = round(float(dfHeatkW['Heating kWh']].loc[' 06/01 00:05:00':' 08/31

23:55:00'].sum()),1)

WinHeatTI = round(float(dfHeatkWI['Heating kWh']].loc[' 06/01 00:05:00':' 08/31

23:55:00'].sum()),1)

\# Annual heating energy consumption

AnnualHeat T = round(float(dfHeatkW[['Heating kWh']].sum()),1)

AnnualHeatTI = round(float(dfHeatkWI[['Heating kWh']].sum()),1) 


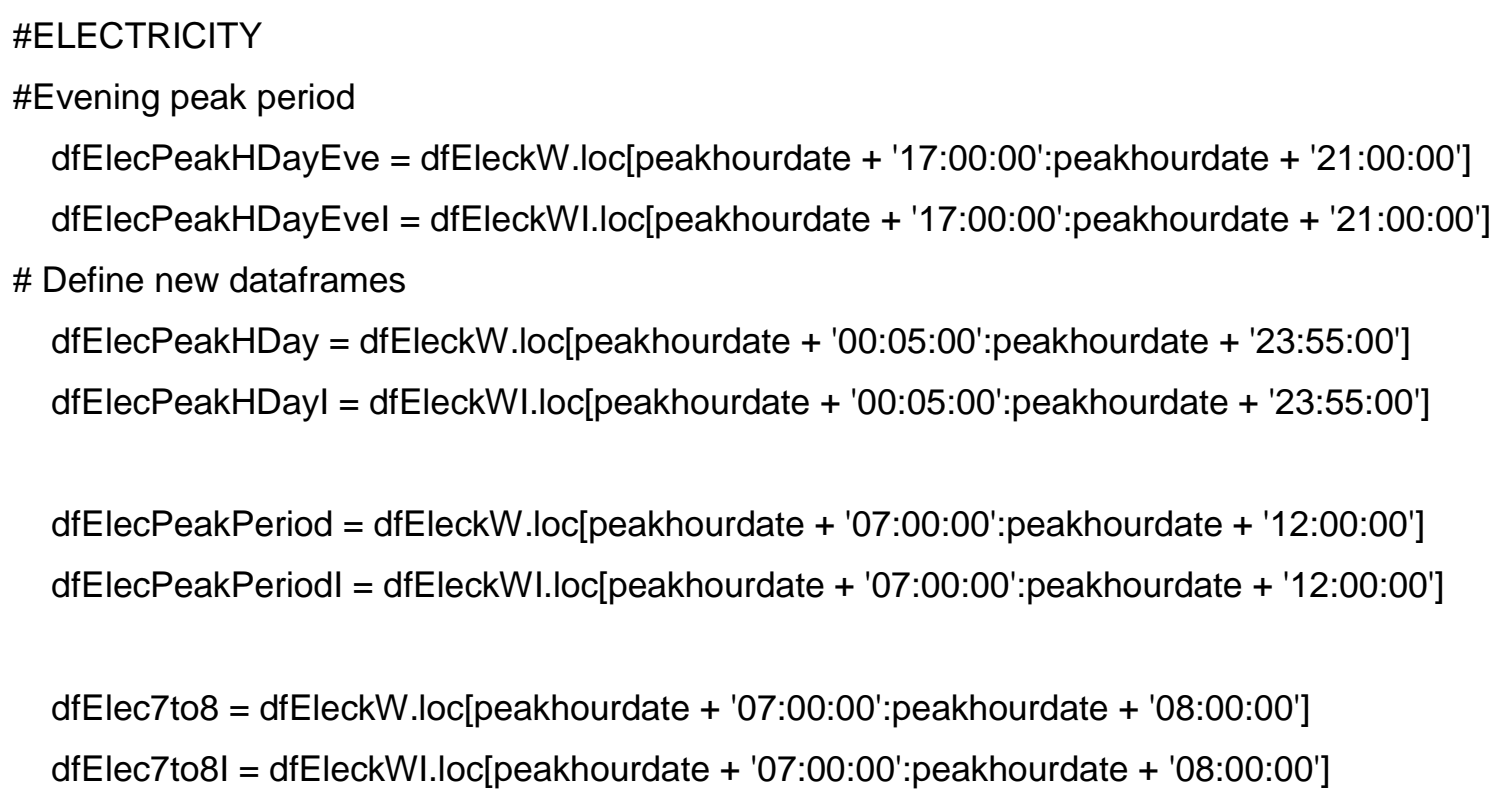

\#7am to 8am heating consumption

BaseHeatCons7to8 = round(float(dfHeat7to8[['Heating kWh']].sum()),1)

IterHeatCons7to8 = round(float(dfHeat7to8I[['Heating kWh']].sum()),1)

\#7am to 8am heating demand

BaseHeatPower7to8 = round(float(dfHeat7to8[['Heating kW']].max()),1)

IterHeatPower7to8 = round(float(dfHeat7to8I[['Heating

kW']].loc[BaseHeatPower7to8T].max()),1)

\#7am to 8am electricity consumption

BaseElecCons7to8 $=$ round(float(dfElec7to8[['Electricity kWh']].sum()),1) 


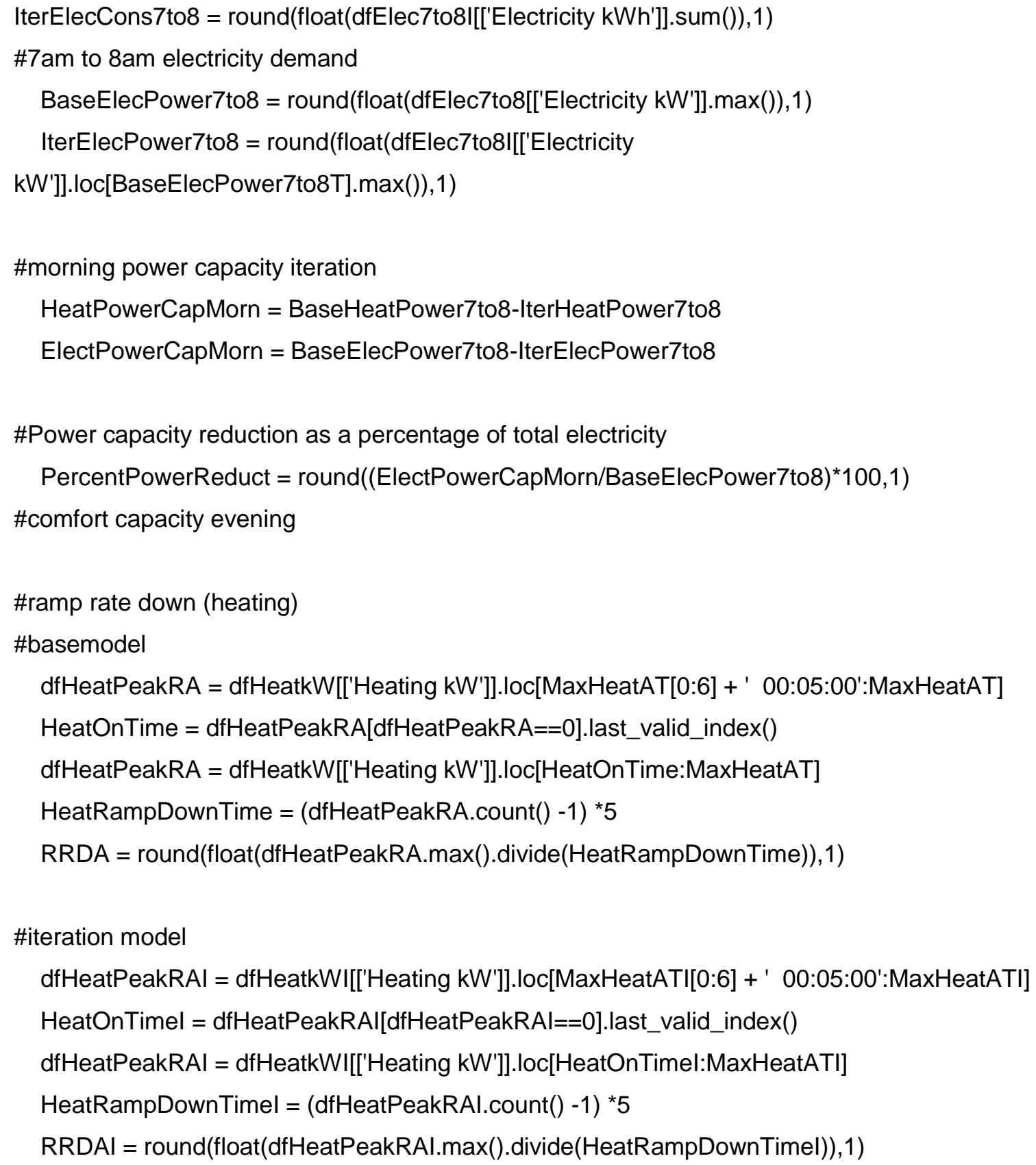




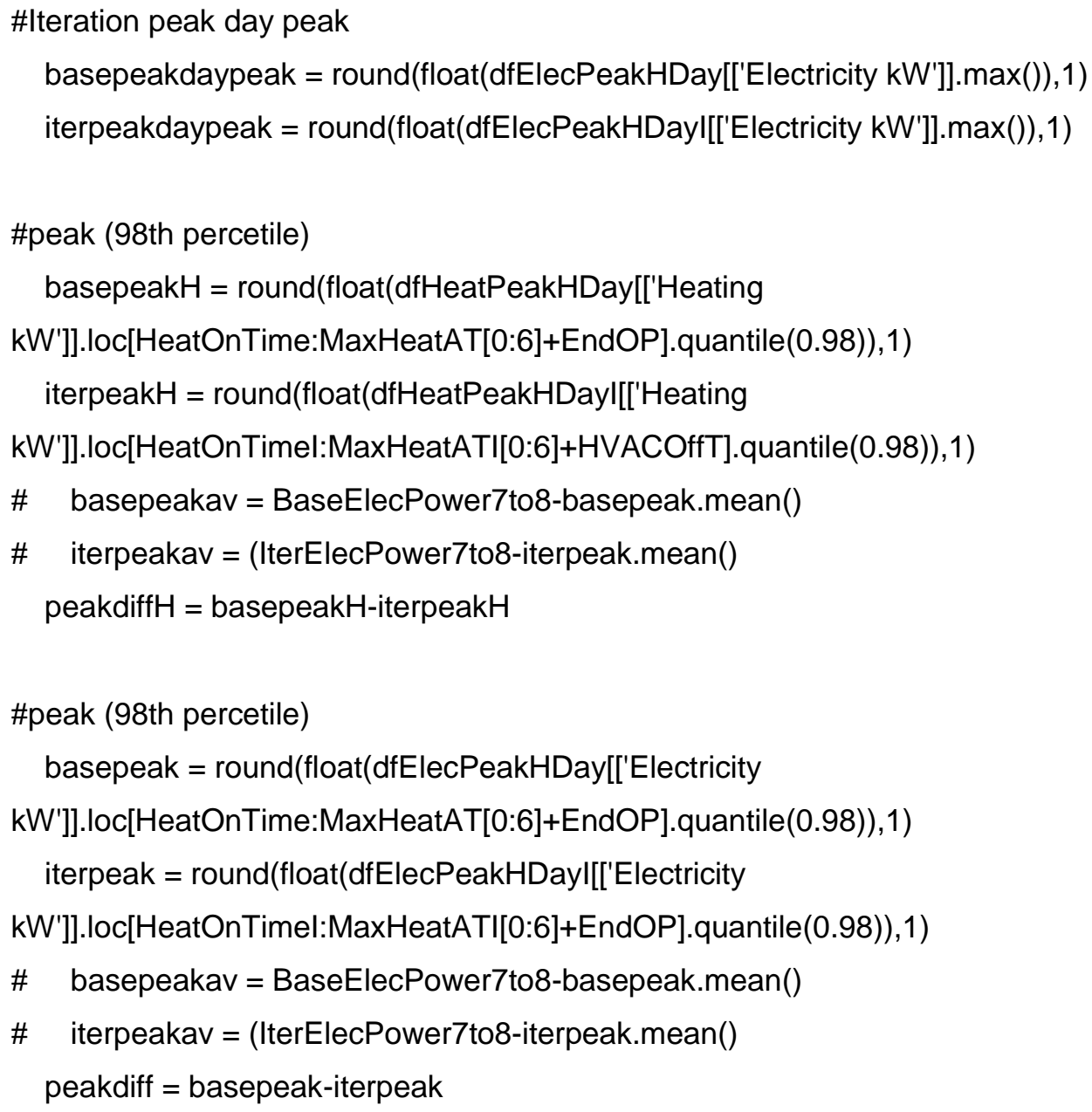

\#highest peak and 98th peak difference/spread

basepeakrange $=$ basepeakdaypeak-basepeak

iterpeakrange $=$ iterpeakdaypeak-iterpeak

\#peak factor heating

$\mathrm{PF}=$ round(float(dfHeatkW[['Heating

kW']].loc[HeatOnTime:peakhourdate1+EndOP].quantile(0.98).divide(dfHeatkW[['Heating kW']].loc[HeatOnTime:peakhourdate1+EndOP].mean())),1)

$\mathrm{PFI}=$ round $($ float $(\mathrm{dfH}$ HeatkWI[['Heating

kW']].loc[HeatOnTimel:peakhourdate1+HVACOffT].quantile(0.98).divide(dfHeatkWI[['Heating kW']].loc[HeatOnTimel:peakhourdate1+HVACOffT].mean())),1)

\#peak factor electricity 


\section{PFElec $=$ round $($ float $($ dfEleckW[['Electricity}

kW']].loc[HeatOnTime:peakhourdate1+EndOP].quantile(0.98).divide(dfEleckW[['Electricity kW']].loc[HeatOnTime:peakhourdate1+EndOP].mean())),1)

PFElecl = round(float(dfEleckWI['Electricity

kW']].loc[HeatOnTimel:peakhourdate1+EndOP].quantile(0.98).divide(dfEleckWI['Electricity kW']].loc[HeatOnTimel:peakhourdate1+EndOP].mean())),1)

\#ramp rate down (heating)

\#basemodel

dfHeatPeakRU5 = dfHeatkW[['Heating kW']].loc[MaxHeat5T:MaxHeat5T[0:6] + ' 11:00:00']

LowHeatTime5 =

dfHeatPeakRU5[dfHeatPeakRU5==dfHeatPeakRU5.min()].last_valid_index()

dfHeatPeakRU5 = dfHeatkW[['Heating kW']].loc[MaxHeat5T:LowHeatTime5]

HeatRampUpTime5 $=($ dfHeatPeakRU5.count ()$-1){ }^{*} 5$

RRUPD = round(float((MaxHeat5-dfHeatPeakRU5.min()).divide(HeatRampUpTime5)),1)

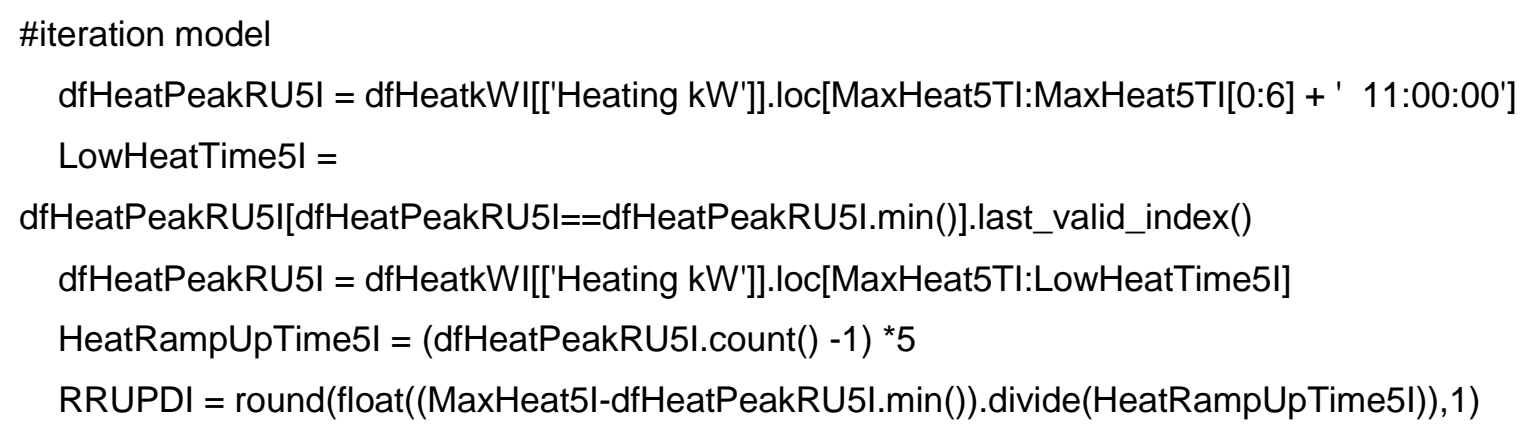

\#Comfort Capacity evening

HeatOffEnd = dfHeatkWI['Heating kW']].loc[MaxHeatATI[0:6] + HVACOffT:MaxHeatATI[0:6] + EndOP]

TempOffEnd = tempsI['Average Zone Temperature']].loc[MaxHeatATI[0:6] + HVACOffT:MaxHeatATI[0:6] + EndOP]

\#time until uncomfortable

MaxComfT $=$ TempOffEnd[TempOffEnd $>$ LowerTband].last_valid_index()

ComfCapDiff $=($ TempOffEnd.loc[HVACOffT:MaxComfT].count ()$-1) * 5$

CompCapEve $=$ float (ComfCapDiff)

\#Max and Min power evening $5 \mathrm{pm}$ to $9 \mathrm{pm}$

PPEVEMX = round(float(dfHeatPeakHDayEve[['Heating kW']].max()),1)

PPEVEMXI = round(float(dfHeatPeakHDayEvel[['Heating kW']].max ()),1) 


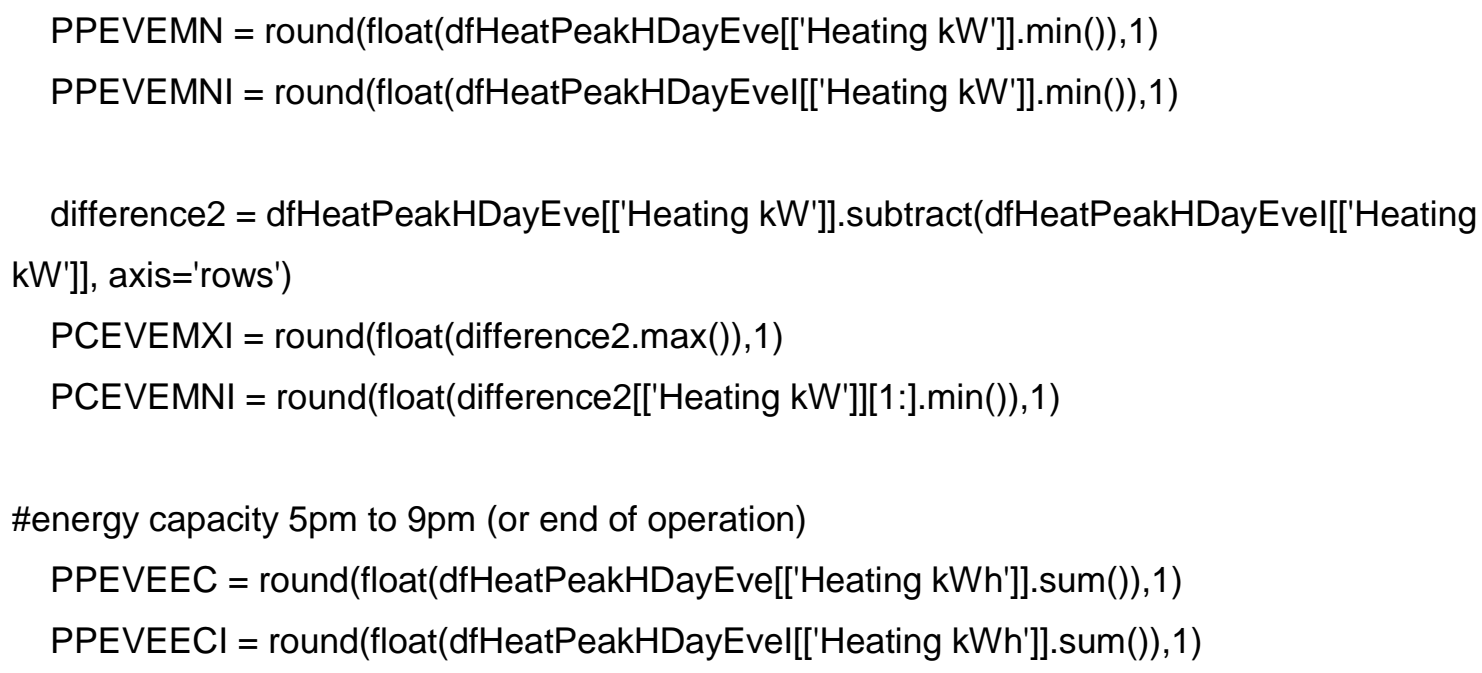


('Annual Peak Heating Demand Date/Time Iteration', [MaxHeat5TI]), \#non EFB information

('Winter Heating Consumption Basemodel (kWh)', $\quad$ [WinHeatT]),

('Winter Heating Consumption Iteration (kWh)', [WinHeatTI]),

('Annual Heating Consumption Basemodel (kWh)', [AnnualHeatT]),

('Annual Heating Consumption Iteration (kWh)', [AnnualHeatTI]),

('Annual Electricity Consumption Basemodel (kWh)', [AnnualElecT]),

('Annual Electricity Consumption Iteration (kWh)', [AnnualElecTl]),

\#7am to 8am heating and electricity power and consumption on the peak day

('Electricity Consumption 7am to 8am Basemodel (kWh)', [BaseElecCons7to8]),

('Electricity Consumption 7am to 8am Iteration (kWh)', [IterElecCons7to8]),

('Peak Electricity Demand 7am to 8am Basemodel (kW)', [BaseElecPower7to8]),

('Peak Electricity Demand 7am to 8am Iteration (kW)', [IterElecPower7to8]),

('Peak Electricity Demand 7am to 8am Date/Time Basemodel (kW)',

[BaseElecPower7to8T]),

('Peak Electricity Demand 7am to 8am Date/Time Iteration (kW)',

[IterElecPower7to8T]),

('Heating Consumption 7am to 8am Basemodel (kWh)', [BaseHeatCons7to8]),

('Heating Consumption 7am to 8am Iteration (kWh)', [IterHeatCons7to8]),

('Peak Heating Demand 7am to 8am Basemodel (kW)', [BaseHeatPower7to8]),

('Peak Heating Demand 7am to 8am Iteration (kW)', [IterHeatPower7to8]),

('Peak Heating Demand 7am to 8am Date/Time Basemodel (kW)',

[BaseHeatPower7to8T]),

('Peak Heating Demand 7am to 8am Date/Time Iteration (kW)', [IterHeatPower7to8T]),

\#peak day information

('Peak Electricity Demand Basemodel (kW)', [basepeakdaypeak]),

('Peak Electricity Demand Iteration (kW)', [iterpeakdaypeak]),

('Peak Electricity Demand Basemodel $98(\mathrm{~kW})$ ', [basepeak]),

('Peak Electricity Demand Iteration 98 (kW)', [iterpeak]),

('Peak reduction 98 (kW)', [peakdiff]),

('Peak range Basemodel (kW)', [basepeakrange]),

('Peak range Iteration $(\mathrm{kW})$ ', [iterpeakrange]),

('Peaking Factor Basemodel (kW/kW)', [PF]),

('Peaking Factor Iteration (kW/kW)', [PFI]),

\#energy flexibility indicators

('Morning Ramp Down Rate Basemodel (kW/min)', $\quad$ [RRDA]), 
('Morning Ramp Down Rate Iteration (kW/min)', $\quad$ [RRDAl]),

('Morning Ramp Up Rate Basemodel (kW/min)', , [RRUPD]),

('Morning Ramp Up Rate Iteration (kW/min)', , [RRUPDI]),

('Electricity Power Capacity Morning Basemodel (kW)', [BaseElecPower7to8]),

('Electricity Power Capacity Morning Iteration (kW)', [ElectPowerCapMorn]),

('Electricity Energy Capacity Morning Basemodel (kW)', [BaseElecCons7to8]),

('Electricity Energy Capacity Morning Iteration (kW)', [BaseElecCons7to8-

IterElecCons7to8]),

('Heating Power Capacity Morning Basemodel (kW)', [BaseHeatPower7to8]),

('Heating Power Capacity Morning Iteration (kW)', [HeatPowerCapMorn]),

('Power capacity reduction as a percentage of total electricity (\%)',

[PercentPowerReduct]),

\#Dependent on temperatures

\# ('Energy Consumption 5pm to 9pm Basemodel', [PPEVEEC]),

\# ('Energy Consumption 5pm to 9pm Iteration', [PPEVEECI]),

('Comfort Capacity Evening Basemodel (min)', ['NA']),

('Comfort Capacity Evening Iteration (min)', [CompCapEve]),

('End of Comfortable period', [MaxComfT]),

('Power Capacity Max Evening (kW)', [PCEVEMXI]),

('Power Capacity Min Evening (kW)', [PCEVEMNI]),

('Electricity Consumption Evening Iteration (kWh)', [EnergyCon]),

('Electricity Energy Capacity Evening (kWh) ', $\quad$ [PPEVEECPOT]),

('Normalised Comfort Cap (\%)', $\quad$ [round((CompCapEve/shift) $\left.\left.\left.{ }^{\star} 100,1\right)\right]\right)$,

('Normalised Comfort Rec (\%)', [ ['NA']),

('Normalised Power Cap (\%)',

[round((ElectPowerCapMorn/BaseElecPower7to8) $\left.\left.\left.{ }^{*} 100,1\right)\right]\right)$,

('Normalised Energy Cap (\%)', $\quad$ [round(((BaseElecCons7to8-

IterElecCons7to8)/BaseElecCons7to8)*100,1)]),

('Normalised Ramp Up (\%)', [round((RRUPDI/iterpeakdaypeak)*100,1)]),

('Normalised Ramp Down (\%)', $\quad$ [round((RRDAl/iterpeakdaypeak)*100,1)]),

('Normalised Ramp Up $2(\%)$ ', $\quad$ [round((RRDANT/iterpeakdaypeak)*100,1)]),

('Normalised Ramp Down 2 (\%)', $\quad$ [round((RRDAINT/iterpeakdaypeak)*100,1)]) 


\subsection{COMFORT CAPACITY AND BUILDING CHARACTERISTICS}

Figure 58 and Figure 59 present some physical and operational building characteristics plotted from highest to lowest. The hatched bars represent the buildings with comfort capacities less than $100 \%$ after a Short shift morning + evening test.

Building codes:

\begin{tabular}{|l|l|}
\hline R0007 & S2/O1/CS1 \\
\hline R0017 & S1/O1/BT \\
\hline R0020 & S2/O1/CSC \\
\hline R0031 & S1/O1/CS2 \\
\hline R0037 & S1/O1/CS3 \\
\hline R0087 & S2/O2/CS \\
\hline R0150 & S1/O1/CS4 \\
\hline R0175 & S1/O1/CGS \\
\hline R0186 & S1/O1/BCS \\
\hline R0433 & S1/O2/BRS \\
\hline R0678 & S2/O4/FCAS \\
\hline R0831 & S2/O3/CWBS \\
\hline
\end{tabular}



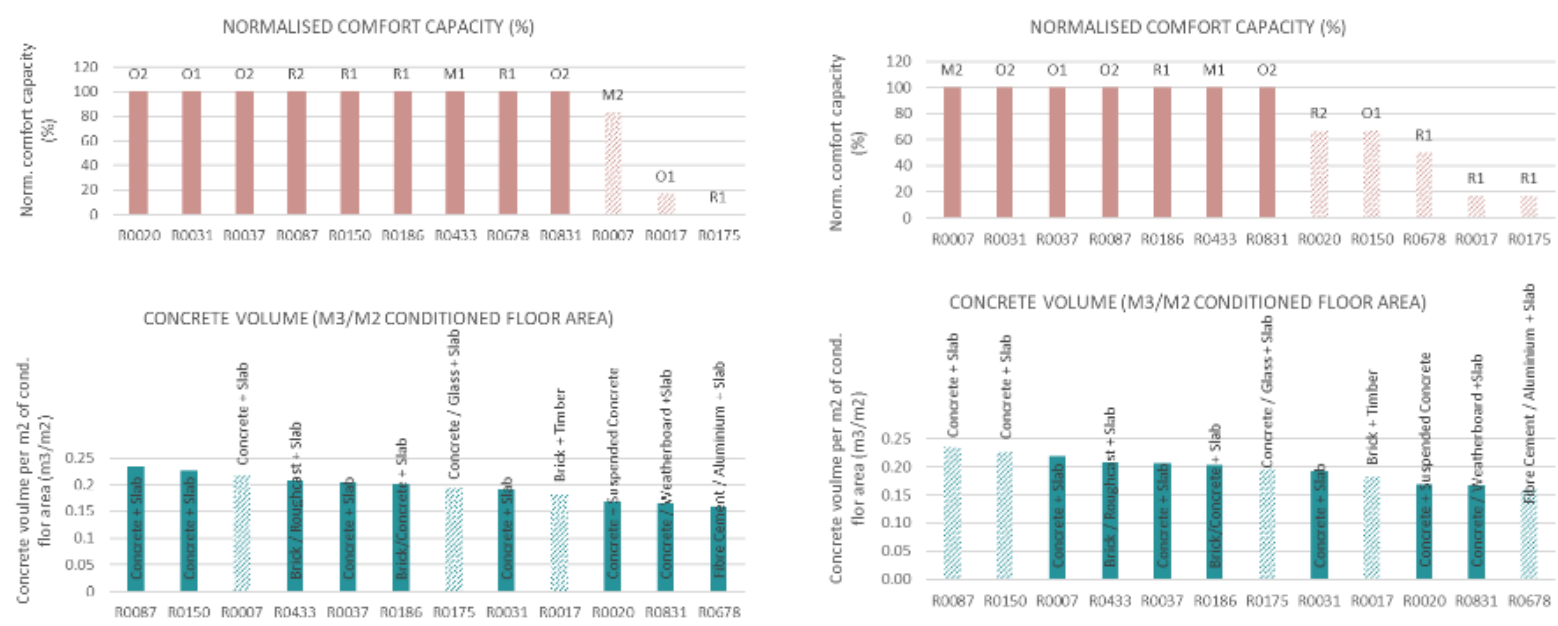

CONCRETE VOLUME (M3)
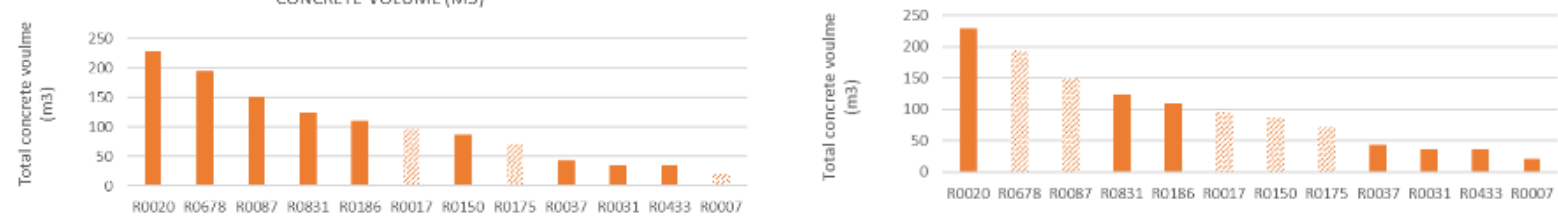

WWR $(\%)$
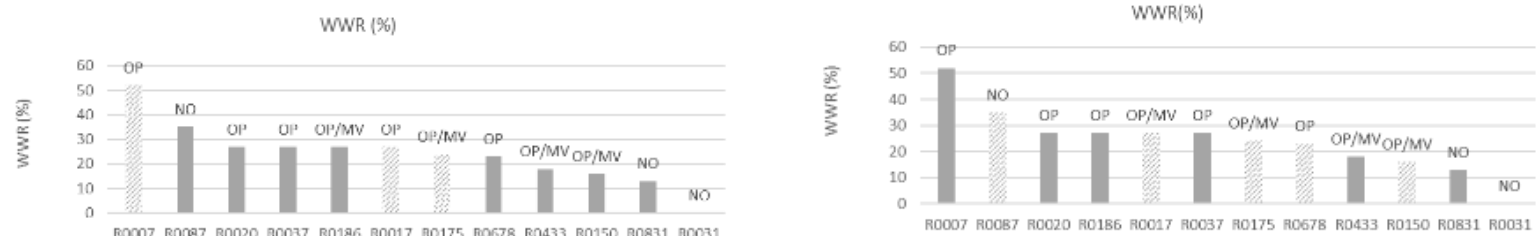

CONDITIONED FLOOR AREA (M2)
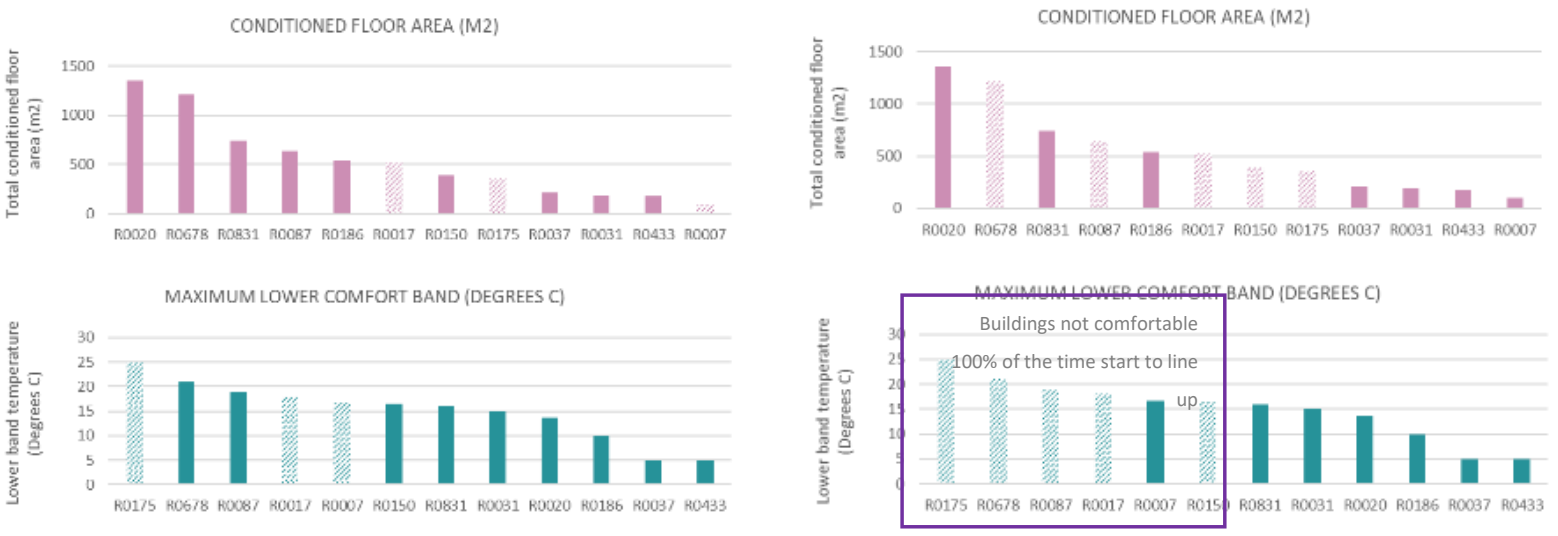

Figure 58 Warmer region.

Figure 59 Cooler region. 
Figure 60 and Figure 61 present some physical and operational building characteristics plotted from highest to lowest. The hatched bars represent the buildings with comfort capacities less than $100 \%$ after a Long shift morning + evening test.
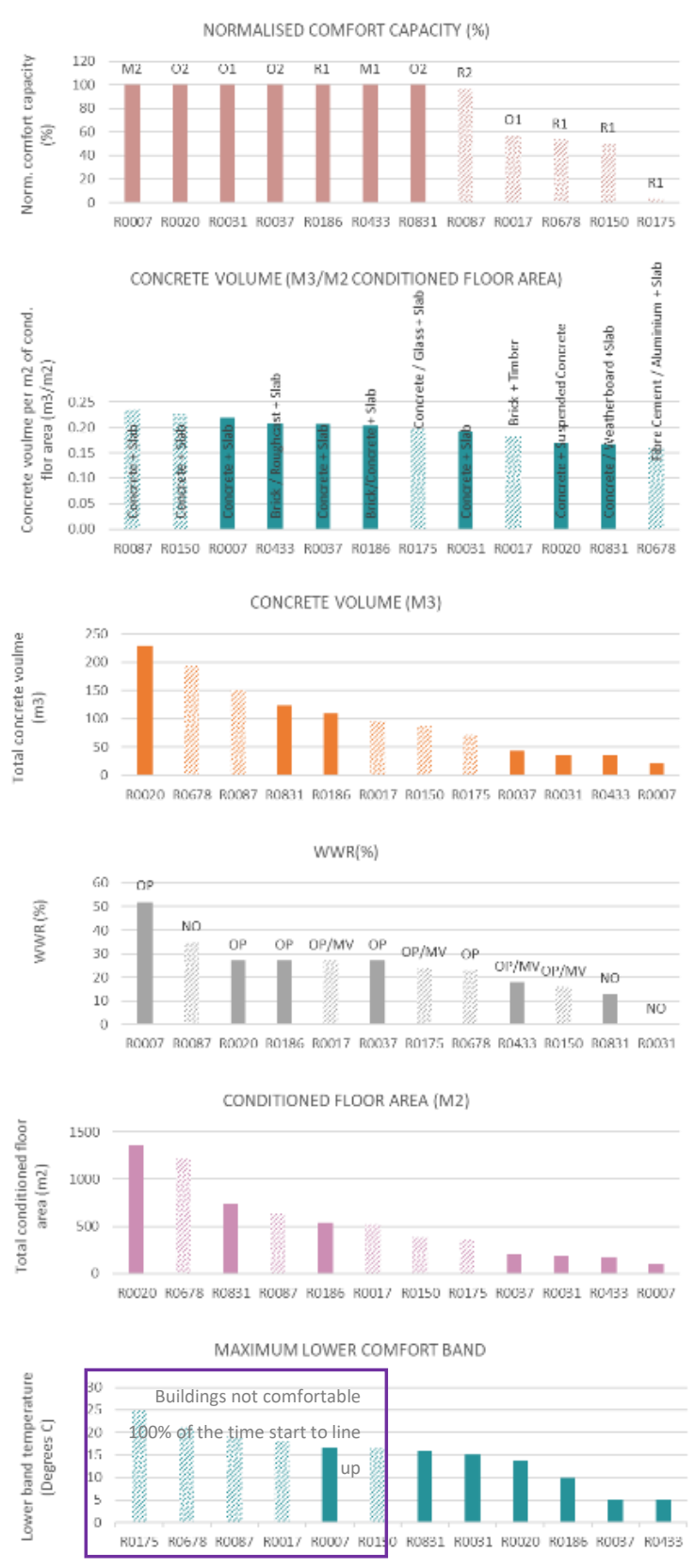

Figure 60 Warmer region
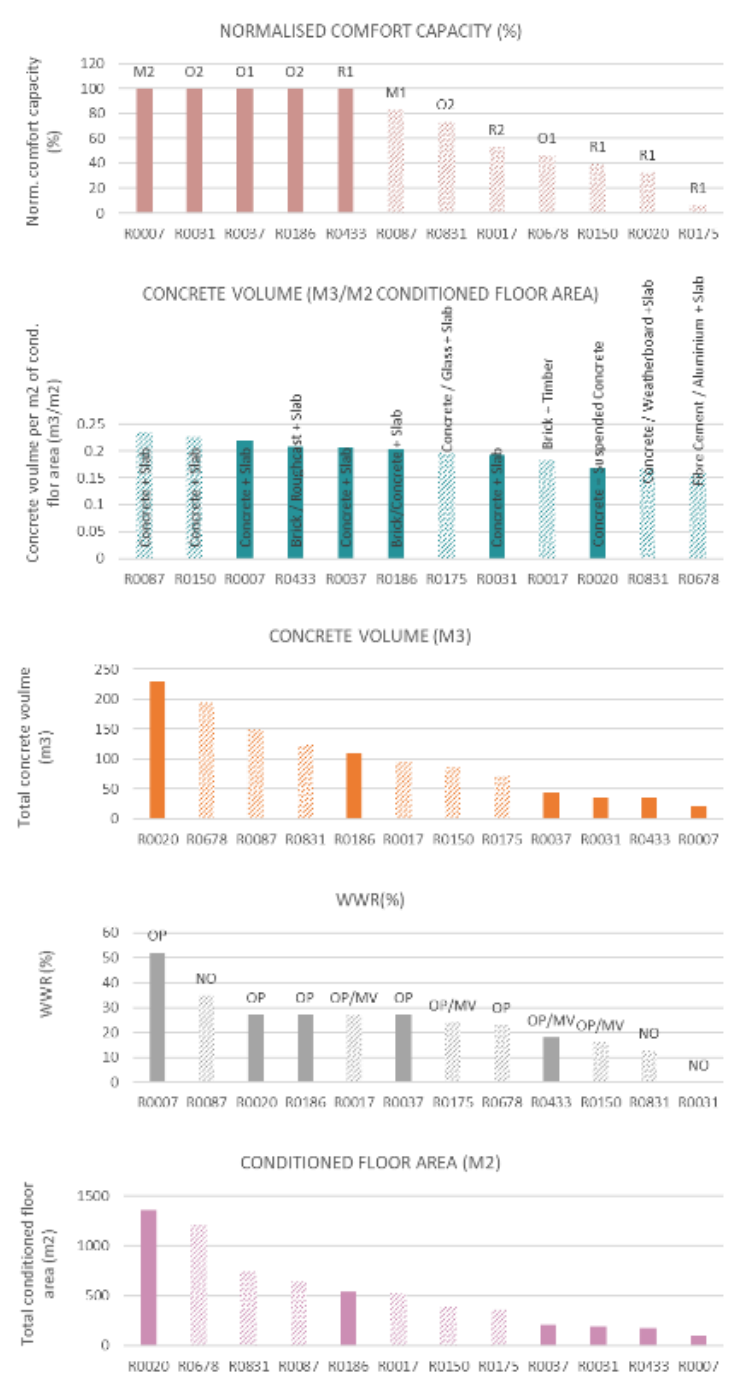

MAXIMUM LOWER COMFORT BAND (DEGREES C)

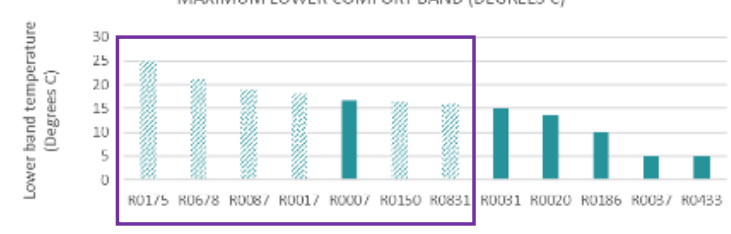

Figure 61 Cooler region 


\subsection{NUMBER OF BUILDINGS THAT MET THE AGGREGATION CRITERIA}

\begin{tabular}{|c|c|}
\hline $\begin{array}{c}\text { Code name in copied spreadsheet on following } \\
\text { page }\end{array}$ & Energy flexibility test name \\
\hline SS30 & Short shift morning only \\
\hline SS150 & Long shift morning only \\
\hline S30 & Short shift morning + evening \\
\hline S150 & Long shift morning + evening \\
\hline T1 & Minor shed \\
\hline T3 & Major shed \\
\hline
\end{tabular}




\begin{tabular}{|c|c|c|c|c|c|c|c|c|c|}
\hline Code & R0017 & R0031 & R0037 & R0069 & R0086 & R0150 & R0175 & R0186 & R0433 \\
\hline Climate region & S1/O1/BT & S1/01/CS2 & S1/01/CS3 & & & S1/01/CS4 & S1/01/CGS & S1/01/BCS & S1/O2/BRS \\
\hline \multicolumn{10}{|c|}{ All buildings in size group one and two } \\
\hline Auckland & 264 & 264 & 264 & 471 & 471 & 471 & 471 & 471 & 771 \\
\hline Hamilton & 211 & 211 & 211 & 415 & 415 & 415 & 415 & 415 & 318 \\
\hline Napier & 122 & 122 & 122 & 239 & 239 & 239 & 239 & 239 & 313 \\
\hline Manawatu & 162 & 162 & 162 & 257 & 257 & 257 & 257 & 257 & 121 \\
\hline Wellington & 68 & 68 & 68 & 211 & 211 & 211 & 211 & 211 & 227 \\
\hline Christchurch & 135 & 135 & 135 & 267 & 267 & 267 & 267 & 267 & 200 \\
\hline Dunedin & 98 & 98 & 98 & 254 & 254 & 254 & 254 & 254 & 205 \\
\hline SUM & 1061 & 1061 & 1061 & 2114 & 2114 & 2114 & 2114 & 2114 & 2154 \\
\hline All buildings & 22385 & & & & & & & & \\
\hline \multicolumn{10}{|c|}{ Buildings in the sub-sample } \\
\hline Code & R0017 & R0031 & R0037 & R0069 & R0086 & R0150 & R0175 & R0186 & R0433 \\
\hline Climate region & S1/O1/BT & S1/01/CS2 & S1/01/CS3 & & & S1/01/CS4 & S1/01/CGS & S1/O1/BCS & S1/O2/BRS \\
\hline Auckland & 264 & 264 & 264 & & & 471 & 471 & 471 & 771 \\
\hline Hamilton & 211 & 211 & 211 & & & 415 & 415 & 415 & 318 \\
\hline Napier & 122 & 122 & 122 & & & 239 & 239 & 239 & 313 \\
\hline Manawatu & 162 & 162 & 162 & & & 257 & 257 & 257 & 121 \\
\hline Wellington & 68 & 68 & 68 & & & 211 & 211 & 211 & 227 \\
\hline Christchurch & 135 & 135 & 135 & & & 267 & 267 & 267 & 200 \\
\hline Dunedin & 98 & 98 & 98 & & & 254 & 254 & 254 & 205 \\
\hline SUM & 1061 & 1061 & 1061 & 0 & 0 & 2114 & 2114 & 2114 & 2154 \\
\hline All buildings & 13884 & & & & & & & & \\
\hline \multicolumn{10}{|c|}{ Sum of buildings which achieved the aggregation criterion after SS30 test } \\
\hline Code & R0017 & R0031 & R0037 & R0069 & R0086 & R0150 & R0175 & R0186 & R0433 \\
\hline Climate region & S1/O1/BT & S1/01/CS2 & S1/01/CS3 & & & S1/01/CS4 & S1/01/CGS & S1/01/BCS & S1/O2/BRS \\
\hline Auckland & 264 & 264 & 264 & & & 471 & 471 & 471 & 771 \\
\hline Hamilton & 211 & & 211 & & & 415 & & 415 & \\
\hline Napier & 122 & 122 & 122 & & & 239 & 239 & & \\
\hline Manawatu & 162 & 162 & 162 & & & 257 & 257 & 257 & 121 \\
\hline Wellington & & & 68 & & & 211 & 211 & 211 & 227 \\
\hline Christchurch & 135 & 135 & 135 & & & & 267 & & 200 \\
\hline Dunedin & 98 & 98 & 98 & & & 254 & 254 & 254 & 205 \\
\hline SUM & 993 & 782 & 1061 & 0 & 0 & 1847 & 1699 & 1608 & 1523 \\
\hline All buildings & 10695 & & & & & & & & \\
\hline \multicolumn{10}{|c|}{ Sum of buildings which achieved the aggregation criterion after SS150 test } \\
\hline Code & R0017 & R0031 & R0037 & R0069 & R0086 & R0150 & R0175 & R0186 & R0433 \\
\hline Climate region & S1/O1/BT & $\mathrm{S} 1 / 01 / \mathrm{CS} 2$ & S1/01/CS3 & & & S1/01/CS4 & S1/O1/CGS & S1/O1/BCS & S1/O2/BRS \\
\hline Auckland & 264 & 264 & 264 & & & 471 & 471 & 471 & \\
\hline Hamilton & & 211 & & & & 415 & 415 & 415 & \\
\hline Napier & 122 & 122 & 122 & & & 239 & 239 & 239 & \\
\hline Manawatu & 162 & 162 & 162 & & & 257 & 257 & 257 & 121 \\
\hline Wellington & & 68 & 68 & & & 211 & 211 & 211 & 227 \\
\hline Christchurch & & & 135 & & & & 267 & & 200 \\
\hline Dunedin & 98 & 98 & 98 & & & 254 & 254 & 254 & \\
\hline SUM & 647 & 926 & 850 & 0 & 0 & 1847 & 2114 & 1847 & 548 \\
\hline All buildings & 10046 & & & & & & & & \\
\hline
\end{tabular}

\section{$1 / 4$}

\begin{tabular}{|l|l|}
\hline $1 / 4$ & $2 / 4$ \\
\hline $3 / 4$ & $4 / 4$ \\
\hline
\end{tabular}




\begin{tabular}{|c|c|c|c|c|c|c|c|c|c|c|c|}
\hline R0433 & R0890 & RO020 & R0831 & R0087 & R0269 & R0620 & R0678 & R0912 & R0007 & R0239 & R0725 \\
\hline S1/O2/BRS & & $\mathrm{S} 2 / 01 / \mathrm{CSC}$ & S2/O3/CWBS & $\mathrm{S} 2 / \mathrm{O} 2 / \mathrm{CS}$ & & & S2/O4/FCAS & & S2/01/CS1 & & \\
\hline 771 & 771 & 181 & 181 & 88 & 88 & 88 & 88 & 88 & 163 & 163 & 163 \\
\hline 318 & 318 & 79 & 79 & 75 & 75 & 75 & 75 & 75 & 70 & 70 & 70 \\
\hline 313 & 313 & 35 & 35 & 43 & 43 & 43 & 43 & 43 & 66 & 66 & 66 \\
\hline 121 & 121 & 51 & 51 & 57 & 57 & 57 & 57 & 57 & 18 & 18 & 18 \\
\hline 227 & 227 & 32 & 32 & 40 & 40 & 40 & 40 & 40 & 45 & 45 & 45 \\
\hline 200 & 200 & 57 & 57 & 48 & 48 & 48 & 48 & 48 & 50 & 50 & 50 \\
\hline 205 & 205 & 38 & 38 & 46 & 46 & 46 & 46 & 46 & 52 & 52 & 52 \\
\hline 2154 & 2154 & 473 & 473 & 398 & 398 & 398 & 398 & 398 & 463 & 463 & 463 \\
\hline & & & & & & & & & & & \\
\hline R0433 & R0890 & R0020 & R0831 & R0087 & R0269 & R0620 & R0678 & R0912 & R0007 & R0239 & R0725 \\
\hline S1/O2/BRS & & $\mathrm{S} 2 / 01 / \mathrm{CSC}$ & S2/O3/CWBS & $\mathrm{S} 2 / \mathrm{O} 2 / \mathrm{CS}$ & & & S2/O4/FCAS & & $\mathrm{S} 2 / 01 / \mathrm{CS} 1$ & & \\
\hline 771 & & 181 & 181 & 88 & & & 88 & & 163 & & \\
\hline 318 & & 79 & 79 & 75 & & & 75 & & 70 & & \\
\hline 313 & & 35 & 35 & 43 & & & 43 & & 66 & & \\
\hline 121 & & 51 & 51 & 57 & & & 57 & & 18 & & \\
\hline 227 & & 32 & 32 & 40 & & & 40 & & 45 & & \\
\hline 200 & & 57 & 57 & 48 & & & 48 & & 50 & & \\
\hline 205 & & 38 & 38 & 46 & & & 46 & & 52 & & \\
\hline 2154 & 0 & 473 & 473 & 398 & 0 & 0 & 398 & 0 & 463 & 0 & 0 \\
\hline & & & & & & & & & & & \\
\hline R0433 & R0890 & R0020 & R0831 & R0087 & R0269 & R0620 & R0678 & R0912 & R0007 & R0239 & R0725 \\
\hline S1/O2/BRS & & S2/01/CSC & S2/O3/CWBS & $\mathrm{S} 2 / \mathrm{O} 2 / \mathrm{CS}$ & & & S2/O4/FCAS & & $\mathrm{S} 2 / 01 / \mathrm{CS} 1$ & & \\
\hline 771 & & & 181 & 88 & & & 88 & & & & \\
\hline & & & 79 & 75 & & & 75 & & & & \\
\hline & & & & 43 & & & 43 & & & & \\
\hline 121 & & & & 57 & & & 57 & & & & \\
\hline 227 & & & 32 & 40 & & & 40 & & & & \\
\hline 200 & & & 57 & 48 & & & 48 & & & & \\
\hline 205 & & & 38 & 46 & & & 46 & & & & \\
\hline 1523 & 0 & 0 & 387 & 398 & 0 & 0 & 398 & 0 & 0 & 0 & 0 \\
\hline & & & & & & & & & & & \\
\hline R0433 & R0890 & R0020 & R0831 & R0087 & R0269 & R0620 & R0678 & R0912 & R0007 & R0239 & R0725 \\
\hline S1/O2/BRS & & $\mathrm{S} 2 / 01 / \mathrm{CSC}$ & $\mathrm{S} 2 / 03 / \mathrm{CWBS}$ & $\mathrm{S} 2 / \mathrm{O} 2 / \mathrm{CS}$ & & & S2/O4/FCAS & & $\mathrm{S} 2 / \mathrm{O} 1 / \mathrm{CS} 1$ & & \\
\hline & & & 181 & 88 & & & 88 & & & & \\
\hline & & & 79 & 75 & & & 75 & & & & \\
\hline & & & 35 & 43 & & & 43 & & & & \\
\hline 121 & & & 51 & 57 & & & 57 & & & & \\
\hline 227 & & & 32 & 40 & & & 40 & & & & \\
\hline 200 & & & 57 & 48 & & & 48 & & & & \\
\hline & & & 38 & 46 & & & 46 & & & & \\
\hline 548 & 0 & 0 & 473 & 398 & 0 & 0 & 398 & 0 & 0 & 0 & 0 \\
\hline & & & & & & & & & & & \\
\hline
\end{tabular}

$2 / 4$

\begin{tabular}{|l|l|}
\hline $1 / 4$ & $2 / 4$ \\
\hline $3 / 4$ & $4 / 4$ \\
\hline
\end{tabular}




\begin{tabular}{|c|c|c|c|c|c|c|c|c|c|}
\hline \multicolumn{10}{|c|}{ Sum of buildings which achieved the aggregation criterion after $\mathrm{S} 30$ test } \\
\hline Code & R0017 & R0031 & R0037 & R0069 & R0086 & R0150 & R0175 & R0186 & R0433 \\
\hline Climate region & S1/O1/BT & S1/O1/CS2 & S1/01/CS3 & & & $\mathrm{S} 1 / 01 / \mathrm{CS} 4$ & S1/O1/CGS & S1/O1/BCS & S1/O2/BRS \\
\hline Auckland & & 264 & 264 & & & 471 & & 471 & \\
\hline Hamilton & & & 211 & & & 415 & & 415 & 318 \\
\hline Napier & & 122 & 122 & & & 239 & & 239 & \\
\hline Manawatu & & 162 & 162 & & & 257 & & 257 & 121 \\
\hline Wellington & & & 68 & & & 211 & & 211 & 227 \\
\hline Christchurch & & 135 & 135 & & & & & & 200 \\
\hline Dunedin & & 98 & 98 & & & & & 254 & \\
\hline SUM & 0 & 782 & 1061 & 0 & 0 & 1592 & 0 & 1847 & 866 \\
\hline All buildings & 7377 & & & & & & & & \\
\hline \multicolumn{10}{|c|}{ Sum of buildings which achieved the aggregation criterion after S150 test } \\
\hline Code & R0017 & R0031 & R0037 & R0069 & R0086 & R0150 & R0175 & R0186 & R0433 \\
\hline Climate region & S1/O1/BT & $\mathrm{S} 1 / 01 / \mathrm{CS} 2$ & S1/01/CS3 & & & S1/01/CS4 & S1/01/CGS & S1/O1/BCS & S1/O2/BRS \\
\hline Auckland & & 264 & 264 & & & & & 471 & \\
\hline Hamilton & & 211 & 211 & & & & & 415 & \\
\hline Napier & & 122 & 122 & & & & & 239 & \\
\hline Manawatu & & 162 & 162 & & & & & 257 & 121 \\
\hline Wellington & & 68 & 68 & & & & & 211 & 227 \\
\hline Christchurch & & & 135 & & & & & & 200 \\
\hline Dunedin & & 98 & 98 & & & & & 254 & \\
\hline SuM & 0 & 926 & 1061 & 0 & 0 & 0 & 0 & 1847 & 548 \\
\hline Total number of buildings & 4620 & & & & & & & & \\
\hline \multicolumn{10}{|c|}{ Sum of buildings which achieved the aggregation criterion after T1 test } \\
\hline Code & R0017 & R0031 & R0037 & R0069 & R0086 & R0150 & R0175 & R0186 & R0433 \\
\hline Climate region & S1/O1/BT & S1/01/CS2 & S1/O1/CS3 & & & S1/O1/CS4 & S1/O1/CGS & S1/O1/BCS & S1/O2/BRS \\
\hline Auckland & 264 & 264 & 264 & & & 471 & & 471 & 771 \\
\hline Hamilton & 211 & & 211 & & & & & 415 & 318 \\
\hline Napier & 122 & 122 & 122 & & & 239 & & 239 & 313 \\
\hline Manawatu & 162 & 162 & 162 & & & 257 & & 257 & 121 \\
\hline Wellington & & 68 & 68 & & & 211 & & 211 & 227 \\
\hline Christchurch & & 135 & 135 & & & & & 267 & 200 \\
\hline Dunedin & 98 & 98 & 98 & & & 254 & & 254 & 205 \\
\hline SUM & 858 & 850 & 1061 & 0 & 0 & 1432 & 0 & 2114 & 2154 \\
\hline Total number of buildings & 9889 & & & & & & & & \\
\hline \multicolumn{10}{|c|}{ Sum of buildings which achieved the aggregation criterion after T3 test } \\
\hline Code & R0017 & R0031 & R0037 & R0069 & R0086 & R0150 & R0175 & R0186 & R0433 \\
\hline Climate region & S1/O1/BT & S1/O1/CS2 & S1/O1/CS3 & & & S1/01/CS4 & S1/O1/CGS & S1/O1/BCS & S1/O2/BRS \\
\hline Auckland & 264 & 264 & 264 & & & 471 & 471 & 471 & 771 \\
\hline Hamilton & 211 & & 211 & & & 415 & 415 & 415 & 318 \\
\hline Napier & 122 & 122 & 122 & & & 239 & 239 & 239 & 313 \\
\hline Manawatu & 162 & 162 & 162 & & & 257 & 257 & 257 & 121 \\
\hline Wellington & 68 & 68 & 68 & & & 211 & 211 & 211 & 227 \\
\hline Christchurch & & 135 & 135 & & & 267 & 267 & 267 & 200 \\
\hline Dunedin & 98 & 98 & 98 & & & 254 & 254 & & 205 \\
\hline SUM & 926 & 850 & 1061 & 0 & 0 & 2114 & 2114 & 1859 & 2154 \\
\hline Total number of buildings & 12736 & & & & & & & & \\
\hline
\end{tabular}

$3 / 4$

\begin{tabular}{|l|l|}
\hline $1 / 4$ & $2 / 4$ \\
\hline $3 / 4$ & $4 / 4$ \\
\hline
\end{tabular}




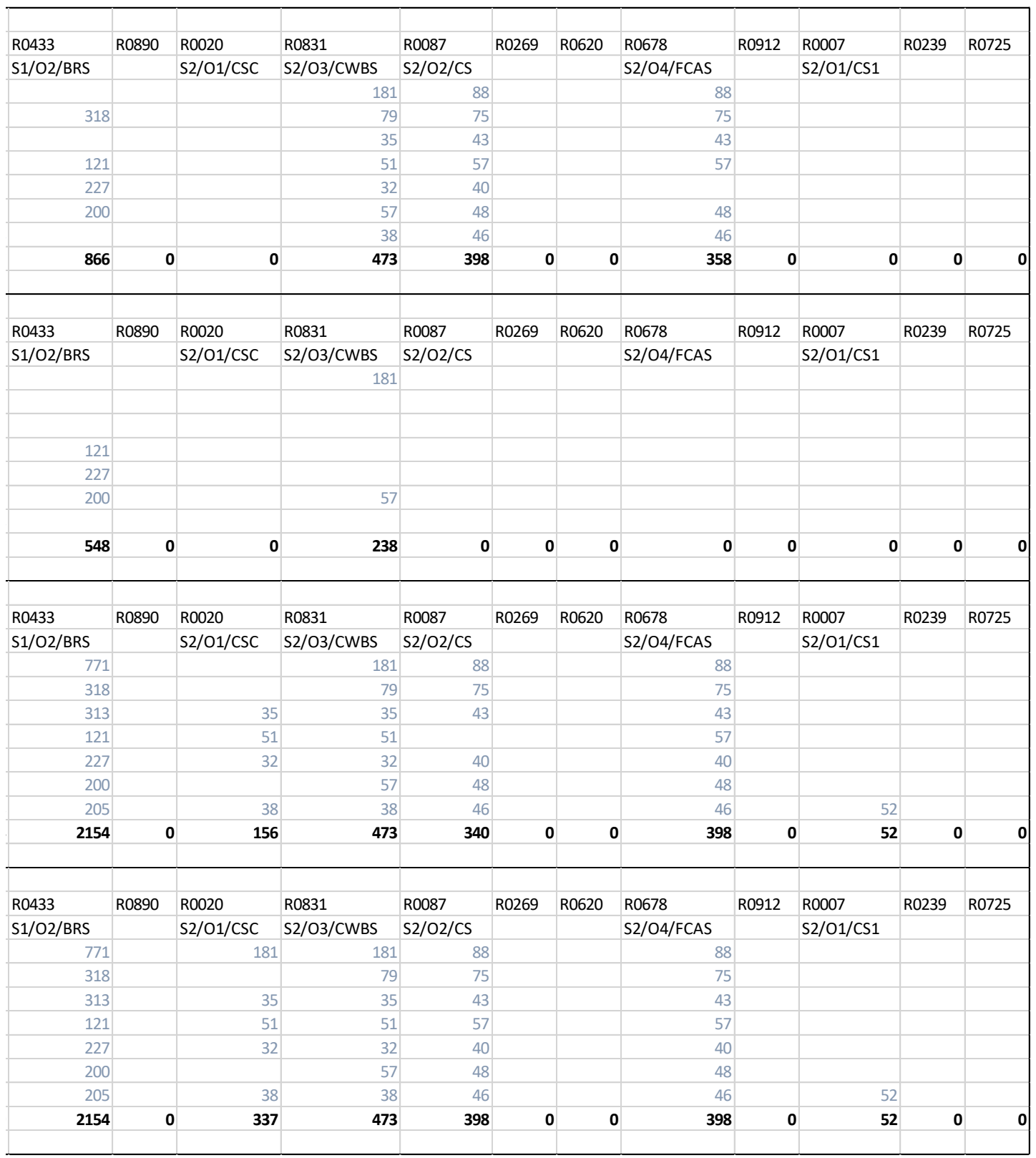

$4 / 4$

\begin{tabular}{|l|l|}
\hline $1 / 4$ & $2 / 4$ \\
\hline $3 / 4$ & $4 / 4$ \\
\hline
\end{tabular}




\subsection{REDUCTION IN THE COMMERCIAL BUILDING STOCK'S PEAK DEMAND FROM EACH ENERGY FLEXIBILITY TEST}

The following graphs show the daily load profile and an ordered daily load profile of the commercial building stock with no energy flexibly operated buildings (blue line), and the commercial building stock with some energy flexibly operated buildings (pink and green line).

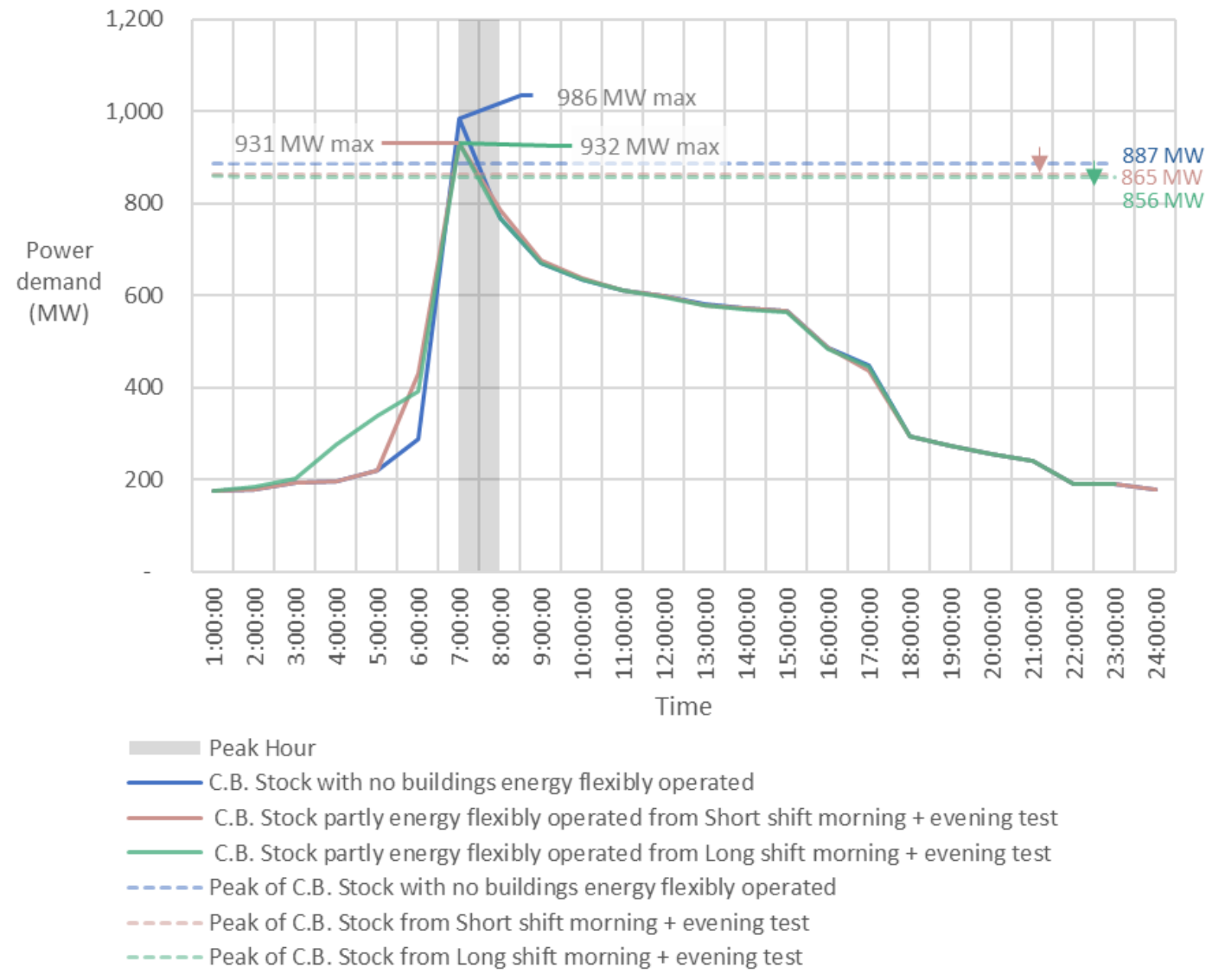

Figure 62 Daily load profile on the peak day after Long and Short shift Morning + Evening test. 


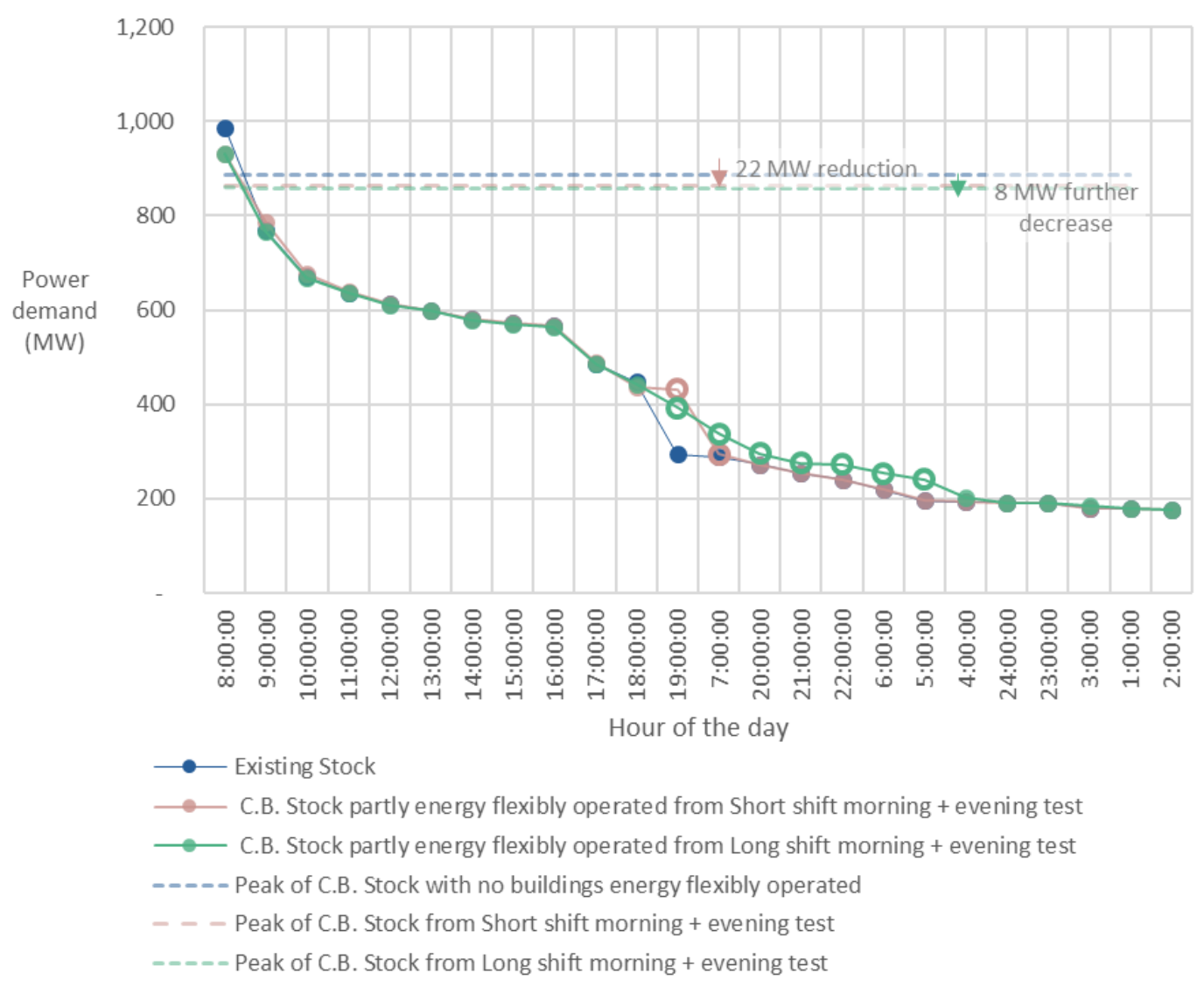

Figure 63 Ordered daily load profile on the peak day after Long and Short shift Morning + Evening test. 


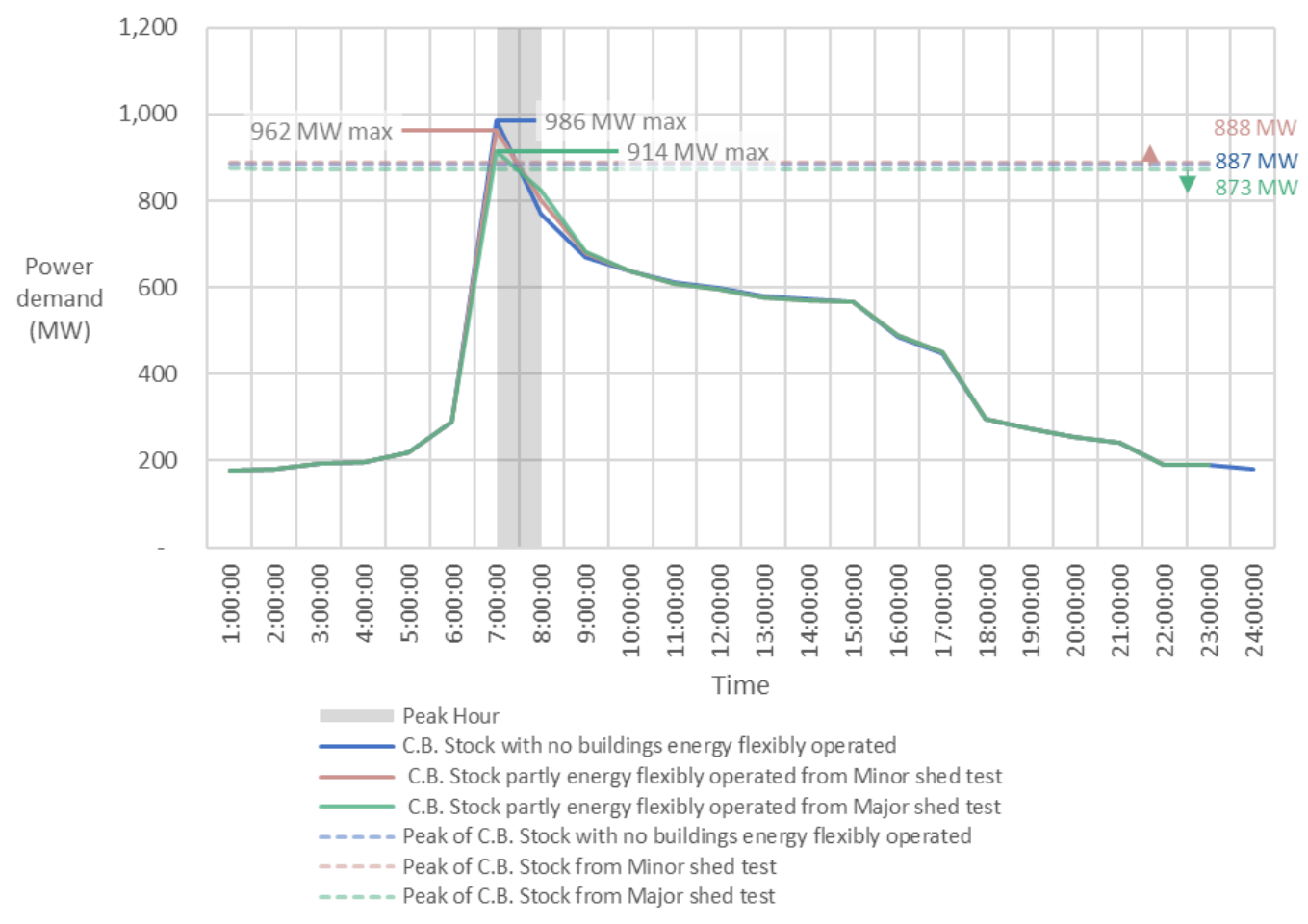

Figure 64 Daily load profile on the peak day after Minor and Major Shed test.

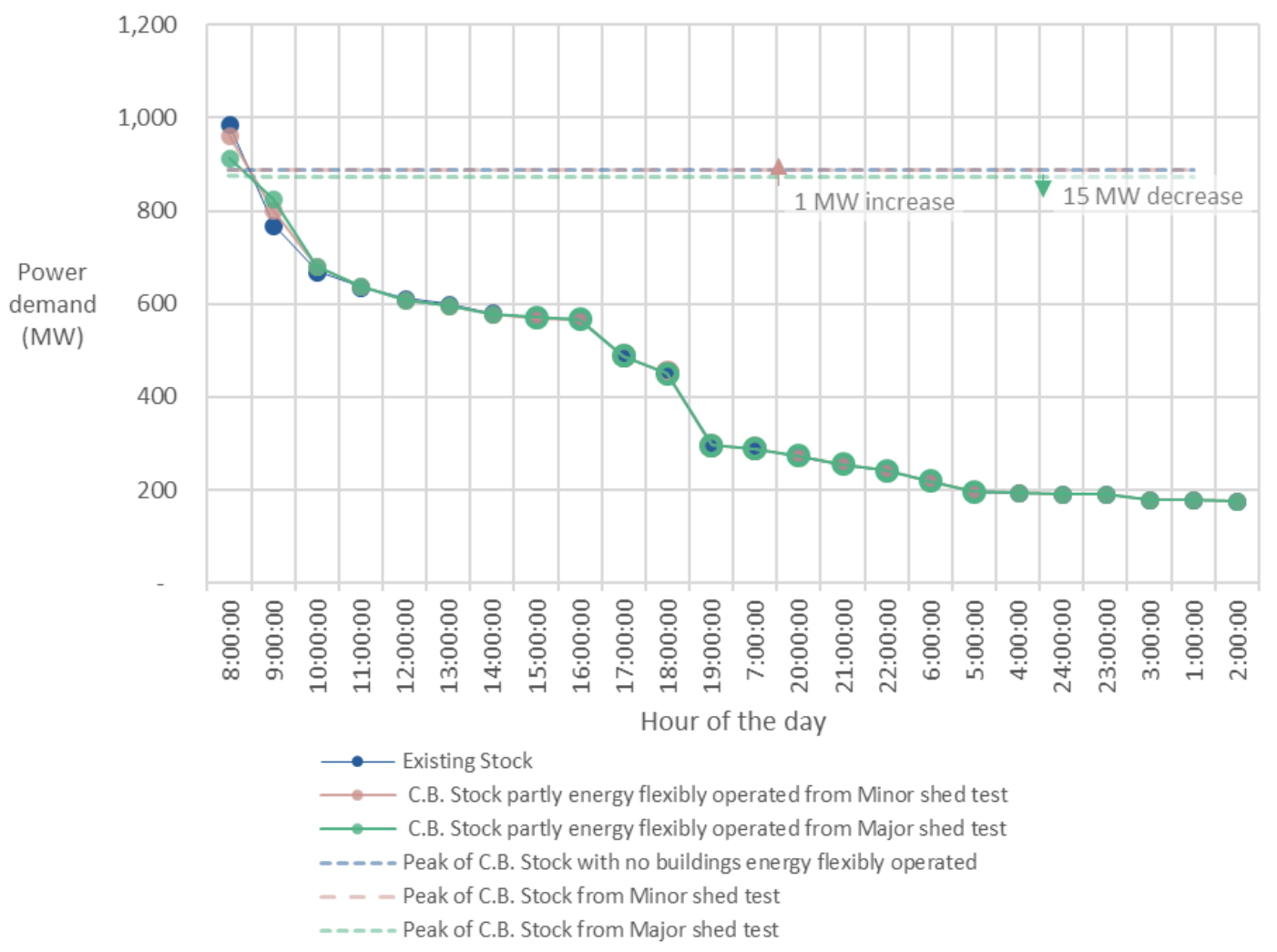

Figure 65 Ordered daily load profile on the peak day after Minor and Major Shed test. 